\title{
Universitat Politècnica de València
}

Departamento de Ingeniería Cartográfica, Geodesia y Fotogrametría

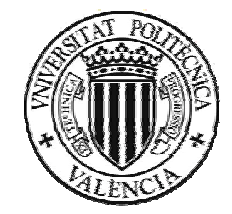

\section{TESIS DOCTORAL}

Análisis de los factores que influyen en la precisión de un MDE y estimación de parámetros forestales en zonas arbustivas de montaña mediante datos LiDAR

Valencia, junio 2011

Autor: Javier Estornell Cremades

Director: Dr. Luis Ángel Ruiz Fernández 

A mi hija Lourdes, a María a mis padres y a mi hermano Juan. 



\section{Agradecimientos}

En primer lugar, quiero expresar mi más especial agradecimiento al director de la tesis, el Dr. Luis Ángel Ruiz Fernández, no sólo por su ayuda en la realización de este trabajo de investigación, sino también por todos sus consejos y contribuciones que ha realizado como mentor en mi dedicación universitaria en la Universidad Politécnica de Valencia. Asimismo, quiero agradecer la colaboración especial del profesor Dr. Borja Velázquez Martí, del Departamento de Ingeniería Rural y Agroalimentaria, por su ayuda y recomendaciones en todo el proceso de realización de esta tesis doctoral.

Además quiero agradecer las revisiones y consejos del profesor Dr. Juan Orengo Femenía, de la Universidad de Murcia, a mis compañeros del Departamento de Ingeniería Cartográfica, Geodesia y Fotogrametría de la Universidad Politécnica de Valencia, Txomin Hermosilla Gómez y Sergio Navarro Martínez, por su colaboración en las tareas de programación y por su ayuda en la preparación y manejo de los equipos de medición. Reconocer también la ayuda prestada en las salidas de campo al Ayuntamiento de Chiva, a Gerson Rafael Colmenarez López, doctorando del Departamento de Ingeniería Cartográfica, Geodesia y Fotogrametría, y a Elena Fernández González, del Departamento de Ingeniería Rural y Agroalimentaria de la Universidad Politécnica de Valencia.

Finalmente, deseo agradecer al Dr. Warren Cohen, a Maureen Duane, a Dirk Pflugmacher y a YunSuk Kim del Laboratory for Applications of Remote Sensing in Ecology del USFS Pacific Northwest Research Station en Oregón, por su excelente acogida y la formación recibida en el manejo de los datos LiDAR y su aplicación en el ámbito forestal durante mi estancia pre-doctoral en verano de 2008.

Este trabajo ha sido posible gracias a la ayuda material que han supuesto los proyectos de investigación:

- Análisis de la biomasa arbustiva forestal en los ecosistemas mediterráneos con tecnología LiDAR y teledetección. (2008-2010). Proyecto financiado por el Vicerrectorado de Investigación, Desarrollo e Innovación de la Universidad Politécnica de Valencia.

- Desarrollo y aplicación de nuevas técnicas de actualización e interpolación cartográficas y análisis morfométrico del terreno como herramientas de utilidad en la caracterización de sistemas hidrológicos (ctm2006-11767). Proyecto financiado por el Ministerio de Educación (2006-2010). 



\section{Resumen}

Un alto porcentaje de la superficie forestal de la zona Mediterránea está cubierta por masas arbustivas densas y bajas. La elevada dificultad que supone su gestión, junto con el desconocimiento del comportamiento de estas masas, hace necesario el desarrollo de herramientas eficaces para su mejor gestión y análisis. El sistema LiDAR (Light Detection and Ranging) ha sido ampliamente utilizado en el ámbito forestal para estimar variables que caracterizan la estructura de los bosques. Sin embargo, pocas investigaciones se han centrado en la vegetación arbustiva. Para realizar estos estudios es necesario, previamente, calcular un modelo digital de elevaciones (MDE). Los objetivos de esta investigación han sido: adaptar un algoritmo basado en procesos iterativos de búsqueda de elevaciones mínimas a partir de datos LiDAR para el cálculo de un MDE en zonas de montaña mediterránea, y desarrollar modelos para la estimación de parámetros de la vegetación arbustiva tanto en parcelas como en subparcelas.

Para el cálculo del MDE, se estudiaron tres parámetros: tamaño de las ventanas de búsqueda, umbrales de alturas y el formato de los datos de entrada. La combinación de estos parámetros permitió generar una serie de ensayos, que se evaluaron mediante el cálculo del error medio cuadrático (RMSE). Para ello se realizó un levantamiento topográfico con un total de 1379 puntos medidos utilizando un GPS-RTK. También se analizaron las variaciones del RMSE al aumentar la pendiente, la densidad de datos LiDAR y en zonas con vegetación. Para la estimación de la altura, la biomasa y el volumen de la vegetación arbustiva se calcularon diferentes estadísticos a partir de los datos LiDAR y de una imagen espectral que se utilizaron como variables independientes en los modelos de regresión. El mejor resultado en el cálculo del MDE se obtuvo tras utilizar ventanas de 10, 5 y 2,5 m, umbrales a partir de 1,5 $\mathrm{m}$ y el formato imagen como datos de partida, siendo el RMSE, 0,19 m. Considerando estos parámetros, se detectó que el RMSE aumentó $0,11 \mathrm{~m}$ cuando las pendientes varían del 0-10\% a 50-60\% y descendió 0,06 m al utilizar una densidad igual o superior a los 8 puntos $/ \mathrm{m}^{2}$. En zonas con vegetación arbustiva el RMSE aumentó $0.05 \mathrm{~m}$.

En cuanto a la vegetación arbustiva, los modelos de predicción de altura, biomasa y volumen presentaron mayores coeficientes de determinación al considerar como unidad de estudio la parcela, siendo los valores de $R^{2}$ de $0,73,0,77$ y 0,84 , respectivamente. Para las subparcelas se comprobó que las mejores estimaciones se produjeron al seleccionar las alturas LiDAR incluidas en un área de influencia de radio entre 1,5 $\mathrm{m}$ y 2,25 $\mathrm{m}$ alrededor del punto medido en campo. Los análisis realizados muestran la importancia de obtener un MDE preciso y una densidad de datos LiDAR superior a los 8 puntos $/ \mathrm{m}^{2}$ para estimar con mayor precisión la altura, biomasa y volumen de la vegetación arbustiva en subparcelas.

Los resultados muestran el potencial de los datos LiDAR para caracterizar la estructura de la vegetación arbustiva permitiendo estimar y realizar mapas de la biomasa para un mejor conocimiento y gestión de este tipo de vegetación frecuente en las áreas mediterráneas. 



\section{Resum}

Un alt percentatge de la superfície forestal de la conca Mediterrànea està coberta per masses arbustives denses i baixes. L'elevada dificultat que suposa la seua gestió, junt amb el desconeixement del comportament d'aquestes masses, fa necessari el desenvolupament d'eines adients per a millorar la seua gestió i anàlisi. El sistema LiDAR (Light Detection and Ranging) ha sigut àmpliament utilitzat a l'àmbit forestal per a estimar variables que caracteritzen l'estructura dels boscos. No obstant això, poques investigacions s'han centrat en la vegetació arbustiva. En aquests estudis, prèviament és necessari calcular un model digital d'elevacions (MDE). Els objectius d'aquest treball d'investigació han estat: adaptar un algoritme basat en processos iteratius de búsqueda d'elevacions mínimes a partir de dades LiDAR per a calcular un MDE en zones de boscos mediterranis i desenvolupar models per a l'estimació dels paràmetres forestals de la vegetació arbustiva en parcel·les i subparcel·les.

Per al càlcul del MDE, s'estudiaren tres paràmetres: tamany de les finestres de búsqueda, valors d'umbrals i format de les dades d'entrada. La combinació d'aquests paràmetres va permetre realitzar una sèrie de càlculs de MDE, que s'evaluaren mitjançant l'error quadràtic mitjà (RMSE) calculat a partir de les dades d'un alçament topogràfic amb un total de 1379 punts mesurats utilitzant un GPS-RTK. També s'analitzaren les variacions del RMSE al aumentar el pendent, la densitat de dades LiDAR i en zones amb vegetació. Per a l'estimació de l'altura, la biomassa i el volum de la vegetació arbustiva es calcularen diferents estadístics mitjançant les dades LiDAR i una imatge espectral que s'utilitzaren com a variables independents en els models de regressió a calcular. El millor resultat al càlcul del MDE s'obtingué en utilitzar finistres de 10, 5 i 2,5 m, umbrals a partir de 1,5 m i el format imatge com a dades de partida. L'error quadràtic mitjà (RMSE) fou de $0,19 \mathrm{~m}$. Considerant aquests paràmetres, el RMSE aumentà $0,11 \mathrm{~m}$ al variar els pendents de $0-10 \%$ a 50-60\% i baixà $0.06 \mathrm{~m}$ al utilitzar una densitat igual o superior als 8 punts $/ \mathrm{m}^{2}$. En zones amb vegetación arbustiva el RMSE aumentà $0.05 \mathrm{~m}$.

Pel que fa a la vegetació arbustiva, l'altura, la biomassa i el volum presentaren majors coeficients de determinació al considerar com unitat d'estudi la parcella, sent els valors de $R^{2}$ de $0,73,0,77$ i 0,84, respectivament. En les subparcel.les, es comprovà que les millors estimacions s'obtingueren en seleccionar les altures LiDAR incloses en una superfície d'influència de radi entre 1,5 m i 2,25 $\mathrm{m}$ al voltant del punt mesurat al camp. Els anàlisis realitzats mostren la importància d'obtindre un MDE precís i una densitat de dades LiDAR superior als 8 punts $/ \mathrm{m}^{2}$ per a estimar amb precisió l'altura, biomassa i volum de la vegetació arbustiva en subparcel.les.

Els resultats mostren el potencial de les dades LiDAR per a caracteritzar l'estructura de la vegetació arbustiva. Aquests permeten estimar i calcular mapes de la biomassa, la qual cosa fa que milloren el coneixement i la gestió de la vegetació arbustiva freqüent als boscos mediterranis. 



\section{Abstract}

A high percentage of Mediterranean forest is covered by dense, low shrub. The difficulty involved in shrub management and the lack of information about shrub behavior explain the necessity of developing efficient tools to improve the analysis of these areas. The LiDAR system (Light Detection and Ranging) has been widely used in forest studies to estimate variables that characterize the forest structure. However, little research has been conducted into shrub vegetation. In these studies, previously, a digital elevation model (DEM) is calculated. The goals of this research were: to adapt an iterative algorithm to select minimum elevations from LiDAR data in a steep mountain area with shrub vegetation, and to develop prediction models for estimating forest variables of shrub vegetation in plots and subplots.

For computing a DEM three parameters were analyzed: window size for selecting minimum elevations, height threshold, and input data type. Combining these parameters, several DEM were computed. They were assessed by 1379 ground-surveyed checkpoints measured with a RTK-GPS system. For estimating the height, the biomass and the volume of shrub vegetation several statistics were derived from LiDAR data and a spectral image that were used as independent variables in the regression models. The results showed that the lowest root mean square error (RMSE) was obtained for the DEM computed with an analysis window size of 10,5, and $2.5 \mathrm{~m}$, rasterized data as input data, and height thresholds equal to or greater than $1.5 \mathrm{~m}$. These parameters produced a RMSE of $0.19 \mathrm{~m}$. Relationships between RMSE and slope, point density and vegetation were also analyzed. For these parameters, it has been detected that when terrain slope varied from $0-10 \%$ to $50-60 \%$, the RMSE increased $0.11 \mathrm{~m}$, and that when point density was increased from $1-4$ to more than 8 points $/ \mathrm{m}^{2}$, the RMSE decreased up to $0.06 \mathrm{~m}$. From 8 points density upwards, RMSE remained stable. In shrub vegetation areas, RMSE increased $0.05 \mathrm{~m}$.

The highest determination coefficients in the estimation of height, biomass, and volume of shrub vegetation were obtained when a plot was considered as study area, being the values of $R^{2}$ of $0.73,0.77$ and 0.84 , respectively. For subplots, it was found that the best results were obtained when height LIDAR were selected from concentric areas with different radii between $1.5 \mathrm{~m}$ and $2.25 \mathrm{~m}$, around the point measured at field. These analysis reveal the importance of computing an accurate DTM and using a density of LiDAR data greater than 8 points $/ \mathrm{m}^{2}$ to estimate with accuracy height, biomass, and volume of shrub vegetation in subplots.

These results show the potential of LiDAR data to characterize shrub structure and make it possible to estimate and map the biomass and volume of this vegetation improving the knowledge and the management of this vegetation very often in Mediterranean forestry. 



\section{Índice}

\begin{tabular}{|c|c|c|}
\hline 1. INTRDDUCCIÓN & & 3 \\
\hline \multirow[t]{2}{*}{ 2. ANTECEDENTES } & & 9 \\
\hline & $\begin{array}{l}\text { 2.1. CÁLCULO DE MODELOS DIGITALES } \\
\text { 2.1.1. Definición de MDE, aplicaciones y métodos de captura } \\
\text { 2.1.2. Modelos de datos para el MDE } \\
\text { 2.1.3. Algoritmos en la generación de MDE a partir de datos LiDAR } \\
\text { 2.1.4. Factores que afectan a la precisión de un MDE } \\
\text { 2.1.5. Cálculo del MDS y MDV } \\
\text { 2.1.6. Discusión } \\
\text { 2.2. ESTIMACIÓN DE VARIABLES FORESTALES A PARTIR } \\
\text { DE DATOS LiDAR } \\
\text { 2.2.1. Estudios sobre estimación de variables dasométricas basadas en } \\
\text { la distribución de alturas LiDAR } \\
\text { 2.2.2. Estudios sobre estimación de variables considerando árboles indi- } \\
\text { viduales } \\
\text { 2.2.3. Aplicaciones en vegetación arbustiva } \\
\text { 2.2.4. Discusión }\end{array}$ & $\begin{array}{l}11 \\
11 \\
12 \\
13 \\
16 \\
18 \\
20 \\
20 \\
21 \\
23 \\
25 \\
27\end{array}$ \\
\hline 3. OBJETIVDS & & 29 \\
\hline \multirow[t]{2}{*}{$\begin{array}{l}\text { 4. MATERIAL Y } \\
\text { MÉTDDOS }\end{array}$} & & 33 \\
\hline & $\begin{array}{l}\text { 4.1. MATERIAL Y DATOS } \\
\text { 4.1.1. Zona de estudio } \\
\text { 4.1.2. Datos utilizados } \\
\text { 4.1.3. Levantamientos topográficos } \\
\text { 4.1.4. Cálculo de la biomasa, volumen y altura a partir de datos de campo } \\
\text { 4.1.5. Software utilizado } \\
\text { 4.2. GENERACIÓN DE MODELOS DIGITALES } \\
\text { 4.2.1. Cálculo del MDE } \\
\text { 4.2.2. Análisis de los factores que influyen en la precisión del MDE } \\
\text { 4.2.3. Cálculo del MDS y del MDV } \\
\text { 4.3. EXTRACCIÓN DE VARIABLES EXPLICATIVAS A PARTIR DE } \\
\text { DATOS LiDAR E IMAGEN ESPECTRAL } \\
\text { 4.4. ESTIMACIÓN DE VARIABLES FORESTALES } \\
\text { 4.4.1. Estimación de la altura de la vegetación } \\
\text { 4.4.2. Factores que influyen en el radio seleccionado para el estudio de } \\
\text { las alturas de la vegetación por subparcelas } \\
\text { 4.4.3. Estimación de la altura de la vegetación a partir del MDV } \\
\text { 4.4.4. Estimación de la superficie cubierta por la vegetación arbustiva a } \\
\text { partir del MDV y datos espectrales } \\
\text { 4.4.5. Modelos de regresión para la estimación de la biomasa } \\
\text { 4.4.6. Factores que influyen en la estimación de la biomasa por subparcelas } \\
\text { 4.4.7. Modelos de regresión para la estimación del volumen de biomasa } \\
\text { 4.4.8. Estimación de de los volúmenes por subparcelas utilizando facto- } \\
\text { res de ocupación (FO) y datos LiDAR }\end{array}$ & $\begin{array}{l}35 \\
35 \\
38 \\
40 \\
41 \\
47 \\
47 \\
47 \\
50 \\
51 \\
51 \\
55 \\
56 \\
56 \\
57 \\
57 \\
59 \\
60 \\
61 \\
61\end{array}$ \\
\hline
\end{tabular}




\begin{tabular}{|c|c|c|}
\hline $\begin{array}{l}\text { 5. RESULTADDS } \\
\text { Y DISCUSIÍN }\end{array}$ & & 63 \\
\hline & $\begin{array}{l}\text { 5.1. MODELOS DIGITALES } \\
\text { 5.1.1. Influencia de los parámetros umbrales y tamaño de ventana en la } \\
\text { precisión del MDE (Chiva) } \\
\text { 5.1.2. Influencia de los parámetros umbrales y tamaño de ventana en la } \\
\text { precisión del MDE (EI Saler) } \\
\text { 5.1.3. Comparación de los resultados } \\
\text { 5.1.4. Análisis de los factores que influyen en la precisión del MDE } \\
\text { 5.1.5. Cálculo del MDS y del MDV } \\
\text { 5.2. ESTIMACIÓN DE VARIABLES FORESTALES } \\
\text { 5.2.1. Estimación de la altura de la vegetación } \\
\text { 5.2.2. Factores que influyen en la selección del radio para el estudio de } \\
\text { las alturas de la vegetación por subparcelas } \\
\text { 5.2.3. Estimación de la altura de la vegetación a partir del MDV } \\
\text { 5.2.4. Estimación de la superficie cubierta por la vegetación arbustiva a } \\
\text { partir del MDV y datos espectrales } \\
\text { 5.2.5. Modelos de regresión para la estimación de la biomasa } \\
\text { 5.2.6. Factores que influyen en el cálculo de la biomasa por subparcelas } \\
\text { 5.2.7. Modelos de regresión para la estimación del volumen de biomasa } \\
\text { 5.2.8. Factores que influyen en el cálculo del volumen de la biomasa por } \\
\text { subparcelas } \\
\text { 5.2.9. Validación del método de cálculo de volumen de biomasa a partir } \\
\text { de volúmenes modelos obtenidos de los datos LiDAR }\end{array}$ & $\begin{array}{r}65 \\
65 \\
69 \\
70 \\
72 \\
77 \\
78 \\
78 \\
81 \\
\\
84 \\
85 \\
\\
87 \\
96 \\
99 \\
101 \\
\\
102\end{array}$ \\
\hline \multirow[t]{2}{*}{ 6. CDNCLUSIONES } & & 105 \\
\hline & $\begin{array}{l}\text { 6.1.CÁLCULO DEL MDE } \\
\text { 6.2.ESTIMACIÓN DE LOS PARÁMETROS FORESTALES ALTURA, BIO- } \\
\text { MASA Y VOLUMEN }\end{array}$ & $\begin{array}{l}107 \\
108\end{array}$ \\
\hline $\begin{array}{l}\text { 7. LÍNEAS FUTURAS DE } \\
\text { INVESTIGACIÍN }\end{array}$ & & 113 \\
\hline $\begin{array}{l}\text { 8. REFERENCIAS } \\
\text { BIBLIOGRÁFICAS }\end{array}$ & & 117 \\
\hline 9. ANEJDS & & 127 \\
\hline
\end{tabular}




\section{Índice de figuras}

\begin{tabular}{|c|c|c|}
\hline Figura 1. & $\begin{array}{l}\text { Información generada por un sistema LiDAR aéreo en la que se puede distinguir } \\
\text { puntos correspondientes al suelo, a la vegetación y a la cubierta de una casa. }\end{array}$ & 14 \\
\hline Figura 2. & $\begin{array}{l}\text { Detalle de un MDE (a) y de un MDS (b) en el que se puede observar los edificios } \\
\text { en la zona de la ciudad. }\end{array}$ & 18 \\
\hline Figura 3. & Representación de un MDS, MDE y MDV. & 19 \\
\hline Figura 4. & $\begin{array}{l}\text { Superposición del MDE sobre los puntos LIDAR originales para el cálculo de la al- } \\
\text { tura de cada uno de ellos. }\end{array}$ & 19 \\
\hline Figura 5. & $\begin{array}{l}\text { Definición de umbrales para eliminar puntos asociados al suelo o vegetación ar- } \\
\text { bustiva en estudios forestales con predominio de árboles. }\end{array}$ & 26 \\
\hline Figura 6. & Mapa de la zona de estudio de Chiva. & 36 \\
\hline Figura 7. & Fotografías de la zona de estudio con presencia densa de coscoja (Quercus coccifera). & 36 \\
\hline Figura 8. & Imágenes de la zona de estudio de El Saler. & 37 \\
\hline Figura 9. & Localización general de la zona de estudio de El Saler. & 37 \\
\hline Figura 10. & $\begin{array}{l}\text { Densidad de puntos por } \mathrm{m}^{2} \text { de los datos LIDAR de la zona de estudio de Chiva. El } \\
\text { polígono negro representa la zona de estudio. }\end{array}$ & 38 \\
\hline Figura 11. & $\begin{array}{l}\text { Diferencias entre las elevaciones de } 60 \text { puntos medidos con GPS-RTK y la eleva- } \\
\text { ción media de los datos LIDAR incluidos en un buffer de radio } 0,5 \mathrm{~m} \text { con centro el } \\
\text { punto medido. }\end{array}$ & 39 \\
\hline Figura 12. & $\begin{array}{l}\text { Composición en falso color de la imagen aérea en la que las bandas IR, R y G se } \\
\text { visualizan en los canales R, G, B, respectivamente. }\end{array}$ & 39 \\
\hline Figura 13. & Líneas de vuelo de la zona de estudio de El Saler. & 40 \\
\hline Figura 14. & $\begin{array}{l}\text { Representación del equipo móvil (a) y fijo (b) del sistema GPS -RTK (c) vértice } \\
4033 \text { de la red de } 4^{\circ} \text { orden de la Comunidad Valenciana. }\end{array}$ & 41 \\
\hline Figura 15. & $\begin{array}{l}\text { Distribución de las parcelas en la zona de estudio utilizando cuadrículas de tama- } \\
\text { ño de celda de } 1 \mathrm{~km}^{2} \text { y representada en color rojo. }\end{array}$ & 42 \\
\hline Figura 16. & $\begin{array}{l}\text { Modelos de crecimiento de masas arbustivas en una superficie determinada: (a) } \\
\text { semiesfera, (b) paraboloide, (c) crecimiento cónico, (d) crecimiento cilíndrico. }\end{array}$ & 44 \\
\hline Figura 17. & $\begin{array}{l}\text { Ejemplo de distribución sectorial de la superficie desbrozada de una subparcela } \\
\text { de } 0,785 \mathrm{~m}^{2} \text {. }\end{array}$ & 45 \\
\hline Figura 18. & $\begin{array}{l}\text { Esquema del algoritmo utilizado en el cálculo del MDE (Adaptado de Clark et } \\
\text { al.,2004). }\end{array}$ & 49 \\
\hline Figura 19. & Distribución de los puntos LiDAR por intervalos de altura. & 54 \\
\hline Figura 20. & $\begin{array}{l}\text { Representación de la curva espectral de la vegetación sana (Adaptado de Chu- } \\
\text { vieco, E. 2002) }\end{array}$ & 55 \\
\hline Figura 21. & Diagrama de flujo para la obtención de la cubierta de vegetación arbustiva. & 58 \\
\hline Figura 22. & 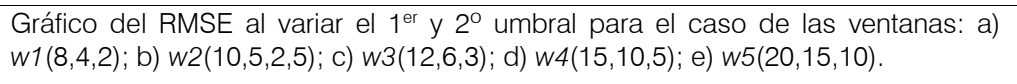 & 66 \\
\hline Figura 23. & $\begin{array}{l}\text { Imagen de sombras en 3D de un DSM (a) y un MDE calculado con los tamaños } \\
\text { de ventana } 10,5, \text { y } 2,5 \text { m; umbrales } 2,5 \text { m; y una imagen como datos de partida (b). }\end{array}$ & 67 \\
\hline
\end{tabular}




\begin{tabular}{|c|c|c|}
\hline Figura 24. & $\begin{array}{l}\text { Seleccón de puntos mínimos en un perfil de terreno característico de la zona de } \\
\text { estudio. }\end{array}$ & 68 \\
\hline Figura 25. & $\begin{array}{l}\text { Gráfico del RMSE en m al variar los umbrales para el caso de las ventanas w1 (a), } \\
\text { w2 (b), w3 (c) w4 (d) y w5 (e) }\end{array}$ & 69 \\
\hline Figura 26. & $\begin{array}{l}\text { Selección de puntos con elevación mínima; a) vector ventana w2 }(10,5,2,5) \text { y um- } \\
\text { bral } 0,5 \mathrm{~m} \text {; b) vector ventana } w 2(10,5,2,5) \text { y umbral } 2 \mathrm{~m} \text {; c) vector ventana } \\
\text { w5(20,10,5) y umbral } 0,5 \text {; d) vector ventana } w 5(20,10,5) \text { y umbral } 2 \mathrm{~m} \text {. }\end{array}$ & 70 \\
\hline Figura 27. & $\begin{array}{l}\text { Comparación del RMSE al variar los umbrales, siendo } u 1=u 2 \text {, en el caso de Chiva } \\
\text { y del Saler para las ventanas w1 (a) y w2 (b). }\end{array}$ & 71 \\
\hline Figura 28. & $\begin{array}{l}\text { RMSE y error medio para los MDE calculados con ventanas w1 (8,4;2), w2 } \\
(10,5,2,5), w 3(12,6,3) \text {, w4 }(15,10,5) \text { y } w 5(20,10,5) \text {, y valores de umbrales } 2,5 \mathrm{~m} \text {. } \\
\text { Datos de partida todos los puntos (a) y toda la imagen (b). }\end{array}$ & 72 \\
\hline Figura 29. & $\begin{array}{l}\text { RMSE al variar la pendiente en los MDE calculados con ventanas w1, w2, w3, w4 y } \\
\text { w5, y valores de umbrales } 2,5 \mathrm{~m} \text {. Datos de partida todos los puntos (a) y una ima- } \\
\text { gen (b). }\end{array}$ & 74 \\
\hline Figura 30. & $\begin{array}{l}\text { RMSE al variar la densidad de puntos en los MDE calculados con ventanas } w 1 \text {, } \\
\text { w2, w3, w4 y w5, y valores de umbrales } 2,5 \mathrm{~m} \text {. Datos de partida: todos los puntos } \\
\text { (a) y una imagen (b). }\end{array}$ & 75 \\
\hline Figura 31. & $\begin{array}{l}\text { RMSE y error medio en los MDE calculados con ventanas w0 }(5,2.5,1) \text {, w1 }(8,4,2) \text {, } \\
\text { w2 }(10,5,2,5) \text {, w3 }(12,6,3) \text {, w4 }(15,10,5) \text { y w5 }(20,10,5) \text { y valores de umbrales } 2,5 \mathrm{~m} \\
\text { en zonas con vegetación }(n=77) \text {. Datos de partida todos los puntos (a) y una } \\
\text { imagen (b). }\end{array}$ & 76 \\
\hline Figura 32. & $\begin{array}{l}\text { Imagen del MDV de la zona de estudio. La visualización se ha realizado agrupan- } \\
\text { do los valores de las alturas en tres clases: } 0-0.3 \mathrm{~m}, 0.3-2.5 \mathrm{~m} \text { y h>2.5 m. Esta } \\
\text { figura también contiene un detalle del MDV y de una imagen multiespectral en una } \\
\text { zona con presencia de caminos, parcelas sin vegetación, vegetación arbustiva y } \\
\text { arbolado. La imagen está visualizada en falso color; las bandas IR, R y G se asig- } \\
\text { nan a los canales R, G, B, respectivamente. }\end{array}$ & 78 \\
\hline Figura 33. & Diagrama de dispersión entre los valores de altura observada y estimada por parcelas. & 79 \\
\hline Figura 34. & $\begin{array}{l}\text { Representación del RMSE entre las } 83 \text { alturas de la vegetación obtenidas a partir } \\
\text { de los datos LiDAR y las medidas en campo para cada radio. }\end{array}$ & 80 \\
\hline Figura 35. & $\begin{array}{l}\text { Representación del RMSE entre las } 82 \text { alturas de la vegetación medidas en cam- } \\
\text { po y las obtenidas a partir de los datos LiDAR, tras utilizar varios radios para los } \\
\text { casos de errores asociados al MDE positivos }(n=32) \text { y negativos }(n=50) \text {. }\end{array}$ & 82 \\
\hline Figura 36. & Efectos sobre la estimación de la vegetación de los errores asociados al MDE. & 82 \\
\hline Figura 37. & $\begin{array}{l}\text { Representación del RMSE al utilizar varios radios entre las } 83 \text { alturas de la vegeta- } \\
\text { ción medidas en campo y las obtenidas a partir de los datos LiDAR y al } \\
\text { considerar los } 34 \text { puntos sin error asociado al MDE y con una pendiente inferior al } \\
20 \% \text {. }\end{array}$ & 83 \\
\hline Figura 38 & $\begin{array}{l}\text { Representación del RMSE entre las alturas de la vegetación medidas en campo y } \\
\text { las obtenidas a partir de los datos LiDAR después de utilizar varios radios en los } \\
\text { casos con densidad de puntos superior }(n=43) \text { e inferior }(n=49) \text { a los } 8 \text { pun- } \\
\text { tos } / \mathrm{m}^{2} \text {. }\end{array}$ & 84 \\
\hline Figura 39. & $\begin{array}{l}\text { RMSE entre las } 83 \text { alturas de la vegetación medidas en campo y las obtenidas a } \\
\text { partir del MDV obtenido de los datos LiDAR para diferentes tamaños de celdas. }\end{array}$ & 85 \\
\hline Figura 40. & Imagen resultado de combinar el MDV y la imagen aérea. & 86 \\
\hline Figura 41. & Dendrograma de las variables derivadas los datos LiDAR. & 87 \\
\hline Figura 42. & $\begin{array}{l}\text { Dendrograma de las variables derivadas de las bandas espectrales de la imagen } \\
\text { aérea. }\end{array}$ & 88 \\
\hline
\end{tabular}




\begin{tabular}{c|l|c}
\hline Figura 43. & $\begin{array}{l}\text { Diagrama de dispersión entre los valores de vegetación seca observada y esti- } \\
\text { mada. }\end{array}$ & 89 \\
\hline Figura. 44. & $\begin{array}{l}\text { Parcela con máximo porcentaje de puntos con altura mayor a 1 m (a); parcela con } \\
\text { máximo porcentaje de puntos en el intervalo 0,75-1 m (b); parcela con el máximo } \\
\text { porcentaje de puntos en el intervalo 0,50-0,75 m (c). }\end{array}$ & 91 \\
\hline Figura 45. & $\begin{array}{l}\text { Histogramas de la banda verde e imagen en falso color (RGB: infrarrojo, rojo, ver- } \\
\text { de) de dos parcelas con alta (arriba) y baja (abajo) presencia de vegetación } \\
\text { arbustiva. La parcela de arriba con 821,27 kg de vegetación seca y desviación es- } \\
\text { tándar en la banda verde de 26,90; la parcela de abajo con 275,5 kg de } \\
\text { vegetación seca y 38,33 en el valor de la desviación estándar de la banda verde. }\end{array}$ & 92 \\
\hline Figura 46. & $\begin{array}{l}\text { Mapa de vegetación seca de la zona de estudio. Las zonas verdes oscuras repre- } \\
\text { sentan áreas con más biomasa, las verdes claras áreas con menos biomasa y las } \\
\text { marrones claras zonas sin vegetación arbustiva. }\end{array}$ & 93 \\
\hline Figura 47. & \begin{tabular}{l} 
Diagrama de dispersión entre los valores de volumen observado y estimado. \\
\hline
\end{tabular} & 100 \\
\hline
\end{tabular}





\section{Índice de tablas}

\begin{tabular}{|c|c|c|}
\hline Tabla 1. & Factores de forma del modelo de volumen analizado (cilindro). & 43 \\
\hline Tabla 2. & Factores ocupación para el volumen aparente cilindro $\left(\mathrm{dm}^{3} / \mathrm{m}^{3}\right)$. & 44 \\
\hline Tabla 3. & $\begin{array}{l}\text { Estadísticos de biomasa y volumen derivados de los datos de campo por sub- } \\
\text { parcelas. }\end{array}$ & 45 \\
\hline Tabla 4. & $\begin{array}{l}\text { Estadísticos de biomasa y volumen derivados de los datos de campo por par- } \\
\text { celas. }\end{array}$ & 46 \\
\hline Tabla 5. & $\begin{array}{l}\text { Estadísticos de las alturas máximas dominantes medidas en las } 86 \text { subparce- } \\
\text { las. }\end{array}$ & 47 \\
\hline Tabla 6. & $\begin{array}{l}\text { Vectores que definen la secuencia del tamaño de cuadrícula aplicados para la } \\
\text { búsqueda de puntos de cota mínima en el caso de Chiva. }\end{array}$ & 50 \\
\hline Tabla 7. & $\begin{array}{l}\text { Vectores } t_{a b} \text { que definen la secuencia umbrales aplicados para la selección de } \\
\text { puntos de cota mínima en el caso de Chiva. }\end{array}$ & 50 \\
\hline Tabla 8. & Variables derivadas de la distribución de las alturas de los datos LiDAR. & 52 \\
\hline Tabla 9. & Variables asociadas al porcentaje de puntos LiDAR por intervalos de altura. & 53 \\
\hline Tabla 10. & Variables derivadas de la imagen espectral área. & 54 \\
\hline Tabla 11. & $\begin{array}{l}\text { Estimación de la altura de la vegetación arbustiva por parcela a partir de datos } \\
\text { LiDAR. }\end{array}$ & 79 \\
\hline Tabla 12. & $\begin{array}{l}\text { Cálculo del valor mínimo (min), máximo (max), media y desviación de las dife- } \\
\text { rencias entre las alturas de la vegetación de los datos LiDAR y las medidas en } \\
\text { campo para cada radio. }\end{array}$ & 81 \\
\hline Tabla 13. & $\begin{array}{l}\text { Estimación de la altura de la vegetación arbustiva por subparcelas a partir de } \\
\text { datos LiDAR. }\end{array}$ & 81 \\
\hline Tabla 14. & $\begin{array}{l}\text { Fiabilidad global, del usuario y del productor de las clases suelo y arbusto cuan- } \\
\text { do el MDV y la imagen espectral se combinan y cuando se usa sólo el MDV. }\end{array}$ & 85 \\
\hline Tabla 15. & Modelos de regresión en la estimación de vegetación seca por parcelas. & 89 \\
\hline Tabla 16. & Modelos de regresión en la estimación de biomasa húmeda. & 94 \\
\hline Tabla 17. & $\begin{array}{l}\text { Estimación de la vegetación seca en } 83 \text { subparcelas considerando las alturas } \\
\text { máximas en áreas de radio } 0,5 \mathrm{~m} \text { (a) y } 1,5 \mathrm{~m} \text { (b). }\end{array}$ & 94 \\
\hline Tabla 18. & $\begin{array}{l}\text { Estimación de la vegetación seca en } 83 \text { subparcelas considerando modelos li- } \\
\text { neales. }\end{array}$ & 95 \\
\hline Tabla 19. & $\begin{array}{l}\text { Estimación de la vegetación seca en } 83 \text { subparcelas considerando modelos } \\
\text { cuadráticos. }\end{array}$ & 95 \\
\hline Tabla 20. & $\begin{array}{l}\text { Tabla 20. Estimación de la biomasa húmeda en } 83 \text { subparcelas a partir del pa- } \\
\text { rámetro elevación máxima de los puntos LIDAR en un área de radio } 0,5 \mathrm{~m} \text { (a) y } \\
1,5 \mathrm{~m} \text { (b). }\end{array}$ & 95 \\
\hline Tabla 21. & $\begin{array}{l}\text { Estimación de la biomasa húmeda en } 83 \text { subparcelas considerando modelos li- } \\
\text { neales. }\end{array}$ & 96 \\
\hline Tabla 22. & $\begin{array}{l}\text { Estimación de la biomasa húmeda en } 83 \text { subparcelas considerando modelos } \\
\text { cuadráticos. }\end{array}$ & 96 \\
\hline
\end{tabular}




\begin{tabular}{|c|c|c|}
\hline Tabla 23. & $\begin{array}{l}\text { Estimación de la vegetación seca y de la biomasa húmeda en las subparcelas } \\
\text { con presencia de Quercus coccifera } r(n=47) \text { y para el resto de vegetación } \\
(n=36) \text {. }\end{array}$ & 97 \\
\hline Tabla 24. & $\begin{array}{l}\text { Estimación de la vegetación seca y de la biomasa húmeda en subparcelas con } \\
\text { densidad mayor a } 8 \text { puntos } / \mathrm{m}^{2}(n=47) \text { y menor }(n=36) \text {. }\end{array}$ & 97 \\
\hline Tabla 25. & $\begin{array}{l}\text { Estimación de la vegetación seca y de la biomasa húmeda en las subparcelas } \\
\text { con error asociado al MDE menor a 0, } 20 \mathrm{~m}(n=52) \text { y mayor }(n=31) \text {. }\end{array}$ & 98 \\
\hline Tabla 26. & $\begin{array}{l}\text { Estimación de la vegetación seca y de la biomasa húmeda en subparcelas con } \\
\text { densidad mayor a } 8 \text { puntos } / m^{2} \text { y error asociado al MDE menor a } 0,20 \text { m }(n=39) \text {. }\end{array}$ & 98 \\
\hline Tabla 27. & $\begin{array}{l}\text { Estimación de la vegetación seca y de la biomasa húmeda en subparcelas con } \\
\text { vegetación Quercus coccifera y densidad mayor a } 8 \text { puntos } / \mathrm{m}^{2}(\mathrm{n}=32) \text {. }\end{array}$ & 98 \\
\hline Tabla 28. & $\begin{array}{l}\text { Estimación de la vegetación seca y de la biomasa húmeda en subparcelas con } \\
\text { vegetación Quercus coccifera y error asociado al MDE menor a 0,20 m }(n=30) \text {. }\end{array}$ & 98 \\
\hline Tabla 29. & Modelos de regresión en la estimación del volumen. & 100 \\
\hline Tabla 30. & Estimación del volumen en 83 subparcelas considerando modelos lineales. & 101 \\
\hline Tabla 31. & $\begin{array}{l}\text { Estimación del volumen por subparcelas con presencia de Quercus coccifera } \\
(n=47) \text { y para el resto de vegetación }(n=36) \text {. }\end{array}$ & 101 \\
\hline Tabla 32. & $\begin{array}{l}\text { Estimación del volumen por subparcelas con densidad superior }(n=47) \text { e infe- } \\
\text { rior }(n=36) \text { a } 8 \text { puntos } / \mathrm{m}^{2} \text {. }\end{array}$ & 101 \\
\hline Tabla 33. & $\begin{array}{l}\text { Estimación del volumen en las subparcelas considerando el factor error asocia- } \\
\text { do al MDE menor a 0,20 m }(n=52) \text { y mayor }(n=31) \text {. }\end{array}$ & 102 \\
\hline Tabla 34. & $\begin{array}{l}\text { Estimación de la biomasa en subparcelas combinando los factores vegetación } \\
\text { Quercus coccifera, densidad mayor a } 8 \text { puntos/m2 y error asociado al MDE } \\
\text { menor a } 0,20 \mathrm{~m} \text {. }\end{array}$ & 102 \\
\hline Tabla 35. & $\begin{array}{l}\text { Prueba de muestras relacionadas entre los volúmenes medidos en campo y los } \\
\text { calculados a partir del FO y de los datos LiDAR. }\end{array}$ & 103 \\
\hline
\end{tabular}


Análisis de los factores que influyen en la precisión de un MDE y estimación de parámetros forestales en zonas arbustivas de montaña mediante datos LiDAR 

1. Introducción 

Un alto porcentaje de la superficie forestal de la zona Mediterránea está cubierta por masas arbustivas densas y bajas. La elevada dificultad que supone su gestión, junto con el desconocimiento del comportamiento de estas masas, hace que en ocasiones se prescindan de ellas en los proyectos de ordenación del territorio, siendo sin embargo un medio de enorme relevancia paisajística y ambiental. Estas masas impiden la erosión y desertización del suelo (Rango et al., 2000), explican la presencia de diferentes especies de animales (Mundt et al., 2006), influyen en la recarga de los acuíferos (Mikšys et al., 2007), suponen un sumidero relevante de $\mathrm{CO}_{2}$ (Velázquez-Martí et al., 2010). Su estudio es necesario para crear mapas de combustibles forestales para la simulación del comportamiento espacial de los incendios forestales (Riaño et al., 2007). El desarrollo de herramientas eficaces para su manejo se convierte en un reto científico con el objeto de realizar acciones de mantenimiento, restauración de zonas erosionadas y de superficies incendiadas, así como la caracterización de hábitats optimizando los recursos. Para ello, es necesario disponer de información geográfica actualizada que permita realizar un diagnóstico medioambiental e inferir indicadores para una gestión sostenible de estos lugares, frecuentemente protegidos. Algunos estudios han demostrado el potencial de la tecnología LiDAR en el análisis y diagnóstico de ecosistemas forestales (Kim et al., 2008; Martinuzzi et al., 2009).

La tecnología LiDAR (Light Detection and Ranging), es un sistema activo de teledetección que se basa en la medición del tiempo transcurrido entre la emisión de un pulso de energía y su llegada al sensor, después de haber sido reflejado por algún elemento de la superficie terrestre. Estos datos contienen información de las coordenadas de los puntos donde se producen las reflexiones, tanto si se produce en el suelo como en cualquier objeto que sobresalga de la superficie terrestre, como es el caso de la vegetación y edificios. Con esta información es posible transformar los datos registrados en alturas y estudiar su distribución para obtener datos de la cubierta forestal, de cualquier otro objeto por encima de la superficie terrestre y definir la topografía del suelo. De esta manera se podrían obtener diferentes modelos digitales: modelo digital de elevación (MDE), modelo digital de superficie (MDS), modelo digital de la vegetación (MDV) y sus derivados. Estos datos son aplicados en áreas como por ejemplo: creación de modelos hidrológicos (Cobby et al., 2001; Casas et al., 2006), extracción de edificios (Sohn y Dowman, 2007), cambios en la arena de la playa (Shrestha et al., 2005) y, fundamentalmente, aplicaciones forestales (Li et al., 2008; García et al., 2010).

Para el cálculo del MDE a partir de datos LiDAR, es necesario utilizar algoritmos que permitan descartar de entre todos los puntos, aquellos que no pertenecen al suelo como los que representan vegetación, edificios o cualquier otro elemento que sobresale sobre esta superficie. Este proceso, denominado filtrado, ha sido estudiado a partir de diferentes algoritmos que suelen proporcionar buenos resultados en zonas de campo con poca pendiente. Sin embargo, los resultados son peores en áreas urbanas, con superficies rugosas y con vegetación (Sithole y Vosselman, 2004). Los algoritmos de filtrado suelen ignorar áreas con las características de esta investigación (Meng et al., 2010): predominio de vegetación arbustiva y pendientes elevadas con variación irregular. Por lo tanto, aunque existan diferentes metodologías y 
programas comerciales que permitan calcular un MDE, es necesario la selección de un algoritmo para el análisis y la selección de los parámetros adecuados que deben usarse en el cálculo del MDE y su adaptación a las características de la zona de estudio.

El sistema LiDAR ha sido ampliamente utilizado en el ámbito forestal para estimar variables que caracterizan árboles, variables dendrométricas, y otras relacionadas con los bosques, variables dasométricas como la altura, la biomasa y el volumen (Lefsky et al., 1999; Næsset 2002; Maltamo et al., 2004; Popescu et al., 2007). La biomasa es una variable importante para evaluar el ecosistema y la estructura a lo largo del paisaje (Zheng et al., 2004) y permite estimar la cantidad de carbono retenida por la vegetación y el material celuloso como fuente potencial de energía renovable (Popescu et al. 2007). Por otro lado, la altura es una variable que permite clasificar los diferentes tipos de vegetación arbustiva (Riaño 2007), es importante para detectar crecimientos y muestra una correlación muy alta con la biomasa. Esto se pudo observar en diversos estudios como los realizados por Hyyppä e Inkinen (1999), Lim et al., (2003) y Nelson et al., (2004) que trabajaron en zonas con presencia de árboles. En contraste, las zonas arbustivas han sido objeto de pocas investigaciones por su dificultad técnica (baja altura y superficie uniforme). En el caso de los árboles se han seguido dos enfoques (Hyyppä et al., 2008): estimación de variables dasométricas a partir del cálculo de regresiones entre los datos de campo y estadísticos derivados de los datos LiDAR en una parcela que han sido referenciados a la superficie topográfica (Nelson et al., 1998; Naesset et al., 2004; Andersen et al., 2005; Li et al.,2008; García etal.,2010); y estudios en los que se estiman propiedades físicas de árboles a partir de la extracción de las copas mediante la distribución de las alturas de los datos LiDAR que también han sido referenciados a la superficie topográfica (Hyyppä et al., 2001; Holmgren et al., 2003; Persson et al., 2002; Maltamo et al., 2004; Popescu, 2007). De esta manera, la altura de cada punto LiDAR indica la distancia a la superficie del suelo. Con la vegetación arbustiva sólo el primer enfoque es posible ya que se trata de una estructura continua y de reducida altura, lo que implica una mayor dificultad en su análisis. Por ello, su aplicación e inferencias estarán condicionadas a una buena caracterización previa del comportamiento de las masas arbustivas en diferentes escenarios de acuerdo a parámetros o indicadores tomados en campo que puedan ser correlacionados con los datos aportados por el sistema LiDAR. Para ello, la precisión de un MDE es un factor relevante en estas áreas debido a las pequeñas diferencias en altura entre la vegetación y el terreno. No sucede lo mismo en los trabajos realizados en bosques, en los que las diferencias en altura entre el suelo y los árboles son mayores y en los que es frecuente descartar los puntos LiDAR asociados al suelo y al sotobosque (Popescu et al., 2002; Naesset, 2004; Kim et al., 2009).

La mayoría de las investigaciones sobre vegetación arbustiva basados en datos LiDAR han tenido como objetivos la estimación de la altura y el cálculo de mapas de ocupación de este tipo de vegetación (Streutker y Glenn, 2006; Riaño et al., 2007). Sin embargo, pocos estudios se han centrado en la estimación de la biomasa y volumen que son variables importantes en aplicaciones forestales. Una de las razones es la dificultad que supone la medición en campo de estas variables para ser correlacionadas con los datos 
LiDAR. Otra razón, es el menor conocimiento de este tipo de vegetación, a diferencia de los árboles, en los que se aplican ecuaciones definidas para estimar variables dendrométricas a partir de simples medidas en campo. Una última razón puede ser el menor interés de estas zonas desde un punto de vista económico en contraposición a lo que ocurre con otras zonas forestales con predominio de árboles.

El objetivo de este trabajo fue determinar parámetros óptimos para el cálculo de un MDE a partir de datos LiDAR utilizando filtros basados en la selección de cotas mínimas. Los parámetros a analizar fueron: datos de entrada, tamaños de ventana y umbrales aplicados a los algoritmos iterativos de selección de puntos mínimos. También se analizaron los factores densidad de puntos, pendientes y presencia de vegetación arbustiva en la precisión del MDE. Estos resultados se utilizarán como base para la estimación de las alturas, biomasa y volumen ocupado por la vegetación arbustiva en terrenos muy accidentados, característicos de la zona Mediterránea.

A partir de los resultados de esta investigación se podría orientar mejor las políticas de promoción del uso y conservación de la superficie forestal arbustiva; evaluar cual es el potencial de biomasa existente en los sistemas mediterráneos y definir la tecnología apropiada para las actuaciones de conservación y mejora de biomasa potencial que todavía no ha sido gestionada. Los resultados de este estudio también se podrían aplicar en la generación de mapas de combustibles forestales para la simulación de modelos de propagación de incendios. Este estudio puede contribuir en mejorar el conocimiento de los hábitats de la Comunidad Valenciana pudiendo analizar evoluciones de los mismos. Finalmente, los resultados de este estudio podrían ser relevantes como herramienta de cuantificación de recursos alimenticios en los estudios de carga ganadera.

Este trabajo de investigación tendrá dos bloques. En el primero se abordarán cuestiones relacionadas con el cálculo del MDE. Se obtendrán los parámetros óptimos del algoritmo utilizado para el cálculo del MDE en zonas con diferentes características y se analizará los efectos de la pendiente, tipo vegetación y densidad de datos. El segundo bloque estará relacionado con la definición de modelos para la estimación de la altura, biomasa y volumen de la vegetación arbustiva en parcelas y subparcelas. También se obtendrá la capa de la vegetación arbustiva presente en la zona de estudio. Se analizará si la combinación de información espectral y datos LiDAR mejora dichas estimaciones. 

2. Antecedentes 

En este apartado se abordará la terminología utilizada en la definición de un MDE, se revisarán los algoritmos para su cálculo y los factores que afectan a la precisión de los mismos utilizando datos LiDAR. También se describirán los algoritmos de cálculo de un MDS y MDV. Finalmente se abordarán los antecedentes relacionados con la extracción de variables forestales a partir de datos LiDAR.

\subsection{CÁLCULO DE MODELOS DIGITALES}

En este apartado se desarrollarán aspectos relacionados con el cálculo del modelo digital de elevaciones (MDE), del modelo digital de superficies (MDS) y del modelo digital de vegetación (MDV) empezando por las definiciones y nomenclaturas, analizando los modelos más utilizados para sus cálculos y revisando la bibliografía relacionada para sus determinaciones a partir de datos LiDAR.

\subsubsection{Definición de MDE, aplicaciones y métodos de captura}

Un Modelo Digital del Terreno (MDT) es un conjunto ordenado de números que representa la distribución espacial de características del terreno (Doyle, 1978). Aunque esta definición suele utilizarse para referirse a la distribución de las elevaciones del terreno, también se puede encontrar en la bibliografía reciente (Koukoulas et al., 2004; Reutebuch, 2005; Evans etal., 2007) el término modelo digital de elevaciones (MDE) para expresar tal distribución y diferenciarlos de otros modelos que describen diferentes características del terreno (Doyle, 1978; Burrough y McDonnell, 1998). Por este motivo en este trabajo se utilizará MDE para hacer referencia a la distribución de las elevaciones del terreno. Según Felicísimo (1994) "un modelo digital de elevaciones es una estructura numérica de datos que representa la distribución espacial de la altitud de la superficie del terreno".

Los modelos digitales de elevaciones tienen muchas aplicaciones. Entre ellas se encuentra la generación de modelos hidrológicos, cuencas hidrográficas, estudios de vegetación, cartografía de riesgos de inundación, modelos de propagación de incendios forestales, estudios de cuencas visuales, generación de perfiles del terreno, cálculo del movimiento de tierras y generación de modelos derivados como son el mapa de pendientes, orientaciones y rugosidad del terreno.

Existen diferentes técnicas para la captura de esta variable geográfica. Felicísimo (1994) establece una clasificación de los métodos de captura en directos o secundarios. En los primeros, se mide la altura directamente a través de una estación total, un GPS o los altímetros radar o láser. En los segundos, se obtiene la altura tras aplicar procesos fotogramétricos sobre fotografías aéreas o imágenes de satélite con recubrimiento. También se pueden obtener datos de manera indirecta a partir de la interferometría radar y la digitalización automática o manual de curvas de nivel y puntos acotados sobre cartografía existente. De 
entre todas estas técnicas, los sistemas LiDAR permiten medir una mayor cantidad de puntos por superficie. Sin embargo, las estaciones totales y los equipos GPS permiten definir con precisión elementos de la superficie, los puntos se distribuyen de manera más eficiente y se pueden repetir las medidas. La principal desventaja de estos métodos frente a los sistemas LiDAR es que resultan poco adecuados para superficies grandes y de difícil acceso, como las áreas forestales. Si comparamos los sistemas LiDAR y los productos obtenidos a partir de técnicas fotogramétricas, estos últimos se ven afectados por sombras (Andersen et al., 2007). Además, en los casos de vegetación densa, la medición de las alturas de los árboles es menos precisa y la capacidad de penetración menor (Hyde et al., 2006). En estos casos es necesario localizar zonas abiertas para medir la elevación del suelo, pudiéndose encontrar a una distancia demasiado grande del árbol cuya altura se quiere medir (St-Onge et al., 2004). En el caso de los sistemas LiDAR, aunque las precisiones en el cálculo del MDE y de variables forestales disminuyen en zonas densas de vegetación (Cobby et al., 2001; Raber at al., 2002; Hodgson et al., 2005), son mejores a las obtenidas en los procesos de restitución ya que entre un 20 y $40 \%$ de los pulsos pueden alcanzar el suelo (Ackermann 1999). Por otro lado, y a diferencia de lo que ocurre en fotogrametría, no es necesario que los puntos aparezcan en dos imágenes (Kraus y Pfeifer, 1998), ni la toma de puntos de apoyo, ya que la georrefenciación del sistema LiDAR se basa en la utilización de un GPS diferencial, un sistema inercial, y de los tiempos emisión-recepción del haz de energía. Según Baltsavias (1999) las principales ventajas del sistema LiDAR frente a la fotogrametría serían: una mayor densidad de puntos, una mayor precisión y la automatización de los procesos y la entrega más rápida de los datos.

Los sistemas LiDAR tienen la desventaja de que en zonas con presencia de agua el haz de energía tiende a ser absorbido (Huising y Gomes, 1998) generando áreas vacías sin información, sobre todo en zonas de aguas profundas (Charlton, 2003). Otro problema sería la subestimación de las alturas de los árboles cuando se utilizan datos LiDAR ya que el haz de energía penetra hacia el interior de la vegetación antes de ser reflejado (Magnussen et al 1999; Gaveau y Hill, 2003). Por otro lado, para el cálculo del MDE a partir de datos LiDAR es necesario la utilización de algoritmos que permitan separar los puntos que pertenecen al suelo de los que no, lo que puede ser difícil en áreas cubiertas de vegetación en terrenos con elevadas pendientes.

\subsubsection{Modelos de datos para el MDE}

Para obtener un MDE a partir de datos LiDAR es necesario convertir los puntos obtenidos por este sistema en una superficie continua. Para realizar esta conversión, se utilizan frecuentemente dos estructuras: cálculo de TINs (Triangular Irregular Nets) o una imagen basada en una malla regular formada por celdas (Korte, 1997). El cálculo de un TIN se basa en el cálculo de triángulos formados por los puntos LiDAR. Este modelo presupone que los puntos incluidos en su interior pertenecen al plano formado por los puntos del triángulo (Bosque, 1997). La elevación de cualquier punto que pertenezca al triángulo se obtiene por interpolación. La estructura basada en una imagen utiliza celdas como unidades de observación y en su 
interior asignan un único valor de altura. El modelo TIN tiene la ventaja de utilizar una densidad de puntos en función de la dificultad orográfica de la zona y permite seleccionar puntos críticos como cumbres, collados y líneas de cambio de pendiente (Casas et al., 2006). Por contra, las estructuras basadas en una imagen resultan más apropiadas para realizar operaciones de análisis de superposición, como la creación de modelos y detección de cambios (Burrough y McDonell, 1998). En el caso de los datos LiDAR, en los que se dispone de una alta densidad de puntos, ambos sistemas podrían considerarse adecuados para definir un MDE, siempre y cuando se utilice un tamaño de celda pequeño para el modelo imagen.

\subsubsection{Algoritmos en la generación de MDE a partir de datos LiDAR}

Los datos que registra un sistema LiDAR contienen información de las coordenadas de los puntos donde se producen las reflexiones, tanto si se producen en el suelo como en cualquier objeto que sobresalga de la superficie terrestre, como son los casos de la vegetación y edificios (Figura 1). Para obtener el MDE es necesario clasificar estos datos según pertenezcan al suelo o a objetos por encima de la superficie topográfica. Aunque este proceso, denominado filtrado, ha sido estudiado a partir de diferentes algoritmos, es muy difícil automatizarlo completamente (Baltsavias 1999). Los algoritmos de filtrado se pueden agrupar en las siguientes clases (Sithole y Vosselman, 2004): basados en el cálculo de TIN, contornos activos, interpolación, morfológicos y los basados en la pendiente. Estos últimos suelen representar modificaciones de los cuatro primeros algoritmos. Por este motivo se analizarán de manera conjunta.

\section{Filtros basados en el cálculo de TIN}

Estos filtros se basan en el hecho de que la superficie topográfica no suele presentar grandes discontinuidades en el relieve. Para el cálculo del MDE se parte de una primera triangulación a partir de una búsqueda inicial de puntos mínimos. A partir de aquí, Axelsson (2000) aplicó un proceso iterativo para la búsqueda de nuevos puntos mínimos. Para ello, se establecieron dos condiciones: que el ángulo del nuevo triángulo que se formó con el punto candidato fuera inferior a un umbral, y que el nuevo punto estuviera a una determinada distancia del punto más cercano del triángulo a modificar. Este algoritmo sirvió de referencia en el programa Terra Scan de 3D Laser Mapping. Sohn y Dowman (2002) realizaron una primera triangulación con los cuatro puntos mínimos más cercanos a los vértices del rectángulo que incluyó la nube original de puntos. A continuación, el punto más bajo de cada triángulo fue añadido en la siguiente triangulación. El proceso se repitió hasta que no hubiera ningún triángulo con un punto por debajo de ellos. Debido a que existían puntos pertenecientes al suelo que no fueron seleccionados, se estableció un nuevo algoritmo de búsqueda. Se basó en el cálculo de un área de influencia vertical y en seleccionar aquellos puntos que generaron tetraedros más planos. 


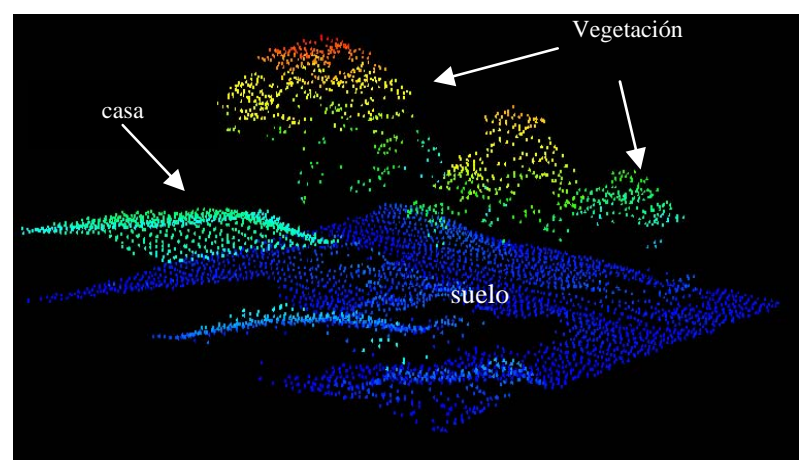

Figura 1. Información generada por un sistema LiDAR aéreo en la que se pueden distinguir puntos correspondientes al suelo, a la vegetación y a la cubierta de una casa.

\section{Filtros basados en contornos activos}

Este algoritmo utiliza un modelo de formas activo para representar un contorno tridimensional, el cual funciona como una red para eliminar puntos no pertenecientes al suelo. Elmqvist (2003) calculó una superficie horizontal por debajo de todos los puntos. A continuación, esta superficie se ajustó hacia arriba para encajarse con los puntos del terreno y descartar los puntos pertenecientes a la vegetación y edificios.

\section{Filtros basados en interpolación}

El principal objetivo de los filtros basados en interpolación es comparar las elevaciones de los puntos y las estimadas a partir de varios métodos de interpolación. Para minimizar la influencia de puntos locales no pertenecientes al suelo son necesarios procesos iterativos (Lohmann et al., 2000). Kraus y Pfeifer (1998) aplicaron un proceso iterativo basado en el cálculo de una superficie media usando todos los datos LiDAR. Para ello aplicaron una interpolación lineal basada en el cálculo de mínimos cuadrados con un conjunto de funciones de pesos. Los puntos pertenecientes a la superficie topográfica tenían residuos negativos, mientras que los puntos pertenecientes a la vegetación presentaban residuos muy pequeños o positivos. A partir de estos valores, se definió la función de peso con valores entre 1 y 0 . A los puntos con residuos muy negativos se les asignaron pesos próximos a 1 y a los positivos el valor 0 . Este algoritmo fue considerado en el programa SCOP++ del Instituto de Fotogrametría y Teledetección de TU Viena e INPHO GmbH.

Otro método de interpolación utilizado es el thin-plate spline (TPS). Brovelli (2002) utilizó este método para la separación de los puntos pertenecientes al suelo y los que pertenecieron a objetos por encima de la superficie topográfica. Para ello, los puntos situados por encima del spline calculado se clasificaron como puntos asociados a objetos potenciales y los puntos por debajo, como puntos potenciales pertenecientes 
al suelo. Los bordes de los puntos pertenecientes a objetos se pudieron defininir. Uniendo los bordes se obtiene que todos los puntos de su interior pertenecen a objetos si la altura es igual o mayor a la altura media de los puntos en el borde. Algunas modificaciones de este algoritmo adaptado a zonas con pendientes elevadas se pueden encontrar en Lee (2003). Evans y Hudak (2007) utilizaron un proceso iterativo aplicando una interpolación TPS modificando el tamaño de celda.

\section{Filtros morfológicos}

Un grupo importante de algoritmos está basado en la utilización de filtros morfológicos. Estas operaciones se basan en la aplicación de operaciones matemáticas sobre un conjunto de puntos incluidos en una ventana que se desplaza sobre la zona de estudio y de tamaño determinado. Dos operaciones básicas se suelen utilizar: dilatación y erosión.

La dilatación consiste en la selección del punto de cota máxima dentro de la ventana definida. Por el contrario, la erosión se basa en la selección del punto mínimo dentro de una ventana. Se pueden combinar estas operaciones dando lugar a una apertura y a un cierre. En la apertura, primero se aplica una erosión y luego una dilatación. En el cierre pasa lo contrario. Kilian et al., (1996) utilizaron un proceso iterativo en el que se aplicó un filtro de apertura incrementando el tamaño de la ventana entre pasos. A los puntos clasificados como suelo se les asignó un peso en función de la ventana utilizada, siendo menor al utilizar ventanas grandes. Una mejora de este método consistió en utilizar umbrales entre pasos. Si se elige un umbral para la diferencia entre la elevación de un punto seleccionado en un paso de la iteración y la asociada a ese punto en el MDE calculado en un paso previo, permitirá eliminar puntos seleccionados en cada paso cuya elevación difiera más de un cierto valor. De esta manera se puede obtener un MDE más preciso ya que se eliminarían puntos asociados a cualquier objeto sobre la superficie terrestre, como la vegetación y los edificios (Zhang et al., 2003)

Dentro del grupo de filtros morfológicos se puede incluir el algoritmo basado en un proceso iterativo de selección de puntos con elevación mínima, definiendo una ventana de búsqueda. Con estos datos se obtendría un MDE inicial. Posteriormente se realiza, a partir de los datos iniciales, una nueva selección de cotas mínimas aplicando ventanas de búsqueda menores. Los nuevos puntos seleccionados se comparan con el MDE inicial y se definen umbrales para eliminar, de entre estos puntos, aquellos cuya diferencia respecto al MDE inicial supere un determinado valor. De esta manera se eliminarían puntos pertenecientes a cualquier objeto sobre la superficie terrestre como la vegetación. Hyyppä et al., (2001b) obtuvieron un primer MDE a partir de los puntos mínimos considerando una tamaño de ventana de 8x8 m. A continuación, se superpuso esta superficie con los puntos originales para determinar los que pertenecen a la superficie topográfica. Para ello, se utilizaron umbrales de 0,5 y 1 m. Popescu et al., (2002) seleccionaron los puntos mínimos incluidos en celdas de tamaño 5x5 m. A partir de estos datos calcularon una imagen a la que se le aplicó un filtro de mínimo de 3×3. Wack y Wimmer (2002) calcularon el MDE a partir de la selección del punto más bajo entre el 99\% de los puntos dentro de una celda con un tamaño decreciente en 
cada paso. Se utilizaron los tamaños 9, 3 y $1 \mathrm{~m}$. En cada paso se aplicó un filtro laplaciano para eliminar objetos no pertenecientes al suelo. Clark et al. (2004) empezaron la búsqueda con una ventana inicial de $20 \times 20 \mathrm{~m}$ y luego utilizaron los tamaños $15 \times 15 \mathrm{~m}$ y 10×10 m. El umbral entre pasos con el que obtuvieron mejores resultados fue 0,25 m. Yu et al., (2004) consideraron para la búsqueda de puntos mínimos los siguientes vecindarios decrecientes: 7, 5, 3, 2, 1 y 0,5 m. Una variante de esta metodología fue utilizar un tamaño de ventana según la heterogeneidad estructural del dosel (Patenaude et al., 2004). El tamaño de ventana idóneo para la búsqueda de puntos pertenecientes al suelo dependerá de varios factores entre los que se encuentra las dimensiones de los objetos por encima del suelo, la pendiente del terreno y la densidad de datos LiDAR. En zonas con una cubierta densa de árboles, lo que dificulta la penetración del haz de energía, cabe esperar que la utilización de ventanas de mayor tamaño proporcionen mejores resultados (Clark et al., 2004)

Vosselman (2000) utilizó un filtro centrado en cada punto y aplicado a su vecindario basado en un cono para buscar los puntos por debajo de él. Si no hay puntos por debajo del cono, entonces el punto del centro del cono es considerado como punto terreno. El resto de los objetos son considerados puntos no pertenecientes al suelo. De esta forma, se puede modelar la variación de altura admisible en función de la distancia y con estos datos clasificar los puntos pertenecientes al suelo de los que no lo son. Variaciones de este método, en las que se tiene en cuenta la pendiente, pueden encontrarse en Sithole (2002) y en Roggero (2002).

\subsubsection{Factores que afectan a la precisión de un MDE}

La precisión en el cálculo del MDE a partir de datos LiDAR depende de varios factores. Hyyppä et al. (2008) los agruparon en cuatro clases: errores asociados al sistema LiDAR (GPS, INS, laser escáner), metodología y algoritmos, características asociadas a los datos y la complejidad de la superficie terrestre. En cuanto a los primeros, las empresas que realizan los vuelos suelen llevar a cabo un estudio sobre la precisión de las mediciones realizadas por el equipo GPS y el sistema inercial. Una forma de validar la precisión del sistema LiDAR es analizar las diferencias entre los datos medidos en campo y los obtenidos con los datos LiDAR en zonas de control, como pueden ser las zonas llanas sin vegetación o en tejados planos (Huising y Gomes, 1998; Hopkinson et al., 2005).

Por otro lado, es necesario tener en cuenta otro tipo de errores asociados a un mal funcionamiento del sistema que genera puntos con un valor anómalo de elevación, pudiendo ser más altos o más bajos de lo real. A veces, los valores más altos están causados por la intersección del haz de energía con aves. Estos errores se pueden eliminar a partir de la selección de los puntos con elevación superior o inferior a un percentil calculado a partir de todos los datos (Wack y Wimmer, 2002; Riaño et al., 2004). 
En cuanto al factor de la metodología y algoritmos, se puede encontrar una comparación y clasificación de ellos en Sithole y Vosselman (2004). De los métodos analizados, los algoritmos que utilizan superficies locales suelen dar mejores resultados. Todos los métodos comparados por estos autores dieron buenos resultados en áreas abiertas con poca pendiente. Sin embargo, los errores aumentaron en zonas urbanas complejas y en terrenos rugosos con pendiente elevada.

Otro de los factores a considerar en la precisión de un MDE lo constituye las características de los datos asociadas a su adquisición o registro como pueden ser la altura de vuelo, la densidad de puntos, si hay varios retornos o el ángulo de escaneo. A mayor altura de vuelo y de ángulo de escaneo aumenta el error (Baltasvias, 1999; Akokas et al., 2003). La densidad y distribución de los puntos es un factor decisivo en la fiabilidad y calidad de los MDE (Baltasvias, 1999). Hyyppä et al., (2005) analizaron el efecto de la variación de la altura de vuelo y la densidad de pulsos sobre la precisión en el cálculo del MDE. Al pasar de una altura de $400 \mathrm{~m}$ con una densidad de 8 puntos $/ \mathrm{m}^{2}$ a otra de $1500 \mathrm{~m}$ con una densidad de 1-2 puntos $/ \mathrm{m}^{2}$, aumentó el error aleatorio de 0,12 a $0,18 \mathrm{~m}$

Por último, las características de la superficie a medir es otro factor determinante de la precisión de un MDE. La presencia de vegetación densa hace que sea muy difícil que algún pulso alcance el suelo, disminuyendo la precisión del MDE. Kraus y Pfeifer, (1998) afirmaron que un porcentaje inferior al 25\% de los puntos LiDAR penetran en las zonas forestales y que, al aumentar la rugosidad y la pendiente del terreno, decrece la precisión en la altura de 0,5-1 m para una altura de vuelo de $1.000 \mathrm{~m}$. En general, la precisión de un MDE decrece en zonas con vegetación densa y con pendientes elevadas (Raber et al., 2002; Hodgson et al., 2005; Clark et al., 2004). Según Hollaus et al., (2006), el RMSE aumentó de 0,1 m a 0,3 m cuando las pendientes pasaron del 10\% al 40-50 \% en una zona forestal de los Alpes austriacos con una pendiente media de 40 grados y una densidad media de 2 puntos $/ \mathrm{m}^{2}$.

Las precisión del MDE obtenido a partir de datos LiDAR fue 0,1 m con una desviación estándar de 0,15 m en zonas llanas y sin errores sistemáticos asociados al sistema LiDAR (Huising and Gomes, 1998; Hyyppä et al., 2001). Raber et al., (2002) calcularon el MDE en un ámbito forestal con un error absoluto medio y RMSE de 0,20 y 0,29 m, respectivamente. Andersen et al., (2005) estimaron la precisión del MDE bajo el dosel forestal formado por coníferas midiendo 347 puntos de control. Para este estudio se registraron 4 puntos $/ \mathrm{m}^{2}$. El error medio fue de 0,22 m con una desviación típica de $\pm 0,24 \mathrm{~m}$. Kobler et al., (2007) calcularon un MDE en una zona forestal con una pendiente media del $58 \%$ y una densidad de 8.5 puntos $/ \mathrm{m}^{2}$. El RMSE varió entre $\pm 0,16 \mathrm{~m}$ y $\pm 0,37 \mathrm{~m}$. Estos resultados, errores inferiores a 0,40 $\mathrm{m}$, pueden considerarse como referencia en las precisiones a obtener en el cálculo de un MDE en las condiciones más complejas: áreas forestales con alta densidad de árboles y pendientes altas. 


\subsubsection{Cálculo del MDS y MDV}

Además de los MDE, los datos registrados por un sistema LiDAR permiten obtener modelos digitales de superficies (MDS). Un MDS representa la superficie topográfica del terreno que incluye edificios, vegetación, carreteras y elementos naturales del terreno (Figura 2b). Un MDS es una descripción geométrica de la superficie topográfica y de los objetos localizados sobre ella como árboles y edificios (Haala et al., 1999; Priestnall et al., 2000).

A diferencia del MDE, el MDS se calcula a partir de la selección de los puntos con elevación máxima en un vecindario de tamaño determinado. Hyyppä et al., (2001b) seleccionaron el valor máximo de los puntos incluidos en una celda de $0,5 \mathrm{~m}$ de lado. En las zonas desprovistas de datos se realizó una interpolación basada en las alturas de los puntos más cercanos. Del mismo modo, Persson et al., (2002) calcularon el MDS utilizando un tamaño de celda de 0,66 m. En los casos en los que una celda no tuviera ningún punto LiDAR, se le asignaba la media de las elevaciones de los píxeles contiguos. Otros autores (Maltamo et al., 2004; Takahashi et al., 2005; Popescu et al., 2007) utilizaron sólo los datos del primer retorno para detectar los puntos con elevación máxima, utilizando un tamaño de píxel entre 0,5 y 0,66 m. Patenaude et al., (2004) calcularon el MDS utilizando los datos del primer retorno sin selección de máximos.

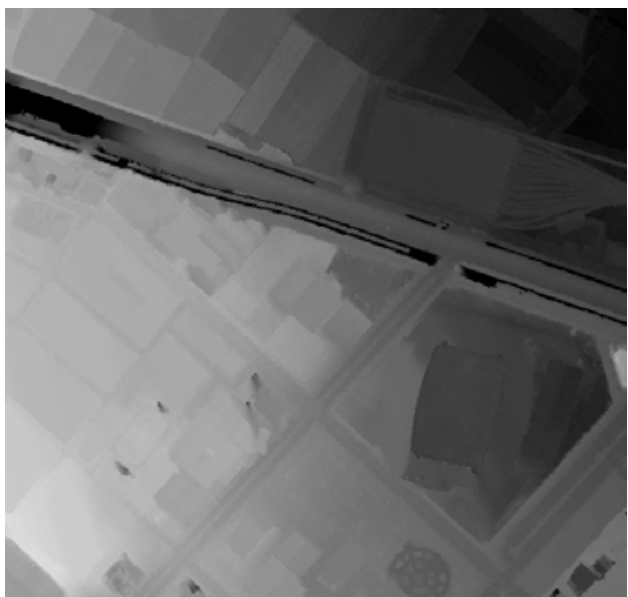

(a)

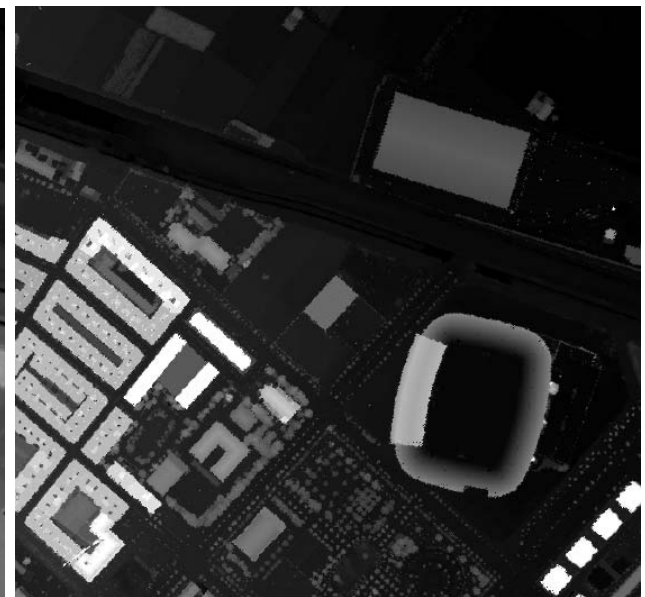

(b)

Figura 2. Detalle de un MDE (a) y de un MDS (b) en el que se pueden observar los edificios en la zona de la ciudad. Fuente: DIELMO 3D S.L.

A partir del MDE y del MDS puede calcularse su diferencia (MDS-MDE), que en zonas forestales representa el modelo digital de la vegetación (MDV). Cada celda de esta imagen contiene la altura de la vegetación (Figura 3). El MDV es la superficie de partida para el cálculo de estadísticos con los que se puede estimar variables dasométricas (Nelson et al., 2004; Naesset 1997; Means et al., 2000; Lim et al; 
2003; Andersen et al., 2005; Kim et al., 2009; García et al., 2010). El MDV también es la superficie de partida sobre la que se aplican procesos de segmentación de imágenes a partir de los cuales pueden obtenerse características de árboles individuales (Hyyppä and Inkinen, 1999; Hyyppä et al., 2001b; Person et al., 2002; McCombs et al., 2003; Popescu et al., 2004; Bortolot 2005).

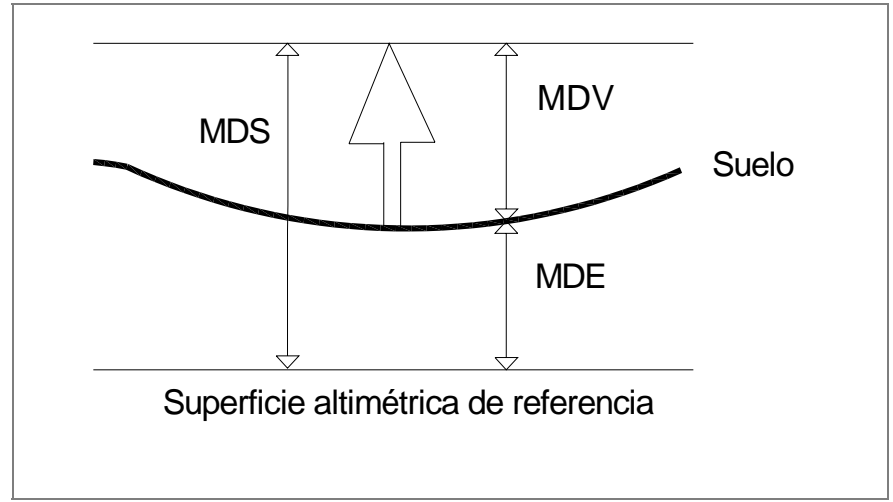

Figura 3. Representación de un MDS, MDE y MDV.

No todos los estudios sobre la vegetación a partir de datos LiDAR consideran el MDV para obtener variables forestales. En otros estudios (Riaño et al., 2004) se trabaja con los puntos LiDAR originales. Para calcular su altura se aplica una superposición entre los puntos y el MDE (Figura 4). A continuación se resta al valor de la elevación del punto la del MDE. Con estos datos se calculan ciertos índices que se utilizarán para estimar variables dendrométricas-dasométricas.

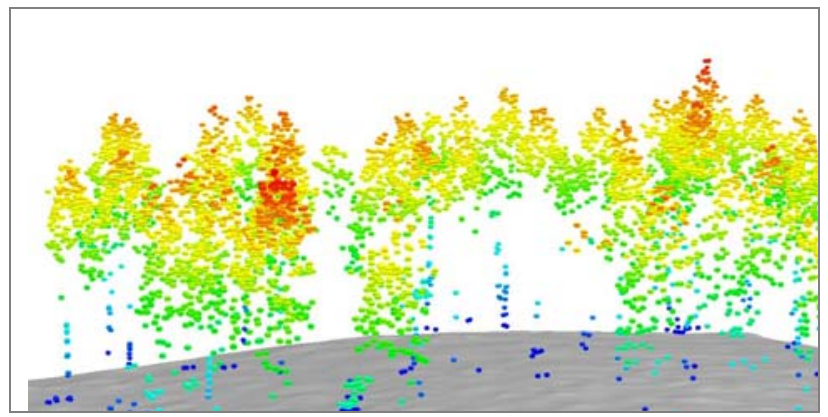

Figura 4. Superposición del MDE sobre los puntos LIDAR originales para el cálculo de la altura de cada uno de ellos. 


\subsubsection{Discusión}

Como se ha visto en las apartados precedentes la precisión de un MDE depende de las características de los datos. En la adquisición de datos LiDAR se tienen que tener en cuenta una serie de parámetros entre los que se pueden citar: la altura de vuelo, frecuencia de escaneado, frecuencia de pulsación láser, ángulo de escaneado y densidad de puntos por $\mathrm{m}^{2}$. La altura de vuelo condicionará la precisión horizontal y vertical en el cálculo de las coordenadas de los pulsos. A mayor altura, menor precisión. El ángulo de escaneado interesará que sea lo más pequeño posible. De este modo, en zonas en las que la presencia de vegetación sea muy densa y los huecos entre ella escasos hay mayor probabilidad de que algún pulso alcance el suelo. Una frecuencia de pulsación y de escaneado alta posibilitará la generación de una densidad de puntos LiDAR por $\mathrm{m}^{2}$ alta, lo que permitirá obtener una mayor precisión del MDE.

En cuanto a las características de la superficie se ha comprobado que el error aumenta en zonas con presencia de vegetación y elevada pendiente ya que en estos casos es más difícil seleccionar puntos LiDAR que pertenezcan al suelo. Lo contrario sucede en áreas llanas sin vegetación. En estos casos el error obtenido en el cálculo de un MDE estará relacionado con la precisión del sistema LiDAR en la adquisición de los datos. En cuanto a los algoritmos a utilizar según Sithole y Vosselman (2004) generan mejores resultados aquellos que utilizan superficies locales en la selección de puntos pertenecientes a la superficie topográfica. De esta manera no se eliminan las variaciones pequeñas del relieve. Los algoritmos basados en procesos iterativos de búsqueda de puntos con elevación mínima en ventanas decrecientes son un ejemplo. En los ensayos realizados por estos autores todos los algoritmos proporcionan buenos resultados en áreas llanas sin vegetación y todos generan errores mayores en áreas urbanas, con vegetación y pendientes elevadas. A pesar de los estudios realizados, son necesarias nuevas investigaciones en áreas con vegetación baja, ya que los algoritmos de filtrado suelen ignorar estas áreas (Meng et al., 2010).

\subsection{ESTIMACIÓN DE VARIABLES FORESTALES A PARTIR DE DATOS LIDAR}

Uno de los ámbitos en los que más se están utilizando los sistemas LiDAR es en el forestal. Entre las aplicaciones y líneas de investigación llevadas a cabo en este área se pueden citar: utilización de los sistemas LiDAR para la gestión y ordenación de montes e inventarios (Hyyppä et al 2001b; Reutebuch et al., 2005; Donoghue et al., 2007); detección de cambios en la vegetación (Yu et al., 2004); conservación y análisis de hábitats (Mundt et al., 2006); estimación de parámetros forestales para la generación de modelos de propagación de incendios forestales (Erdody y Moskal, 2010); cuantificar sumideros de $\mathrm{CO}_{2}$ en zonas forestales (García et al., 2010). Para llevar a cabo estos trabajos se definen dos aproximaciones. Por una lado, se considera como unidad de estudio la parcela y, por otro, el árbol individual. Así, se estimarán variables dasométricas en el primer caso y dendrométricas en el segundo. 


\subsubsection{Estudios sobre estimación de variables dasométricas basadas en la distribución de alturas LiDAR}

Existen numerosos estudios en los que se ha utilizado el sistema LiDAR para la estimación de variables dasométricas. Naesset (1997) estimó la altura media de los árboles contenidos en 36 rodales. En este trabajo se alcanzaron buenos resultados cuando se utilizaron ventanas variables, entre 15-30 m, para el cálculo de la media de las alturas dominantes de los puntos incluidos en ellas. De esta manera se obtuvo una diferencia entre las medias de las alturas medidas en campo y las alturas estimadas con los datos LiDAR que osciló entre -0,4 - 1,9 m. Nelson et al. (1998) consideraron la altura media cuadrática de los puntos pertenecientes a las copas de los árboles para estimar la biomasa y el volumen. Los mejores modelos explicaron entre el $53 \%$ y $65 \%$ de la variabilidad de la biomasa y volumen. Means et al. (2000) utilizaron los datos LiDAR para estimar la altura, área basal y volumen de 19 parcelas de Pseudotsuga menziesii. Para estimar la altura, utilizaron la altura máxima y el percentil 90 de las alturas de los puntos incluidos dentro de cada parcela. Obtuvieron un $\mathrm{R}^{2}$ de 0,93 y un error medio cuadrático (RMSE) de 3,4 m. Para el caso del área basal se utilizaron los percentiles 0 y 80 de las alturas de los puntos incluidos en cada parcela y el 20 de la cubierta del dosel. Para el caso del volumen, se consideraron las mismas variables. Los valores de $R^{2}$ fueron 0,95 y 0,97, respectivamente. Naesset (2004) calculó diferentes estadísticos de los puntos LiDAR incluidos en cada una de las 16 celdas en las que se dividieron las 116 parcelas de estudio. Las diferencias entre las medias y desviación estándar de los valores estimados a partir de los datos LiDAR y los medidos en campo fueron: para la altura media de $-0,58$ a 0,85 $\mathrm{m}$ y de 0,64 a1,01 m; para la altura dominante, de -0,60 a -0,99 m y de 0,67 a 0,84 m; para el diámetro medio, de

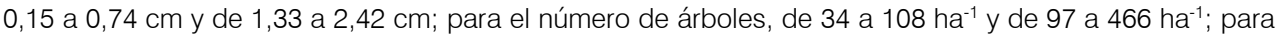
el área basal de 0,43 a 2,51 $\mathrm{m}^{2} \mathrm{ha}^{-1}$ y de 1,83 a 3,94 $\mathrm{m}^{2} \mathrm{ha}^{-1}$; para el volumen de 5,9 a 16,1 $\mathrm{m}^{3} \mathrm{ha}^{-1}$ y de 15,1 a $35,1 \mathrm{~m}^{3} \mathrm{ha}^{-1}$. En este estudio, además de los percentiles relacionados con la distribución de las alturas, se utilizaron otras variables considerando perfiles de densidad de datos LiDAR. Para ello, se dividieron los datos del primer pulso en 10 niveles y se calculó el número de pulsos perteneciente a cada uno de ellos. Holmgren y Jonsson (2004) calcularon estadísticos de la distribución de los datos LIDAR en 29 parcelas y el porcentaje de ocupación de la vegetación para estimar variables en la altura media, media de los diámetros, área basal y volumen con unos valores de RMSE de 0,8 m (5\%), 1,9 cm (8,9\%), 3 $m^{2} h a^{-1}(12,5 \%)$ y $28 m^{3} h a^{-1}(14,1)$, respectivamente.

Además de las variables dasométricas anteriores, hay otras que se pueden estimar a partir de los datos LiDAR. Riaño et al., (2004) estimaron variables para definir modelos de propagación de incendios forestales. Para ello, calcularon diferentes parámetros estadísticos como la altura media, máxima, mínima, los percentiles 1 y 99, y el porcentaje de ocupación a partir de la distribución de los datos LiDAR en parcelas. Con estos datos se estimó la biomasa foliar, altura máxima del árbol, la altura mínima de la copa, percentil 10 de la base de la copa, el volumen de la copa y la densidad aparente con unos resultados máximos en $R^{2}$ de 0,84, 0,95, 0,34, 0,97, 0,92 y 0,80, respectivamente. Con el mismo objetivo, Andersen et al., 
(2005) determinaron el peso del material combustible, la densidad aparente, la altura de la base del dosel y la altura del dosel con un $\mathrm{R}^{2}$ de $0,86,0,84,0,77$ y 0,98, respectivamente. Para ello, obtuvieron estadísticos extraídos de la distribución de los datos LiDAR como los percentiles 10, 25, 50, 75 y 90, la altura máxima, el coeficiente de variación y la fracción del número de pulsos superiores a una altura de $2 \mathrm{~m}$. Morsdorf et al., (2004) determinaron el Índice de Área Foliar (LAl) a partir de la relación entre el número de primeros pulsos y el resto con unos resultados en $\mathrm{R}^{2}$ de 0,6 en parcelas con diámetros superiores a los $30 \mathrm{~m}$. Patenaude et al., (2004) estimaron la cantidad de $\mathrm{CO}_{2}$ a partir de un modelo exponencial en el que se introdujo el percentil 80 como estadístico que mejores resultados proporcionó. Li et al., (2008) realizaron un estudio en el que demostraron que las variables derivadas de los datos LiDAR en parcelas, altura media, coeficiente de variación y densidad de puntos pertenecientes al dosel, proporcionaron los valores más altos en el coeficiente de determinación. Estos ensayos se llevaron a cabo en tres bosques con especies diferentes: Pseudotsuga menziesi y Tsuga heterophyll $\left(\mathrm{R}^{2}=0,87\right)$; Pseudotsuga menziesi y Pinus ponderosa $\left(R^{2}=0,74\right)$; Picea y Betula $\left(R^{2}=0,68\right)$. Pascual et al., (2008) estimaron parámetros relacionados con la estructura forestal en rodales de Pinus sylvestris mediante datos LiDAR. Los rodales se delinearon a partir de un proceso de segmentación del MDV utilizando eCognition. Las mejores variables para la definición y caracterización de la estructura forestal fueron la mediana y la desviación típica de los datos LiDAR en el interior de cada rodal.

En algunos trabajos, además de la distribución de las alturas dentro de las parcelas, se calculan estadísticos de la distribución de los valores de intensidad por parcelas. Lim et al., (2003) utilizaron modelos multiplicativos para la estimación de la biomasa y sus componentes. La media de las alturas de los datos LiDAR incluidos en 49 parcelas fue utilizada como variable independiente en la estimación de la biomasa con un $\mathrm{R}^{2}$ de 0,85 . Hudak et al., (2006) establecieron regresiones múltiples para obtener el área basal y la densidad de árboles en 165 parcelas. Como variables independientes se utilizaron la altura media, la desviación típica de la altura, la altura mínima, la intensidad media, la desviación típica de la intensidad de los datos LiDAR incluidos en estas parcelas. También se consideraron varios estadísticos del porcentaje de cubierta, como el porcentaje de cubierta media, la desviación típica, el porcentaje mínimo y máximo. A partir de estos parámetros obtuvieron un valor de $\mathrm{R}^{2}$ de 0,92 para el caso de la estimación del área basal y de 0,88 para la densidad de árboles. Van Aart et al., (2006) estimaron el volumen y la biomasa a partir del trabajo de campo en 219 parcelas con vegetación formada por coníferas y árboles de hoja caduca. Para ello, se calcularon estadísticos relacionados con la altura, intensidad, porcentaje de ocupación y el porcentaje de pulsos interceptado por la vegetación. En el caso de la vegetación caducifolia se obtuvieron unos valores de $\mathrm{R}^{2}$ ajustados de 0,59 , con un RMSE de $51,15 \mathrm{~m}^{3} /$ ha y para la biomasa 0,58 con RMSE $37,41 \mathrm{Mg} / \mathrm{ha}$. Para el caso de las coníferas los valores de $\mathrm{R}^{2}$ fueron 0,66 para el volumen y 0,59 para la biomasa. Donoghue et al., (2007) obtuvieron unos valores de $R^{2}=0,85$ en la estimación del volumen de Picea sitchensis al utilizar como estadísticos relacionados con la intensidad, el percentil 75 . Sin embargo, los resultados fueron mejores al utilizar como variables explicativas la altura media o el coeficiente de variación, con unos valores de $R^{2}$ de 0,93 y 91, respectivamente. Kim et al., (2009) 
combinaron ambos conjuntos de datos para distinguir entre la vegetación seca y viva en bosques mixtos de coníferas en el Parque Nacional del Gran Cañón (USA). En el caso de biomasa viva se obtuvo un valor máximo de $R^{2}$ de 0,85 utilizando sólo estadísticos de la distribución de las alturas derivadas de los datos LiDAR. Sin embargo en el caso de la vegetación seca el valor del coeficiente de determinación fue menor $(0,79)$. En este caso sólo se utilizaron estadísticos derivados de los valores de intensidad de los datos LiDAR. García et al., (2010) estimaron la biomasa total de las ramas y las hojas utilizando estadísticos derivados de la distribución de las alturas y porcentajes de valores de intensidad en diferentes intervalos de altura en bosques mediterráneos. Los mejores resultados se obtuvieron al considerar las especies por separado obteniendo valores de $R^{2}$ superiores a 0,85, 0,70 y 0,90 para las especies Pinus negra, Quercus ilex y Juniperus thurifera, respectivamente.

\subsubsection{Estudios sobre estimación de variables considerando árboles individuales}

Otro enfoque en el estudio de la vegetación a partir de datos LiDAR, consiste en extraer árboles individuales y estimar sus variables dendrométricas. A partir de un proceso de segmentación del MDV, Hyyppä et al., (2001b) estimaron la altura media, el área basal y volumen de árboles individuales. Los resultados obtenidos en términos de error medio fueron de $1,8 \mathrm{~m}(9,9 \%), 2 \mathrm{~m}^{2} / \mathrm{ha}(10,2 \%)$ y $18,5 \mathrm{~m}^{3} / \mathrm{ha}(10,5 \%)$, respectivamente. Esta precisión sería mejor que la de los inventarios convencionales por rodales. Lim et al., (2001) realizaron una regresión entre las alturas de los árboles medidos en campo y las obtenidas a partir de los datos LiDAR consiguiendo un valor de $\mathrm{R}^{2}$ de 0,92 . De los 147 árboles considerados, un 81\% se estimaron con un error comprendido entre -1 a 1 m. Persson et al., (2002) estimaron la altura, el diámetro de copa y el diámetro de tronco de árboles individuales a partir de una nube de puntos LiDAR con unos valores de RMSE de 0,63 m, 0,61 m y 3,8 cm, respectivamente. La extracción de la copa se basó en una segmentación del MDV suavizado y la aplicación de una superficie parabólica. Un algoritmo similar utilizaron Brandtberg et al., (2003) para estimar la altura de 48 árboles sin hojas, obteniendo un $\mathrm{R}^{2}$ de 0,68 y un error estándar de 1,1 m. Hopkinson et al. (2004) estimaron la altura y el diámetro de tronco de Pinus resinosa y Acer saccharum a partir de la selección manual de los árboles en la nube de puntos LiDAR. Los resultados presentaron una subestimación media en la altura de 1,5 m (7\% de la media de las alturas) y un $R^{2}$ de 0,85 y para el caso del diámetro del tronco una diferencia de $1 \mathrm{~cm}$ y un $R^{2}$ de 0,85 .

Popescu et al., (2003) estimaron la biomasa y el volumen de pinos y de caducifolias a partir de la extracción de árboles individuales. Para su delineación, se realizó una búsqueda de puntos con altura máxima en una ventana circular de tamaño variable según la altura. Los resultados obtenidos en la biomasa fueron un $\mathrm{R}^{2}$ de 0,32 (RMSE $44 \mathrm{Mg} / \mathrm{ha}$ ) para el caso de los árboles caducifolios y de 0,82 (RMSE $29 \mathrm{Mg} / \mathrm{ha}$ ) para el caso de los pinos. En cuanto al volumen, el valor de $R^{2}$ fue de 0,39 (RMSE $52.84 \mathrm{~m}^{3} / \mathrm{ha}$ ) para las parcelas con árboles caducifolios y de 0,83 (RMSE 47,9 m³/ha) para el caso de los pinos. Maltamo et al., (2004) calcularon la regresión entre las alturas de los árboles Picea abies, Pinus sylvestris y Betula pendu- 
la, medidos en campo y las obtenidas a través de los datos LiDAR. Los resultados de la regresión fueron un coeficiente de determinación de 0,93 y un error estándar de 1,58 m. Morsdorf et al., (2004) realizaron una regresión lineal entre las alturas de los 917 árboles medidos en campo y las correspondientes a los datos LIDAR. Los resultados fueron un $\mathrm{R}^{2}$ de 0,92 y un RMSE de 0,60 m. En contraste, los resultados fueron bajos en la estimación del diámetro de copa con $R^{2}$ de 0,20 y RMSE de 0,47 m. Falkowski et al., (2006) aplicaron el cálculo de wavelets sobre un MDV. El estudio se realizó sobre 30 árboles aislados en bosques abiertos. Los resultados obtenidos en la estimación de la altura y el diámetro de copa fueron un valor de r de 0,97 (RMSE 2,64 m) y 0,86 (RMSE 1,35 m), respectivamente. Popescu, (2007), aplicó modelos de regresión entre los datos medidos en campo y los obtenidos a partir de datos LiDAR para estimar el diámetro de tronco, la biomasa y las componentes de la biomasa con unos valores de $R^{2}$ de $0,90,0,93$ y entre $0,79-0,80$, respectivamente. Para ello, se basó en el cálculo de la altura y el diámetro de copa de árboles individuales delineados a partir del MDV.

Hay estudios en los que se comparan dos métodos para la estimación de variables forestales. Un enfoque sería la identificación de árboles a partir del MDV y a continuación, el cálculo de variables a partir de los puntos-celdas pertenecientes a cada árbol. El otro enfoque consistiría en calcular variables considerando las alturas de los puntos-celdas incluidos en una parcela-subparcela. Holmgren et al., (2003) compararon ambos métodos en 65 parcelas con presencia de Picea abies, Pinus sylvestris y Betula pendula. En la aproximación basada en la distribución de alturas, calcularon en cada parcela cubierta de vegetación, la media de la altura máxima en celdas de área $1 \mathrm{~m}^{2}$, obteniendo un $\mathrm{R}^{2}$ máximo de 0,90 y RMSE de $1,53 \mathrm{~m}$ ( $11 \%$ de la media de las alturas). En el caso del análisis en árboles individuales, el valor máximo de $\mathrm{R}^{2}$ fue 0,91 con un RMSE de 1,45 m (10\% de la media de la altura). También estimaron el volumen de la parcela considerando el número de árboles y su altura con un $R^{2}$ de 0,82 y RMSE de 43 $\mathrm{m}^{3} /$ ha (26\% de la media del volumen) y utilizando porcentajes de ocupación y la altura media dominante de las parcelas, obteniendo un $R^{2}$ de 0,90 y RMSE (37 $\mathrm{m}^{3} / \mathrm{ha}$ ). Popescu et al., (2002) estimaron la altura máxima de cada subparcela utilizando el percentil 75 y el 99 con un $R^{2}$ de 0,79. La estimación de la altura máxima de los árboles identificados a partir del MDV se realizó considerando los estadísticos elevación media y máxima de los puntos-celdas de cada árbol con un valor de $R^{2}$ de 0,85. Hollaus et al., (2006) estimaron la altura media de 103 parcelas utilizando los puntos originales y el MDV. En el primer caso, se consideró el percentil 82 con un valor de $\mathrm{R}^{2}$ 0,73 y RMSE de 3,7 m. Cuando se utilizó el percentil 89 del MDV se obtuvo un valor de $R^{2}$ de 0,68 y RMSE 4 m. En este trabajo también se estimó la altura de 196 árboles, obteniéndose un $R^{2}$ de 0,84 y RMSE de $3 \mathrm{~m}$ al considerar todos los puntos y un $R^{2}$ de 0,87 y RMSE de 2,6 al utilizar el MDV. 


\subsubsection{Aplicaciones en vegetación arbustiva}

Pocos estudios se han centrado en el análisis de la vegetación arbustiva a partir de datos LiDAR. Una de las razones puede ser la dificultad de medir variables que caractericen este tipo de vegetación para ser correlacionadas con datos LiDAR, a diferencia de los árboles, para los que existen ecuaciones que permiten estimar variables dendrométricas de árboles a partir de medidas simples en campo.

La mayor parte de los estudios sobre vegetación a partir de datos LiDAR se centran, por tanto, en el substrato arbóreo. En estos trabajos se suele aplicar un umbral a la altura de los datos LiDAR para eliminar los que pertenecen a las zonas cercanas al suelo (Figura 5), incluida la vegetación arbustiva (Popescu et al., 2002; Naesset, 2004; Kim et al., 2009). En contraste, este valor de umbral sería la elevación máxima a considerar en los estudios sobre vegetación arbustiva.

Los trabajos en los que se analiza este tipo de vegetación se suelen realizar en zonas abiertas con baja presencia de arbolado. La detección de vegetación arbustiva en zonas de arbolado denso es más compleja debido al hecho de que es menos probable que los pulsos alcancen el suelo, siendo necesaria una alta densidad de puntos (Su y Bork, 2007). Estos autores estimaron alturas de la vegetación obteniendo valores de $R^{2}$ para el caso de los árboles superiores a 0,9, mientras que para la vegetación arbustiva no se superó el valor de 0,21.

Un denominador común de los estudios de vegetación arbustiva con datos LiDAR es la utilización de imágenes multiespectrales con el fin de mejorar clasificaciones de vegetación realizadas. Mundt et al. (2006) combinaron ambos tipos de datos para crear un mapa de Artemisia tridentata. Al combinar la imagen multiespectral con la variable rugosidad, obtenida a partir de los datos LiDAR, se mejoró la clasificación de la imagen pasando de una fiabilidad global del 74\% al 89\%. Mutlu et al. (2008) utilizaron datos LiDAR y una imagen QuickBird para realizar una clasificación de la vegetación con el objetivo de crear un modelo de combustibles. Al combinar los dos conjuntos de información, la precisión de la clasificación supervisada mejoró, variando la fiabilidad global de 76,52\% a 90,10\%. De igual modo que en los casos anteriores, Su y Bork (2007), mejoraron los resultados de una clasificación de la vegetación al utilizar datos LiDAR y una imagen multiespectral pasando del 59,4\% al 75,6\% en la fiabilidad global. En otros trabajos, se obtuvieron mapas de comunidades vegetales incorporando la información proveniente del MDV para realizar una clasificación de la vegetación por especies y estructura (Hill y Thomson 2005; Verrelst et al. 2009). La combinación de ambos conjuntos de información también se utilizó para obtener un MDE más preciso (Rango et al. 2000; Riaño et al. 2007). 


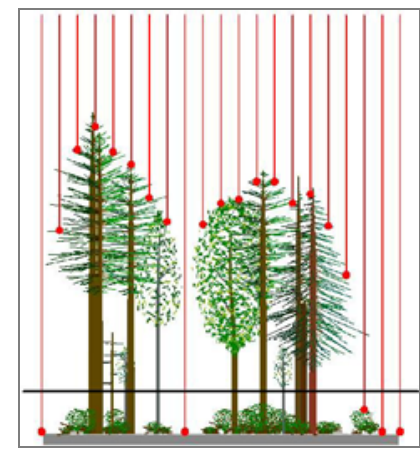

Figura 5. Definición de umbrales para eliminar puntos asociados al suelo o vegetación arbustiva en estudios forestales con predominio de árboles (Fuente: manual software FUSION/LDV. United States Department of Agriculture. Forest Service).

Los estudios en los que se estiman propiedades físicas de árboles se basan en la extracción de las copas a partir de la distribución de las alturas de los datos LiDAR (Hyyppä et al., 2001; Holmgren et al., 2003; Persson et al., 2002; Maltamo et al., 2004; Popescu, 2007). Con la vegetación arbustiva no sucede lo mismo ya que se trata de una estructura continua y más complicada. Por esa razón, cuando se comparan alturas de la vegetación arbustiva medidas en campo con los datos LiDAR se utilizan zonas de influencia. La estrategia común en estos trabajos es seleccionar los puntos LiDAR incluidos en un "buffer" con centro el punto medido en campo y un radio determinado. La selección del radio está relacionada con los factores que pueden afectar a la precisión en el cálculo de las alturas de la vegetación. Según Hyyppä et al., (2008) entre los factores que pueden afectar a la calidad de un MDV se encontrarían: densidad y cubierta de los pulsos láser; algoritmo para el cálculo del MDE; sensibilidad del sistema láser y algoritmos utilizados en la definición de umbrales para el proceso de la señal; penetración de pulsos en el dosel; tipo de vegetación. La subestimación de la altura de la vegetación se debe también al hecho de que el pulso no intercepte la parte alta de la vegetación (Gaveau and Hill, 2003). Para Streutker y Glenn (2006) la selección del radio está relacionada con la precisión horizontal de los datos LiDAR y del equipo GPS. Además de estos factores, Su y Bork (2006), afirmaron que errores del MDE en pendientes elevadas pueden generar errores en los estudios de vegetación herbácea. Por otra parte, el ángulo de observación y el tipo de vegetación también afectaría a la capacidad de penetración del sensor. Si la vegetación es poco densa y abierta, la capacidad de penetración será más alta (Hopkinson et al., 2005).

Al igual que en el caso de la vegetación arbórea, la estimación de la altura de la vegetación arbustiva a partir de datos LiDAR genera subestimaciones (Gaveau y Hill, 2003; Hill y Thomson, 2005; Hopkinson et al., 2005; Streutker y Glenn, 2006; Bork y Su, 2007; Riaño et al., 2007). En términos relativos sería más importante para el caso de la vegetación arbustiva, al ser más baja que la vegetación de sustrato arbóreo (Patenaude et al., 2004; Su y Bork 2007). 
Otros trabajos en los que se utilizaron datos LiDAR para obtener parámetros estructurales de la vegetación arbustiva se centraron en el cálculo de la altura. Streutker y Glenn (2006) establecieron la relación entre las alturas medidas en campo y las obtenidas a partir de datos LiDAR. También determinaron la presencia de Artemisia tridentata y otros tipos de arbustos bajos con una fiabilidad global del $86 \%$. Sin embargo, se consiguió una baja fiabilidad del usuario en la clase ausencia de vegetación (57\%), indicando que los datos LiDAR no reflejan suficientemente la parte alta de la vegetación. Se detectaron diferencias entre la vegetación quemada y no quemada utilizando la variable rugosidad calculada a partir de los datos LiDAR. Esta variable es muy útil para medir la variabilidad dentro de un ecosistema. Riaño et al. (2007) utilizaron datos LiDAR y una imagen Quickbird para la creación de un mapa de combustibles basado en las alturas de la vegetación arbustiva. Con la imagen de satélite se consiguió mejorar la estimación de las alturas de la vegetación variando el valor de $R^{2}$ de 0,48 a 0,65. Para ello, se utilizó el percentil 90 de las alturas de los datos LiDAR por parcelas.

\subsubsection{Discusión}

En los estudios precedentes se ha podido comprobar el potencial del sistema LiDAR en la predicción de variables dasométricas y dendrométricas de áreas forestales, mejorando la precisión en la estimación de estas variables respecto a los métodos tradicionales (Hyyppä etal., 2001b; Holmgren, J. y Jonsson, T. 2004). Para llevar a cabo este tipo de investigaciones se distinguen dos metodologías diferentes: la estimación de variables forestales considerando como unidad de estudio la parcela y la estimación de variables dendrométricas de árboles individuales. En este caso es necesario obtener la copa de los árboles que suele calcularse a partir de la segmentación del modelo digital de vegetación. Esta variable junto a la altura de los árboles muestran una elevada correlación con otras variables como el diámetro del tronco y biomasa de los árboles (Popescu et al., 2007). En estos estudios se obtienen buenas precisiones en coníferas cuyo porte es fundamentalmente vertical, como es el caso de bosques boreales. Sin embargo, las precisiones son más bajas cuando se trata de árboles de hoja caduca debido a la mayor irregularidad de sus copas. Cuando los estudios se centran considerando como unidad de análisis la parcela, se calculan estadísticos de la distribución de las alturas de los LiDAR que se utilizarán como variables independientes en los diferentes modelos de regresión. Diversos autores han demostrado que la altura media del MDV presenta una buena correlación con la altura del dosel (Naesset, 1997; Lim y Treitz, 2004; Magnussen et al., 2002). En el caso de la biomasa, además de esta variable, el coeficiente de variación muestra una correlación muy alta con la biomasa (Donoghue et al., 2007; Hudak et al., 2006; Kim et al., 2009). Además de estas variables, las estimaciones de los parámetros forestales mejoraron al considerar estadísticos obtenidos de la densidad de puntos por intervalos de alturas (Andersen et al., 2005; Van Aart et al., 2006; Li et al., 2008). 
Mientras que numerosas investigaciones se han desarrollado en áreas forestales con presencia de substrato arbóreo, pocos estudios se han centrado en el análisis de la vegetación arbustiva, muy frecuente en el paisaje forestal mediterráneo. Además, estas áreas son relevantes desde un punto de vista paisajístico y medioambiental ya que impiden la erosión del suelo, explican la presencia de diferentes especies de animales y suponen un sumidero relevante de $\mathrm{CO}_{2}$.

De las dos metodologías utilizadas para el estudio las áreas forestales mediante datos LiDAR, sólo es posible aplicar la que utiliza como unidad de estudio la parcela para el estudio de la vegetación arbustiva. Para ello, es necesario analizar si los estadísticos derivados de la distribución de los datos LiDAR por parcela permiten generar buenas estimaciones de la altura, la biomasa y el volumen de este tipo de vegetación. La metodología basada en la selección de árboles como unidad de análisis no se podrá realizar en el caso de la vegetación arbustiva ya que se trata de una estructura continua y de reducida altura, lo que implica una mayor dificultad en su análisis y en la definición de individuos.

La mayor parte de los estudios sobre vegetación arbustiva tuvieron como objetivo el cálculo de mapas de ocupación y estimación de la altura. Todos los estudios demostraron que la altura de la vegetación arbustiva tiende a ser subestimada utilizando el sistema LiDAR. Sin embargo, en estos estudios, realizados en áreas con pendiente bajas a diferencia de las características de la zona de esta investigación, no se analizó cómo influye el factor pendiente, la precisión del MDE y la densidad de datos LiDAR. Por lo tanto, son necesarias nuevas investigaciones para un mejor conocimiento de estas áreas, estimando otros parámetros como el volumen y la biomasa, variables importantes para evaluar un ecosistema y la estructura del paisaje, así como de los bosques (Zimble et al., 2003; Zheng et al., 2004). 
3. OBJETIVOS 

Este trabajo de investigación tiene dos objetivos generales:

- $\quad$ Adaptar un algoritmo basado en procesos iterativos de búsqueda de elevaciones mínimas a partir de datos LiDAR para el cálculo de un MDE en zonas de montaña mediterránea, caracterizadas por la presencia de pendientes elevadas y de vegetación arbustiva.

- Desarrollar y optimizar modelos para la estimación de los parámetros forestales: altura, biomasa y volumen de la vegetación arbustiva, tanto en parcelas como en subparcelas.

Los objetivos específicos relacionados con el primer objetivo general son los siguientes:

- Evaluar los parámetros óptimos del algoritmo de cálculo del MDE para este tipo de zonas y vegetación. Los parámetros analizados fueron: datos de entrada, tamaño de ventana y umbrales.

- Analizar los valores óptimos de los parámetros anteriores en áreas con diferentes características (presencia de arbolado y pendientes bajas).

- $\quad$ Estudiar el efecto de la densidad de puntos LiDAR, pendiente del terreno y presencia de vegetación en la precisión del MDE.

Los objetivos específicos relacionados con el segundo objetivo general de esta investigación son los siguientes:

- $\quad$ Estudiar el efecto de inclusión de información espectral en la precisión de los modelos de estimación de la biomasa y volumen.

- Evaluar el tamaño de subparcela óptimo para la estimación de los parámetros forestales mediante datos LiDAR

- Analizar la influencia de factores como el tipo de vegetación, la precisión del MDE y densidad de puntos LiDAR en el error de estimación de los modelos obtenidos.

- $\quad$ Obtener la capa de vegetación arbustiva presente en la zona de estudio. Analizar el efecto de incluir información espectral sobre la precisión en la obtención del mapa de la cubierta arbustiva.

- Definir una metodología alternativa para la estimación del volumen real y biomasa en matorral por subparcelas, a partir de datos LiDAR, basada en parámetros obtenidos en los muestreos de campo dendrométricos y dasométricos. 

4. MATERIAL Y MÉTODOS 

En este apartado se describirán los datos y metodología utilizada en la generación de los modelos digitales de elevación y en la estimación de parámetros forestales.

\subsection{MATERIAL Y DATOS}

Aunque el estudio se ha realizado fundamentalmente en Chiva, la disponibilidad de datos exhaustivos de las elevaciones del terreno en una zona de El Saler, ha permitido comparar y validar la metodología utilizada en la generación de modelos digitales de elevación en ambas áreas.

\subsubsection{Zona de estudio}

\section{Chiva}

La zona de estudio abarca una superficie de $9 \mathrm{~km}^{2}$ y se encuentra en el término municipal de Chiva (Valencia) a 6,5 km en dirección NO del centro de la ciudad. El límite por el norte coincide con el camino de la Nevera, al este coincide con el paraje de la fuente de la Umbría, el sur con la línea de término municipal que separa Chiva de los municipios de Buñol y Siete Aguas, y al oeste con la loma Charnera.

El área de trabajo está incluida en un rectángulo definido por las coordenadas UTM $X_{\text {máxima, }} Y_{\text {máxima, }}, X_{\text {mínima }}$ $Y_{\text {mínima }}(689800,4376028,683800,4373000)$ en el huso 30 y sistema de referencia European Datum 1950 (Figura 6). Se trata de una zona de montaña con predominio de matorral en la que la cota varía entre los 442 y los $1.000 \mathrm{~m}$ y con una pendiente media del $45 \%$.

El elemento hidrográfico de mayor importancia es el barranco Ballesteros que cruza la zona de estudio. Esta zona presenta una accesibilidad alta a los acuíferos, hecho confirmado por la presencia en la zona de estudio de dos fuentes como son la de la Umbría y la de Enebro. Las temperaturas medias anuales de la zona oscilan alrededor de los $14^{\circ} \mathrm{C}$, correspondiendo los máximos estivales a los meses de julio y agosto. Los valores mínimos se sitúan en torno a los $6^{\circ} \mathrm{C}$ en el mes de enero que, junto con febrero y diciembre, forman un invierno templado-frío. Los valores de precipitación media anual oscilan entre 500 y $600 \mathrm{~mm}$. Existe un período de sequía no muy acusado (3 a 3,5 meses) con mínimo mensual en julio; la máxima pluviosidad se registra en los meses de octubre y noviembre, generalmente debido a precipitaciones torrenciales concentradas en la época otoñal. Los valores de ETP no son muy elevados, 750 a $850 \mathrm{~mm}$ anuales, encontrándose un déficit de lluvia (ETP-P) de unos $160 \mathrm{~mm}$ a $250 \mathrm{~mm}$, con especial incidencia durante el período julio-agosto. El suelo está constituido principalmente por arcillas, areniscas y margas o calizas micríticas y oolíticas. 


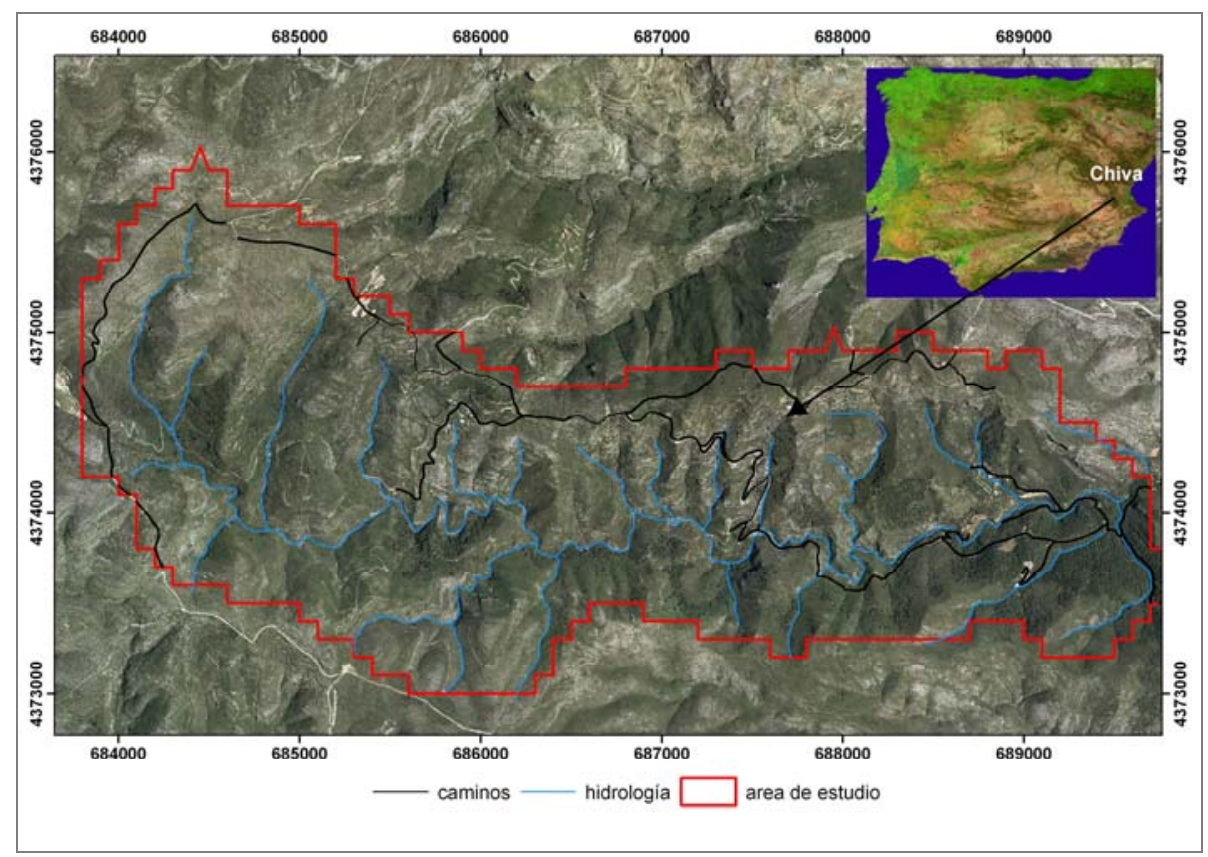

Figura 6. Mapa de la zona de estudio de Chiva.

En cuanto a la vegetación de la zona y según el inventario forestal de la Comunidad Valenciana se trata de una zona forestal con predominio de matorral con un porcentaje de ocupación medio del 55\%. La especie dominante es Quercus coccifera (Figura 7), una de las especies más características de la región Mediterránea (Gómez et al., 1998) y elemento fundamental de las provincias ibéricas y del este del Mediterráneo (Takhtajan, 1986).
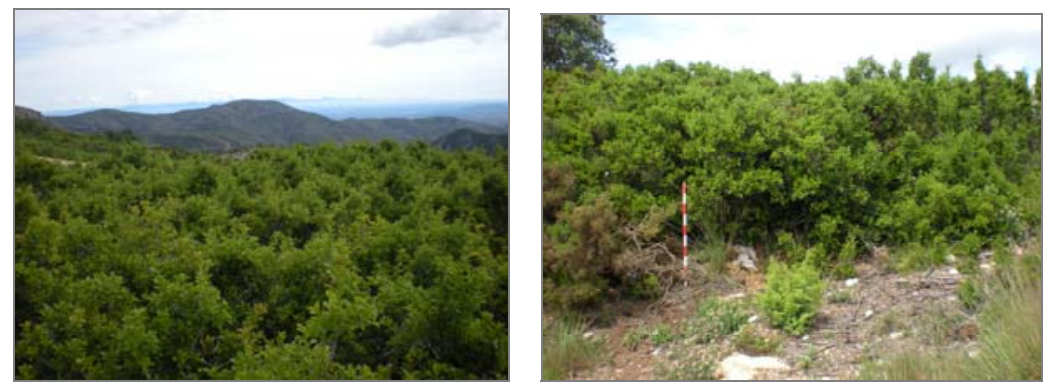

Figura 7. Fotografías de la zona de estudio con presencia densa de coscoja (Quercus coccifera).

Otras especies presentes son Rosmarinus officinalis, Ulex parviflorus, Cistus albidus L. y Erica multiflora L. Aunque bien es cierto que existe presencia de otras especies arbustivas, éstas no llegan a ser un porcentaje significativo en volumen ocupado y biomasa total, ni forman masas propias y diferenciadas. Por esta razón, los análisis dendrométricos y dasométricos realizados se han centrado sobre las cinco especies 
más abundantes. En cuanto al arbolado, éste supone aproximadamente un 5-10\% de la superficie de la zona de estudio. La especie con mayor presencia es el Pinus halepensis, aunque también hay algunas zonas con Quercus ilex.

\section{El Saler}

La zona de estudio forma parte de la Devesa de El Saler, restinga arenosa o cordón litoral que separa la Albufera de Valencia del mar. Se trata de una estructura sedimentaria construida a partir de la arena que la deriva litoral ha transportado desde la desembocadura de los ríos. Los cordones arenosos poseen formaciones dunares construidas por la acción del viento. Incluyen sucesivos subambientes sedimentarios que se distribuyen longitudinalmente desde la costa hasta el sector interno. Así, desde la playa, sometida a la acción de oleajes, se pasa a la zona de dunas incipientes y las dunas móviles, y desde éstas a las fijadas por la vegetación, como es el caso de la zona de estudio (Figura 8).
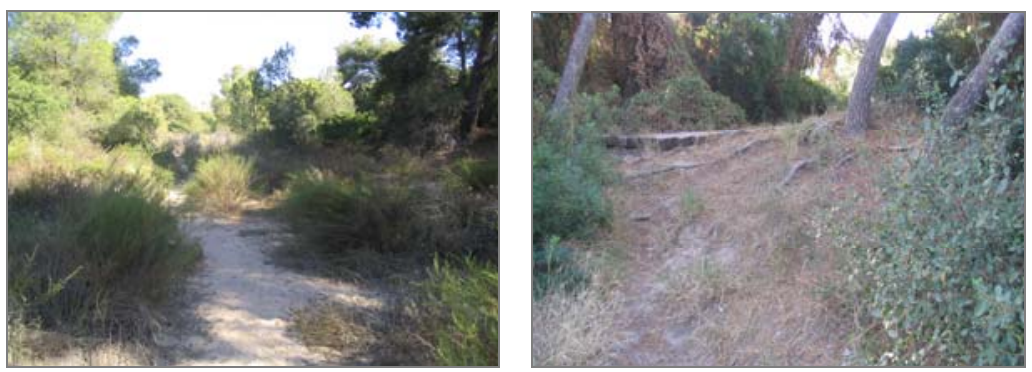

Figura 8. Imágenes de la zona de estudio de El Saler.

La zona de estudio está delimitada al oeste por la carretera CV-500, al norte por la Gola del Pujol y al este por el Estany del Pujol - playa de la Devesa (Figura 9). El área de trabajo está incluida en un rectángulo definido por las coordenadas UTM de los puntos A (730736, 4359130), B (731422, 4359311), C (731587, 4358846) y D $(730897,4358628)$ en el huso 30 y sistema de referencia European Datum 1950.
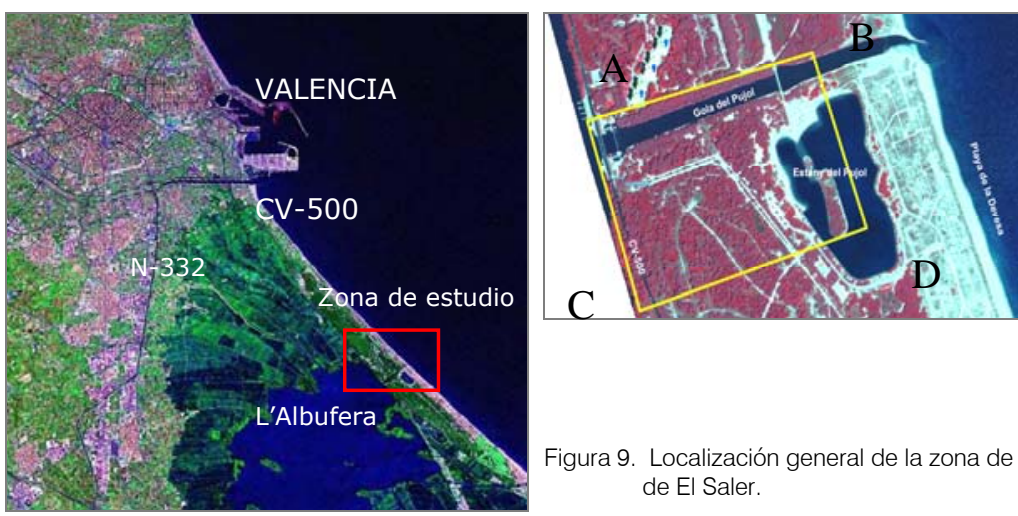

Figura 9. Localización general de la zona de estudio de El Saler. 


\subsubsection{Datos utilizados}

\section{Chiva}

Los datos LiDAR fueron adquiridos mediante un vuelo realizado en diciembre de 2007 utilizando el sensor Optech ALTM 2050 con las siguientes características en la adquisición de los datos: altura de vuelo - 700 m por encima del suelo; frecuencia de pulso - $50 \mathrm{kHz}$; frecuencia de escaneado - $47 \mathrm{~Hz}$; ángulo de escaneado - $\pm 18^{\circ}$; velocidad de vuelo - $70 \mathrm{~m} / \mathrm{s}$; ancho de barrido - $400 \mathrm{~m}$; distancia entre líneas de vuelo $300 \mathrm{~m}$; número de líneas de vuelo - 10; número total de puntos - 78.919.301; densidad nominal de pulsos - 4 puntos $/ \mathrm{m}^{2}$; número de ecos - 2. Sin embargo, algunas áreas tuvieron mayor densidad de puntos (Figura 10) como consecuencia de las 10 líneas de vuelo registradas. Por esta razón, la densidad media de puntos considerando todos los retornos fue 8 puntos $/ \mathrm{m}^{2}$. Aunque el número de retornos fue 2, más del 99\% de los datos LiDAR registrados pertenecieron al primer retorno. Este hecho podría ser explicado teniendo en cuenta la poca altura de las masas arbustivas. Los datos fueron entregados en 40 ficheros en formato LAS con los siguientes campos: tiempo, $X, Y, Z$, ángulo de escaneo y retorno.

Para analizar la precisión altimétrica de los datos LiDAR, se midieron 60 puntos utilizando un equipo GPSRTK en áreas llanas sin vegetación. Las elevaciones de estos puntos se compararon con la media de las elevaciones de los datos LiDAR incluidas en un búfer de radio 0,5 m alrededor de cada punto medido. Como se puede apreciar en la Figura 11 los residuos entre las elevaciones de los datos LiDAR y los datos medidos en campo fueron bajos, siendo el error medio cuadrático (RMSE) $6 \mathrm{~cm}$. Los mismos resultados se obtuvieron en áreas con pendiente media del 40\% sin vegetación. La precisión horizontal de los datos LiDAR fue de 0,5 m según las especificaciones técnicas del vuelo. Estos resultados muestran que los datos LiDAR tienen una precisión adecuada para este estudio.

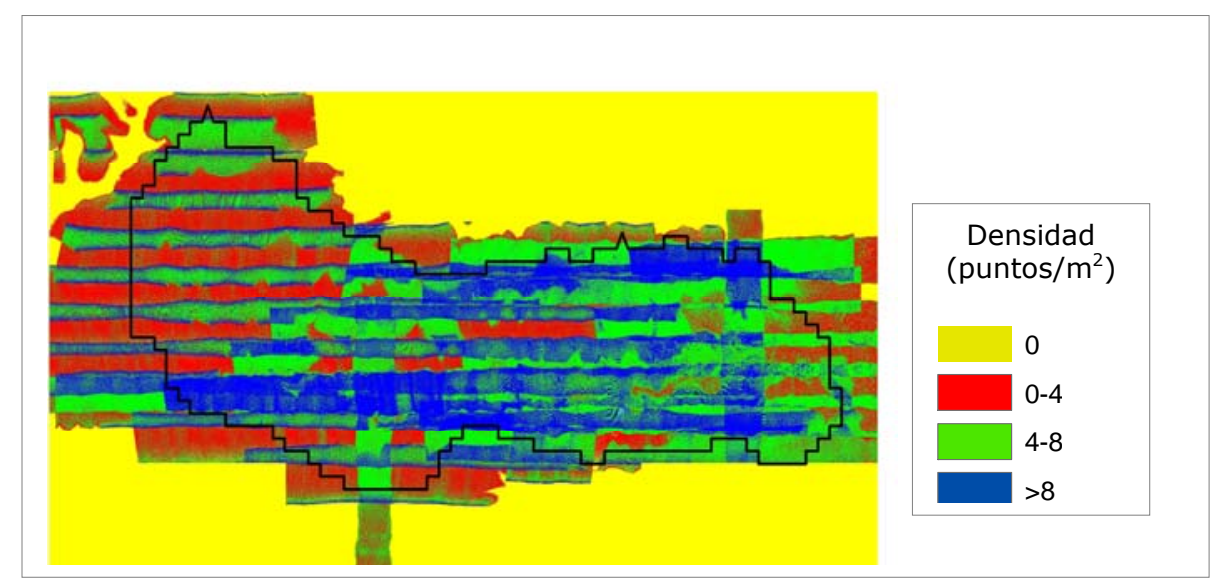

Figura 10. Densidad de puntos por $\mathrm{m}^{2}$ de los datos LIDAR de la zona de estudio de Chiva. El polígono negro representa la zona de estudio. 
También se ha utilizado una imagen aérea registrada por la cámara Ultracam D fabricada por Vexcel Imaging GMBH con tres bandas espectrales: banda 1 (b1) infrarrojo (IR); banda 2 (b2) rojo (R); banda 3 (b3) verde $(G)$. El tamaño de celdas de estas imágenes es $0,5 \mathrm{~m}$ y fueron tomadas durante el mes de julio de 2006. Estas imágenes pertenecen al Plan Nacional de Ortofografía Aérea (PNOA) 2004-2007 (Figura 12).

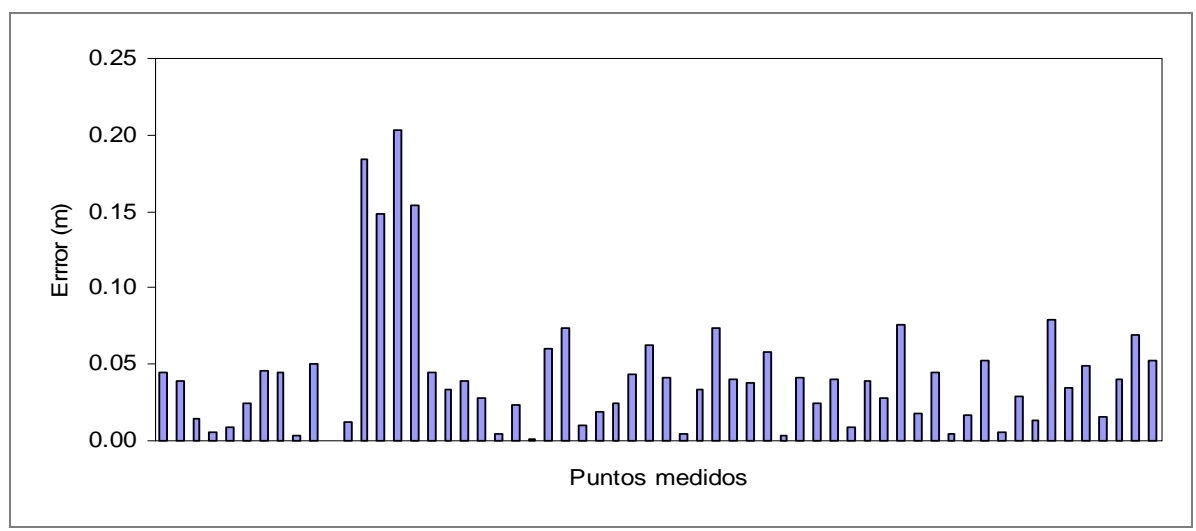

Figura 11. Diferencias entre las elevaciones de 60 puntos medidos con GPS-RTK y la elevación media de los datos LIDAR incluidos en un buffer de radio $0,5 \mathrm{~m}$ con centro en el punto medido.

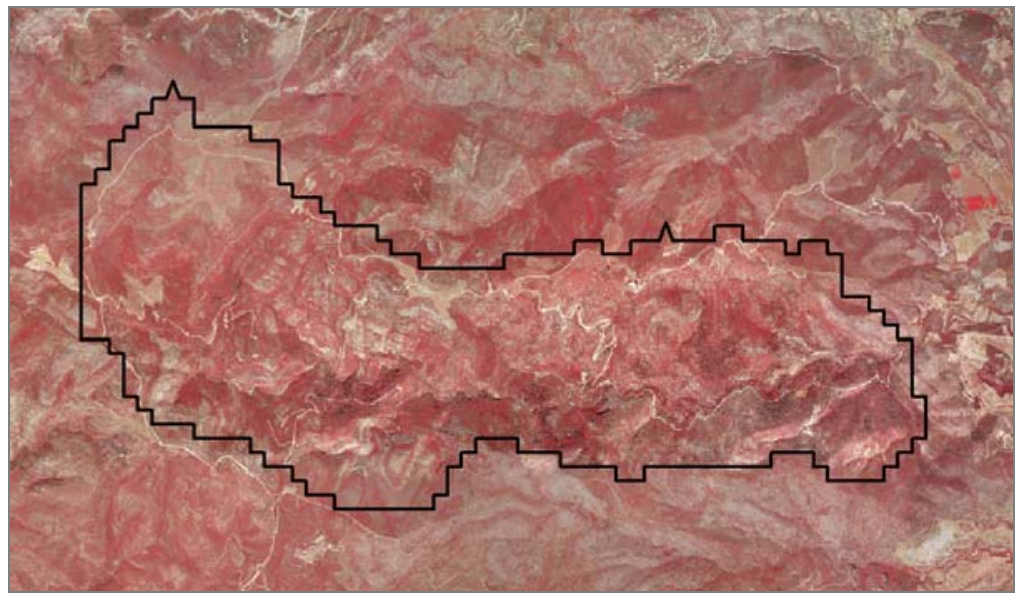

Figura 12. Composición en falso color de la imagen aérea en la que las bandas $I R, R$ y $G$ se visualizan en los canales R, G, B, respectivamente. Los colores rojos corresponden a la vegetación arbustiva. 


\section{El Saler}

En este caso los datos LiDAR fueron adquiridos en un vuelo realizado en mayo de 2005, con el sensor Optech ALTM 2033 con las siguientes características en la adquisición de los datos: altura de vuelo - 875 m por encima del nivel del mar; frecuencia de pulso - $33 \mathrm{kHz}$; frecuencia de escaneado - $28 \mathrm{~Hz}$; ángulo de escaneado - $\pm 20^{\circ}$; velocidad de vuelo - $68 \mathrm{~m} / \mathrm{s}$; ancho de barrido - $630 \mathrm{~m}$; recubrimiento lateral $39 \%$; número de líneas de vuelo - 5 (Figura 13) densidad nominal de pulsos - 1 puntos $/ \mathrm{m}^{2}$; número de ecos 2. Los datos fueron entregados en formato LAS con los siguientes campos: tiempo, $X, Y, Z$, ángulo de escaneo y retorno.

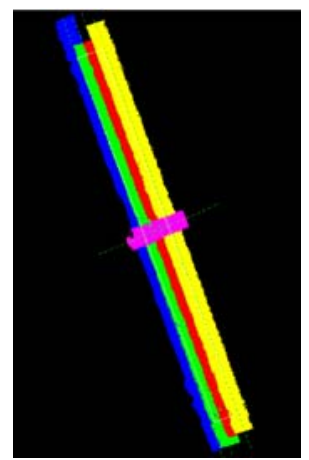

Figura 13. Lineas ae vueı ae Ia zona ae estudio de El Saler.

\subsubsection{Levantamientos topográficos}

En este apartado se describirán los trabajos topográficos en las dos zonas de estudio realizados para validar los diferentes ensayos en el cálculo de modelos digitales de elevaciones.

\section{$\underline{\text { Chiva }}$}

Para la evaluación de los modelos digitales de elevaciones se realizó un levantamiento topográfico con un GPS sistema RTK (Leica System 1200) compuesto por dos equipos, uno fijo y otro móvil (Figuras 14 a y b). Antes de empezar el levantamiento, se realizó una transformación entre los sistemas de referencia ERTS89 y ED50. Para ello, se estacionó en un vértice geodésico de la red de $4^{\circ}$ orden de la Comunidad Valenciana (vértice 4033) y se visitó a otros tres presentes en la zona (Figura 14 c). Los errores en la transformación fueron inferiores a $1 \mathrm{~cm}$ en altimetría e inferiores a $5 \mathrm{~cm}$ en el ajuste planimétrico (Anejo 1).

En el levantamiento topográfico se midieron 1379 puntos distribuidos por toda la zona de estudio de manera aleatoria. Según las especificaciones técnicas del equipo GPS, los errores medios cuadráticos (RMSE) horizontal y verticalmente fueron de $1 \mathrm{~cm}$ y $2 \mathrm{~cm}$, respectivamente. El error horizontal y vertical medio de los puntos medidos fue $1 \mathrm{~cm}$ y $1,5 \mathrm{~cm}$, respectivamente. El sistema GPS-RTK no registró ningún punto con error superior a los $5 \mathrm{~cm}$. 


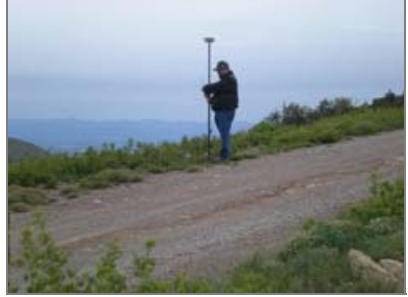

(a)

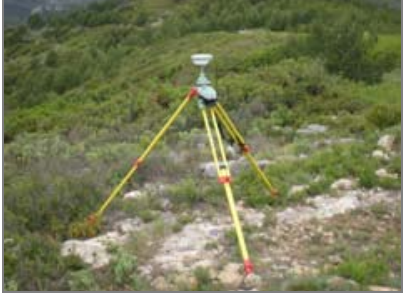

(b)

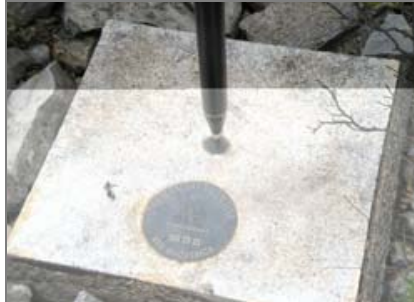

(c)

Figura 14. Representación del equipo móvil (a) y fijo (b) del sistema GPS -RTK; (c) vértice 4033 de la red de $4^{\circ}$ orden de la Comunidad Valenciana.

\section{El Saler}

Para evaluar y seleccionar los parámetros óptimos de la metodología seguida en el cálculo de un MDE, se realizó un levantamiento topográfico mediante un equipo GPS sistema RTK y una estación total para obtener datos en zonas con alta presencia de árboles en las que no se pudo realizar la medición con el equipo GPS. En el primer caso se utilizó un equipo de doble frecuencia Trimble 5700 y en el segundo una estación Leica TC-407, midiéndose 185 puntos distribuidos de manera aleatoria, siendo todos ellos representativos de la zona de estudio.

\subsubsection{Cálculo de la biomasa, volumen y altura a partir de datos de campo}

Los resultados de este apartado hacen referencia al artículo publicado "Dendrometric and dasometric analysis of the bushy biomass in Mediterranean forests" en la revista Forest Ecology and Management (2010).

Para el cálculo de las variables forestales (biomasa y volumen) a partir de datos medidos en campo, que serán correlacionadas con los estadísticos derivados de los datos LiDAR, se realizaron dos tipos de análisis. Primero, un análisis dendrométrico que pretende determinar el volumen y la biomasa de cada planta a partir de medidas morfológicas simples, como son el diámetro del tallo, longitud y peso. Este estudio fue necesario para un análisis dasométrico posterior. Con este se pretende determinar la biomasa y el volumen real (sin huecos) ocupado por los vegetales en una parcela o subparcela a partir de la medición dendromética de algunos de los individuos en su interior y del porcentaje de ocupación de cada especie arbustiva en cada parcela.

\section{Análisis dendrométrico}

Para el análisis dendrométrico se analizaron muestras de 100-150 plantas de cada especie extraídas de 29 parcelas de $100 \mathrm{~m}^{2}$ y localizadas en diferentes capas bioclimáticas (elevación), pendientes y orientación. Las parcelas fueron distribuidas aleatoriamente en el interior de las celdas de una cuadrícula con la que se dividió la zona de estudio. El tamaño de la celda fue de $1 \mathrm{~km}^{2}$ y dentro de ellas se eligió al menos una parcela, siempre y cuando tuviera vegetación (Figura 15). 


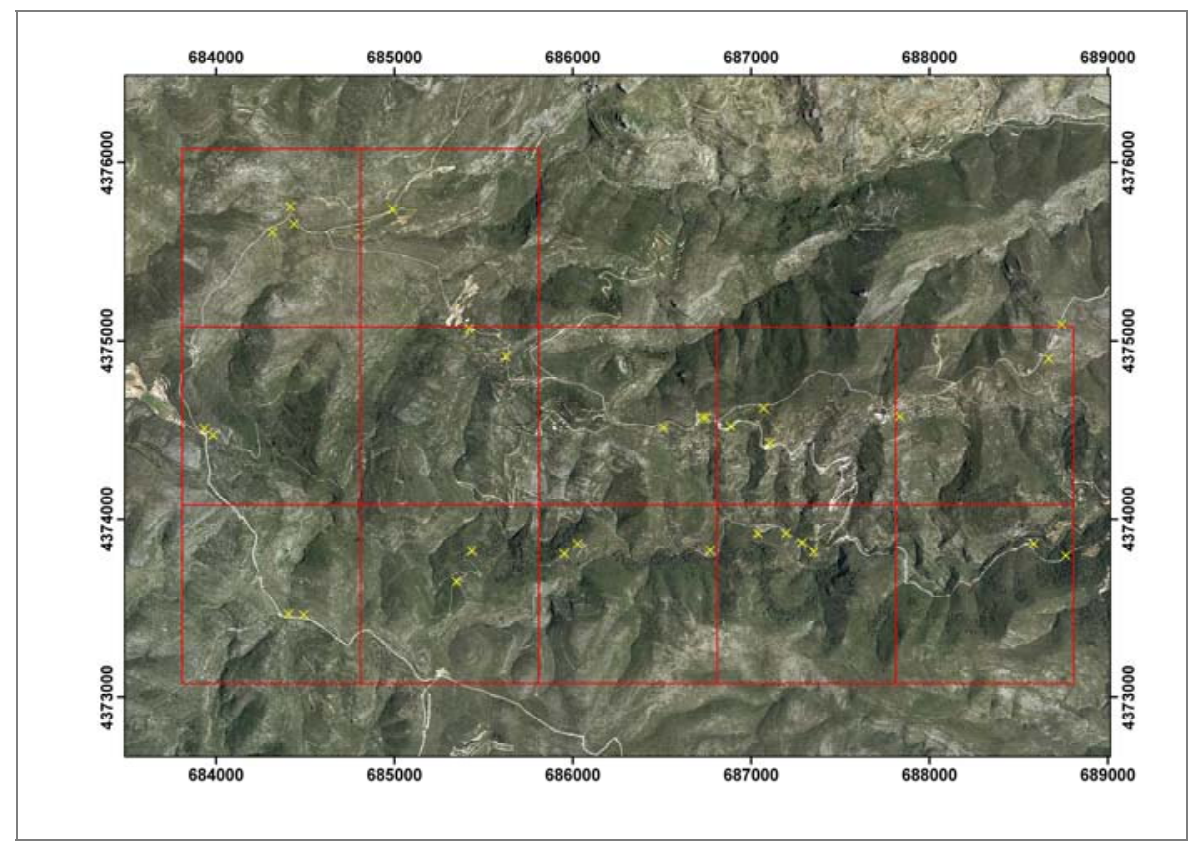

Figura 15. Distribución de las parcelas en la zona de estudio utilizando cuadrículas de tamaño de celda de $1 \mathrm{~km}^{2}$ y representada en color rojo

Para poder determinar el volumen real de un individuo se definió un coeficiente mórfico global f, determinado por el cociente entre el volumen real y el volumen de un modelo tomado como referencia (ecuación 1).

$$
f=\frac{\text { Volumen real del vegetal }}{\text { Volumen del modelo }}
$$

El volumen real de cada planta se obtuvo sumergiendo cada individuo en agua y determinando el volumen desplazado. Como volumen modelo de referencia se suele utilizar un sólido de revolución (cilindro, paraboloide, cono o neiloide). En este trabajo se utilizó como sólido de revolución el cilindro, ya que fue el que mejor se adaptó a las especies estudiadas (Velázquez-Martí, 2010).

La determinación del coeficiente de forma permite estimar el volumen real de un individuo en campo a partir de variables como la altura y el diámetro, medidas in situ sin tener que emplear métodos destructivos (ecuación 2).

$$
V_{i}=\frac{\pi \cdot d^{2}}{4} \cdot h \cdot f
$$

Donde $V_{i}$ es el volumen real del individuo, $d$ es el diámetro de la base del tallo principal y $h$ la altura del vegetal, que han sido medidos para cada individuo de la muestra, y $f$ el factor de forma. 
En principio, el coeficiente mórfico global debe ser un parámetro característico de la especie y clase diamétrica para cada uno de los modelos probados, no obstante, para cada una de las determinaciones realizadas existe una variabilidad estadística, caracterizada por la media y la desviación estándar (Tabla 1) Junto con el volumen real se ha determinado la humedad de la planta recién cortada. Una vez secos los materiales, se ha determinado su peso, obteniendo la densidad de los mismos.

\begin{tabular}{ccc} 
Tabla 1. Factores de forma del modelo de volumen analizado (cilindro) \\
\hline Especie & $\mu_{\mathrm{f}}$ & $\sigma_{\mathrm{f}}$ \\
\hline Quercus coccifera & 2,19 & 0,75 \\
Rosmarinus officinalis & 2,19 & 0,90 \\
Ulex parviflorus & 2,33 & 0,79 \\
Cistus albidus & 1,60 & 0,78 \\
Erica multiflora & 2,25 & 0,61 \\
\hline
\end{tabular}

\section{Análisis dasométrico}

Una vez caracterizadas las especies desde el punto de vista dendrométrico, se realizó un análisis dasométrico que tuvo como objetivo determinar el volumen real y biomasa de las plantas contenidas en una superficie caracterizada por su área y altura máxima dominante. Si consideramos áreas circulares, a partir del diámetro de la superficie y la altura máxima dominante de las plantas, se pueden calcular diferentes superficies geométricas de volumen modelo (Figura 16) ocupado por materiales vegetales y huecos. De igual modo que para el estudio dendrométrico, el sólido de revolución que mejor se adaptó a las especies estudiadas fue el cilindro (Velázquez-Martí, 2010), por tanto, fue el utilizado en este trabajo.

La relación entre el volumen real de los vegetales que crecen en una subparcela y el volumen modelo de la misma, la denominamos Factor de ocupación, FO, que viene expresado por la ecuación 3.

$$
\mathrm{FO}=\frac{\text { Volumen real de los vegetales contenidos }}{\text { Volumen modelo del rodal }}
$$

El análisis dasométrico (cubicación de superficies arbustivas) de la vegetación se ha realizado en las mismas 29 parcelas del estudio dendrométrico. En cada una de las parcelas, se ha contabilizado a través de métodos terrestres el porcentaje de superficie cubierta por la vegetación arbustiva y, además, se han definido 3 subparcelas de sección circular de un metro de diámetro, lo que supone áreas de 0,785 m². Cada subparcela ha sido desbrozada y se han identificado todas las especies de vegetales contenidas en esta superficie, midiéndose altura, diámetro y peso de cada planta. El volumen real de los vegetales con- 
tenidos en una superficie es el resultado de medir los diámetros y longitudes de todas las plantas aplicando la ecuación 2, siendo el coeficiente mórfico el ya calculado anteriormente. El volumen modelo de la subparcela se obtiene al medir el radio de la misma y la altura dominante a través de las funciones conocidas de los sólidos de revolución de la Figura 16. Así, aplicando la ecuación 3 se obtuvo el factor de ocupación de cada una de las especies de la zona de estudio. Los valores medios resultan muy bajos por lo que se representan en $\mathrm{dm}^{3}$ de volumen real de materiales por cada $\mathrm{m}^{3}$ de volumen modelo (materiales y huecos).

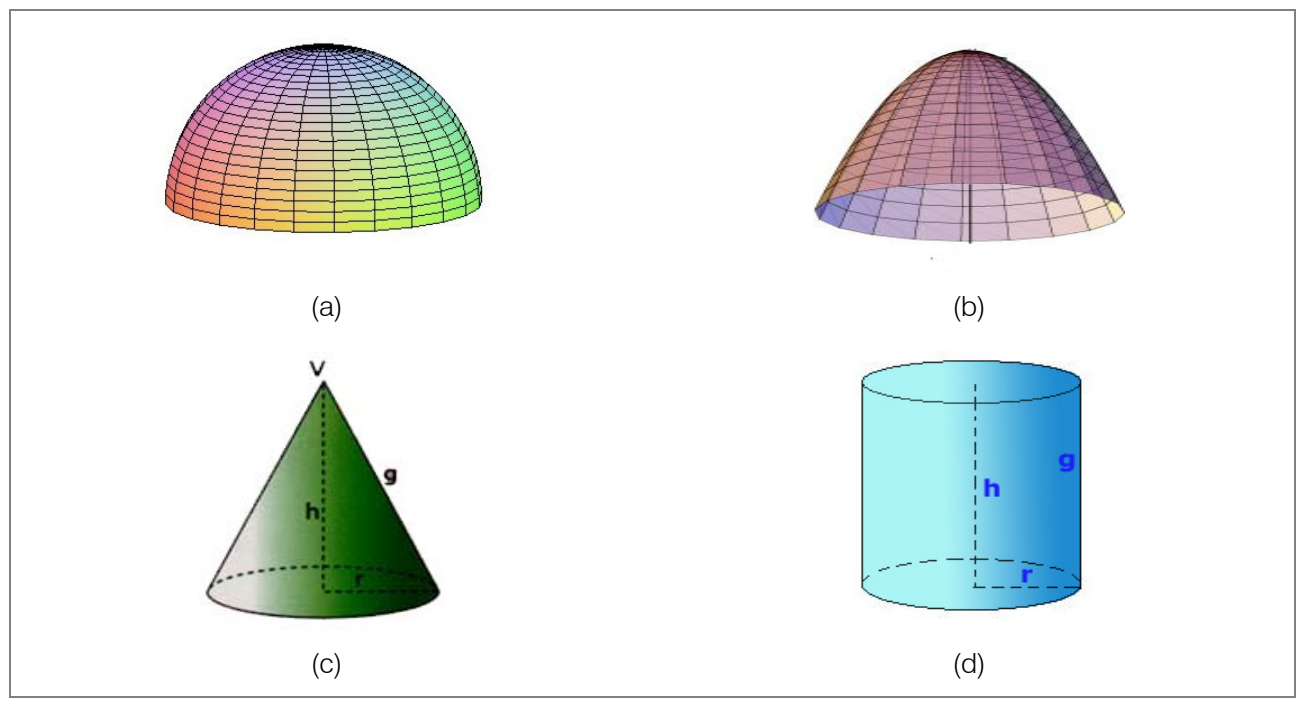

Figura 16. Modelos de crecimiento de masas arbustivas en una superficie determinada: (a) semiesfera, (b) paraboloide, (c) crecimiento cónico, (d) crecimiento cilíndrico.

Tabla 2. Factores ocupación para el volumen aparente cilindro $\left(\mathrm{dm}^{3} / \mathrm{m}^{3}\right)$

\begin{tabular}{ccc}
\hline Especie & $\mu \mathrm{FO}$ & $\sigma \mathrm{FO}$ \\
\hline Quercus coccifera & 4,20 & 1,68 \\
Rosmarinus officinalis & 3,69 & 1,35 \\
Ulex parviflorus & 5,48 & 1,30 \\
Cistus albidus & 4,87 & 1,58 \\
Erica multiflora & 4,42 & 2,22 \\
\hline
\end{tabular}

La determinación del factor de ocupación permitiría predecir el volumen real de los vegetales arbustivos contenidos en una subparcela, midiendo su superficie y altura dominante de la vegetación. Conocido el volumen real, se puede calcular la biomasa total a partir de la densidad y humedad. En el anejo 5, se pueden observar los valores de biomasa y volumen reales por subparcelas. La tabla 3 muestra estadísticos de estas variables considerando todas las subparcelas. 
Tabla 3. Estadísticos de biomasa y volumen derivados de los datos de campo por subparcelas

\begin{tabular}{cccc}
\hline Estadístico & Biomasa húmeda $(\mathrm{kg})$ & Vegetación seca $(\mathrm{kg})$ & Volumen $\left(\mathrm{dm}^{3}\right)$ \\
\hline Media & 6,33 & 4,17 & 4568,86 \\
Mínimo & 1,67 & 0,99 & 1130,76 \\
Máximo & 15,90 & 10,65 & 11095,16 \\
Desviación típica & 2,96 & 1,98 & 2201,84 \\
\hline
\end{tabular}

Para la aplicación del FO de las especies incluidas en la parcela y calcular el volumen real ocupado por la vegetación en cada parcela (de $100 \mathrm{~m}^{2}$ ) se siguieron los siguientes pasos:

- Se determinó el porcentaje de superficie ocupada por cada especie en la parcela.

- En cada subparcela desbrozada (3 por parcela) se midió el porcentaje de individuos de cada especie dentro de la subparcela.

- Se determinó el volumen real de cada especie por separado contenido en la subparcela, contando los individuos, midiendo sus dimensiones y aplicando la ecuación 2 a cada uno de ellos.

- Aplicando el porcentaje de individuos de cada especie existente en la subparcela a la superficie de la misma, se calculó el área correspondiente a cada especie dentro de la subparcela como si estuviera dividida en sectores (Figura 17).

- El volumen real de cada especie incluida en las subparcelas se dividió por el área de los sectores correspondientes, obteniendo el volumen por $\mathrm{m}^{2}$ de la superficie ocupada

- El volumen real total ocupado por la vegetación en la parcela se obtuvo multiplicando la superficie ocupada por cada especie dentro de la parcela por el volumen por metro cuadrado calculado en el paso anterior.

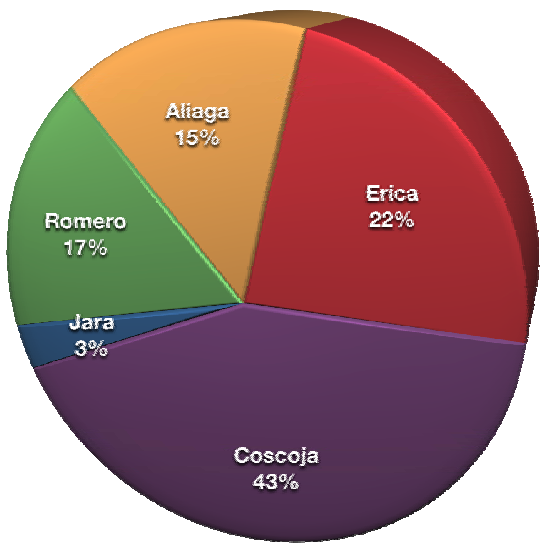

Figura 17. Ejemplo de distribución sectorial de la superficie desbrozada de una subparcela de 0,785 $\mathrm{m}^{2}$ 
Para el cálculo de la biomasa por parcela se siguieron los mismos pasos que para la determinación de volumen, sólo que en este caso se pesaron todos los individuos de cada especie contenidos en la subparcela, es decir:

- Se determinó el porcentaje de superficie ocupada por cada especie en la parcela.

- En cada rodal desbrozado (3 por parcela) se midió el porcentaje de individuos de cada especie dentro de la subparcela.

- Se pesaron todos los individuos de cada especie por separado contenidos en la subparcela, descontándoles la fracción de agua contenida en su estructura por su humedad. Así obteníamos el peso seco de cada especie.

- Aplicando el porcentaje de individuos de cada especie existente en la subparcela a la superficie del mismo, se calculó el área correspondiente a cada especie como si la subparcela estuviera dividida por sectores

- La biomasa de cada especie incluida en las subparcelas se dividió por el área de los sectores correspondientes, obteniendo la masa por $\mathrm{m}^{2}$ de la superficie ocupada.

- La biomasa total de los vegetales de la parcela se obtuvo multiplicando la superficie ocupada por cada especie dentro de la parcela por la biomasa por metro cuadrado calculado en el paso anterior.

Los resultados de los volúmenes y biomasa por parcelas se pueden observar el anejo 6. La tabla siguiente muestra estadísticos de los valores de estas variables considerando las 29 parcelas.

\begin{tabular}{cccc} 
Tabla 4. Estadísticos de biomasa y volumen derivados de los datos de campo por parcelas \\
\hline Estadístico & Biomasa húmeda $(\mathrm{kg})$ & Vegetación seca $(\mathrm{kg})$ & Volumen $\left(\mathrm{m}^{3}\right)$ \\
\hline Media & 659,45 & 421,95 & 0,48 \\
Mínimo & 245,63 & 166,84 & 0,16 \\
Máximo & 1233,51 & 821,27 & 1,08 \\
Desviación típica & 280,17 & 185,74 & 0,22 \\
\hline
\end{tabular}

\section{$\underline{\text { Alturas }}$}

La altura de la vegetación arbustiva medida en campo que se comparará con la estimada mediante datos LiDAR, fue la altura máxima dominante en las mismas subparcelas de los análisis precedentes. Las tres subparcelas incluidas en cada parcela tenían diferentes alturas dominantes; algunas de ellas presentaban diferentes especies o mezclas de diferentes especies. Por esta razón, las alturas medidas en campo fueron consideradas como valores independientes. En la Tabla 5 se pueden observar algunos estadísticos de los valores de altura de la vegetación arbustiva medida en campo correspondientes a todas las subparcelas. 
Tabla 5. Estadísticos de las alturas máximas dominantes medidas en las 86 subparcelas.

\begin{tabular}{cc}
\hline Estadístico & Valor $(\mathrm{m})$ \\
\hline Media $(\mathrm{m})$ & 1,27 \\
Desviación típica $(\mathrm{m})$ & 0,29 \\
Mínimo $(\mathrm{m})$ & 0,80 \\
Máximo $(\mathrm{m})$ & 2,50 \\
\hline
\end{tabular}

\subsubsection{Software utilizado}

Para la realización de este trabajo se utilizaron los siguientes programas:

- $\quad$ ArcGis 9.2: para la consulta de datos LiDAR y otras fuentes cartográficas. Estimar la precisión de los datos LiDAR y generar diferentes mapas.

- Envi v 4.2: generación de un programa en IDL para el cálculo de los modelos digitales de elevaciones.

- Fusion 1.5: para la edición de los datos LiDAR, cálculo de estadísticos y generación del MDV.

- $\quad$ Autodesk Map 2002: utilizado para la digitalización de las cuadrículas de la zona.

- $\quad$ STATGRAPHICS Plus 5.1: utilizado para el cálculo de los modelos de regresión.

- GvSIG 1.1.2 para la visualización de los datos LiDAR.

\subsection{GENERACIÓN DE MODELOS DIGITALES}

En este apartado se explicará la metodología seguida para el cálculo de los modelos digitales de elevación. El estudio se realizó fundamentalmente en Chiva. Además, la disponibilidad de datos LiDAR y del terreno en una zona de El Saler permitió comparar y analizar los resultados obtenidos en ambas zonas. En este apartado también se analizarán los factores que influyen en la precisión de un MDE. Finalmente se abordará la metodología llevada a cabo para el cálculo del modelo digital de superficies y el modelo de vegetación. La metodología descrita en esta sección se recoge en el artículo aceptado para su publicación en la revista International Journal of Digital Earth, (Estornell et al., 2010).

\subsubsection{Cálculo del MDE}

Para el cálculo del MDE a partir de datos LiDAR es necesario utilizar algoritmos que permitan descartar de entre todos los puntos, aquellos que no pertenecen al suelo, como los que representan vegetación, edificios o cualquier otro elemento que sobresale sobre esta superficie. Para ello, se generó un programa en IDL (Interactive Data Language, ITT Visual Systems) basado en procesos iterativos para la selección de puntos mínimos. 
El algoritmo consta de los siguientes pasos mostrados en la Figura 18:

Paso 1. Se dividió el área de estudio en ventanas, fijando un tamaño de ventana inicial (v1). En cada una de ellas, se seleccionó el punto de cota mínima. Con estos puntos se calculó un primer MDE (MDE1), aplicando el método de interpolación triangulación de Delaunay.

Paso 2. Se seleccionó un segundo tamaño de ventana (v2), menor a v1, con la que se realizó una nueva búsqueda de puntos mínimos a partir de los datos originales.

Paso 3. De entre todos los puntos seleccionados en el paso 2, se eligieron aquellos cuya diferencia respecto al MDE1, calculado en el paso 1, fuera inferior al umbral determinado (u1). Los puntos cuyas diferencias fueron superiores a este umbral se descartaron. Con los puntos mínimos no eliminados se calculó el modelo MDE2.

Paso 4. Se eligió un tercer tamaño de ventana (v3), menor a v2, seleccionando los puntos mínimos en su interior.

Paso 5. De igual modo que en el caso anterior, se eliminaron los puntos seleccionados cuya diferencia respecto al MDE2, calculado en el paso anterior, superó el umbral determinado (u2). Con los puntos seleccionados no eliminados se calculó el MDE final MDE3 (Figura 18)

Los algoritmos basados en procesos iterativos para la selección de puntos mínimos han sido utilizados por Popescu et al., (2002) y Clark et al. (2004). Dado que estos autores utilizaron diferentes tamaños de ventanas en áreas con alta presencia de arbolado fue necesario realizar varios ensayos con el objetivo de analizar los tamaños de ventana óptimos en una zona con las características de la zona de Chiva (presencia de vegetación arbustiva y pendientes muy elevadas). Por otro lado, también se analizó a diferencia de los estudios anteriores, si la combinación y utilización de un amplio rango de umbrales mejora la precisión del MDE.

El algoritmo definido en nuestro trabajo se aplicó en dos zonas diferentes. El caso de Chiva se trata de una zona de montaña con presencia de vegetación arbustiva y pendientes elevadas con variación irregular. La densidad media fue de 8 puntos $/ \mathrm{m}^{2}$. El caso de El Saler se trata de una zona con dunas y presencia densa de arbolado. La densidad media fue de 1 punto $/ \mathrm{m}^{2}$. El objetivo de este apartado fue analizar los parámetros más adecuados de este algoritmo de cálculo del MDE para zonas de estudio con diferentes características.

Para el caso de Chiva el algoritmo se aplicó sobre dos tipos de datos de entrada: puntos LiDAR originales y una imagen de tamaño de celda de $1 \mathrm{~m}^{2}$ con valor igual a la cota mínima del total de puntos incluidos en ella. En adelante, nos referiremos a estos datos como imagen. El objetivo de utilizar ambos tipos de datos fue analizar cómo afecta en la precisión del MDE la simplificación del formato que contiene la información. La utilización de una imagen implica trabajar con ficheros más pequeños, lo que significa que los proce- 
sos sean más rápidos. Además, se realizó una evaluación de la precisión del MDE3 (Figura 18) para 5 grupos de tamaño de ventana definidas por los vectores wi(v1,v2,v3) y mostrados en la Tabla 6.

Las componentes del vector wi representan la secuencia decreciente de tamaños de ventana aplicados para la selección de los puntos con elevación mínima. Como se puede apreciar en la Figura 18, para el cálculo de cada MDE final se aplicaron 3 tamaños de ventanas decrecientes. También se puede observar que por cada MDE final calculado se utilizan dos umbrales, cuyos valores quedan definidos por los vectores $t_{a b}(u 1, u 2)$, mostrados en la Tabla 7 . Por cada grupo de ventana se utilizaron cada una de las posibles combinaciones de los umbrales definidos. Por tanto, para cada grupo de ventanas se calcularon 25 MDE. Considerando los 5 grupos de ventanas, se calcularon y evaluaron en total 125 MDE.

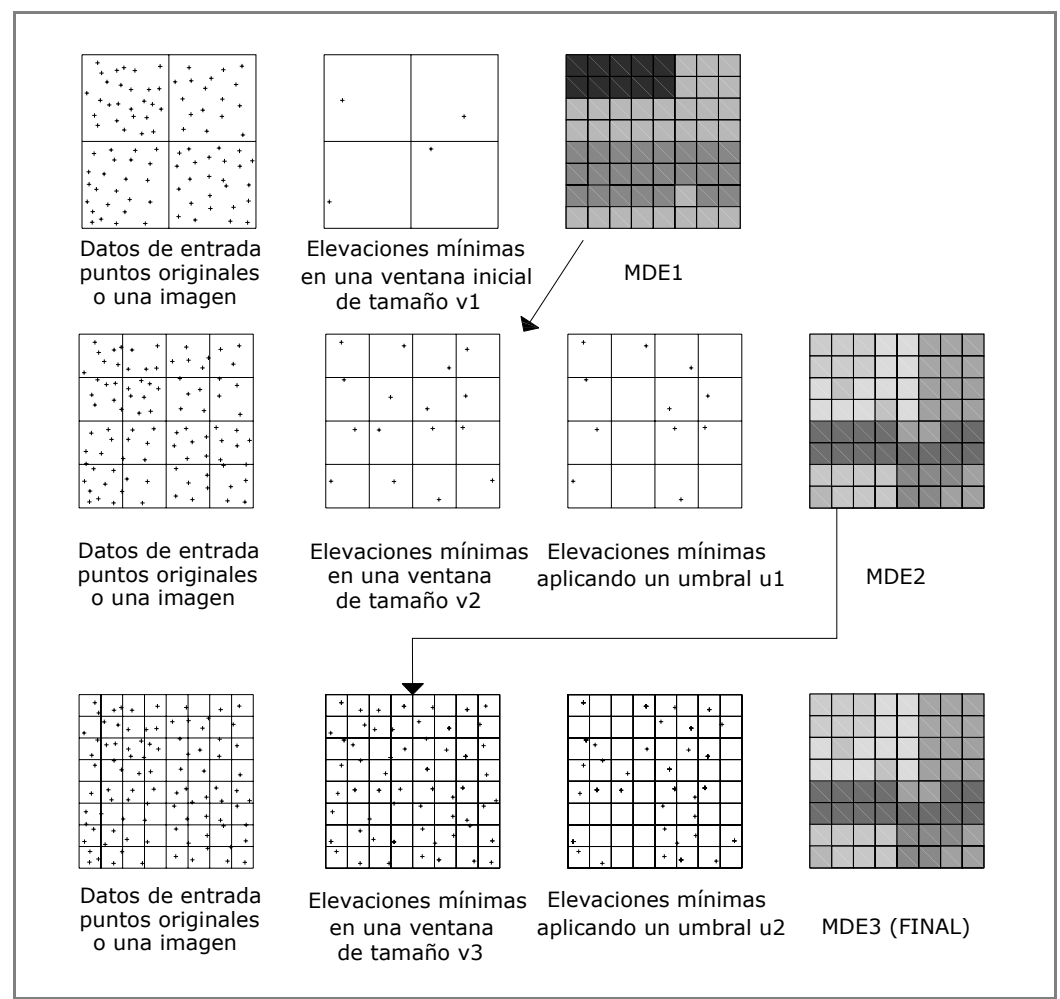

Figura 18. Esquema del algoritmo utilizado en el cálculo del MDE (Adaptado de Clark et al., 2004). 
Los MDE calculados se evaluaron a partir de los puntos medidos con GPS-RTK. Un primer análisis consistió en analizar el error medio cuadrático (RMSE) (4) al variar los umbrales y el tamaño de ventana.

$$
\operatorname{RMSE}=\sum_{\substack{\sum_{i=1}^{N}\left(Z_{i}-z_{i}\right)^{2} \\ N}}^{N}
$$

Donde $Z_{i}$ es valor medido en campo con GPS; $Z_{i}$ es valor obtenido del MDE calculado y $N$ número de puntos medidos.

Tabla 6. Vectores que definen la secuencia del tamaño de cuadrícula aplicados para la búsqueda de puntos de cota mínima en el caso de Chiva.

\begin{tabular}{cccc}
\hline \multirow{2}{*}{ Vector } & \multicolumn{3}{c}{ Tamaño de cuadrícula $(\mathrm{m})$} \\
\cline { 2 - 4 } & $\mathrm{v} 1$ & $\mathrm{v} 2$ & $\mathrm{~V} 3$ \\
\hline w1 & 8 & 4 & 2 \\
w2 & 10 & 5 & 2,5 \\
w3 & 12 & 6 & 3 \\
w4 & 15 & 10 & 5 \\
w5 & 20 & 10 & 5 \\
\hline
\end{tabular}

Tabla 7. Vectores $t_{a b}$ que definen la secuencia umbrales aplicados para la selección de puntos de cota mínima en el caso de Chiva.

\begin{tabular}{|c|c|c|c|c|c|c|}
\hline & & \multicolumn{5}{|c|}{$\mathrm{u} 2(\mathrm{~m})$} \\
\hline & & 0,5 & 1 & 1,5 & 2 & 2,5 \\
\hline \multirow{5}{*}{$\mathrm{u} 1(\mathrm{~m})$} & 0,5 & $t_{11}$ & $t_{12}$ & $t_{13}$ & $t_{14}$ & $t_{15}$ \\
\hline & 1 & $t_{21}$ & $t_{22}$ & $t_{23}$ & $t_{24}$ & $t_{25}$ \\
\hline & 1,5 & $t_{31}$ & $t_{32}$ & $\mathrm{t}_{33}$ & $\mathrm{t}_{34}$ & $t_{35}$ \\
\hline & 2 & $t_{41}$ & $\mathrm{t}_{42}$ & $t_{43}$ & $t_{44}$ & $t_{45}$ \\
\hline & 2,5 & $t_{51}$ & $t_{52}$ & $t_{53}$ & $\mathrm{t}_{45}$ & $t_{55}$ \\
\hline
\end{tabular}

Para el caso de El Saler, dado que la densidad de puntos era menor que en el caso de Chiva, sólo se consideró como datos de entrada una imagen de tamaño $1 \mathrm{~m}^{2}$. En cuanto a las ventanas, se utilizó el mismo grupo de ventanas definidas por los vectores w(v1, v2,v3) de la Tabla 6. En cuanto a los umbrales sólo se seleccionaron 5 , definidos por los vectores $t_{a b}(u 1, u 2)$, siendo $u 1=u 2$ cuyos valores fueron $0,5,1$, 1,5, 2, y 2,5 m. En este caso, se escogieron en total 25 MDE para analizar los parámetros del tamaño de ventana y de los umbrales

\subsubsection{Análisis de los factores que influyen en la precisión del MDE}

La disponibilidad de datos con una densidad variable y la presencia de pendientes elevadas en el caso de Chiva permitió analizar estos factores cómo afectan a la precisión de un MDE. Además, también se analizó el tipo de datos de entrada y la presencia de vegetación arbustiva. Para ello, se consideraron 10 MDE calculados con los siguientes parámetros:

- 5 MDE calculados con ventanas w1, w2, w3, w4 y w5, umbrales u1, u2 en los que el valor de RMSE sea mínimo y datos de entrada todos los puntos.

- 5 MDE calculados con ventanas w1, w2, w3, w4 y w5, umbrales u1, u2 en los que el valor de RMSE sea mínimo y datos de entrada una imagen. 
Para analizar el factor pendiente en la precisión de cada MDE se realizó una clasificación de la pendiente de los 1379 puntos, según los siguientes intervalos: 0-10\% ( $n=169) ; 10-20 \%$; $(n=255) ; 20-30 \%(n=353)$; 30-40\% ( $n=249) ; 40-50 \%(n=189) ; 50-60 \%(n=97) ;>60 \%(n=67)$. Donde $n$ es el número de puntos medidos en campo y pertenecientes a cada intervalo. Para cada uno de los 10 MDE anteriores, se calculó el RMSE de los puntos incluidos en cada clase.

En el estudio de la influencia de la densidad de datos LiDAR, se cuantificaron para cada punto medido en campo todos los datos LiDAR incluidos en un área de $1 \mathrm{~m}^{2}$, tomando el punto estudiado como centro Según el número de datos se clasificó cada punto medido con GPS-RTK con los siguientes rangos (puntos $\left./ m^{2}\right)$ : 1-2 ( $\left.n=84\right) ; 3-4(134) ; 5-6(n=174) ; 7-8 \quad(n=230) ; 9-10 \quad(n=250) ; 11-12(n=180) ;>12(n=327)$. Donde $n$ es el número de puntos medidos en campo y pertenecientes a cada intervalo. Para cada uno de los $10 \mathrm{MDE}$, se calculó el RMSE de los puntos GPS-RTK incluidos en cada clase.

Finalmente, se estudió el factor vegetación en la precisión de los MDE calculado. Para ello, se utilizaron 77 puntos medidos con GPS-RTK en zonas donde la vegetación arbustiva ocupaba totalmente la superficie de un círculo de radio 2 m y centro el punto medido. Esto significó áreas 100\% cubiertas con una altura media dominante de la vegetación de 1,27 m. Este análisis fue llevado a cabo mediante el cálculo del RMSE y error medio para los 10 MDE cuyos parámetros están definidos en esta sección. Para este análisis también se consideró un tamaño de ventana inferior wo $(5,2,5,1)$.

\subsubsection{Cálculo del MDS y del MDV}

El cálculo del MDS se obtuvo seleccionando para cada celda de $0,5 \mathrm{~m}^{2}$ el valor máximo de los datos LiDAR incluidos en cada una de ellas (Maltamo et al., 2004; Takahashi et al., 2005; Popescu et al., 2007). En las zonas desprovistas de datos se calculó una interpolación basada en las alturas de los puntos más cercanos (Hyyppä et al., 2001b; Persson et al., 2002). El MDV se calculó restando al MDS el MDE (Figura 3).

\subsection{EXTRACCIÓN DE VARIABLES EXPLICATIVAS A PARTIR DE DATOS LIDAR E IMAGEN ESPECTRAL}

Para la estimación de la biomasa y volumen de la vegetación arbustiva se calculó diferentes estadísticos a partir de los datos LiDAR y de las imágenes espectrales que se utilizaron como variables independientes en los modelos de regresión a calcular. En cuanto a los datos LiDAR, se calculó la altura de los puntos incluidos en las parcelas y en las subparcelas, restando a la elevación de los mismos el valor de MDE. Para ello, se utilizó el MDE con menor RMSE según los resultados del apartado correspondiente. Por cada parcela se calcularon los parámetros de la Tabla 8 derivados de la distribución de las alturas. 
Tabla 8 Variables derivadas de la distribución de las alturas de los datos LiDAR.

\begin{tabular}{|c|c|c|}
\hline Variable & Símbolo & Características \\
\hline Percentil 5 & $\mathrm{P}_{5}$ & Variables relacionadas con la biomasa, altura y volumen \\
\hline Percentil 10 & $P_{10}^{5}$ & basadas en la relación existente entre estas variables físi- \\
\hline Percentil 20 & $\mathrm{P}_{20}$ & cas y la altura \\
\hline Percentil 25 & $P_{25}$ & \\
\hline Percentil 30 & $\mathrm{P}_{30}$ & \\
\hline Percentil 40 & $\mathrm{P}_{40}$ & \\
\hline Percentil 50 & $P_{50}$ & \\
\hline Percentil 60 & $P_{60}$ & \\
\hline Percentil 70 & $P_{70}$ & \\
\hline Percentil 80 & $P_{80}$ & \\
\hline Percentil 90 & $P_{90}$ & \\
\hline Percentil 95 & $P_{95}$ & \\
\hline Altura máxima & $h_{\max }$ & \\
\hline Altura media & $\mathrm{h}_{\mathrm{m}}$ & \\
\hline Desviación estándar de las alturas & $h_{d}$ & $\begin{array}{l}\text { Caracteriza la estructura del dosel basada en la distribu- } \\
\text { ción de los retornos. Aporta información del factor de } \\
\text { cabida cubierta en una parcela }\end{array}$ \\
\hline Coeficiente de variación & CV & $\begin{array}{l}\text { Describe la dispersión de los datos de alturas de las par- } \\
\text { celas }\end{array}$ \\
\hline Asimetría & $g_{1}$ & Caracteriza la estructura de la vegetación y su relación \\
\hline Curtosis & $g_{2}$ & $\begin{array}{l}\text { con el porcentaje de suelo desnudo basada en la forma } \\
\text { de la distribución de las alturas }\end{array}$ \\
\hline
\end{tabular}

Los diferentes valores de percentiles fueron calculados utilizando la siguiente metodología (ecuación 5):

$$
(n-1) p=i+d\left\{\begin{array}{r}
i \text { es la parte entera de }(n-1) p \\
d \text { es la parte decimal de }(n-1) p
\end{array}\right.
$$

Donde $n$ es el número de observación y $p$ es el percentil dividido por 100.

$$
\begin{aligned}
& \text { Si } d=0 \text { entonces Percentil }=x_{i+1} \\
& \text { Si } d>0 \text { entonces Percentil }=x_{i+1}+d\left(x_{i+2}-x_{i+1}\right)
\end{aligned}
$$

Siendo $x_{i}$ el valor de la observación. Las observaciones están ordenadas en orden ascendente

La variable asimetría fue calculada utilizando la ecuación 6 :

$$
\text { Asimetría }=\frac{\sum_{i=1}^{N}\left(Y_{i}-\bar{Y}\right)^{3}}{(N-1) \sigma^{3}}
$$

Donde $Y_{i}$ cada una de las altura LiDAR, $\bar{Y}$ la media de la muestra, $N$ el número total de puntos LiDAR en la muestra y $\sigma$ es la desviación estándar. 
La variable curtosis fue calculada utilizando la ecuación 7 :

$$
\text { Curtosis }=\frac{\sum_{i=1}^{N}\left(Y_{i}-\bar{Y}\right)^{4}}{(N-1) \sigma^{4}}
$$

Donde $Y_{i}$ cada una de las altura LiDAR, $\bar{Y}$ la media de la muestra, $N$ el número total de puntos LiDAR en la parcela y $\sigma$ es la desviación estándar.

Dado que existen investigaciones en zonas arboladas en las que se han determinado variables relacionadas con la densidad de puntos por intervalos de alturas con resultados satisfactorios (Naeseet, 2004, Andersen et al., 2005; Van Aart et al., 2006), se calcularon para cada parcela porcentajes de puntos LiDAR pertenecientes a determinados intervalos de alturas. Los intervalos considerados fueron: 0,25-0,5 m; 0,50,75 m; 0,75-1 m; y porcentaje de puntos con altura mayor a $1 \mathrm{~m}$. En la Tabla 9 se describen las variables relacionadas con la densidad de puntos. Como se puede apreciar en la Figura 19 la distribución de los puntos LiDAR por intervalos aporta información sobre la densidad de la vegetación y altura de la misma. Mientras que la figura de la izquierda presenta mayores concentraciones de puntos en los intervalos 0.75$1 \mathrm{~m}$ y alturas mayores a $1 \mathrm{~m}$, la figura de la derecha presenta mayores concentraciones de puntos en los intervalos menores. Cabe esperar que la biomasa y volumen de la parcela de la izquierda sea mayor que la de la derecha.

Tabla 9. Variables asociadas al porcentaje de puntos LiDAR por intervalos de altura

\begin{tabular}{ll}
\hline Variable & \multicolumn{1}{c}{ Descripción } \\
\hline $\mathrm{d}_{0-0,25}$ & Porcentaje de puntos LiDAR en una parcela cuya altura está comprendida entre 0 y $0,25 \mathrm{~m}$ \\
$\mathrm{~d}_{0,25-0,50}$ & Porcentaje de puntos LiDAR en una parcela cuya altura está comprendida entre 0,25 y $0,50 \mathrm{~m}$ \\
$\mathrm{~d}_{0,50-0,75}$ & Porcentaje de puntos LiDAR en una parcela cuya altura está comprendida entre 0,50 y $0,75 \mathrm{~m}$ \\
$\mathrm{~d}_{0,75-1}$ & Porcentaje de puntos LiDAR en una parcela cuya altura está comprendida entre 0,75 y $1 \mathrm{~m}$ \\
$\mathrm{~d}_{1}$ & Porcentaje de puntos LiDAR en una parcela cuya altura es superior a $1 \mathrm{~m}$ \\
\hline
\end{tabular}

A partir de la imagen aérea se calcularon las variables de la Tabla 10. Para ello, se consideraron los valores de las celdas incluidas solamente en las parcelas de las bandas infrarrojo (IR), rojo (R), verde (G) y el Índice de Vegetación de la Diferencia Normalizada (NDVI). Esta imagen es el resultado de aplicar operaciones de álgebra de imágenes, entre diferentes bandas para determinar presencia de vegetación (8). Los valores de las celdas de la nueva imagen estarán comprendidos entre -1 y 1. Los valores mayores estarán correlacionados con la fracción de cabida cubierta de la vegetación y la biomasa (Carlson y Ripley, 1997). 

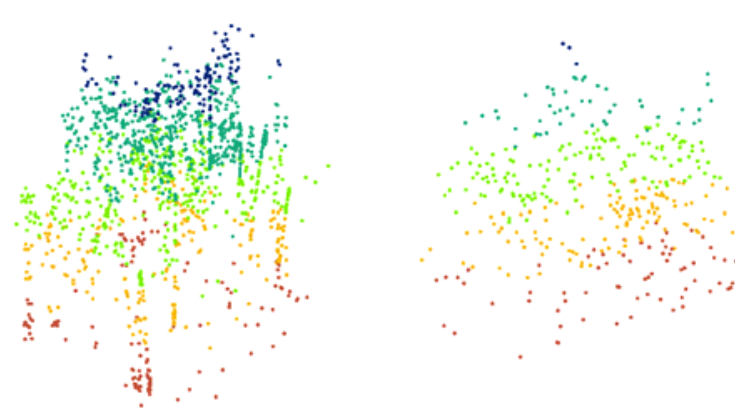

\section{Elevation (m)}

\section{$0 \quad 0.00-0.25$ \\ $0.25-0.50$ \\ ○ $\quad 0.50-0.75$ \\ $\circ \quad 0.75-1.00$ \\ $1.00-2.65$}

Figura 19. Distribución de los puntos LiDAR por intervalos de altura.

Tabla 10. Variables derivadas de la imagen espectral aérea.

\begin{tabular}{|c|c|}
\hline Nombre & Descripción \\
\hline $\mathrm{G}_{\min }$ & Valor mínimo de la banda del verde por parcela \\
\hline$G_{\max }$ & Valor máximo de la banda del verde por parcela \\
\hline $\mathrm{G}_{\mathrm{m}}$ & Valor medio de la banda del verde por parcela \\
\hline $\mathrm{G}_{\mathrm{d}}$ & Desviación estándar de la banda del verde por parcela \\
\hline$R_{\min }$ & Valor mínimo de la banda del rojo por parcela \\
\hline $\mathrm{R}_{\max }$ & Valor máximo de la banda del rojo por parcela \\
\hline $\mathrm{R}_{\mathrm{m}}$ & Valor medio de la banda del rojo por parcela \\
\hline $\mathrm{R}_{\mathrm{d}}$ & Desviación estándar de la banda del rojo por parcela \\
\hline $\mathrm{IR}_{\min }$ & Valor mínimo de la banda del infrarrojo por parcela \\
\hline $\mathrm{IR}_{\max }$ & Valor máximo de la banda del infrarrojo por parcela \\
\hline $\mathrm{IR}_{\mathrm{m}}$ & Valor medio de la banda del infrarrojo por parcela \\
\hline $\mathrm{IR}_{\mathrm{d}}$ & Desviación estándar de la banda del infrarrojo por parcela \\
\hline$N D V I_{\min }$ & Valor mínimo de la banda del NDVI por parcela \\
\hline$N D V I_{\max }$ & Valor máximo de la banda del NDVI por parcela \\
\hline $\mathrm{NDVI}_{\mathrm{m}}$ & Valor medio de la banda del NDVI por parcela \\
\hline $\mathrm{NDVI}_{\mathrm{d}}$ & Desviación estándar de la banda del NDVI por parcela \\
\hline
\end{tabular}

$$
N D V I=\frac{I R-R}{I R+R}
$$

Siendo NDVI, la imagen resultado con valores comprendidos entre -1 y 1 , IR la imagen que contiene información relacionada con la energía reflejada con $\lambda$ entre 0,7 y $1,2 \mu \mathrm{m}$ y $\mathrm{R}$ la imagen que contiene información relacionada con la energía reflejada con $\lambda$ entre 0,6 y 0,7 $\mu \mathrm{m}$. El fundamento de este índice se encuentra en la respuesta espectral de la vegetación sana. Como se puede apreciar en la Figura 20, en la región del IR (0,8-1,2 $\mu \mathrm{m})$ se produce una elevada reflectividad cuando la planta está sana. Esto origina que las celdas con presencia de vegetación presenten valores digitales altos. En cambio, en la zona del $\mathrm{R}$ 
(0,6-0,7 $\mu \mathrm{m})$ sucede lo contrario debido al efecto de absorción de la clorofila. Por lo tanto, al combinar estas bandas con un comportamiento espectral específico es más fácil detectar donde se encuentra la vegetación.

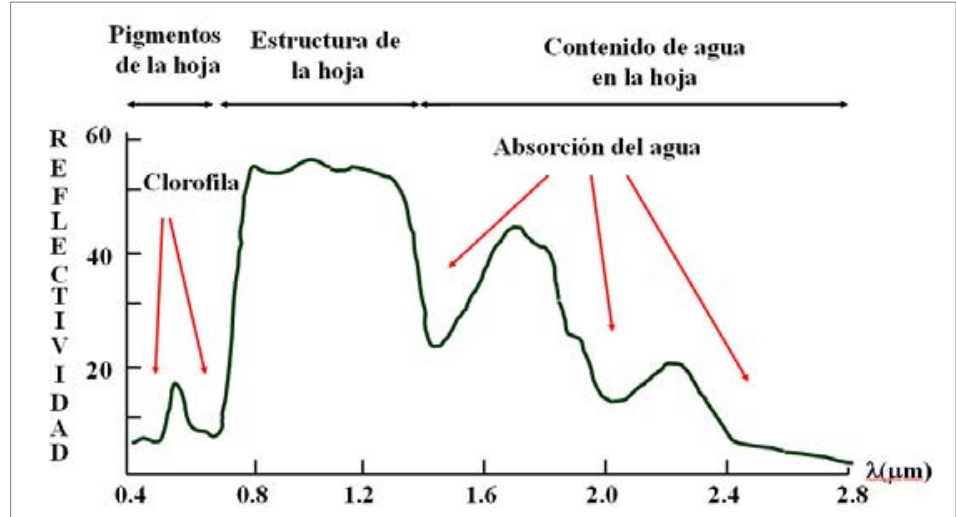

Figura 20. Representación de la curva espectral de la vegetación sana (Adaptado de Chuvieco, E. 2010).

En el caso de las subparcelas, no se calcularon estadísticos derivados de la imagen debido a que el radio era demasiado pequeño para contener un número significativo de celdas. Además, estas subparcelas están cubiertas completamente por vegetación, lo que evita que exista variabilidad entre el suelo y la vegetación.

Para reducir el número de posibles variables explicativas ( 23 variables calculadas a partir de los datos LiDAR y 16 variables calculadas a partir de la información espectral) se calcularon matrices de correlación y se realizó un análisis clúster. De esta manera se evitará modelos con un gran número de variables que harían difícil la explicación física de los mismos y la selección de variables altamente correlacionadas.

\subsection{ESTIMACIÓN DE VARIABLES FORESTALES}

En este apartado se describirá la metodología seguida para la estimación de la altura, biomasa y volúmenes de la vegetación arbustiva, tanto por parcelas como por subparcelas. También se analizarán los factores que influyen en la estimación de estas variables, se abordará cómo se ha obtenido el mapa de ocupación de la vegetación arbustiva en la zona de estudio y se analizará si la inclusión de información espectral mejora la precisión de estos cálculos. Finalmente, se desarrollará una metodología alternativa para el cálculo del volumen y biomasa basada en los trabajos dendrométricos-dasométricos de campo. 


\subsubsection{Estimación de la altura de la vegetación}

En este apartado se describirá como se han obtenido los modelos de regresión para la estimación de las alturas de la vegetación por parcelas y subparcelas. La metodología descrita en esta sección se recoge en el artículo aceptado, para su publicación en la revista Forest Science de la Society of American Foresters, (Estornell et al., 2011).

\section{Parcelas}

La altura real de la vegetación arbustiva por parcela fue obtenida a partir del cálculo de la media de las tres alturas dominantes medidas en campo en cada subparcela. Para analizar las diferencias entre estos valores y las alturas de la vegetación obtenidas de los datos LiDAR se consideraron las siguientes variables derivadas de los datos LiDAR por parcelas: altura media, desviación estándar, altura máxima, percentil 80, percentil 90 y percentil 95. A partir de estas variables se calcularon modelos de regresión, siendo analizados los valores de $\mathrm{R}^{2}$ y RMSE. Estos estadísticos se han utilizado con resultados satisfactorios en otros trabajos en los que predomina la vegetación arbórea (Means et al., 2000; Clark et al., 2004; Naesset, 2004; Hollaus et al., 2006).

\section{Subparcelas}

El análisis de la altura de la vegetación arbustiva por subparcelas se realizó mediante la comparación de 83 alturas máximas dominantes medidas en campo con el valor de la altura máxima obtenida de los datos LiDAR. Dado que algunas subparcelas contenían pocos puntos LiDAR, se buscaron áreas concéntricas con el objetivo de encontrar el mínimo RMSE entre la altura de la vegetación medida en campo y los datos LiDAR. Estas áreas se definieron a partir del cálculo de áreas de influencia (búfer) con determinados radios. Los radios utilizados fueron: $0,50,0,75,1,1,25,1,5,1,75,2,2,25,2,5,2,75,3,3,25$, y 3,5 m. Por cada búfer y subparcela se seleccionó la altura máxima de los datos LiDAR (Hopkinson et al., 2005; Streutker and Glenn, 2006). A partir de estos datos y las alturas de la vegetación medidas en campo se calculó el RMSE. Las diferencias entre los datos LiDAR y las medidas tomadas en campo ( $h_{\text {vegetación-LiDAR }}-h_{\text {vegetación- }}$ campo) también se obtuvieron para cada subparcela y radio. Se calculó el valor mínimo, máximo, error medio y desviación estándar de esas diferencias.

\subsubsection{Factores que influyen en la selección del radio para el estudio de las alturas de la vegeta- ción por subparcelas}

\section{Error asociado MDE}

Una vez detectado el radio con el que se produjo el mínimo RMSE, se analizó la influencia de los factores signo del error asociado al MDE, pendiente y densidad de puntos en la definición de este radio. Para analizar el factor error asociado al MDE, se calculó la diferencia entre la coordenada z de los 82 puntos medidos en campo con GPS-RTK y la coordenada z obtenida del MDE. A partir de estos datos, se realizó una clasificación de los puntos en los que se ha medido la vegetación según el signo de los residuos del 
MDE: error $>0 m(n=30)$ y error $<0 m(n=52)$, siendo $n$ el número de puntos medidos. En cada punto del grupo y subparcela, se seleccionó la altura máxima de los datos LiDAR en un búfer cuyo radio variaba de 0,5 hasta 3,5 m. Estos datos se compararon con las alturas de la vegetación medidas en campo por subparcelas. Para cada radio y grupo se calculó el RMSE.

También se estudió la precisión de la altura de la vegetación a partir de los datos LiDAR corregidas del error asociado al MDE en áreas con pendiente menor al 20\% $(n=34)$. Las alturas de campo de estos puntos se compararon con las alturas máximas obtenidas de los datos LiDAR en un búfer cuyo radio varió de 0,5 hasta 3,5 m calculando el RMSE.

\section{Densidad de datos LiDAR}

Para el análisis del factor densidad, se calculó el número de puntos LiDAR incluidos en un área de radio $0,5 \mathrm{~m}$ para cada punto de los 82 medidos en campo. Los puntos medidos en campo se clasificaron en dos grupos: densidad $<8$ puntos $/ m^{2}(n=43)$ y densidad $>8$ puntos $/ m^{2}(n=49)$, siendo $n$ el número de puntos medidos en campo. Por cada grupo, se compararon las alturas medidas en campo de cada punto y las alturas máximas obtenidas de los datos LiDAR de los búferes con los mismos radios utilizados en los análisis previos. Para ello, se calculó el RMSE por cada grupo de datos.

\subsubsection{Estimación de la altura de la vegetación a partir del MDV}

En este apartado se analizó el tamaño de celda del MDV con el que se obtuvo el mínimo RMSE entre las alturas de esta imagen y las alturas máximas dominantes definidas en campo. Para ello, se calcularon MDV con los siguientes tamaños de celdas: 0,$5 ; 1 ; 1,5 ; 2 ; 2,5 ; 3 ; 4 ;$ y 5 m. En cada una de estas celdas se calculó la altura máxima de los datos LiDAR. Para cada MDV, se calculó el RMSE entre las alturas medidas en campo y las obtenidas a partir del MDV.

\subsubsection{Estimación de la superficie cubierta por la vegetación arbustiva a partir del MDV y datos espectrales}

Para determinar la capa de vegetación arbustiva se siguieron dos aproximaciones. En la primera se utilizó únicamente el MDV, donde se clasificaron las celdas siguiendo los siguientes intervalos: 0-0,3 m suelo, 0,3-2,5 m vegetación arbustiva, y valores mayores a 2,5 m, árboles. El umbral 0,30 m se obtuvo al restar el valor mínimo de altura de vegetación arbustiva medida en campo, el RMSE en la determinación de las alturas para un radio de $0,50 \mathrm{~m}$. Para validar la clasificación realizada se utilizaron 166 puntos medidos en campo y distribuidos por toda la zona de estudio, 83 correspondientes a vegetación arbustiva y 83 al suelo. La segunda aproximación para el estudio de la determinación de la vegetación arbustiva se basó en la combinación del MDV y una imagen NDVI siguiendo el diagrama de flujo de la Figura 21. 
A partir de la imagen espectral aérea se calculó el NDVI, al que se le aplicó una clasificación no supervisada con cuatro clases. Después de superponer visualmente la imagen original con el resultado de la clasificación se asignó a la clase 1, no vegetación, y al resto, vegetación. A continuación se superpuso esta imagen con el MDV. El resultado de esta operación fueron tres nuevas clases: arbustos, si la celda del MDV estaba comprendida entre 0,30-2,5 m y pertenecía a las clases 2, 3 ó 4 de la imagen clasificada; suelo, si la celda del MDV era inferior a 0,3 m o perteneciente a la clase 1 de la imagen clasificada; árbol, si la celda del MDV era superior a 2,5 m. En la zona de estudio a excepción de alguna edificación aislada, todas las celdas con altura superior a los 2,5 $\mathrm{m}$ pertenecen a la clase árbol.

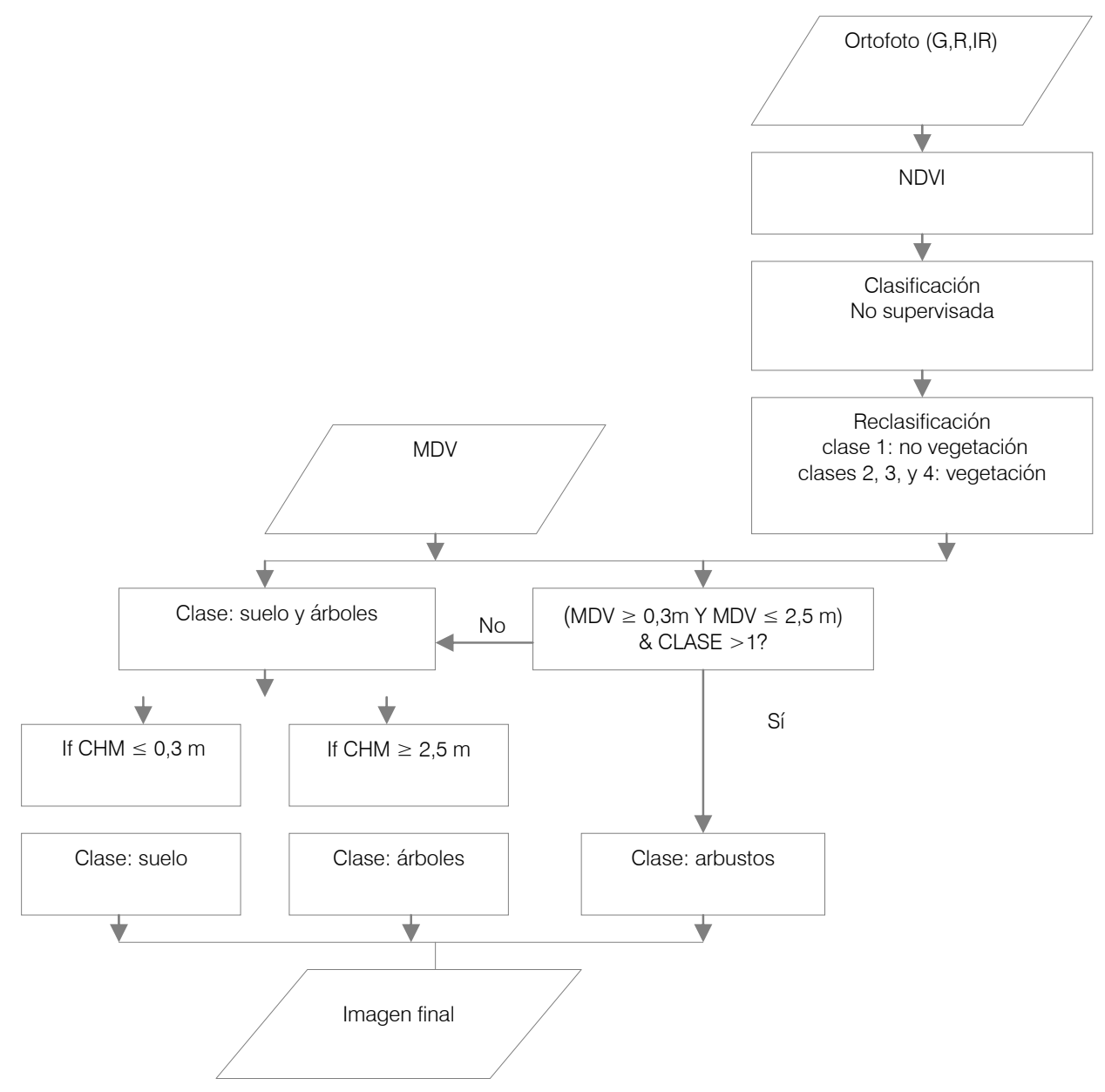

Figura 21. Diagrama de flujo para la obtención de la cubierta de vegetación arbustiva. 


\subsubsection{Modelos de regresión para la estimación de la biomasa.}

En este apartado se abordará la metodología seguida en la estimación de la biomasa húmeda y de la vegetación seca por parcelas y subparcelas.

\section{Parcelas}

Para la estimación de la vegetación seca y de la biomasa húmeda por parcelas se aplicó una regresión múltiple por pasos con una preselección de variables, utilizando análisis cluster y matrices de correlación. Dado que existen investigaciones en zonas arboladas en las que la combinación de los datos LiDAR y datos extraídos de imágenes espectrales mejoraban los modelos de predicción (Hyde et al., 2006; van Aardt et al., 2006; Donoghue et al.2007) se analizaron tres grupos de modelos predictivos para la estimación de vegetación seca y de biomasa húmeda. En primer lugar, se consideraron sólo variables extraídas de los datos LiDAR. En segundo lugar, se utilizaron variables obtenidas de las bandas espectrales de la imagen aérea. Por último, en tercer lugar se estimó la biomasa de las parcelas combinando datos LiDAR y datos espectrales de la imagen aérea. Los modelos obtenidos fueron comparados a partir del cálculo del RMSE $y R^{2}$.

Los modelos con el coeficiente de determinación mayor fueron seleccionados para realizar el mapa de biomasa de la zona de estudio. Para ello, se dividió esta superficie en celdas de $100 \mathrm{~m}^{2}$, el mismo tamaño de las parcelas, en las que el valor de cada variable explicativa fue calculada. Con estos valores y sobre cada celda de la zona de estudio se aplicó el modelo.

\section{Subparcelas}

En este apartado se estimó la vegetación seca y la biomasa húmeda medida en campo en subparcelas de $0,5 \mathrm{~m}$ de radio con distintos estadísticos extraídos de los datos LiDAR. Al seleccionar los puntos incluidos en las subparcelas de este radio, se produjo el problema de que en algunas de ellas sólo había dos, uno o ningún punto. Ello obligó a estudiar la relación de la biomasa contenida en las subparcelas con un sólo parámetro, la altura máxima. Por este motivo, de las 86 subparcelas se utilizaron 83 para realizar este análisis. No se determinaron variables relacionadas con el cálculo de percentiles y otros estadísticos pues para el radio de 0,5 $\mathrm{m}$ había pocos puntos en algunas subparcelas. Los modelos utilizados fueron simples y cuadráticos comparándose los valores de $R^{2}$ y RMSE.

Por otra parte, se ha procedido también a relacionar la biomasa medida en campo con la altura máxima de los puntos LiDAR incluidos en círculos concéntricos cuyo radio generaba un menor RMSE entre las alturas máximas estudiadas por subparcelas y la altura real de vegetación, tal y como se explica en el apartado 4.4.1. Para mejorar la precisión de los análisis se estudió la inclusión de otros estadísticos de las alturas de los datos LiDAR: la media y los percentiles 80, 90 y 95. Se calcularon regresiones simples y cuadráticas y se compararon los valores de $R^{2}$ y RMSE. 


\subsubsection{Factores que influyen en la estimación de la biomasa por subparcelas}

En este apartado se analizaron diferentes factores que influyen en la estimación de la biomasa por subparcelas: tipo de vegetación, densidad de puntos y errores asociados al MDE. Este análisis se realizó a partir del cálculo de los estadísticos de los puntos LiDAR incluidos en un área de radio con el que se produce la máxima correlación entre las alturas medidas en campo y las obtenidas de los datos LiDAR.

\section{Tipo de vegetación}

Para analizar el primer factor (tipo de vegetación) se hizo una clasificación de las subparcelas en dos clases. Las subparcelas con presencia de vegetación Quercus coccifera superior al 75\% se asignaron a la primera clase $(n=47)$. Esta vegetación es la dominante de la zona de estudio. El resto de subparcelas con diferentes tipos de vegetación y porcentajes fueron asignados a la segunda clase $(n=36)$. Para estas subparcelas se estimó la vegetación seca y la biomasa húmeda, y se obtuvieron valores de $\mathrm{R}^{2}$ y RMSE.

\section{Densidad de datos LiDAR}

Para analizar el factor densidad se calculó la densidad de puntos LiDAR por $\mathrm{m}^{2}$ para cada subparcela y se agruparon en dos clases: densidad $>8$ puntos $/ \mathrm{m}^{2}(\mathrm{n}=47)$ y densidad $<8$ puntos $/ \mathrm{m}^{2}(\mathrm{n}=36)$. La densidad media y desviación típica de las subparcelas del primer grupo fueron 12 puntos $/ \mathrm{m}^{2}$ y 4 puntos $/ \mathrm{m}^{2}$, respectivamente. La densidad media y desviación típica de las subparcelas del segundo grupo fueron 4 puntos $/ \mathrm{m}^{2}$ y 2 puntos $/ \mathrm{m}^{2}$, respectivamente. Se calcularon regresiones y se compararon los valores de $R^{2}$ y RMSE.

\section{Error asociado al MDE}

En cuanto a los errores asociados al MDE, en primer lugar se calculó la diferencia entre la coordenada z del punto del centro del rodal medida con GPS-RTK y la obtenida del MDE. A continuación, se agruparon las subparcelas en dos clases. Las subparcelas cuya diferencia fue inferior a 0,20 m en valor absoluto pertenecieron a la primera clase $(n=52)$ y las que tuvieron una diferencia superior a 0,20 m en valor absoluto, a la segunda $(n=31)$. Este valor correspondió al menor RMSE obtenido en el cálculo de los MDE. Se calcularon regresiones y se compararon los valores de $\mathrm{R}^{2} \mathrm{y}$ RMSE.

Además, se estimó la biomasa en las subparcelas con densidad mayor a 8 puntos/m2 y error asociado al MDE menor a 0,20 m ( $n=39)$, en las subparcelas con vegetación Quercus coccifera y densidad mayor a 8 puntos/m2 $(n=32)$ y en subparcelas con vegetación Quercus coccifera y error asociado al MDE menor a $0,20 m(n=30)$. Se calcularon regresiones y se compararon los valores de $R^{2}$ y RMSE. 


\subsubsection{Modelos de regresión para la estimación del volumen de biomasa}

En este apartado se abordará la metodología seguida para la estimación de los volúmenes de las parcelas y subparcelas.

\section{Parcelas}

Siguiendo la misma metodología que para el caso de la biomasa, se aplicó una regresión múltiple por pasos para la estimación del volumen con una preselección de variables (22 variables calculadas a partir de Ios datos LiDAR y 16 variables calculadas a partir de la información espectral). Para el cálculo de los modelos se utilizaron tres conjuntos de datos. En primer lugar, se consideraron sólo variables extraídas de los datos LiDAR. En segundo lugar, las variables derivadas de la información espectral de la imagen aérea. Por último, en tercer lugar, se estimó el volumen de las parcelas combinando datos LiDAR y datos de la imagen aérea. Los modelos obtenidos fueron comparados a partir del cálculo del RMSE y R².

\section{Subparcelas}

Se estimaron los volúmenes ocupados por la vegetación en las subparcelas de radio 0,5 m. Para ello, se utilizaron los estadísticos media, el valor máximo y los percentiles 80, 90 y 95 de los datos LiDAR incluidos en áreas circulares con centro en la subparcela y el radio con el que se obtenían las mejores correlaciones entre las alturas medidas en campo y las obtenidas a partir de los datos LiDAR. Se calcularon regresiones simples y cuadráticas y se compararon los valores de $\mathrm{R}^{2}$ y RMSE. De igual modo que para el caso de la biomasa, se analizaron en el cálculo de los volúmenes los factores tipo de vegetación, densidad de puntos y errores asociados al MDE.

\subsubsection{Estimación de de los volúmenes por subparcelas utilizando factores de ocupación (F0) y datos LiDAR}

Los resultados de este apartado hacen referencia al artículo publicado "Dendrometric and dasometric analysis of the bushy biomass in Mediterranean forests" en la revista Forest Ecology and Management (2010).

Los volúmenes reales ocupados por la vegetación se obtuvieron a partir de la ecuación 3 considerando los FO obtenidos en los trabajos dendrométricos y dasométricos del apartado 4.1.4. En esta ecuación se utilizó como altura, la máxima obtenida de los datos LiDAR incluidos en el radio en el que se produce la máxima correlación entre estos datos y los medidos en campo (apartado 4.4.1)

Con el objetivo de analizar la existencia de diferencias entre los volúmenes reales obtenidos a partir de los datos de campo y los obtenidos aplicando los FO y datos LiDAR, se aplicó la prueba t de Student para la comparación de dos muestras pareadas. La hipótesis nula fue que la media de la diferencia entre los valores de las dos muestras de volúmenes era igual a 0 , frente a la hipótesis alternativa en la que era distinta a 0 , con un nivel de significación de $\alpha=0,05$. 

5. Resultados y discusión 

En este apartado se presentarán los resultados y discusión de la parte de la investigación relacionada con el cálculo de modelos digitales de elevación y de las variables forestales de la vegetación arbustiva. En cuanto a la primera parte, se obtendrán los parámetros óptimos para el cálculo del MDE en la zona de Chiva, con presencia de vegetación arbustiva y pendientes elevadas, y en El Saler, con presencia de arbolado y pendientes bajas. La disponibilidad de diferentes densidades de datos LiDAR y de pendientes variables en la zona de Chiva permitirá analizar como afectan estos factores en la precisión del MDE. Finalmente, se presentarán y se analizarán los resultados del MDS y MDV.

Respecto al segundo bloque de esta investigación, en primer lugar se presentarán y analizarán los resultados relacionados con la estimación de las alturas de la vegetación arbustiva tanto en parcelas como en subparcelas. A continuación, se evaluarán los resultados obtenidos relacionados con la superficie cubierta por la vegetación arbustiva a partir del MDV y datos espectrales. Finalmente se abordarán los resultados y discusión de las estimaciones de la vegetación seca y la biomasa húmeda, y del volumen.

\subsection{MODELOS DIGITALES}

Este apartado se centra en el análisis de los resultados de los modelos digitales de elevación utilizando el algoritmo iterativo de búsqueda de elevaciones mínimas en ventanas decrecientes. Los parámetros de este algoritmo (tamaño ventanas y umbrales) serán comparados en dos zonas distintas.

\subsubsection{Influencia de los parámetros umbrales y tamaño de ventana en la precisión del MDE. Chiva.}

En total, se han analizado 5 grupos de 25 MDE definidos por cada tipo de vector w aplicado, cuyas componentes indican la secuencia de tamaños de ventana donde se ha buscado la elevación mínima. Para cada uno de estos grupos se estudió la variación del RMSE de acuerdo a los vectores $t_{a b}$ cuyas componentes $u 1$ y $u 2$ representan los umbrales, diferencias máximas admitidas en la altura de un punto mínimo seleccionado y la obtenida en un MDE anterior.

Se observa en la Figura 22 que el RMSE del MDE presenta una tendencia decreciente con el aumento del valor del umbral 41 y u2. Para las ventanas w1 y w2, a partir del umbral con valor 1,5 m el RMSE se mantiene mínimo y constante. La tendencia decreciente se observa para todos los vectores $w$ ensayados tanto si los MDE fueron generados a partir de todos los datos LiDAR como en los generados a partir de una imagen inicial. Los resultados obtenidos fueron diferentes a otros trabajos, en los que se utilizaron valores de umbrales iguales o menores a $1 \mathrm{~m}$ (Clark et al., 2004; Yu et al., 2004; Estornell et al; 2007). Esto es debido a que estos trabajos se realizaron en zonas con bajas pendientes y presencia de vegetación arbórea, de mayor altura que la arbustiva de nuestro trabajo. Pero en nuestro estudio, donde existen pendientes elevadas e irregularidad, al utilizar umbrales muy pequeños se corre el riesgo de no incluir puntos pertenecientes al suelo, aumentando el error cometido. 


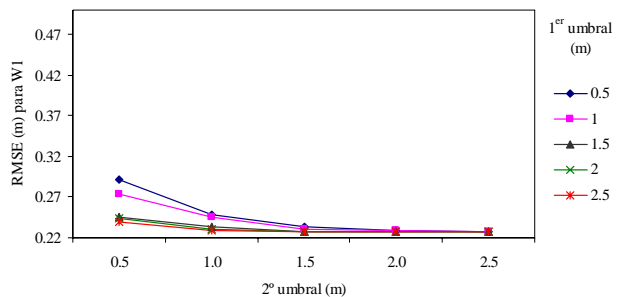

(a)

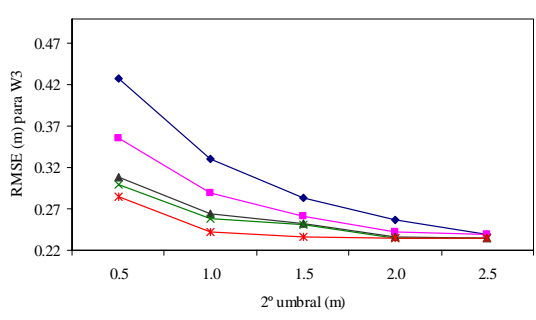

(c)

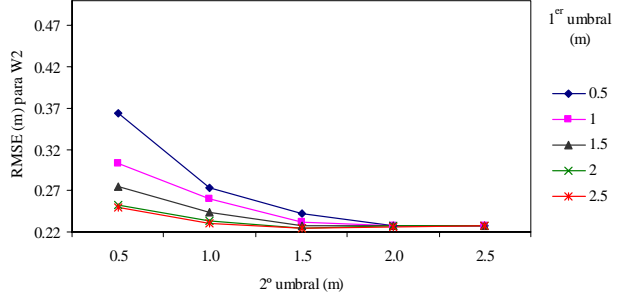

(b)

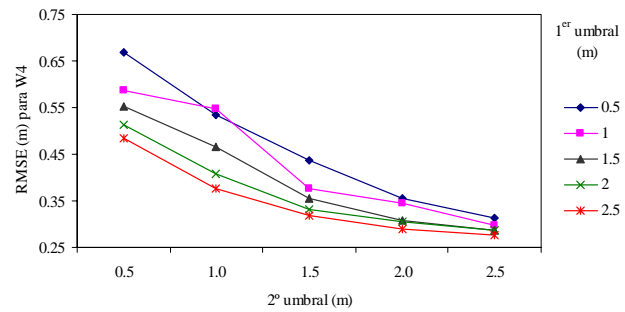

(d)

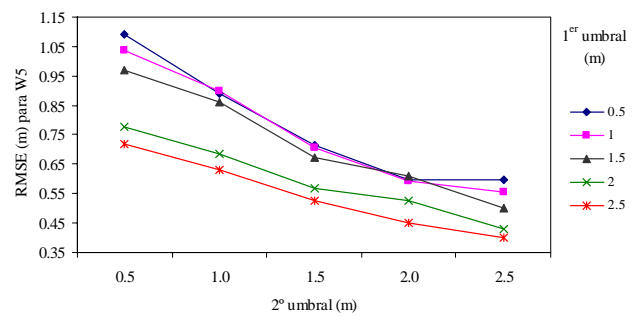

(e)

Figura 22. Gráfico del RMSE al variar el $1^{\mathrm{er}}$ y $2^{\circ}$ umbral para el caso de las ventanas: a) w1 $(8,4,2)$; b) w2 (10,5,2,5); c) w3(12,6,3); d) w4(15,10,5); e) w5(20,10,5).

Por lo que se refiere al tamaño de ventana, se puede apreciar en la Figura 22 una tendencia decreciente en los valores de RMSE al disminuir el tamaño de ventana. Los valores mínimos de RMSE para cada vector de ventana fueron $0,23 \mathrm{~m}$ para los vectores $w 1$, w2 y w3, $0.28 \mathrm{~m}$ y 0,43 $\mathrm{m}$ para los vectores $w 4$ y $w 5$, respectivamente. Esto indicaría que la utilización de ventanas menores generaría RMSE menores. Lo contrario ocurre al utilizar tamaños grandes, pudiendo no caracterizar adecuadamente el microrrelieve de la zona (Popescu et al., 2002). Por tanto, el empleo de ventanas grandes sólo esta justificado en zonas de pocos huecos que permitieran que un pulso alcanzara el suelo como en el caso de Clark et al. (2004) que utilizaron las ventanas 20, 15 y 10 m para seleccionar puntos mínimos en una cubierta arbórea densa. En resumen, el valor de ventana debería ser lo suficientemente pequeño para preservar con detalle la topografía del suelo, y lo suficientemente grande para eliminar cualquier objeto que no pertenezca al terreno. Desafortunadamente, una ventana ideal no existe en el mundo real (Zhang et al., 2003). 
Clark et al. (2004) aplicando la misma metodología con ventanas mayores de 20, 15 y 10 m obtuvieron precisiones inferiores, (RMSE $=2,29 \mathrm{~m}$ ), que los logrados en este trabajo (RMSE mínimo $=0.19 \mathrm{~m}$ ). En nuestro estudio, se comprobó que al utilizar estas ventanas se generan RMSE más grandes, hecho confirmado también por Suárez et al., 2005. En este trabajo, el RMSE obtenido resultó ser inferior a 0,25 m aunque las condiciones de la zona de estudio fueron diferentes (pendientes suaves).

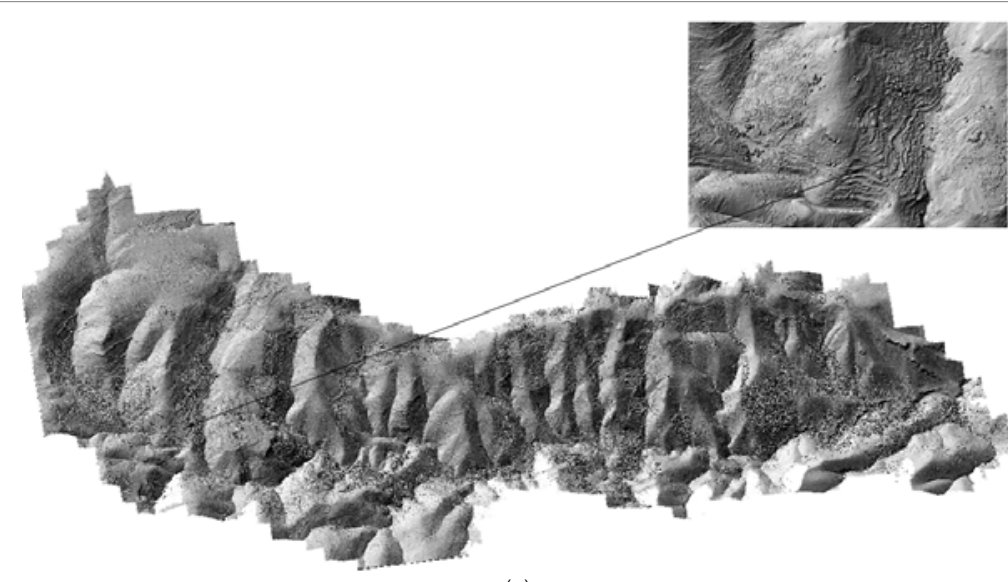

(a)

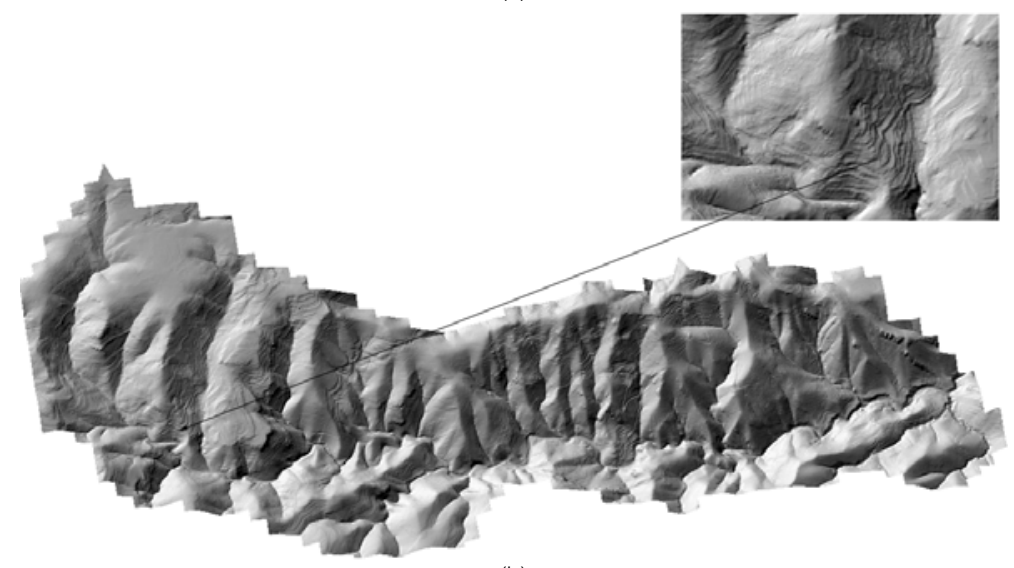

(b)

Figura 23. Imagen de sombras en 3D de un DSM (a) y un MDE calculado con los tamaños de ventana 10, 5, y 2,5 m; umbrales 2,5 m; y una imagen como datos de partida (b). En los detalles se puede apreciar que las áreas con vegetación arbustiva han sido eliminadas correctamente en el proceso de filtrado para el cálculo del MDE.

Con el análisis de los datos obtenidos en terrenos de pendiente elevada e irregular se ha detectado que los umbrales donde se alcanza RMSE mínimo son iguales o superiores al desnivel existente en el tamaño de ventana. Teniendo en cuenta que nuestra área de estudio posee un $45 \%$ de pendiente media, para una ventana de tamaño $v_{i}=4 \mathrm{~m}$ el RMSE se hace mínimo al utilizar un umbral $\mathrm{u}_{\mathrm{i}}=1,8 \mathrm{~m}$, para una ventana 
$v_{i}=5 \mathrm{~m}$ el RMSE se hace mínimo en $u_{i}=2,25 \mathrm{~m}$, para $v_{i}=6 \mathrm{~m}$ el RMSE se hace mínimo en $\mathrm{u} 2=2,7 \mathrm{~m}$ y para $v_{\mathrm{i}}=10$ el RMSE se hace mínimo en $\mathrm{u} 2=4,5 \mathrm{~m}$.

Para explicar los valores de los umbrales con los que se obtiene un RMSE mínimo, se ha representado el perfil del terreno con pendiente media del $45 \%$ y que varía de manera irregular (Figura 24). Inicialmente, la ventana 1 es grande y el punto mínimo seleccionado B está en el extremo. El punto A corresponde al punto mínimo seleccionado en la ventana contigua. Con estos datos se obtendría el MDE1. Al existir pendiente no uniforme entre los puntos A y B, el MDE1 queda por encima del terreno real (MDE). Al aplicar la ventana v2, más pequeña, A y B se vuelven a seleccionar y aparece otro punto, $C$, sin saber con exactitud si éste pertenece a la superficie del terreno o a la vegetación. Si se elige un umbral considerando la pendiente media y el tamaño de ventana, $\mathrm{C}$ es seleccionado si no supera 41 con una probabilidad muy alta de que pertenezca al terreno y no a la vegetación. Si se utilizan umbrales pequeños el punto C no sería seleccionado y el RMSE del MDE2 sería el mismo que el del MDE1. Cuando se aplica la siguiente ventana $\checkmark 3$, se sigue el mismo razonamiento. En este caso se seleccionarían los puntos D y E.

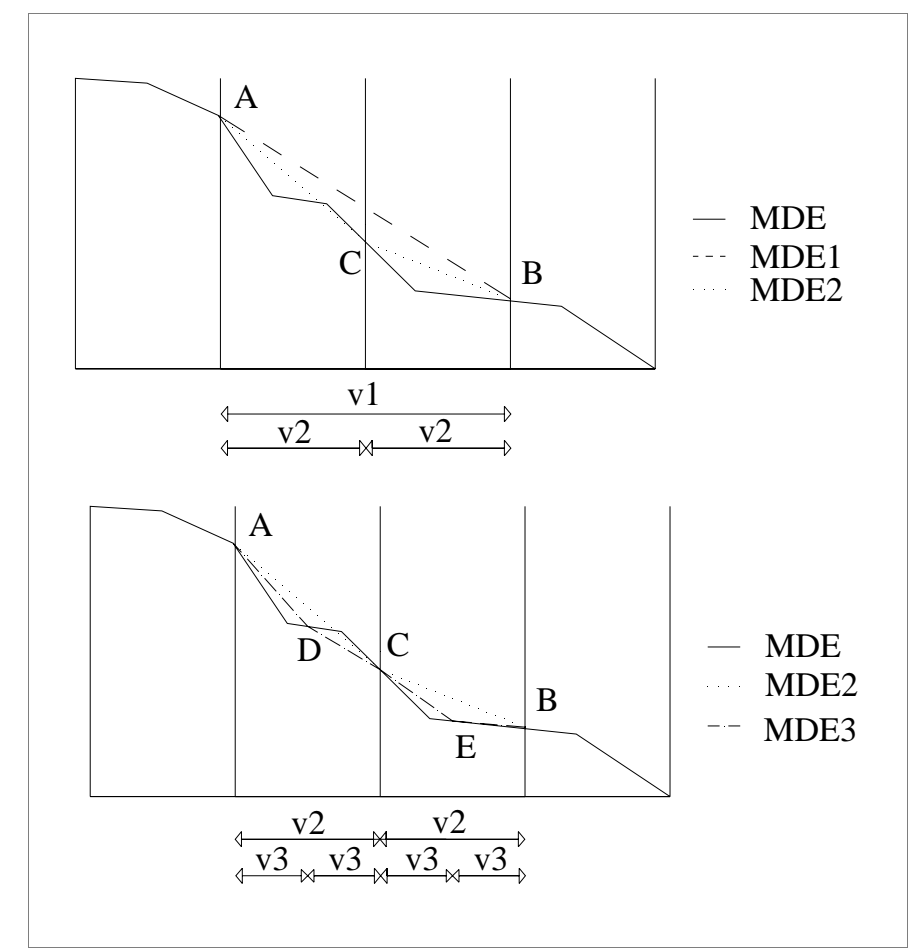

Figura 24. Selección de puntos mínimos en un perfil del terreno característico de la zona de estudio. 


\subsubsection{Influencia de los parámetros umbrales y tamaño de ventana en la precisión del MDE. El Saler.}

Como se puede observar en la Figura 25, se aprecia una tendencia lineal creciente del RMSE al aumentar los umbrales. Este efecto es más importante en el caso de las ventanas w1, w2 y w3. Para el caso w4, se puede apreciar un ligero descenso del RMSE, de 0,72 a 0,65 m, al variar los umbrales de 0,5 a 1,5. La misma situación se repite para el caso de la ventana w5. En este caso el RMSE varía de 0.61 a $0.51 \mathrm{~m}$ al aumentar el umbral de 0,5 a $2 \mathrm{~m}$. Para este umbral y ventana el RMSE es mínimo.

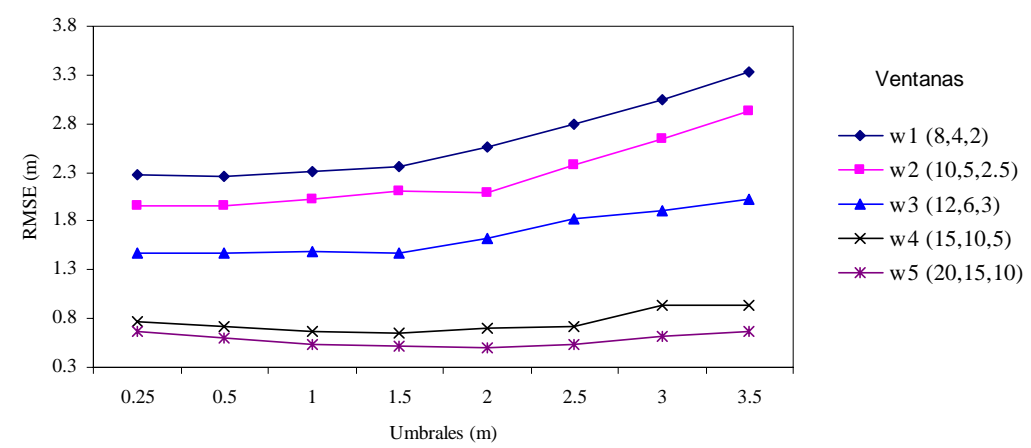

Figura 25. Gráfico del RMSE en $m$ al variar los umbrales para el caso de las ventanas w1 (a), w2 (b), w3 (c) w4 (d) y w5 (e)

En cuanto a las ventanas, el RMSE decrece al utilizar ventanas grandes (w4 y w5). Para explicar las causas de estos resultados es importante recordar que en el caso de El Saler la densidad de puntos era menor, con presencia densa de arbolado. Esto significa que será menos probable que los pulsos alcancen el suelo. Por ese motivo, es necesario aumentar el tamaño de ventana para que la probabilidad de que alguno de ellos alcance el suelo sea mayor. De esta manera, el RMSE decrece cuando el tamaño de ventana aumenta. Lo contario sucede al utilizar ventanas menores ya que en este caso se seleccionan puntos con elevación mínima pertenecientes a la vegetación. Esto se puede observar en las Figuras 26a y $26 \mathrm{~b}$ en las que aparecen los puntos seleccionados con elevación mínima al utilizar el vector w2. Se puede apreciar presencia de puntos en zonas de árboles debido a que el tamaño de ventana es más pequeño que las dimensiones de los mismos. Sin embargo, al utilizar un tamaño de ventana más grande, se seleccionan menos puntos pertenecientes a la vegetación, como se aprecia en las Figuras 26c y 26d. En estas figuras también se observa menos puntos seleccionados, ya que el tamaño de la primera componente del vector $w$ es mayor. 


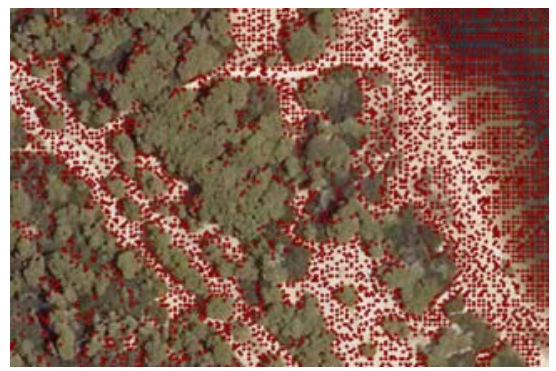

(a)

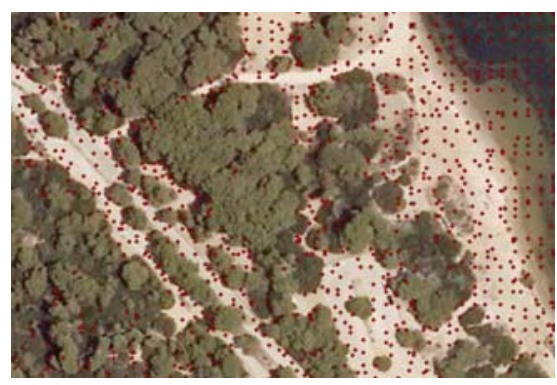

(c)

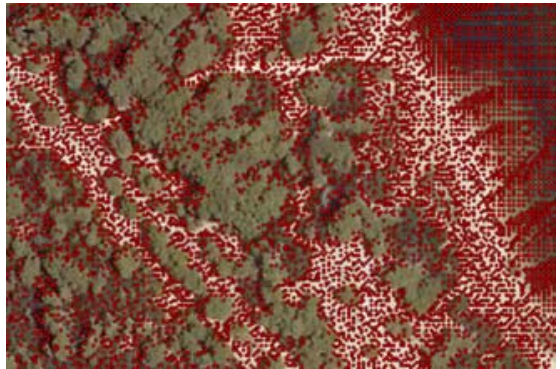

(b)

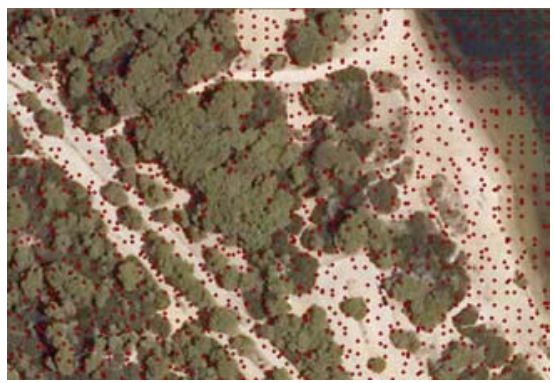

(d)

Figura 26. Selección de puntos con elevación mínima; a) vector ventana w2 (10, 5, 2.5) y umbral 0,5 $\mathrm{m}$; b) vector ventana $w 2(10,5,2.5)$ y umbral $2 \mathrm{~m}$; c) vector ventana $w 5(20,10,5)$ y umbral $0,5 ; d)$ vector ventana $w 5(20,10,5)$ y umbral $2 \mathrm{~m}$.

\subsubsection{Comparación de los resultados}

Para la comparación de los dos casos se han considerado los valores de RMSE correspondientes a los $10 \mathrm{MDE}$ calculados combinando los siguientes parámetros: vector de ventanas w2 y w5; componentes de los umbrales $u 1=u 2$ 0,5, 1, 1,5, 2 y 2,5 m; una imagen como datos de entrada. Como se puede apreciar en la Figura 27a, hay una tendencia creciente del RMSE para el caso de El Saler al utilizar el vector de ventanas w2 $(10,5,2,5 \mathrm{~m})$. Lo contrario se puede observar en el caso de Chiva. Para todos los umbrales utilizados, el RMSE es mayor para el caso de El Saler al utilizar el vector de ventanas w2. Esto se debe a que la vegetación en El Saler es arbórea y muy densa, dificultando que el pulso de energía llegue al suelo. También la densidad de puntos influye ya que en estas zonas de vegetación, al disponer de una menor densidad de puntos, la probabilidad de que algún pulso alcance el suelo es menor. 


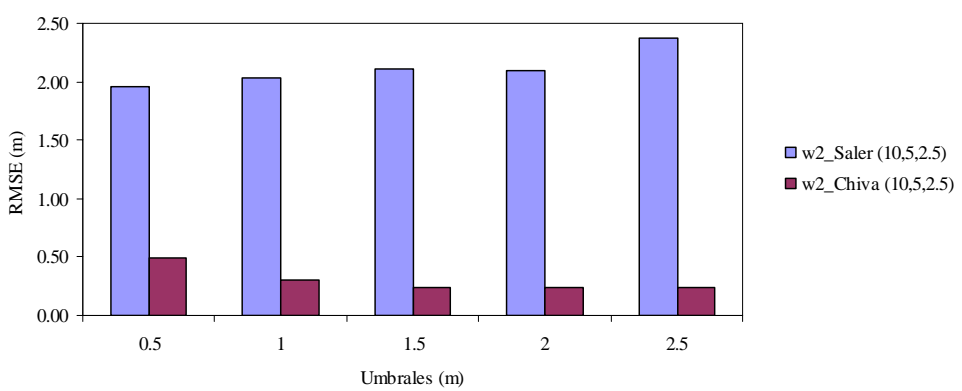

(a)

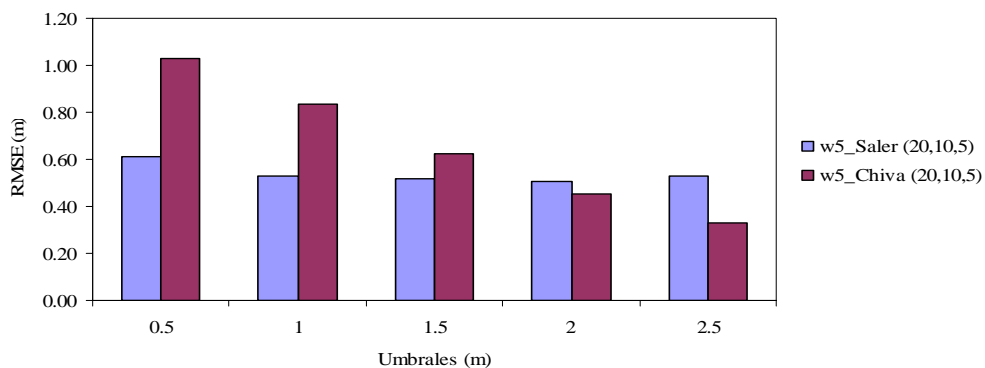

(b)

Figura 27. Comparación del RMSE al variar los umbrales, siendo $u 1=u 2$, en el caso de Chiva y del Saler para las ventanas w2 (a) y w5 (b).

En cuanto a la utilización del vector de ventanas w5 (20,15, 10 m) se puede observar que el RMSE es mayor para los MDE de la zona de Chiva al utilizar los valores de umbrales 0,5, 1 y 1,5 m (Figura 27b). Esto se podría explicar a partir del hecho de que la orografía de Chiva es muy irregular, con pendientes muy elevadas. Al utilizar ventanas grandes y umbrales pequeños se elimina la variación del relieve existente en su interior. Para el caso de Chiva se puede observar una tendencia decreciente hasta el umbral 2,5 m. Como se había demostrado en el apartado 5.1.1, en el caso de Chiva es necesario utilizar umbrales a partir de 1,5 m en los MDE calculados con las ventanas w1, w2 y w3 y de 2,5 en las ventanas w4 y w5 para evitar eliminar la topografía local. En el caso de El Saler, se observa una tendencia con ligero decrecimiento hasta el umbral $2 \mathrm{~m}$. En este caso y dado que la densidad de puntos es baja ( 1 punto $/ \mathrm{m}^{2}$ ), la probabilidad de considerar puntos pertenecientes a la vegetación es mayor, por lo que se recomienda la utilización de umbrales menores. 


\subsubsection{Análisis de los factores que influyen en la precisión del MDE}

En este apartado se analizará cómo afectan en la precisión del cálculo del MDE los factores tipo de datos de entrada, pendiente del terreno, densidad variable de datos LiDAR y la vegetación en la zona de Chiva.

Influencia de los datos de partida en la precisión del MDE

En la Figura 28 se representa el RMSE y errores medios de los MDE obtenidos para cada uno de los tamaños de ventanas $w$, umbrales $2,5 \mathrm{~m}$ y utilizando como datos de entrada todos los puntos LiDAR y una imagen obtenida de la selección de puntos mínimos en celdas de $1 \mathrm{~m}^{2}$. Se puede observar que los MDE obtenidos a partir de la imagen presentan un RMSE menor que los MDE obtenidos a partir de todos los datos LiDAR. Por otro lado, también se observa que el RMSE disminuye cuando el tamaño de las componentes de los vectores $\mathrm{w}$ (v1, v2, v3) también lo hacen.

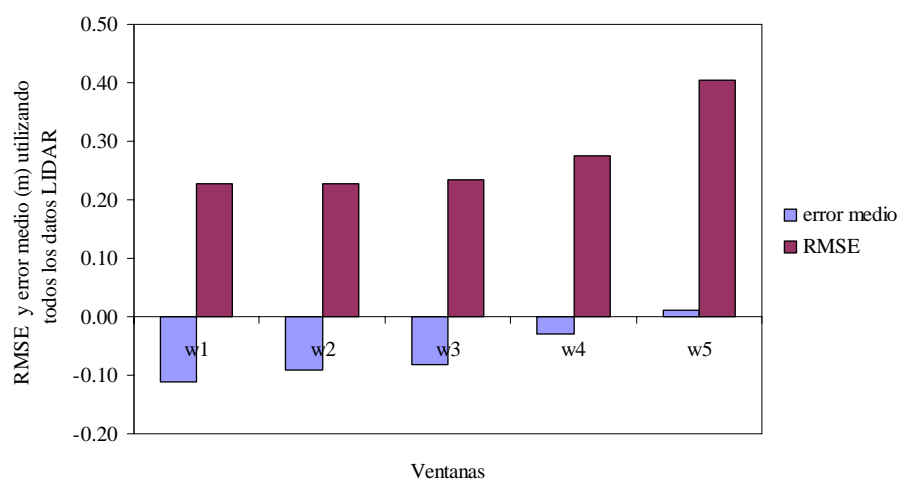

(a)

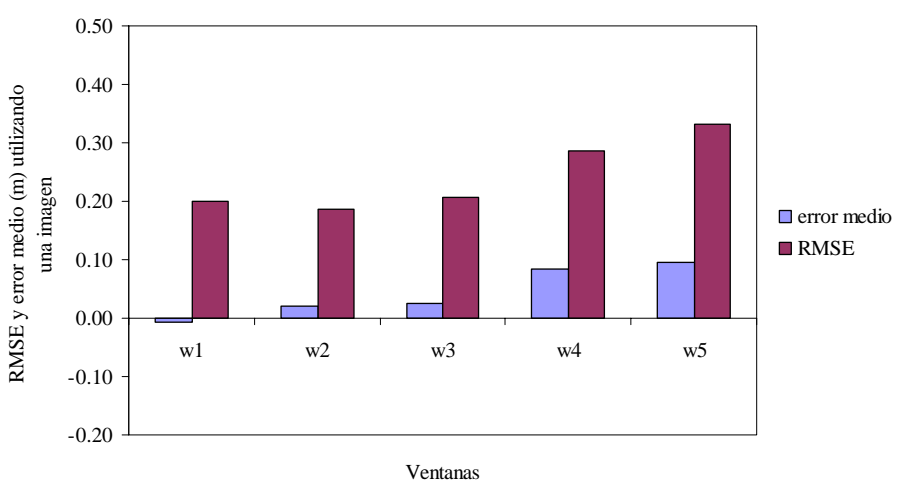

(b)

Figura 28. RMSE y error medio para los MDE calculados con ventanas w1 $(8,4,2)$, w2 $(10,5,2,5)$ w3 $(12,6,3)$, w4 $(15,10,5)$ y w5 $(20,10,5)$, y valores de umbrales $2,5 \mathrm{~m}$. Datos de partida todos los puntos (a) y la imagen (b). 
El valor mínimo del RMSE fue de 0,19 m para el vector w2-imagen y los valores de RMSE más altos se registraron al considerar los vectores w4 y w5 y al utilizar los datos LiDAR originales, con valores de 0,28 y $0,40 \mathrm{~m}$, respectivamente (Figura 28). En términos de error medio, los valores más bajos correspondieron a los MDE calculados con la utilización de imágenes de partida y vectores w1 y w2, con un error medio de 0,01 y 0,02 m, respectivamente. La desviación estándar fue 0,20 m en ambos casos. Los valores en error medio fueron similares a los obtenidos por Wang et al., (2009) en áreas con vegetación arbustiva. Sin embargo, los valores más altos de desviación estándar obtenidos en nuestro trabajo pueden ser explicados porque la vegetación ocupa áreas de mayor superficie, la vegetación es más cerrada y alta, y las pendientes más elevadas. Todos estos factores originan una mayor dificultad en la selección de puntos pertenecientes al suelo.

En la Figura 28, también se puede observar una tendencia creciente al aumentar el tamaño de ventana al cambiar el signo del error de negativo, cuando se utilizan todos los puntos, a positivo cuando se utiliza la imagen. Este resultado indicaría que la utilización de la nube de puntos LiDAR tiende a sobrestimar el MDE al diminuir el tamaño de ventana y la utilización de la imagen de partida tiende a subestimar el MDE a medida que se aumenta el tamaño de ventana.

\section{Influencia de la pendiente del terreno en la precisión del MDE}

Otro de los análisis realizados fue estudiar el RMSE en función de la pendiente. En la Figura 29b se puede observar que al utilizar los vectores w1, w2, w3 y w4 con los datos de la imagen, se aprecia una tendencia creciente y lineal tras aumentar la pendiente.

Las mismas tendencias de crecimiento del error con la pendiente, aunque con valores superiores de RMSE, se observan en los MDE calculados utilizando como datos de partida todos los puntos (Figura 29a). Resultados similares se obtuvieron en otros trabajos. Hyyppä et al., 2001 con una variación del error estándar de 0,15 a 0,40 m y en Hollaus et al., 2006 de un RMSE de 0,1 a 0,31 m al pasar de pendientes de $0-10 \%$ a valores entre $40-50 \%$. En nuestro estudio, considerando los mismos intervalos de pendiente, el RMSE varía de 0,16 a 0,27 m para w1, de 0,13 a 0,30 m para w2, de 0,14 a 0,26 m para w3, de 0,24 a $0,41 \mathrm{~m}$ para w4. Para las ventanas w5 no se observa una relación directa entre el RMSE y la pendiente. Al utilizar ventanas grandes (w5), el microrelieve de la zona puede ser eliminado, aumentando el RMSE. Estos resultados podrían indicar que los parámetros seleccionados para el cálculo del MDE son adecuados en el caso de pendientes elevadas e irregulares. Si se compara la pendiente y la información de partida, se puede observar que los RMSE son mayores cuando se utilizan todos los puntos. Estos resultados confirmarían la idoneidad de la utilización de la imagen como datos de partida. 


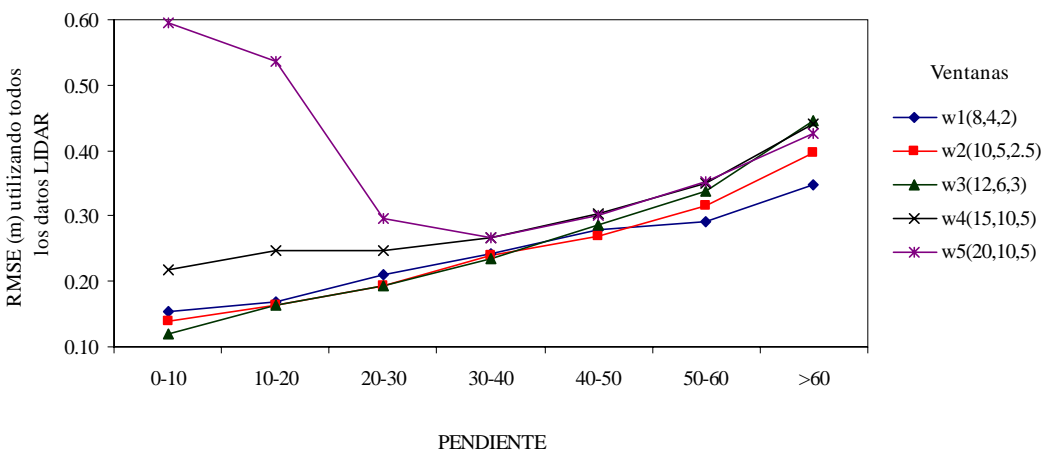

(a)

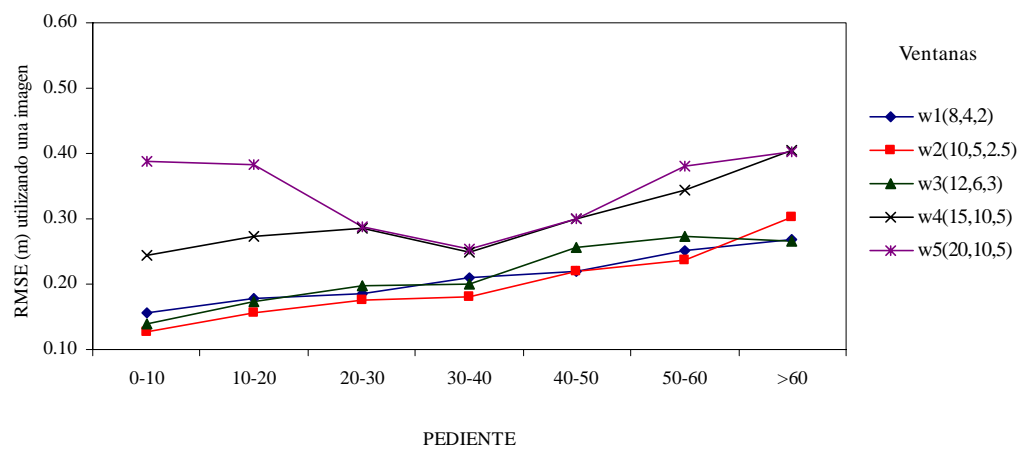

(b)

Figura 29. RMSE al variar la pendiente en los MDE calculados con ventanas w1, w2, w3, w4 y w5, y valores de umbrales $2,5 \mathrm{~m}$. Datos de partida: todos los puntos (a) y una imagen (b).

\section{Influencia de la densidad de puntos en la precisión del MDE}

La densidad de puntos es otra variable a considerar cuando se estudia la precisión de un MDE (Baltasvias 1999). De nuestros análisis se desprende que se reduce el RMSE cuando se aumenta la densidad de puntos. Los valores de RMSE más bajos fueron en los MDE calculados utilizando como ventanas w1 y w2 y datos de partida la imagen (Figura 30b). En estos casos, los valores de RMSE variaron de 0,29 a 0,19 m para $w 1$, y de 0,24 a 0,17 m para w2, al pasar de una densidad de 1-2 puntos $/ \mathrm{m}^{2}$ a 8 puntos $/ \mathrm{m}^{2}$. Estos resultados coincidirían con los encontrados en Hyyppä et al., 2005. En este trabajo el error aleatorio varió de 0,12 a $0,18 \mathrm{~m}$ al pasar de una altura de vuelo y de densidad de puntos de 400 a $1500 \mathrm{~m}$ y de 8 a $1-2$ puntos $/ \mathrm{m}^{2}$, respectivamente. Exceptuando el caso de las ventanas w5, se puede observar que el RMSE se mantuvo constante a partir de una densidad de 8 puntos $/ \mathrm{m}^{2}$. En la ventana w5 no se aprecia una relación clara debido al gran tamaño de las ventanas utilizadas (Figuras 30a y 30b). 


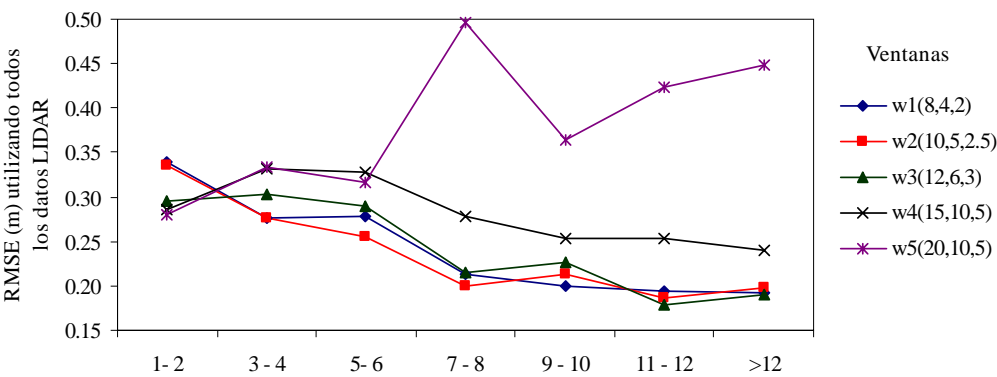

Densidad puntos $/ \mathrm{m}^{2}$

(a)

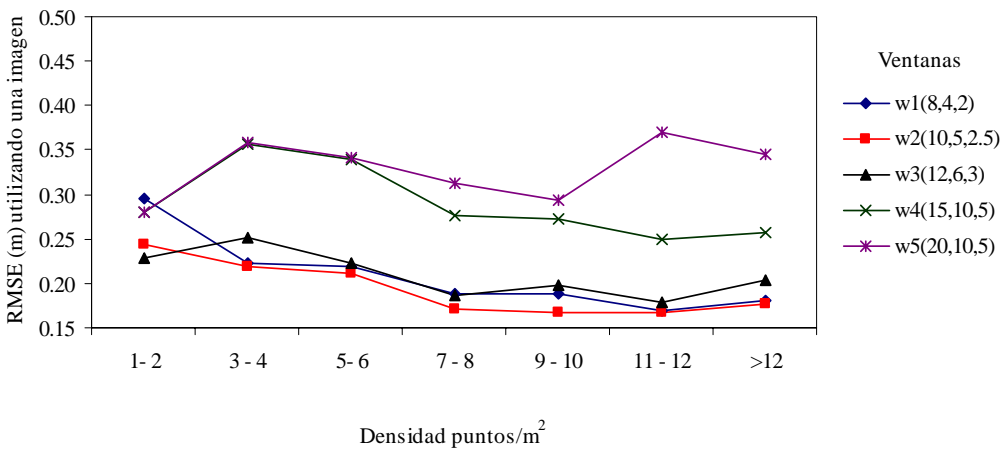

(b)

Figura 30. RMSE al variar la densidad de puntos en los MDE calculados con ventanas w1, w2, w3, w4 y $w 5, y$ valores de umbrales $2,5 \mathrm{~m}$. Datos de partida todos los puntos (a) y una imagen (b).

Influencia de la vegetación en la precisión de MDE

Para analizar la presencia de vegetación en la precisión del MDE se utilizaron 77 puntos medidos con GPS-RTK en zonas con vegetación arbustiva densa. Los valores más bajos de RMSE corresponden a tamaños de ventanas intermedias con datos de origen la imagen (w2-imagen y w3-imagen). El valor de RMSE obtenido es de 0,24 m (Figura 31). Este valor es 0,05 m superior al valor mínimo de RMSE calculado a partir de los 1.379 puntos medidos en campo. 


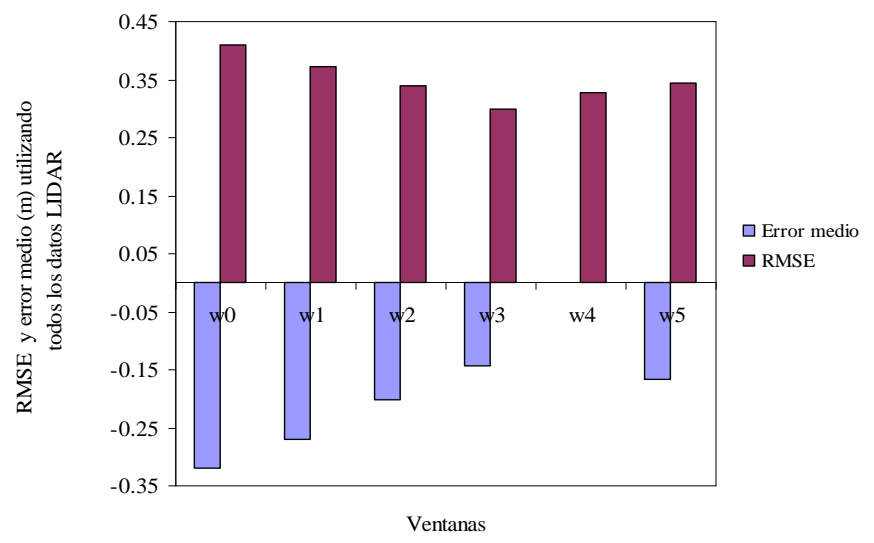

(a)

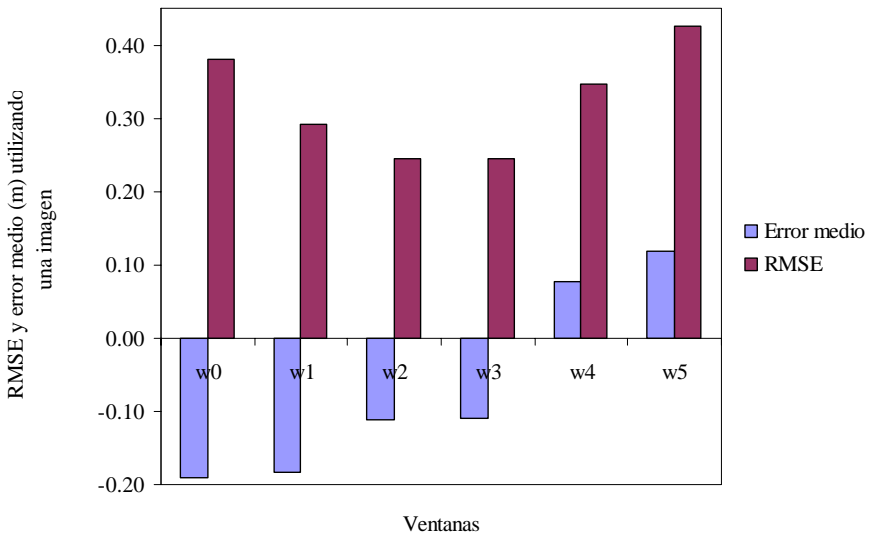

(b)

Figura 31. RMSE y error medio en los MDE calculados con ventanas wo $(5,2,5,1)$, w1 $(8,4,2)$, w2 $(10,5,2,5)$, w3 $(12,6,3)$, w4 $(15,10,5)$ y w5 $(20,10,5)$ y valores de umbrales $2,5 \mathrm{~m}$ en zonas con vegetación $(\mathrm{n}=77)$. Datos de partida todos los puntos (a) y una imagen (b)

Su and Bork (2006) obtuvieron un RMSE mayor (0,5 m) en el cálculo del MDE en áreas con presencia de Elaeagnus cuya estructura es similar a la vegetación de nuestra zona de estudio. Estos resultados sugieren que este algoritmo podría ser usado en áreas con vegetación arbustiva con pendientes elevadas, aunque la precisión decrece en zonas ocupadas por la vegetación (Cobby et al., 2001; Raber at al., 2002; Hodgson et al., 2005; Riaño et al., 2007). En la Figura 23 se puede visualizar que la vegetación ha sido correctamente filtrada en el proceso de cálculo de un MDE. 
El error medio es negativo y alto en valor absoluto cuando se utilizan las ventanas w0 (5, 2.5, $1 \mathrm{~m}$ ) y w1 (8, 4 y $2 \mathrm{~m}$ ), especialmente al utilizar la nube de puntos LiDAR como datos de entrada. Esto puede indicar que puntos pertenecientes a la vegetación estarían siendo seleccionados como puntos-terreno, sobreestimando el MDE. Para evitar este efecto, sería recomendable utilizar las ventanas intermedias w2 y w3 y datos de partida la imagen.

\subsubsection{Cálculo del MDS y del MDV}

La obtención del MDS se realizó a partir de la selección de los puntos máximos en celdas de 0,5×0,5 $\mathrm{m}^{2}$. En la Figura 23 se pueden observar las diferencias entre el MDS y el MDE. Estas diferencias se aprecian con mayor claridad en los detalles de esta figura, que corresponden a una zona con presencia de vegetación.

En el detalle de la Figura 23b se observa que no se han seleccionado puntos correspondientes a la vegetación arbustiva, es decir, estos datos fueron filtrados correctamente al utilizar el algoritmo para la generación del MDE. Este resultado apoyaría la idoneidad de los parámetros seleccionados para el cálculo del MDS y del MDE, analizados previamente.

El cálculo del MDV fue obtenido restando al MDS el MDE. En la Figura 32 se ha visualizado el MDV clasificado en tres intervalos: 0-0,3m; 0,3-2,5 m; $\mathrm{h}>2,5 \mathrm{~m}$. Se puede observar que el número de celdas correspondiente al último intervalo es menor al resto de clases. Las alturas de este intervalo corresponden a las de los árboles, lo que indica que la zona de estudio tiene una baja presencia de arbolado. En cambio la clase con mayor número de celdas es la segunda $(0,3 \mathrm{~m}<\mathrm{h}<2,5 \mathrm{~m})$. Estas alturas son características de la vegetación arbustiva.

Con el objetivo de analizar la imagen anterior, se han representado dos detalles en la Figura 32, uno correspondiente al MDV y otro a una imagen aérea en una zona con caminos, parcelas sin vegetación, con vegetación arbustiva y arbolado. Se puede apreciar una buena correspondencia entre las dos imágenes en zonas sin vegetación, como son los caminos y las parcelas de la izquierda de la imagen, así como de las zonas con arbolado y vegetación arbustiva. 


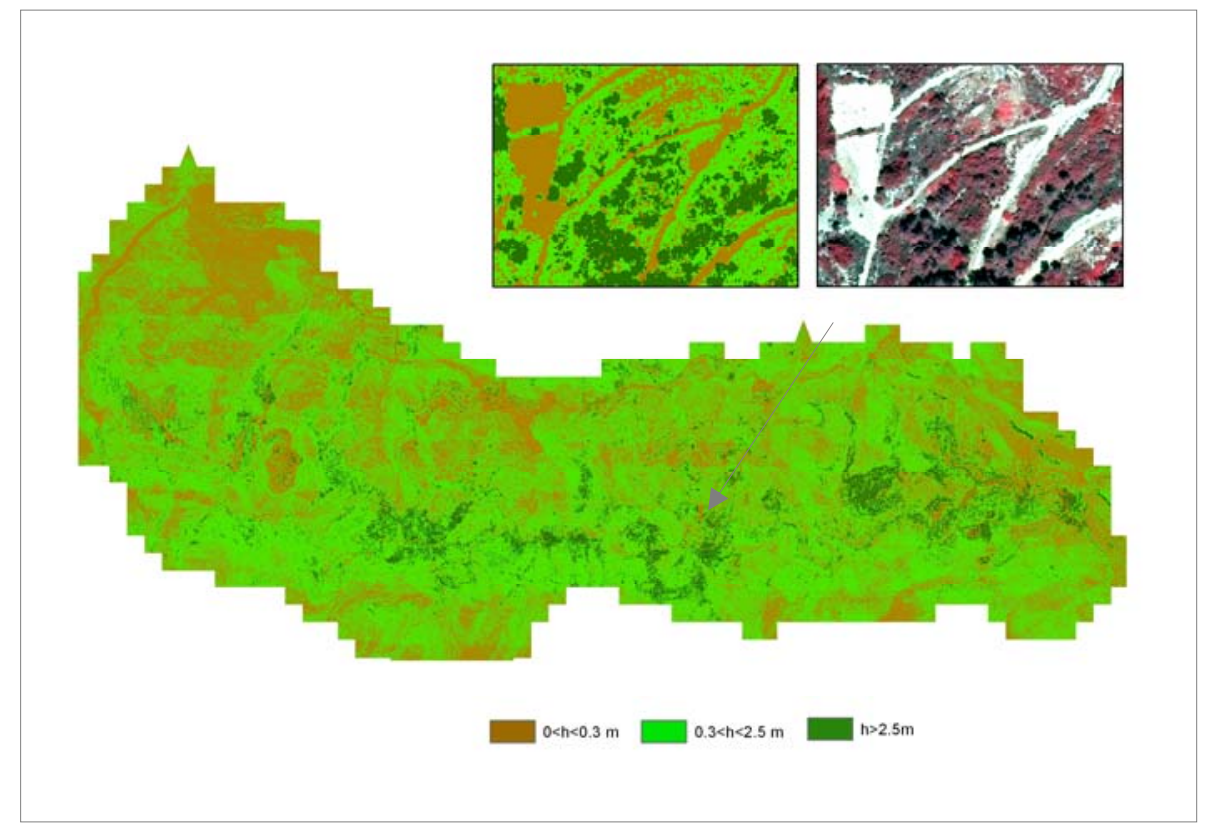

Figura 32. Imagen del MDV de la zona de estudio. La visualización se ha realizado agrupando los valores de las alturas en tres clases: 0-0.3 m, 0.3-2.5 m y h>2.5 m. Esta figura también contiene un detalle del MDV y de una imagen multiespectral en una zona con presencia de caminos, parcelas sin vegetación, vegetación arbustiva y arbolado. La imagen está visualizada en falso color; las bandas IR, R y G se asignan a los canales $R, G, B$, respectivamente.

\subsection{ESTIMACIÓN DE VARIABLES FORESTALES}

En este apartado se describen los resultados y discusión sobre las estimaciones de las variables forestales: altura, biomasa y volumen por parcelas y subparcelas. También se analizan los resultados relacionados con la estimación de la superficie cubierta de la vegetación arbustiva en la zona de estudio.

\subsubsection{Estimación de la altura de la vegetación}

\section{$\underline{\text { Parcelas }}$}

Para la estimación de las alturas de la vegetación mediante datos LiDAR se realizaron 5 regresiones simples utilizando como variables independientes los estadísticos calculados a partir de los datos LiDAR por parcela: altura media $\left(h_{m}\right)$, altura máxima $\left(h_{\text {max }}\right)$ y los percentiles $80\left(P_{80}\right), 90\left(P_{90}\right)$ y $95\left(P_{95}\right)$. Como variable dependiente se utilizó la media de las medidas realizadas en campo por parcelas. Como se puede observar en la Tabla 11, el coeficiente de determinación máximo se alcanza en los modelos que utilizan como variable independiente el percentil 95 con valores de $R^{2}$ y RMSE, 0,71 y 0,13 m, respectivamente. Dado 
que el p-valor en la tabla ANOVA es inferior a 0,01, existe relación estadísticamente significativa entre la altura medida en campo y dicho percentil. En la Figura 33 se puede observar una buena correlación entre los valores observados y estimados con una diferencia máxima de 0,25 m.

Los modelos con peor aproximación ( $\mathrm{R}^{2}$ y RMSE) se obtuvieron al utilizar la altura máxima de los datos LiDAR de la parcela. Esto se podría explicar a partir del hecho que en la parcela hay alturas máximas aisladas que no representan las alturas dominantes de la vegetación de la parcela. Resultados similares fueron encontrados en Riaño et al., 2007. En este trabajo, basado también en el análisis de la vegetación arbustiva, se utilizó el percentil 90 para el cálculo de la altura por parcelas, obteniendo un valor de $\mathrm{R}^{2}$ de 0,48 y RMSE 0,18 m. Las condiciones del área de trabajo fueron similares: áreas con densa vegetación y muy rugosas. Sin embargo, la altura de la vegetación media fue inferior $(1,01 \mathrm{~m})$, al igual que la densidad de puntos siendo de 3,5 puntos $/ \mathrm{m}^{2}$. Estos factores, junto a la metodología seguida en el cálculo del MDE, podrían explicar las diferencias.

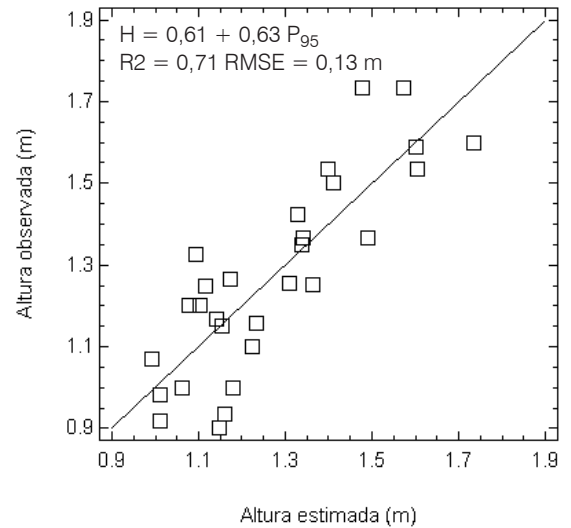

Figura 33. Diagrama de dispersón entre los valores de altura observada y estimada por parcelas.

Tabla 11. Estimación de la altura de la vegetación arbustiva por parcela a partir de datos LiDAR

\begin{tabular}{cccccc}
\hline $\begin{array}{c}\text { Variables independientes } \\
\text { (LIDAR data) }\end{array}$ & Símbolo & Modelo & $\mathrm{R}^{2}$ & P-valor & RMSE (m) \\
\hline altura media & $\mathrm{h}_{\mathrm{m}}$ & $\mathrm{H}=0,97+0,79 \mathrm{~h}_{\mathrm{m}}$ & 0,48 & $<0,01$ & 0,18 \\
percentil 80 & $\mathrm{P}_{80}$ & $\mathrm{H}=0,74+0,72 \mathrm{P}_{80}$ & 0,57 & $<0,01$ & 0,16 \\
percentil 90 & $\mathrm{P}_{90}$ & $\mathrm{H}=0,66+0,67 \mathrm{P}_{90}$ & 0,64 & $<0,01$ & 0,15 \\
percentil 95 & $\mathrm{P}_{95}$ & $\mathrm{H}=0,61+0,63 \mathrm{P}_{95}$ & 0,71 & $<0,01$ & 0,13 \\
altura máxima & $\mathrm{h}_{\max }$ & $\mathrm{H}=0,23+0,86 \mathrm{~h}_{\max }$ & 0,39 & $<0,01$ & 0,19 \\
\hline
\end{tabular}

H: altura máxima dominante media en campo 


\section{Subparcelas}

Se analizó el radio que genera el mínimo RMSE entre la altura máxima derivada de los datos LiDAR y los datos de campo. La Figura 34 muestra el mínimo RMSE al utilizar radios entre $1,5 \mathrm{~m}$ y 2,25 m. Este resultado también es observado en la Tabla 12. A medida que aumenta el radio, el error medio cambia de signo lo que indica que la media de las alturas de la vegetación obtenidas a partir de los datos LiDAR son mayores a las medidas en campo. Para un radio de 3,5 m se puede apreciar más este efecto. Para este valor, el error medio es positivo, mientras que el error máximo y desviación estándar son los más altos. En el radio 1,5 m se obtiene un valor mínimo de la desviación estándar. Estos resultados coincidirían con los obtenidos por Streutker y Glenn, 2006 aunque las condiciones del trabajo fueron diferentes: densidad 1,2 puntos $/ \mathrm{m}^{2}$, zona con relieve suave.

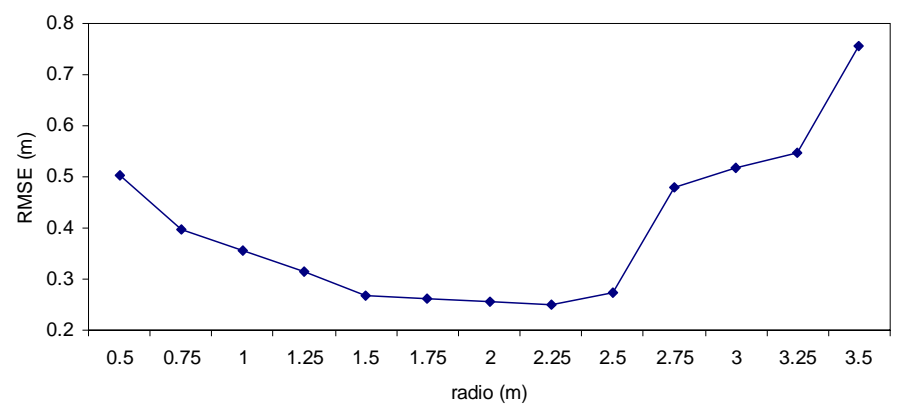

Figura 34. Representación del RMSE entre las 83 alturas de la vegetación obtenidas a partir de los datos LiDAR y las medidas en campo para cada radio.

Por otro lado, en la Tabla 12 se puede observar que el error medio entre las alturas de la vegetación obtenidas a partir de los datos LiDAR y de los datos de campo para cada radio es negativo hasta un valor de radio de 2,75 m, lo que indica que se tiende a subestimar las alturas de la vegetación a partir de datos LiDAR. Este resultado coincidiría con el detectado en otros trabajos en los que se analizó alturas de vegetación arbustiva (Gaveau and Hill, 2003;Hill and Thomson, 2005; Hopkinson et al., 2005; Streutker and Glenn, 2006; Bork and Su, 2007; Riaño et al., 2007).

La altura máxima dominante en las subparcelas se estimó a partir de los datos LiDAR seleccionados en el interior de un área con radio 1,5 $\mathrm{m}$. Se eligió este radio porque estuvo incluido en el rango de radios con menor RMSE entre las alturas de la vegetación medidas en campo y las derivadas de los datos LiDAR (Figura 34). Además, este radio produjo la mínima desviación estándar entre datos LiDAR y datos de campo. Se realizaron 5 regresiones simples utilizando como variables independientes los siguientes estadísticos calculados a partir de los datos LiDAR incluidos en un buffer con centro el de las subparcelas y radio 1,5 m: altura media $\left(h_{m}\right)$, altura máxima $\left(h_{\max }\right)$ y los percentiles $80\left(\mathrm{P}_{80}\right), 90\left(\mathrm{P}_{90}\right)$ y $95\left(\mathrm{P}_{95}\right)$. Como variable dependiente se utilizó la altura máxima dominante de cada subparcela. 
Como se puede observar en la Tabla 13, la correlación máxima se alcanza en los modelos que utilizan como variable independiente la altura máxima con valores de $R^{2}$ y RMSE, 0,61 y 0,18 m, respectivamente. Dado que el p-valor en la tabla ANOVA es inferior a 0,01, existe relación estadísticamente significativa entre la altura medida en campo y la altura máxima. A diferencia de lo que ocurre en las parcelas, en este caso no es el percentil 95 el que origina mejores correlaciones, sino la altura máxima de los datos LiDAR. Esto se puede explicar a partir del hecho de que el área de este análisis es menor al de las parcelas, siendo menos probable seleccionar a partir de los datos LiDAR, alturas que sean superiores a la altura dominante real del rodal.

Tabla 12. Cálculo del valor mínimo (min), máximo (max), media y desviación de las diferencias entre las alturas de la vegetación de los datos LiDAR y las medidas en campo para cada radio.

\begin{tabular}{ccccccccccccc}
\hline Radio $(\mathrm{m})$ & 0,5 & 0,75 & 1 & 1,25 & 1,5 & 1,75 & 2 & 2,25 & 2,5 & 2,75 & 3 & 3,5 \\
\hline Min $(\mathrm{m})$ & $-1,04$ & $-0,84$ & $-0,82$ & $-0,80$ & $-0,77$ & $-0,77$ & $-0,77$ & $-0,77$ & $-0,77$ & $-0,77$ & $-0,69$ & $-0,55$ \\
Max $(\mathrm{m})$ & 0,24 & 0,24 & 0,24 & 0,25 & 0,36 & 0,36 & 0,76 & 0,76 & 0,76 & 3,37 & 3,71 & 6,16 \\
Media $(\mathrm{m})$ & $-0,40$ & $-0,31$ & $-0,25$ & $-0,20$ & $-0,15$ & $-0,12$ & $-0,08$ & $-0,06$ & $-0,03$ & 0,05 & 0,08 & 0,16 \\
Des $(\mathrm{m})$ & 0,30 & 0,26 & 0,25 & 0,24 & 0,22 & 0,23 & 0,24 & 0,25 & 0,27 & 0,48 & 0,52 & 0,74 \\
\hline
\end{tabular}

Tabla 13. Estimación de la altura de la vegetación arbustiva por subparcelas a partir de datos LiDAR.

\begin{tabular}{cccccc}
\hline $\begin{array}{c}\text { Variables independiente } \\
\text { (datos LIDAR) }\end{array}$ & Símbolo & Modelo & $\mathrm{R}^{2}$ & $\begin{array}{c}\text { P-valor } \\
\text { RMSE } \\
(\mathrm{m})\end{array}$ \\
\hline Altura media & $\mathrm{h}_{\mathrm{m}}$ & $\mathrm{H}=0,80+0,84 \mathrm{~h}_{\mathrm{m}}$ & 0,42 & $<0,01$ & 0,23 \\
percentil 80 & $\mathrm{P}_{80}$ & $\mathrm{H}=0, .74+0,68 \mathrm{P}_{80}$ & 0,47 & $<0,01$ & 0,21 \\
percentil 90 & $\mathrm{P}_{90}$ & $\mathrm{H}=0,68+0,67 \mathrm{P}_{90}$ & 0,51 & $<0,01$ & 0,21 \\
percentil 95 & $\mathrm{P}_{95}$ & $\mathrm{H}=0,61+0,69 \mathrm{P}_{95}$ & 0,57 & $<0.01$ & 0,19 \\
altura máxima & $\mathrm{h}_{\max }$ & $\mathrm{H}=0,55+0,64 \mathrm{~h}_{\max }$ & 0,61 & $<0,01$ & 0,18 \\
\hline
\end{tabular}

$\mathrm{H}$ : altura máxima dominante medida en campo

\subsubsection{Factores que influyen en la selección del radio para el estudio de las alturas de la vege- tación por subparcelas}

En este apartado se describe cómo afectan los factores error asociado al MDE, pendiente y densidad de datos LiDAR en la selección del radio en el que el RMSE entre las alturas de la vegetación derivadas de los datos LiDAR y las obtenidas a partir de los datos de campo sea mínimo.

\section{Factor de error asociado al MDE}

Aunque Streutker y Glenn, 2006 afirmaron que la selección adecuada del radio debe realizarse de acuerdo a la precisión horizontal de los datos LiDAR y la del GPS, es importante considerar otros factores como el error asociado al MDE y la densidad de puntos. En la Figura 35 se puede observar que los valores de RMSE son más bajos cuando el error asociado al MDE es positivo $\left(z_{\mathrm{GPS}}-\mathrm{Z}_{\mathrm{MDE}}>0\right)$ hasta un radio de 2,25 $m$. Lo contrario sucede para los puntos con un error asociado al MDE negativo ( $\left.z_{G P S}-z_{M D E}<0\right)$. El primer caso indicaría que el MDE se ha subestimado, siendo más bajo de lo que realmente es. De esta manera, 
se obtendrían alturas de la vegetación más altas (Figura 36). En el segundo caso se produciría una sobreestimación del MDE, es decir, la superficie calculada sería más alta de lo que realmente es. Por lo tanto, la altura de la vegetación sería menor. De esta manera, el error asociado al MDE puede generar una subestimación o sobrestimación de la altura de la vegetación. Para ello, es importante seleccionar parámetros adecuados en el cálculo del MDE que minimicen este error, como los obtenidos en este trabajo.

Al calcular el error medio para cada radio en los puntos con errores asociados al MDE positivos, se pudo comprobar que fueron negativos hasta un radio de $2 \mathrm{~m}$, indicando que aún en el caso de que el MDE sea más bajo de lo que realmente es, obteniendo alturas de la vegetación más altas, se produce una subestimación de la vegetación. Esto confirmaría el hecho de que se produce una subestimación de la vegetación arbustiva a partir de los datos LIDAR.

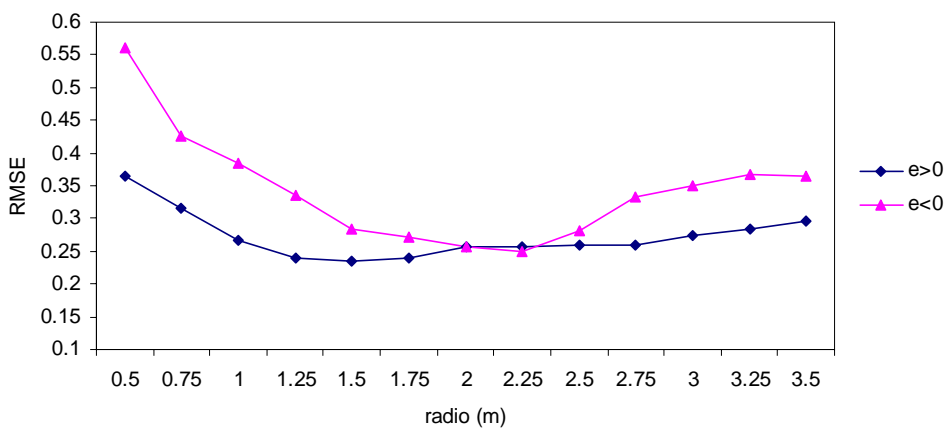

Figura 35. Representación del RMSE entre las 82 alturas de la vegetación medidas en campo y las obtenidas a partir de los datos LiDAR, tras utilizar varios radios para los casos de errores asociados al MDE positivos $(n=32)$ y negativos $(n=50)$.

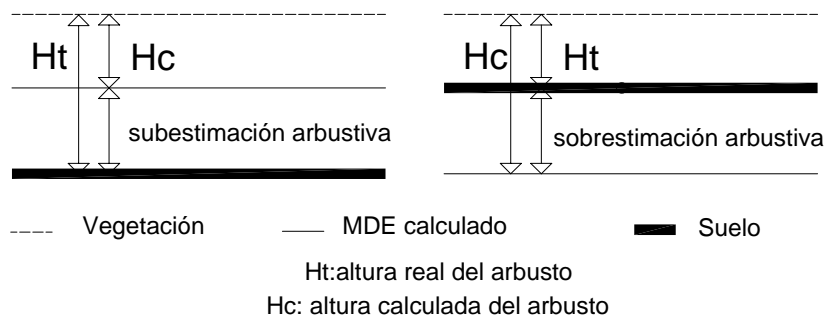

Figura 36. Efectos sobre la estimación de la vegetación de los errores asociados al MDE. 
La Figura 37 muestra las diferencias en la variación del RMSE por cada radio entre las 83 alturas de la vegetación medidas en campo y las derivadas de los datos LiDAR (arriba) y entre las 34 alturas medidas en campo y las correspondientes a los datos LiDAR en zonas cuya pendiente es menor al $20 \%$ y corregidas del error asociado al MDE (abajo). Se puede observar un importante descenso del RMSE cuando el radio pasa de 0,50 a 0,75 m. A partir de este radio, y a diferencia de lo que ocurre en el caso de las 83 alturas, se observan menores variaciones en RMSE en el caso de los 34 alturas. Este resultado sugiere que si el error asociado al MDE y las pendientes son bajos, el mínimo error entre los datos de campo y los datos LiDAR puede ser encontrado para radios menores, en este caso un radio de 0,75 m. Este valor de radio se aproxima a la precisión horizontal de los datos LiDAR (0,5 m).

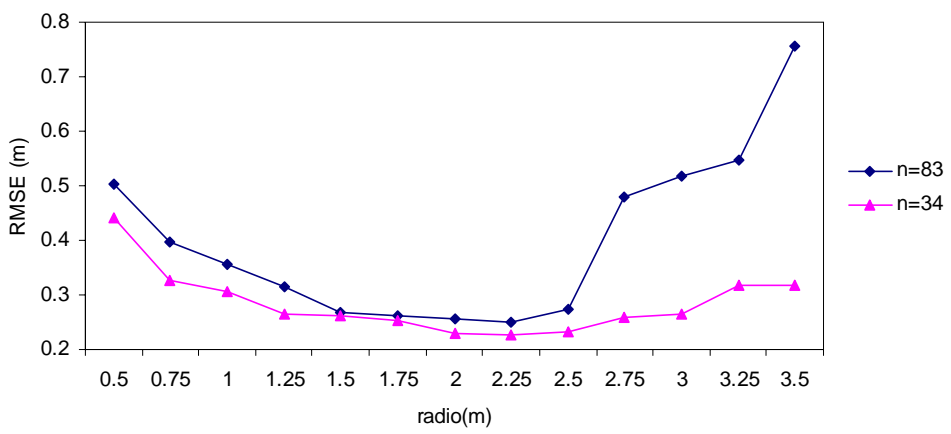

Figura 37. Representación del RMSE al utilizar varios radios entre las 83 alturas de la vegetación medidas en campo y las obtenidas a partir de los datos LiDAR y entre los 34 puntos sin error asociado al MDE y con una pendiente inferior al $20 \%$.

Para explicar cómo puede afectar la pendiente en la precisión de las alturas habría que fijarse en primer lugar en el tamaño de píxel del MDE, 1m. Cuando se superponen los datos LiDAR con el MDE para calcular la altura de la vegetación, es muy probable que algunos de esos puntos no tomen la cota del píxel correspondiente, sino de un píxel vecino debido a los procesos de interpolación y de creación de una imagen. En el caso de pendientes elevadas, con media del 45\%, como es el caso de la zona de estudio, el error podría ser importante considerando que se están estimando alturas con media 1,27 m. No sucedería lo mismo en zonas con pendientes bajas. En este caso, aunque se seleccionara la cota del MDE del píxel contiguo para el cálculo de la altura de la vegetación, el error sería mínimo.

Como se observa en la Figuras 37, para un radio de 1,5 m los valores de RMSE son similares, tanto para el caso de la utilización de todos los puntos sin corrección del error asociado al MDE, como para aquellos en los que se ha tenido en cuenta este factor. Para este valor de radio el RMSE es de 0,26 m. Esta coincidencia puede ser explicada teniendo en cuenta que para el radio de 1,5 $\mathrm{m}$, nueve celdas pueden ser 
seleccionadas del MDE para el cálculo de la altura de la vegetación. Dado que la altura de la vegetación real es similar en el área ocupada por este radio, la posibilidad de obtener un valor de la altura de la vegetación próxima al valor real aumenta.

\section{$\underline{\text { Factor densidad de puntos en el radio de búsqueda }}$}

Según la Figura 38 se puede apreciar que el RMSE es menor al utilizar una densidad mayor a 8 puntos $\mathrm{m}^{2}$ hasta un radio de 2,75 $\mathrm{m}$. Las diferencias entre los RMSE correspondientes a los dos valores de densidad decrecen de los $0,14 \mathrm{~m}$ al utilizar un radio de $0,5 \mathrm{~m}$ a 0 para un radio de $2,5 \mathrm{~m}$.

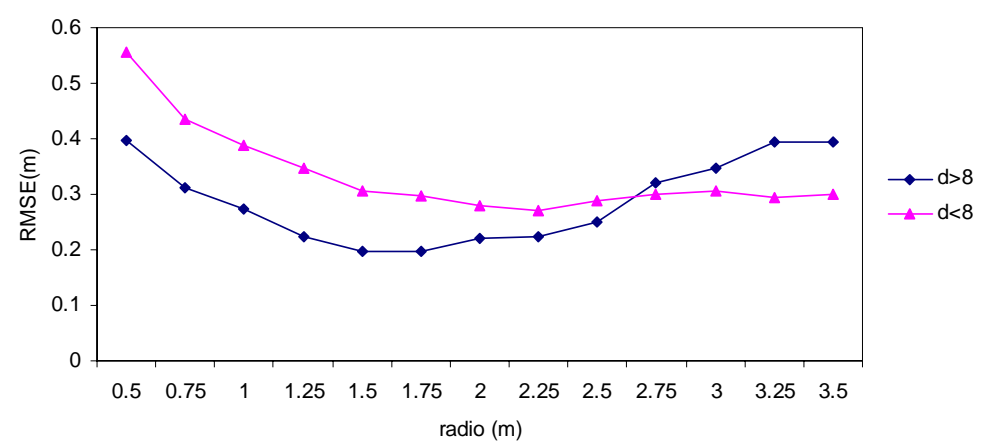

Figura 38. Representación del RMSE entre las alturas de la vegetación medidas en campo y las obtenidas a partir de los datos LiDAR al utilizar varios radios en los casos con densidad de puntos superior $(n=43)$ e inferior $(n=49)$ a los 8 puntos $/ \mathrm{m}^{2}$.

\subsubsection{Estimación de la altura de la vegetación a partir del MDV}

Como se puede apreciar en la Figura 39 el mínimo RMSE entre los datos de campo y los obtenidos del MDV se obtiene al utilizar tamaños de celdas entre 2,5 y $4 \mathrm{~m}$. También se observa que hay un descenso significativo en los valores de RMSE al pasar de un tamaño de celda de 0,5 m a 1,5 m. Los resultados obtenidos se aproximan a los radios obtenidos en el caso de la estimación de las alturas de la vegetación de los análisis predecedentes. También se observa que al utilizar un tamaño de $5 \mathrm{~m}$ la correlación disminuye de manera significativa, lo que indica que se están seleccionando alturas más altas que las medidas en campo. 


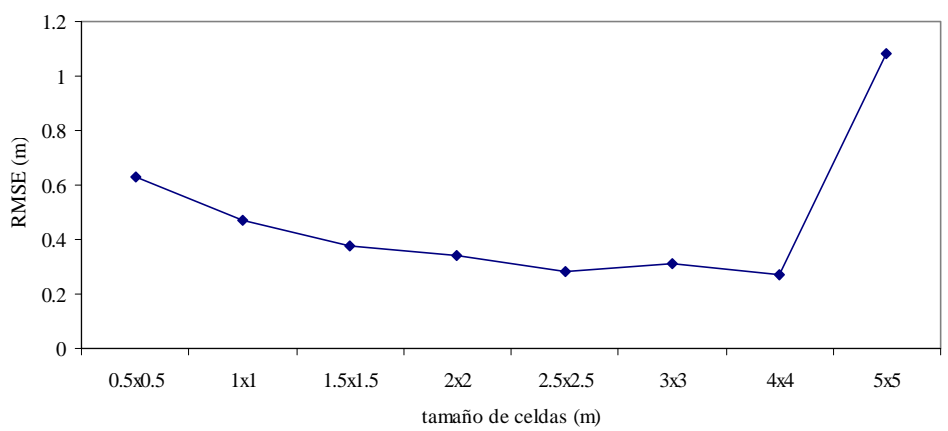

Figura 39. RMSE entre las 83 alturas de la vegetación medidas en campo y las obtenidas a partir del MDV obtenido de los datos LiDAR para diferentes tamaños de celdas.

\subsubsection{Estimación de la superficie cubierta de la vegetación arbustiva a partir del MDV y datos espectrales}

La fiabilidad global de la clasificación realizada cuando se utiliza sólo el MDV fue del 87\%, similar a los resultados encontrados en otros trabajos (Streutker and Glenn, 2006). Según la Tabla 14, para la clase vegetación arbustiva, la fiabilidad del usuario es del 84\%. Esto significa que de los 90 puntos clasificados como vegetación, realmente pertenecen a esta clase 76 puntos, es decir, 14 puntos de los 90 pertenecen a la clase suelo. En cuanto a la fiabilidad del productor, es del $92 \%$. De los 83 puntos que pertenecen a esta clase, 76 fueron clasificados correctamente.

Tabla 14. Fiabilidad global, del usuario y del productor de las clases suelo y arbusto cuando el MDV y la imagen espectral se combinan y cuando se usa sólo el MDV.

\begin{tabular}{ccccc}
\hline \multirow{2}{*}{ MDV e imagen espectral } & \multicolumn{3}{c}{ Datos de referencia } & \multirow{2}{*}{ Fiabilidad del usuario (\%) } \\
\cline { 2 - 4 } & Suelo & Arbusto & Total & \\
\hline Suelo & 78 & 11 & 89 & $87,64 \%$ \\
Arbusto & 5 & 72 & 77 & $93,51 \%$ \\
Total & 83 & 83 & 166 & \\
Fiabilidad del Productor (\%) & 93,98 & 86,75 & & 90,36 (Fiabilidad global) \\
MDV sólo & & & & 90,79 \\
Suelo & 69 & 7 & 76 & 84,44 \\
Arbusto & 14 & 76 & 90 & \\
Total & 83 & 83 & 166 & 87,35 (Fiabilidad global) \\
\hline
\end{tabular}


Al utilizar la imagen espectral mejoró la fiabilidad de la clasificación realizada (Mundt et al., 2006; Bork and Su, 2007 y Mutlu et al., 2008), siendo la fiabilidad del usuario de la clase vegetación arbustiva del 94\% (Tabla 14). Esto se debe a que al considerar la imagen, no todos los puntos clasificados como vegetación arbustiva, es decir con una altura entre 0,3 y 2,5 m, pertenecen realmente a esa clase. Al calcular el NDVI es posible detectar la presencia de vegetación y descartar los puntos que aunque con una altura correspondiente a la vegetación arbustiva, no pertenecen a esta clase. Sin embargo, la fiabilidad del productor fue menor que en el caso de utilizar sólo el MDV, siendo del 87\%. Esto significa que al utilizar la imagen, algunos de los puntos pertenecientes a la vegetación arbustiva no se clasificaron como tales. Esto se puede explicar por el hecho de que la imagen multiespectral fue tomada un año y medio antes, pudiendo no haber vegetación en esa fecha. En cualquier caso, la mejora en la fiabilidad del usuario al utilizar la imagen es mayor que la disminución de la fiabilidad del productor lo que originó un aumento de la fiabilidad global del 3\%.La utilización de la imagen espectral, a pesar de no generar un aumento relevante en la fiabilidad global, sirvió para validar los resultados obtenidos de la clasificación del MDV, corrigiendo los efectos de la subestimación o sobreestimación del MDE en aquellas celdas con alturas de la vegetación bajas.

El análisis visual realizado de los resultados combinando el MDV y la imagen aérea confirman los resultados de las fiabilidades anteriores (Figura 40). Se puede comprobar que la clase vegetación arbustiva es la que ocupa mayor superficie dentro de la zona de estudio. Por el contrario, la clase con menor superficie corresponde a la de arbolado. En uno de los detalles de la figura anterior se representa la imagen aérea en una composición en falso color en la que el canal del rojo está asociado con la banda del infrarrojo, el canal del verde a la banda del rojo y el canal del azul a la banda del verde. En los detalles se observa la buena correspondencia entre los resultados obtenidos al aplicar el algoritmo y la imagen aérea.

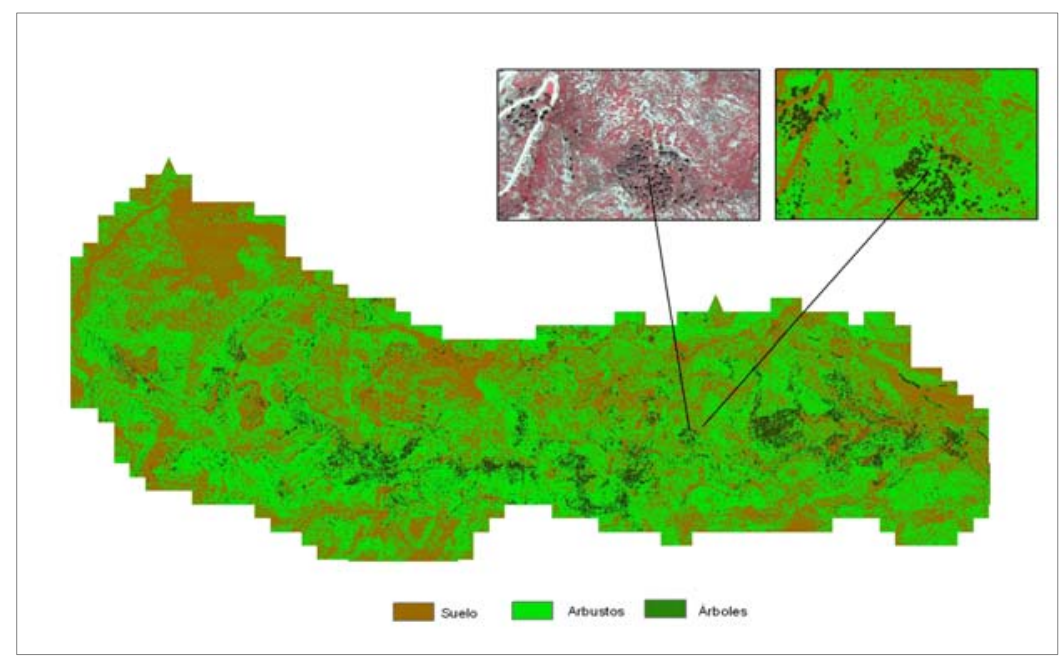

Figura 40. Imagen resultado de combinar el MDV y la imagen aérea. 


\subsubsection{Modelos de regresión para la estimación de la biomasa}

En este apartado se describen los resultados y se realiza una discusión a cerca de la estimación de la vegetación seca y biomasa húmeda, por parcelas y subparcelas. Para el caso de las parcelas se describirán los resultados obtenidos en la preselección de variables.

\section{Parcelas - Vegetación seca}

Previamente al cálculo de los modelos de regresión se realizó una preselección de variables calculando matrices de correlación y aplicando análisis cluster. Los resultados de estos análisis indicaron una alta correlación entre la media de las alturas y los valores de percentil (Anejo 2). Los valores de las variables altura máxima $\left(\mathrm{h}_{\max }\right)$, asimetría $\left(\mathrm{g}_{1}\right)$, curtosis $\left(\mathrm{g}_{2}\right)$ y coeficiente de variación ( $\mathrm{cv}$ ) presentaron las correlaciones más bajas entre todas las variables. La desviación estándar $\left(h_{d}\right)$ también presenta una baja correlación con estas variables. Estos resultados se confirman en el dendrograma de la Figura 41 obtenido de un análisis cluster a partir del método del vecino más próximo y utilizando como distancia euclídea al cuadrado, el vaIor 1. A partir de esta figura, se pueden establecer seis grupos de variables independientes; cuatro grupos de variables definidas por las variables $h_{\max }, g_{1}, g_{2}$ y cv En el grupo 5 , se incluyen las siguientes variables: $h_{m}, h_{d}, P_{20}, P_{25}, P_{30}, P_{40}, P_{50}, P_{60}, P_{70}, P_{80}, P_{90}$ y $P_{95}$. En el grupo 6 se seleccionan las variables $P_{05}$ y $P_{10}$. Según estos resultados, se consideraron $h_{\max }, g_{1}, g_{2}$ y cv como variables explicativas y se eligieron dos variables de los dos grupos adicionales que mostraron una baja correlación entre el resto de variables. Se analizaron todas las posibles combinaciones.

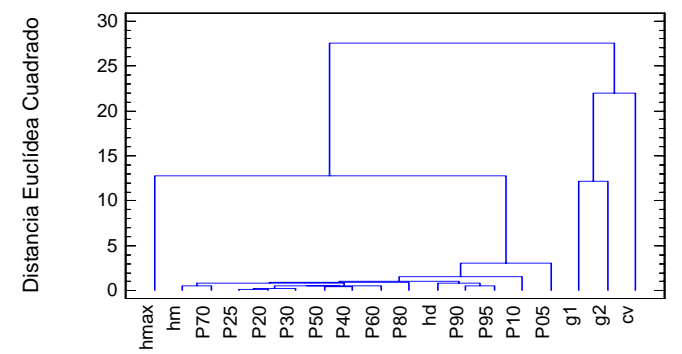

Figura 41. Dendrograma de las variables derivadas los datos LiDAR.

Para el caso de las variables extraídas de las bandas espectrales de la imagen aérea se siguió la misma metodología anterior. En este caso, se definieron tres grupos de variables (Figura 42). En el primer grupo se incluyeron las siguientes variables: $I R_{\min }, R_{\min }, G_{\min }$ y $I R_{m}$; en el segundo grupo: $I R_{\max }, R_{\max }, G_{\max }, \mathbb{R}_{d}, R_{d}$, 
$G_{d}, R_{m}, G_{m}$ y $N D V I_{d}$. En el tercer grupo: NDVI $I_{m}, N D V I_{\min }$ y $N D V I_{\text {max }}$. Se observa una elevada correlación entre las variables de cada grupo en la matriz de correlación (Anejo 3). Una variable de cada grupo fue seleccionada para el cálculo de los modelos de regresión. Se analizaron todas las posibles combinaciones.

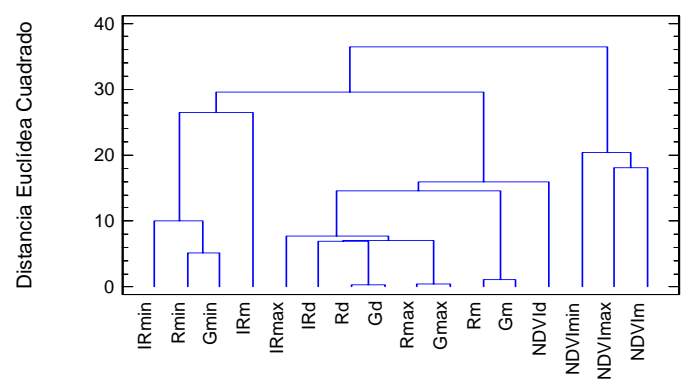

Figura 42. Dendrograma de las variables derivadas de las bandas espectrales de la imagen aérea.

En la Tabla 15 se pueden observar los resultados de las regresiones por pasos para la estimación de la vegetación seca considerando los 3 grupos de variables seleccionadas: variables derivadas de los datos LiDAR, variables derivadas de la imagen aérea y combinación de variables derivadas de los datos LiDAR y la imagen aérea. El modelo con menor coeficiente de determinación $\left(R^{2}=0,34\right)$ se obtuvo al utilizar sólo variables extraídas de la información espectral, lo que indica la baja capacidad de la información espectral para la predicción de biomasa arbustiva. Este resultado coincidió con investigaciones precedentes en las que se afirmó la baja capacidad de estos datos para caracterizar variaciones verticales del dosel (Hudak et al., 2006; Su y Bork, 2007). En contraste, la información espectral se ha utilizado con resultados satisfactorios para realizar mapas en los que se determine la composición por especies (Hill y Thomson, 2005).

Mejores resultados se obtuvieron en la estimación de la biomasa al utilizar variables extraídas de los datos LiDAR $\left(R^{2}=0,67\right)$. Estudios recientes han demostrado la capacidad de estos datos en la predicción de biomasa en bosques con diferentes tipos de especies: Pseudotsuga menziesi, Tsuga heterophyll, Pseudotsuga menzies, Pinus ponderosa, Picea y Betula (Li et al., 2008). Buenos resultados se obtuvieron también en bosques cuyas especies principales fueron Pinus negra, Quercus ilex y Juniperus thurifera (García et al., 2010). Pascual et al., 2008 demostraron que las mejores variables para definir y caracterizar la estructura forestal en bosques de Pinus sylvestris fueron la mediana y desviación típica de los datos LiDAR. Estas variables se han seleccionado en los modelos de predicción de biomasa arbustiva en nuestro estudio. 
Los mejores resultados se obtuvieron al utilizar conjuntamente estadísticos derivados de los datos LiDAR y de la imagen aérea con valores de $R^{2}$ y RMSE, 0,79 y 96,55 kg, respectivamente. Los valores de biomasa observada y estimada mostraron una buena relación lineal próxima a la línea 1:1 (Figura 43). Aunque las variables derivadas de los datos LiDAR explicaron la mayor parte de la variabilidad de este modelo, la predicción de la biomasa mejoró un 10\% al utilizar variables derivadas de la información espectral. Una mejora en la estimación de variables forestales cuando los dos conjuntos de variables (LiDAR-imagen espectral) son combinadas se encontró también en otros estudios forestales (McCombs et al., 2003; Popescu et al., 2004; Erdodi et al.,2010).

Tabla 15. Modelos de regresión en la estimación de vegetación seca por parcelas.

\begin{tabular}{|c|c|c|c|c|}
\hline Variables & Modelo & $R^{2}$ & $\mathrm{R}^{2}$ ajustada & RMSE (kg) \\
\hline LiDAR & $\begin{array}{l}V_{d}=-656,5+3067,4 h_{d}+3102,9 P_{50}-47,1 p_{1}- \\
18,7 p_{0,75-1}-29,2 p_{0,5-0,75}\end{array}$ & 0,67 & 0,60 & 118,2 \\
\hline Imagen aérea & $\mathrm{V}_{\mathrm{d}}=783,5+935,5 \mathrm{NDVI} \mathrm{I}_{\max }-3,2 \mathrm{IR}_{\max }$ & 0,34 & 0,28 & 157,1 \\
\hline $\begin{array}{l}\text { LiDAR e imagen } \\
\quad \text { aérea }\end{array}$ & $\begin{array}{l}V_{d}=-371,5+3200,4 h_{d}+2919,1 P_{50}-47,5 p_{1}- \\
17,8 p_{0,75-1}-32,9 p_{0,5-0,75}-7,4 G_{d}\end{array}$ & 0,79 & 0,73 & 96,6 \\
\hline
\end{tabular}

$V_{d}$ es la vegetación seca en $\mathrm{kg}$ por parcelas de área $100 \mathrm{~m}^{2} ; \mathrm{P}_{50}$ es el percentil 50 de las alturas de los datos LiDAR por parcelas; $h_{d}$ es la desviación estándar de las alturas; $p_{1}$ es el porcentaje de puntos cuya altura es superior a $1 \mathrm{~m}, \mathrm{p}_{0,75-1}$ es el porcentaje de puntos con altura entre 0,75 y $1 \mathrm{~m} ; \mathrm{p}_{0,5-0,75}$ es el porcentaje de puntos con altura entre 0,50 y 0,75 m; $G_{d}$ es la desviación estándar de la banda verde; $I_{\max }$ es el valor máximo de la banda infrarrojo; NDVI max es el valor máximo de la imagen NDVI.

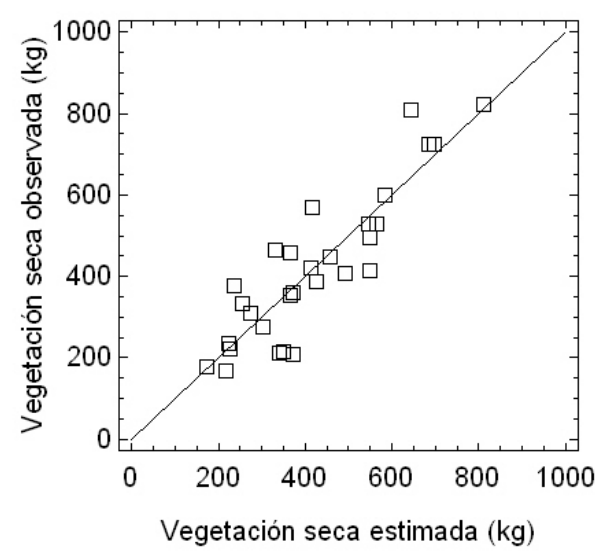

Figura 43. Diagrama de dispersión entre los valores de vegetación seca observada y estimada. 
El modelo con mejores resultados en términos de $\mathrm{R}^{2}$ y RMSE incluye 6 variables, de las que la desviación estándar de las alturas $\left(h_{d}\right)$ explica el mayor porcentaje de la variación de la biomasa. Esta variable caracteriza la estructura del dosel (García et al., 2010) y describe la variabilidad de las alturas de la vegetación en una parcela. En este estudio se pudo observar que a mayor valor de la variable $h_{d}$, mayor fue el valor de biomasa estimada. Por otro lado, señalar la importancia de las variables derivadas de los perfiles de densidad de los datos LiDAR en la estimación de la biomasa. Este resultado coincidió con los obtenidos en otras investigaciones forestales (Næsset , 2004; Van Aardt et al., 2006; Li et al., 2008). En nuestro estudio, se observó que al eliminar estas variables del modelo de regresión, el valor de $R^{2}$ desciende a 0.57.

La Figura 44 muestra la distribución de los datos LiDAR en tres parcelas con máximo porcentaje de alturas mayores a $1 \mathrm{~m}$ (a), con máximo porcentaje de alturas en el intervalo 0,75-1 m (b) y con máximo porcentaje de alturas en el intervalo 0,50-0,75 m (c). La biomasa de la primera parcela fue mayor al de las restantes. La parcela con menos biomasa correspondió con la de menor porcentaje en el intervalo 0,75-1 $\mathrm{m}$ y en el de alturas mayores a $1 \mathrm{~m}$. Estos resultados revelan una clara relación entre la variable biomasa y las derivadas de los perfiles de densidad, es decir, un mayor porcentaje de puntos en una parcela con alturas mayores a $1 \mathrm{~m}$ indica una presencia abundante de vegetación arbustiva que es más alta y que por lo tanto presenta más biomasa.

El modelo con mejores correlaciones también incluye una variable derivada de la información espectral: la desviación estándar de la banda verde (Gd) que fue utilizada también por Erdody y Moskal, 2010 en la predicción de variables asociadas al dosel de árboles de diferentes especies. La Figura 45 muestra la relación entre el valor de Gd y biomasa en dos parcelas con alta y baja presencia de vegetación. En esta figura, la parcela de arriba contiene una alta presencia de vegetación que puede explicarse observando el color rojo de la parcela en la visualización en falso color (RGB: infrarrojo, rojo, verde), la concentración de valores bajos y la menor dispersión de los valores observados en el histograma de la banda del verde. Por el contrario, la parcela de abajo muestra una menor presencia de vegetación arbustiva. En este caso, el histograma de la banda verde presenta dos concentraciones de valores digitales: la primera con valores bajos significa presencia de vegetación; la segunda con una mayor variación de valores digitales está relacionada con la respuesta espectral del suelo (color blanco en la imagen). En este caso, el valor de la variable $G_{d}$ es mayor. En la parcela con menor valor de $G_{d}$ hay más vegetación (más biomasa). Por lo tanto, esta variable contribuye en el modelo de 6 variables a explicar las diferencias entre las zonas de vegetación y el suelo. Aunque la especie dominante de todas las parcelas es Quercus coccifera, hay algunas parcelas con presencia de Cistus albidus $L$. En estas parcelas, el valor de $G_{d}$ es mayor al de las parcelas con predominio de Quercus coccifera de mayor biomasa. Este resultado puede ser explicado a partir del hecho de que la especie Cistus albidus $L$ está caracterizada por un dosel más abierto y por lo tanto la influencia de la respuesta del suelo es más importante, lo que origina una mayor variabilidad en la información espectral. 


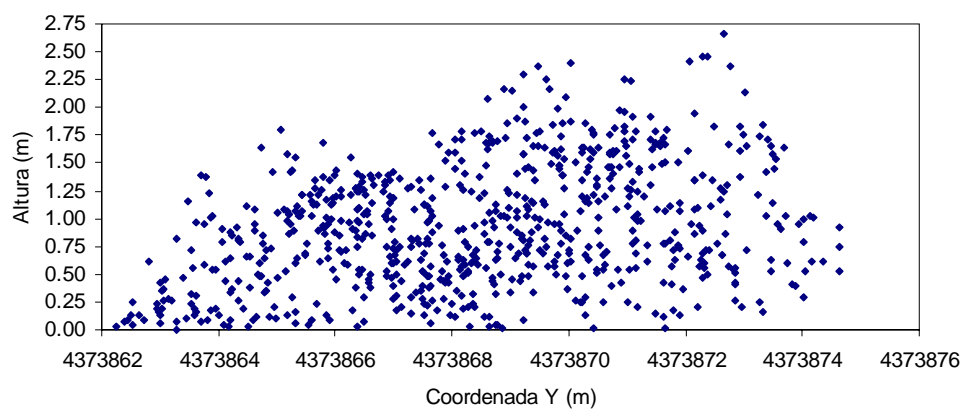

(a)

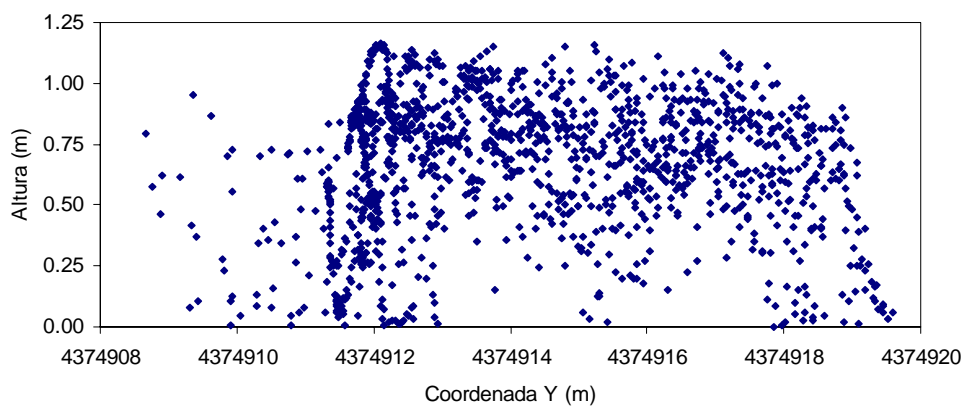

(b)

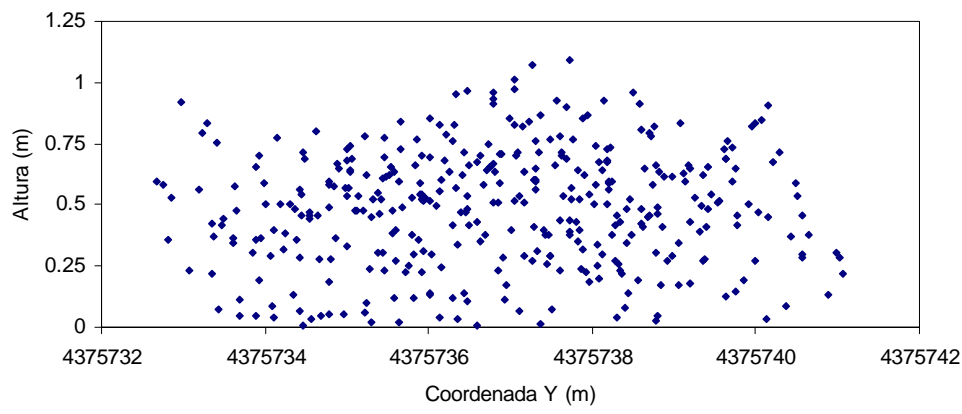

(c)

Figura 44. Parcela con máximo porcentaje de puntos con altura mayor a $1 \mathrm{~m}$ (a); parcela con máximo porcentaje de puntos en el intervalo 0,75-1 m (b); parcela con el máximo porcentaje de puntos en el intervalo 0,50-0,75 m (c). 


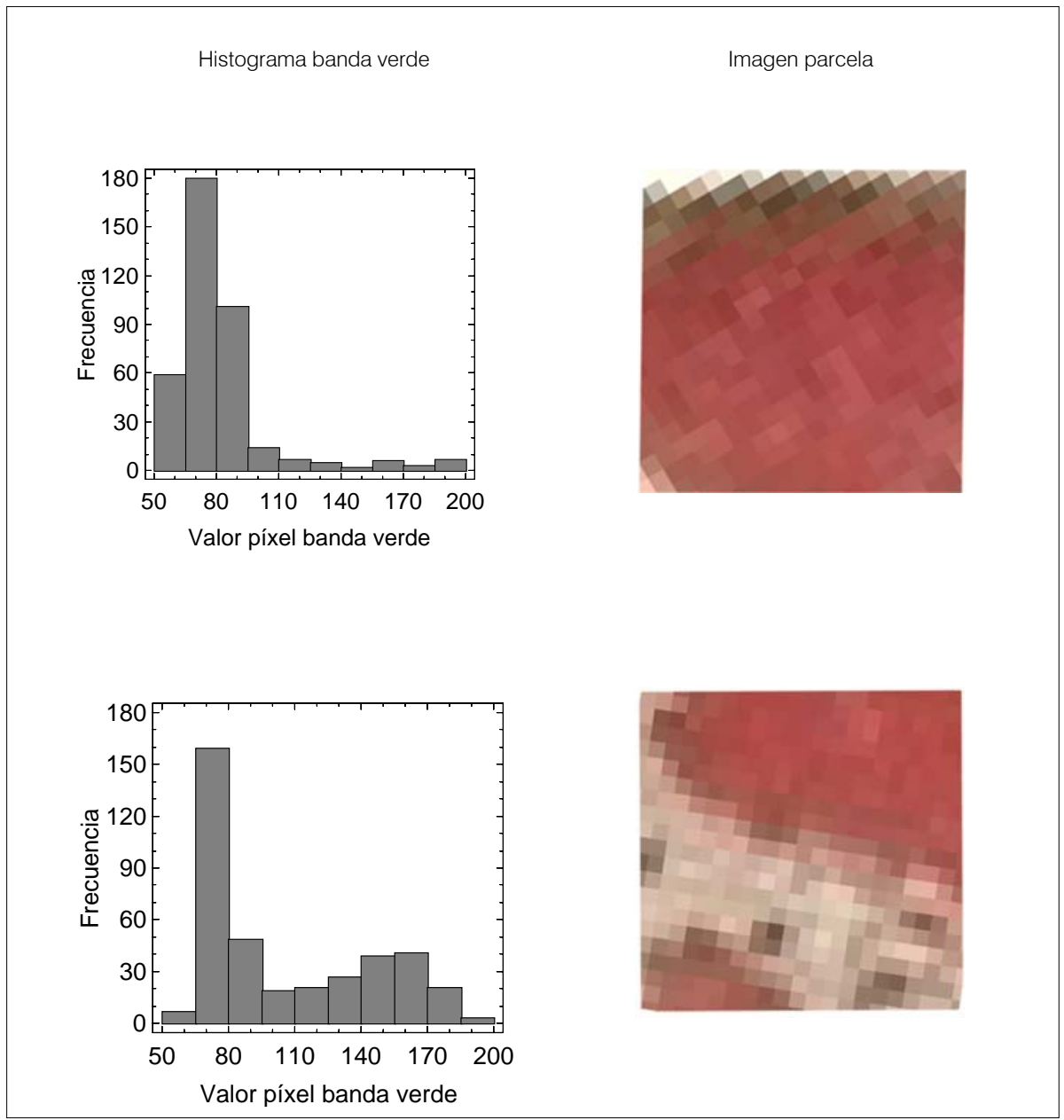

Figura 45. Histogramas de la banda verde e imagen en falso color (RGB: infrarrojo, rojo, verde) de dos parcelas con alta (arriba) y baja (abajo) presencia de vegetación arbustiva. La parcela de arriba con 821,27 $\mathrm{kg}$ de vegetación seca y desviación estándar en la banda verde 26,90; la parcela de abajo con 275,5 kg de vegetación seca y 38,33 en el valor de la desviación estándar de la banda verde.

El mapa de vegetación seca de la zona de estudio se calculó aplicando el modelo de regresión con mayor coeficiente de correlación (combinación de datos LiDAR y la imagen aérea) en celdas de 10×10 m² (Figura 46). Las zonas claras de la imagen indican áreas abiertas sin vegetación. Los valores más altos de biomasa se concentran en las zonas con orientación norte y muestran una buena correlación con los datos de campo. 


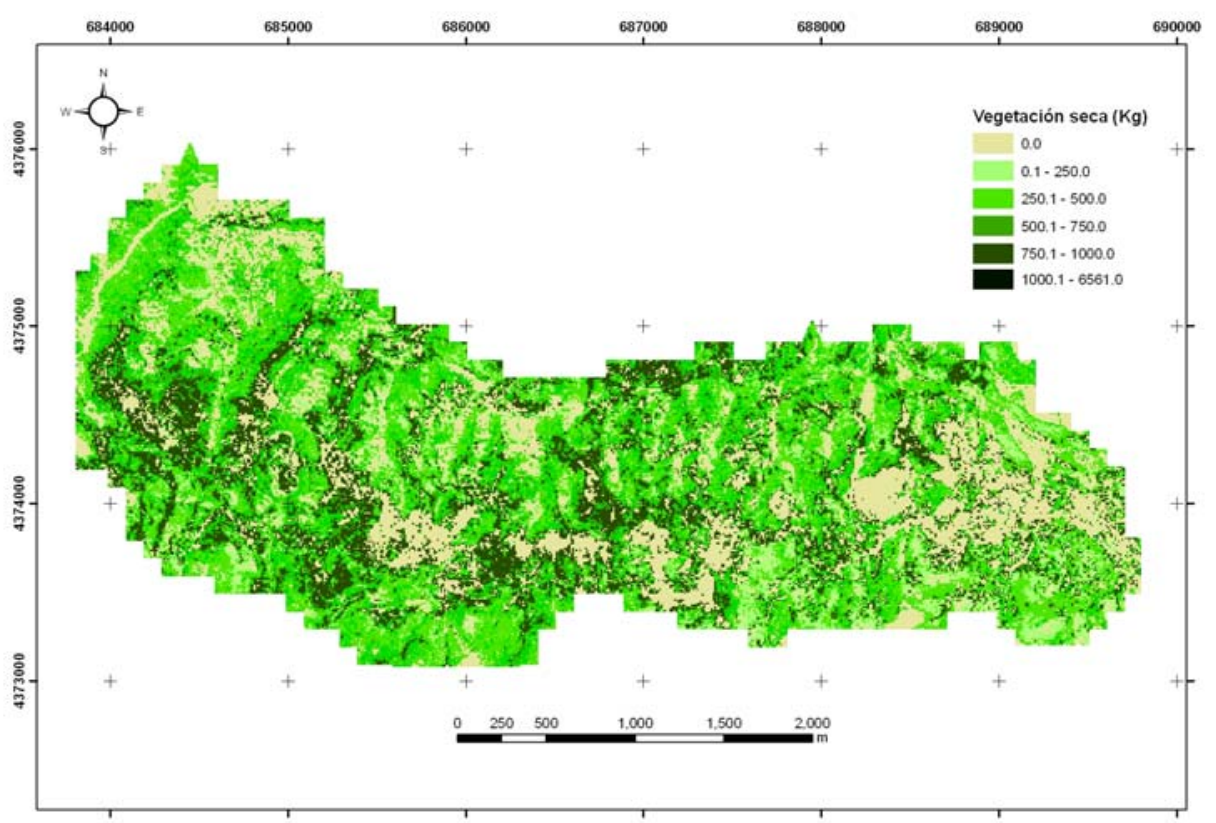

Figura 46. Mapa de vegetación seca de la zona de estudio. Las zonas verdes oscuras representan áreas con más biomasa, las verdes claras áreas con menos biomasa y las marrones claras zonas sin vegetación arbustiva.

\section{Parcelas-Biomasa húmeda}

Previamente al cálculo de los modelos de regresión, se siguió la misma metodología seguida en el caso de la vegetación seca en la preselección de variables. Los modelos de regresión con mayores correlaciones se obtuvieron al utilizar las mismas variables que en el caso anterior. Como se puede apreciar en la Tabla 16, las correlaciones son ligeramente inferiores a las obtenidas para la vegetación seca. Este hecho podría ser explicado teniendo en cuenta que la biomasa húmeda de la coscoja, que es el tipo de vegetación predominante en la zona de estudio, presenta una velocidad de desecación inferior al resto de las especies. La coscoja es una planta más leñosa que las demás y la corteza del tallo evita la salida del vapor de agua durante la desecación. Estos hechos originaron una menor variabilidad en los valores de biomasa, lo que permitió obtener modelos de regresión con mejores correlaciones. Sin embargo, en el caso de la biomasa húmeda la variabilidad fue más alta pues existirán al mismo tiempo plantas con humedades muy dispares, afectando a las correlaciones en los modelos calculados. De igual modo que en el caso de la vegetación seca, los mejores modelos fueron obtenidos al utilizar conjuntamente variables derivadas de los datos LiDAR y de la información espectral con valores de $R^{2}$ y RMSE de 0,77 y $150,2 \mathrm{~kg}$, respectivamente. 
Tabla 16. Modelos de regresión en la estimación de biomasa húmeda.

\begin{tabular}{|c|c|c|c|c|}
\hline Variables & Modelo & $\mathrm{R}^{2}$ & $\mathrm{R}^{2}$ ajustada & RMSE (kg) \\
\hline LiDAR & $\begin{array}{l}B_{w}=-932,9+4411,5 h_{d}+4782 P_{50}-71,4 p_{1}- \\
27,9 p_{0,75-1}-44,7 p_{0,5-0,75}\end{array}$ & 0,64 & 0,56 & 185,9 \\
\hline Imagen aérea & $\mathrm{B}_{\mathrm{w}}=1428,6+1191,7 \mathrm{NDVI}_{\max }-5,3 \mathrm{IR}_{\max }$ & 0,32 & 0,27 & 239,3 \\
\hline $\begin{array}{l}\text { LiDAR e } \\
\text { imagen aérea }\end{array}$ & $\begin{array}{l}B_{w}=-475,1+4625 h_{d}+4486,7 P_{50}-71,9 p_{1}- \\
26,6 p_{0,75-1}-50,8 p_{0,5-0,75}-11,9 G_{d}\end{array}$ & 0,77 & 0,71 & 150,2 \\
\hline
\end{tabular}

$p<0,05$

$\mathrm{B}_{\mathrm{w}}$ es la biomasa húmeda en $\mathrm{kg}$ por parcelas de área $100 \mathrm{~m}^{2} ; \mathrm{P}_{50}$ es el percentil 50 de las alturas de los datos LiDAR por parcelas; $h_{d}$ es la desviación estándar de las alturas; $p_{1}$ es el porcentaje de puntos cuya altura es superior a 1 m, $p_{0.75-1}$ es el porcentaje de puntos con altura entre 0.75 y $1 \mathrm{~m}$; $\mathrm{p}_{0.5-0.75}$ es el porcentaje de puntos con altura entre 0.50 y $0.75 \mathrm{~m}$; $\mathrm{G}_{\mathrm{d}}$ es la desviación estándar de la banda verde; $I_{\max }$ es el valor máximo de la banda infrarrojo; NDVI max es el valor máximo de la imagen NDVI.

\section{Subparcelas - Vegetación seca}

El primer análisis consistió en comparar la vegetación seca medida en campo en subparcelas de 0,5 m de radio y la altura máxima de los puntos LiDAR obtenida en áreas circulares concéntricas a las mismas con radios de 0,5 y 1,5 m. Como se comprobó en el apartado 5.2.1, con el radio 1,5 m se producía la máxima correlación entre las alturas obtenidas de los datos LiDAR y las medidas en campo. Para este análisis sólo se ha considerado una variable explicativa, la altura máxima, ya que al haber muy pocos puntos en las subparcelas de 0,5 m no se pudo obtener otros estadísticos. Como se puede observar en la Tabla 17 el coeficiente de determinación más alto se obtuvo al seleccionar la altura máxima de los datos LiDAR para un radio de $1,5 \mathrm{~m}$ con valor de $\mathrm{R}^{2}$ de 0,41 . Estos datos confirmarían los resultados del análisis basado en la búsqueda del radio óptimo entre los datos LiDAR y las alturas medidas en campo.

Tabla 17. Estimación de la vegetación seca en 83 subparcelas considerando las alturas máximas en áreas de radio $0,5 \mathrm{~m}$ (a) y $1,5 \mathrm{~m}(\mathrm{~b})$.

\begin{tabular}{ccccc}
\hline Variable independiente & Modelo & $\mathrm{R}^{2}$ & P-valor & $\mathrm{RMSE}(\mathrm{kg})$ \\
\hline Altura Máxima $(\mathrm{a})$ & $\mathrm{y}=1,50+3,02 \mathrm{x}$ & 0,31 & $<0,01$ & 1,68 \\
Altura Máxima $(\mathrm{b})$ & $\mathrm{y}=0,39+3,32 \mathrm{x}$ & 0,41 & $<0,01$ & 1,55 \\
\hline
\end{tabular}

Uno de los inconvenientes que se presentan al analizar los datos LiDAR en radios pequeños como los que se han utilizado en los modelos de regresión de la Tabla 17, es que exista una frecuencia muy baja de puntos incluidos en cada una de las áreas. Esta situación limita a una sola variable (altura máxima) el número de variables explicativas a considerar para la estimación de la biomasa generando coeficientes de determinación bajos. Ampliar el radio donde los puntos LiDAR están incluidos a 1,5 m, nos ha permitido analizar otros estadísticos (Tabla 18). Según se puede apreciar, con la utilización de un modelo cuadrático y del percentil 95 se obtiene la máxima correlación, siendo los valores de $R^{2}$ y RMSE, 0,48 y $1,45 \mathrm{~kg}$, respectivamente (Tabla 19). Se han probado combinaciones de más de una variable y no se mejoró sustancialmente el grado de explicación del modelo. 
Tabla 18. Estimación de la vegetación seca en 83 subparcelas considerando modelos lineales.

\begin{tabular}{ccccc}
\hline Variable independientes & Modelo & $\mathrm{R}^{2}$ & P-valor & $\mathrm{RMSE}(\mathrm{kg})$ \\
\hline Altura media & $\mathrm{y}=1,17+5,20 \mathrm{x}$ & 0,37 & $<0,01$ & 1,60 \\
percentil 80 & $\mathrm{y}=0,84+4,14 \mathrm{x}$ & 0,42 & $<0,01$ & 1,54 \\
percentil 90 & $\mathrm{y}=0,57+3,98 \mathrm{x}$ & 0,43 & $<0,01$ & 1,51 \\
percentil 95 & $\mathrm{y}=0,40+3,87 \mathrm{x}$ & 0,44 & $<0,01$ & 1,51 \\
Altura máxima & $\mathrm{y}=0,39+3,22 \mathrm{x}$ & 0,41 & $<0,01$ & 1,55 \\
\hline
\end{tabular}

Tabla 19. Estimación de la vegetación seca en 83 subparcelas considerando modelos cuadráticos.

\begin{tabular}{ccccc}
\hline $\begin{array}{c}\text { Variables } \\
\text { Independientes }\end{array}$ & Modelo & $\mathrm{R}^{2}$ & P-valor & $\mathrm{RMSE}(\mathrm{kg})$ \\
\hline Altura media & $\mathrm{y}=2,70+3,76 \mathrm{x}^{2}$ & 0,39 & $<0,01$ & 1,58 \\
percentil 80 & $\mathrm{y}=2,49+2,237 \mathrm{x}^{2}$ & 0,46 & $<0,01$ & 1,49 \\
percentil 90 & $\mathrm{y}=2,39+1,91 \mathrm{x}^{2}$ & 0,48 & $<0,01$ & 1,46 \\
percentil 95 & $\mathrm{y}=2,34+1,72 \mathrm{x}^{2}$ & 0,48 & $<0,01$ & 1,45 \\
Altura Máxima & $\mathrm{y}=2,31+1,29 \mathrm{x}^{2}$ & 0,45 & $<0,01$ & 1,49 \\
\hline
\end{tabular}

Los valores bajos de los coeficientes de determinación en la estimación de la biomasa por subparcelas se puede explicar teniendo en cuenta que el tamaño de las subparcelas no permitió el cálculo de variables relacionadas con la información espectral y de algunas variables de los datos LiDAR, como son las asociadas a los perfiles de densidad. Estas variables se añadirían en el cálculo de los modelos de predicción lo que podría mejorar la precisión de las estimaciones de biomasa por subparcelas.

Para investigar si se podrían obtener mejores resultados se estudiaron algunos de los siguientes factores: tipo de vegetación, factor densidad de puntos y el error asociado el MDE.

\section{Subparcelas -Biomasa húmeda}

De igual modo que en el caso anterior se puede comprobar en la Tabla 20 que los estadísticos calculados a partir de un área de radio 1,5 m proporcionaron mejores correlaciones que al utilizar un radio de 0,5 m. En este caso se obtuvieron unos valores de $R^{2}$ y RMSE de 0,31 y 2,52 kg mientras que al utilizar el radio $1,5 \mathrm{~m}$ fueron 0,39 y $2,36 \mathrm{~kg}$, respectivamente.

Tabla 20. Estimación de la biomasa húmeda en 83 subparcelas a partir del parámetro elevación máxima de los puntos LIDAR en un área de radio 0,5 m (a) y 1,5 m (b)

\begin{tabular}{ccccc}
\hline Variable independiente & Modelo & $\mathrm{R}^{2}$ & P-valor & $\mathrm{RMSE}(\mathrm{kg})$ \\
\hline Altura Máxima (a) & $\mathrm{y}=2,32+4,52 \mathrm{x}$ & 0,31 & $<0,01$ & 2,52 \\
Altura Máxima (b) & $\mathrm{y}=0,79+4,86 \mathrm{x}$ & 0,39 & $<0,01$ & 2,36 \\
\hline
\end{tabular}


Las tablas siguientes muestran los modelos lineales (Tabla 21) y los modelos cuadráticos (Tabla 22) para la estimación de biomasa considerando como variables independientes los datos LiDAR calculados para un radio de 1,5 m. Los modelos cuadráticos presentan coeficientes de determinación más altos y las variables que mejor explican la variación de la biomasa fueron el percentil 90 y 95. Las correlaciones obtenidas fueron muy parecidas al caso de la vegetación seca. En cuanto a los modelos, del mismo modo que en el caso de la vegetación seca, los cuadráticos generan mejores correlaciones que los lineales.

Tabla 21. Estimación de la biomasa húmeda en 83 subparcelas considerando modelos lineales.

\begin{tabular}{ccccc}
\hline Variable independientes & Modelo & $\mathrm{R}^{2}$ & P-valor & $\mathrm{RMSE}(\mathrm{Kg})$ \\
\hline Altura media & $\mathrm{y}=1,80+7,82 \mathrm{x}$ & 0,38 & $<0,01$ & 2,39 \\
percentil 80 & $\mathrm{y}=1,30+6,23 \mathrm{x}$ & 0,42 & $<0,01$ & 2,31 \\
percentil 90 & $\mathrm{y}=0,95+5,93 \mathrm{x}$ & 0,43 & $<0,01$ & 2,27 \\
percentil 95 & $\mathrm{y}=0,77+5,70 \mathrm{x}$ & 0,43 & $<0,01$ & 2,29 \\
Altura máxima & $\mathrm{y}=0,79+4,85 \mathrm{x}$ & 0,39 & $<0,01$ & 2,36 \\
\hline
\end{tabular}

Tabla 22. Estimación de la biomasa húmeda en 83 subparcelas considerando modelos cuadráticos.

\begin{tabular}{ccccc}
\hline Variables independientes & Modelo & $\mathrm{R}^{2}$ & P-valor & RMSE $(\mathrm{Kg})$ \\
\hline Altura media & $\mathrm{y}=4,14+5,62 \mathrm{x}^{2}$ & 0,38 & $<0,01$ & 2,37 \\
percentil 80 & $\mathrm{y}=3,81+3,38 \mathrm{x}^{2}$ & 0,45 & $<0,01$ & 2,24 \\
percentil 90 & $\mathrm{y}=3,69+2,83 \mathrm{x}^{2}$ & 0,47 & $<0,01$ & 2,21 \\
percentil 95 & $\mathrm{y}=3,64+2,51 \mathrm{x}^{2}$ & 0,46 & $<0,01$ & 2,22 \\
Altura Máxima & $\mathrm{y}=3,61+1,88 \mathrm{x}^{2}$ & 0,43 & $<0,01$ & 2,29 \\
\hline
\end{tabular}

\subsubsection{Factores que influyen en el cálculo de la biomasa por subparcelas}

En este apartado se analizarán los factores tipo de vegetación, densidad de puntos LiDAR y errores asociados al MDE en la predicción de la biomasa por subparcelas.

\section{Tipo de vegetación}

Como se puede apreciar en la Tabla 23, al estimar la biomasa de las subparcelas con presencia de Quercus coccifera, se obtienen correlaciones mayores con valores de $R^{2}$ y RMSE de 0,53 y 1,60 kg, respectivamente. En cambio, para el caso de las subparcelas con presencia de romero, ulex y jara en porcentajes diferentes se obtienen unas correlaciones más bajas, siendo el valor de $R^{2}$ y RMSE 0,33 y $1,27 \mathrm{~kg}$, respectivamente. Sin embargo, los resultados de RMSE son mayores para el caso de la vegetación Quercus coccifera, ya que este tipo de vegetación tiene una biomasa mayor que el resto de las clases. Los resultados obtenidos indican que para obtener estimaciones más precisas se debería considerar algún parámetro que permitiera explicar los diferentes tipos de vegetación. Para ello, y de igual modo que en el caso de las parcelas, se podría incorporar información espectral que permitiera añadir a los modelos la variación correspondiente al tipo de vegetación o suelo. En estos casos, interesaría considerar subparcelas lo suficientemente grandes para que hubiera un número significativo de celdas que permitiera determinar la variabilidad en su interior. Para ello, sería conveniente utilizar imágenes con alta 
resolución espacial, espectral y radiométrica. A partir de los datos de la Tabla 23, se pueden afirmar las mismas conclusiones para el caso de la biomasa húmeda.

Tabla 23. Estimación de la vegetación seca y de la biomasa húmeda en las subparcelas con presencia de Quercus coccifera $(n=47)$ y para el resto de vegetación $(n=36)$.

\begin{tabular}{|c|c|c|c|c|c|}
\hline Tipo & Tipo vegetación & Variable independiente & Modelo & $\mathrm{R}^{2}$ & RMSE (kg) \\
\hline \multirow{2}{*}{$\begin{array}{l}\text { Vegetación } \\
\text { seca }\end{array}$} & Quercus coccifera & percentil $95(n=47)$ & $y=2,17+1,80 x^{2}$ & 0,53 & 1,60 \\
\hline & Otras especies & percentil $95(n=36)$ & $y=2,58+1,55 x^{2}$ & 0,33 & 1,27 \\
\hline \multirow{2}{*}{$\begin{array}{l}\text { Biomasa } \\
\text { húmeda }\end{array}$} & Quercus coccifera & percentil $95(n=47)$ & $y=3,26+2,63 x^{2}$ & 0,53 & 2,34 \\
\hline & Otras especies & percentil $95(n=36)$ & $y=3,99+2,48 x^{2}$ & 0,32 & 2,07 \\
\hline
\end{tabular}

\section{Densidad de datos LiDAR}

Otro de los factores a analizar en la estimación de la biomasa es la densidad de puntos. La Tabla 24 muestra que, al utilizar una densidad mayor a 8 puntos $/ \mathrm{m}^{2}$, para el caso de la estimación de la vegetación seca, se obtienen correlaciones mayores, obteniendo unos valores de $R^{2}$ y RMSE de 0,68 y 1,26 kg, respectivamente. En cambio, las subparcelas con una densidad menor a los 8 puntos $/ \mathrm{m}^{2}$ presentan unas correlaciones más bajas, siendo los valores de $\mathrm{R}^{2}$ y RMSE de 0,26 y 1,55 kg, respectivamente. Esto indicaría que la densidad de puntos es un factor a tener en cuenta y que influye en la estimación de la vegetación seca, sobre todo cuando el tamaño de las subparcelas son pequeñas, como es este caso. Las mismas conclusiones se pueden obtener en el caso de la biomasa húmeda.

Tabla 24. Estimación de la vegetación seca y de la biomasa húmeda en subparcelas con densidad mayor a 8 puntos $/ \mathrm{m}^{2}(\mathrm{n}=47)$ y menor $(\mathrm{n}=36)$

\begin{tabular}{cccccc}
\hline Tipo & $\begin{array}{c}\text { Densidad } \\
\left(\text { puntos } / \mathrm{m}^{2}\right)\end{array}$ & Variable independiente & Modelo & $\mathrm{R}^{2}$ & RMSE $(\mathrm{kg})$ \\
\hline Vegetación & $\mathrm{d}<8$ & 95 percentil $(\mathrm{n}=36)$ & $\mathrm{y}=3,04+1,46 \mathrm{x}^{2}$ & 0,26 & 1,55 \\
seca & $\mathrm{d}>8$ & 95 percentil $(\mathrm{n}=47)$ & $\mathrm{y}=1,66+1,97 \mathrm{x}^{2}$ & 0,68 & 1,26 \\
\hline Biomasa & $\mathrm{d}<8$ & 90 percentil $(\mathrm{n}=36)$ & $\mathrm{y}=4,66+2,19 \mathrm{x}^{2}$ & 0,25 & 2,40 \\
húmeda & $\mathrm{d}>8$ & 90 percentil $(\mathrm{n}=47)$ & $\mathrm{y}=2,61+2,89 \mathrm{x}^{2}$ & 0,66 & 1,90 \\
\hline
\end{tabular}

Errores asociados al MDE

También se ha analizado el factor error asociado al MDE en la estimación de la biomasa. Como se puede apreciar en la Tabla 25, se obtienen correlaciones más altas en las subparcelas que presentan un error asociado al MDE menor. En estos casos se obtuvo un $\mathrm{R}^{2}$ de 0,66 y un RMSE de 1,24 kg, por lo tanto es importante seleccionar parámetros en el cálculo del MDE que minimicen estos errores, especialmente en zonas con presencia de vegetación. En este análisis se ha considerado el valor de 0,20 m como umbral para clasificar las subparcelas, correspondiente al RMSE más bajo obtenido en el cálculo de los MDE. También se utilizaron otros valores de RMSE para clasificar las subparcelas y analizar la influencia del error del MDE en la estimación de la biomasa. Al utilizar el valor de 0,15 m, se obtuvo un valor máximo de $R^{2}(0,73)$, lo que indica que se pueden obtener buenas predicciones de biomasa por subparcelas a partir de datos LiDAR en áreas con errores bajos del MDE. En cambio, para parcelas, este factor podría tener 
menos influencia si se tienen en cuenta los resultados de la estimación de la altura por parcelas analizado en el apartado 5.2.1. Para el caso de la biomasa húmeda se pueden afirmar las mismas conclusiones a partir de los datos de la Tabla 25.

Tabla 25. Estimación de la vegetación seca y de la biomasa húmeda en las subparcelas con error asociado al MDE menor a 0,20 $\mathrm{m}(\mathrm{n}=52)$ y mayor $(n=31)$

\begin{tabular}{cccccc}
\hline Tipo & Variable independiente & Modelo & $\mathrm{R}^{2}$ & P-valor & $\mathrm{RMSE}(\mathrm{kg})$ \\
\hline Vegetación & percentil 95 $(\mathrm{n}=52)$ & $\mathrm{y}=1,84+1,90 \mathrm{x}^{2}$ & 0,66 & $<0,01$ & 1,24 \\
seca & percentil 95 $(\mathrm{n}=31)$ & $\mathrm{y}=3,16+1,36 \mathrm{x}^{2}$ & 0,20 & $<0,01$ & 1,65 \\
\hline Biomasa & percentil 90 $(\mathrm{n}=52)$ & $\mathrm{y}=2,84+2,81 \mathrm{x}^{2}$ & 0,65 & $<0,01$ & 1,87 \\
húmeda & percentil 90 $(\mathrm{n}=31)$ & $\mathrm{y}=4,99+1,90 \mathrm{x}^{2}$ & 0,18 & $<0,01$ & 2,53 \\
\hline
\end{tabular}

También se analizó la combinación de los factores anteriores en la predicción de la biomasa por subparcelas. En la Tabla 26 se pueden observar los modelos de estimación de vegetación seca (a) y biomasa húmeda (b) de las subparcelas con densidad mayor a 8 puntos $/ \mathrm{m}^{2}$ y errores asociados al MDE menores a 0,20 m ( $n=39)$. En este caso se obtiene un coeficiente de determinación máximo en comparación a los modelos anteriores, siendo el valor $\mathrm{R}^{2}=0,73$ y $\mathrm{RMSE}=1,21 \mathrm{~kg}$ para el caso de la vegetación seca, y de $R^{2}=0,73$ y $R M S E=1,80 \mathrm{~kg}$ para el caso de la biomasa húmeda. Considerando la densidad media en la zona de estudio de 8 puntos $/ \mathrm{m}^{2}$ y el RMSE del MDE 0,20 m, los modelos de esta tabla se podrían utilizar para la estimación de la biomasa por subparcelas en la zona de estudio. Como se puede observar en las tablas 26 y 27, los coeficientes determinación también mejoran al combinar las subparcelas con vegetación Quercus coccifera y densidad superior a 8 puntos $/ \mathrm{m}^{2}$ y error asociado al MDE inferior a 0,20 m $(0,71$. $0,73)$.

Tabla 26. Estimación de la vegetación seca y de la biomasa húmeda en subparcelas con densidad mayor a 8 puntos $/ \mathrm{m}^{2}$ y error asociado al MDE menor a $0,20 \mathrm{~m}(\mathrm{n}=39)$.

\begin{tabular}{cccccc}
\hline Tipo & Variable independiente & Modelo & $\mathrm{R}^{2}$ & P-valor & RMSE $(\mathrm{kg})$ \\
\hline Vegetación seca & 95 percentil & $\mathrm{y}=1,53+2,07 \mathrm{x}^{2}$ & 0,73 & $<0,01$ & 1,21 \\
Biomasa húmeda & 95 percentil & $\mathrm{y}=2,38+3,04 \mathrm{x}^{2}$ & 0,73 & $<0,01$ & 1,80 \\
\hline
\end{tabular}

Tabla 27. Estimación de la vegetación seca y de la biomasa húmeda en subparcelas con vegetación Quercus coccifera y densidad mayor a 8 puntos $/ \mathrm{m}^{2}(\mathrm{n}=32)$.

\begin{tabular}{cccccc}
\hline Tipo & Variable independiente & Modelo & $\mathrm{R}^{2}$ & P-valor & RMSE $(\mathrm{kg})$ \\
\hline Vegetación seca & 95 percentil & $\mathrm{y}=1,47+2,02 \mathrm{x}^{2}$ & 0,72 & $<0,01$ & 1,32 \\
Biomasa húmeda & 95 percentil & $\mathrm{y}=2,21+2,97 \mathrm{x}^{2}$ & 0,73 & $<0,01$ & 1,90 \\
\hline
\end{tabular}

Tabla 28. Estimación de la vegetación seca y de la biomasa húmeda en subparcelas con vegetación Quercus coccifera y error asociado al MDE menor a $0,20 \mathrm{~m}(\mathrm{n}=30)$.

\begin{tabular}{cccccc}
\hline Tipo & Variable independiente & Modelo & $\mathrm{R}^{2}$ & P-valor & RMSE (kg) \\
\hline Vegetación seca & 95 percentil & $\mathrm{y}=1,39+2,37 \mathrm{x}^{2}$ & 0,71 & $<0,01$ & 1,36 \\
Biomasa húmeda & 95 percentil & $\mathrm{y}=2,51+1,98 \mathrm{x}^{2}$ & 0,72 & $<0,01$ & 1,95 \\
\hline
\end{tabular}




\subsubsection{Modelos de regresión para la estimación del volumen de biomasa}

En este apartado se abordarán los resultados y discusión de los modelos obtenidos en la estimación del volumen de biomasa en parcelas y subparcelas.

\section{$\underline{\text { Parcelas }}$}

Previamente al cálculo de los modelos de regresión se realizó una preselección de variables explicada en el apartado 5.2.5. El modelo con el valor más bajo en el coeficiente de determinación $\left(R^{2}=0,29\right)$ se obtuvo al utilizar variables derivadas de la imagen aérea (Tabla 29). De igual modo que en caso de la biomasa, estos resultados indican la baja relevancia de la información espectral en la predicción de variables estructurales de la vegetación arbustiva cuando es utilizada de forma independiente. Al utilizar variables extraídas exclusivamente de los datos LiDAR los resultados mejoraron parcialmente, alcanzando un $\mathrm{R}^{2}=0,55$. La combinación de variables derivadas de los datos LiDAR y de la información espectral en la estimación del volumen proporcionó los mejores resultados en términos de $R^{2}$ y RMSE, siendo 0,84 y $0,1 \mathrm{~m}^{3}$, respectivamente.

En la Figura 47 se puede observar la buena correlación entre los datos estimados y observados de volumen. Este modelo incluye siete variables: dos derivadas de la información espectral ( $G_{d}$ y NDVI), dos extraídas de la distribución de alturas de los datos LiDAR $\left(h_{d}\right.$ y $\left.P_{50}\right)$ y tres derivadas de los perfiles de densidad de los datos LiDAR $\left(p_{1}, p_{0,75-1}, p_{0,5-0,75}\right)$. La variable más importante en términos de explicación del modelo fue la desviación estándar de la banda verde $\left(G_{d}\right)$, seguida de la variable porcentaje de puntos con altura entre $0,50-0,75 \mathrm{~m}\left(\mathrm{p}_{0,50-0,75}\right)$ y el percentil $50\left(\mathrm{P}_{50}\right)$. Como se demostró en el apartado 5.2.5, la variable $G_{d}$ permitió explicar las diferencias entre las parcelas con mayor porcentaje de suelo desnudo (menor volumen) y las de mayor ocupación de la vegetación (mayor volumen). En este modelo es importante señalar la relevancia de la información espectral en la predicción del volumen. Al añadir las variables $\mathrm{G}_{\mathrm{d}}$ y NDVI $\mathrm{I}_{\mathrm{m}}$ el coeficiente de determinación pasa de un valor de 0,55 a 0,84.

De igual modo que en el caso de la biomasa, las variables derivadas de la distribución de datos por intervalos de alturas son importantes en la predicción del volumen. En la Figura 44 se pueden observar distribuciones diferentes de alturas en tres parcelas con máximos porcentajes de alturas en tres intervalos: 0,50-0,75 m, 0,75-1 m, y alturas mayores a $1 \mathrm{~m}$. La parcela con el mayor porcentaje de puntos con altura mayor a $1 \mathrm{~m}$ es la que tiene mayor volumen. Sin embargo, la parcela con el máximo porcentaje de puntos en el intervalo 0.50-075 m presenta el menor volumen. Por lo tanto, estas variables muestran una relación con el volumen por parcelas de la vegetación arbustiva. Cuanto mayor sea el porcentaje de datos LiDAR en los intervalos de mayor altura en una parcela indica que la vegetación es más alta y más densa, lo que físicamente equivale a un mayor volumen. 


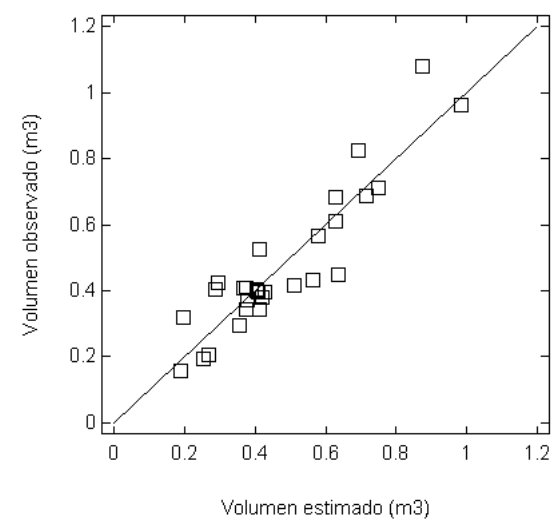

Figura 47. Diagrama de dispersión entre los valores de volumen observado y estimado.

Tabla 29. Modelos de regresión en la estimación del volumen.

\begin{tabular}{|c|c|c|c|c|}
\hline Variables & Modelo & $R^{2}$ & $\mathrm{R}^{2}$ ajustada & $\operatorname{RMSE}\left(\mathrm{m}^{3}\right)$ \\
\hline LiDAR & $\begin{array}{l}V=-0,47+2,53 h_{d}+3,07 P_{50}-0,064 p_{1}- \\
0,02 p_{0,75-1}-0,03 p_{0,5-0,75}\end{array}$ & 0,55 & 0,46 & 0,16 \\
\hline Imagen aérea & $\mathrm{V}=1,77-0,01 \mathrm{IR}_{\max }$ & 0,29 & 0,26 & 0,19 \\
\hline $\begin{array}{l}\text { LiDAR } \\
\text { imagen aérea }\end{array}$ & $\begin{array}{l}V=0,12+3,00 h_{d}+4,08 P_{50}-0,06 p_{1}- \\
0,02 p_{0,75-1}-0,04 p_{0.5-0,75}-0,01 G_{d}-1,58 \\
N D V I_{m}\end{array}$ & 0,84 & 0,79 & 0,1 \\
\hline
\end{tabular}

$\checkmark$ es el volumen en $\mathrm{m}^{3}$ en parcelas con área $100 \mathrm{~m}^{2} ; \mathrm{P}_{50}$ es el percentil 50 de las alturas de los datos LiDAR por parcelas; $h_{d}$ es la esviación estándar de las alturas; $p_{1}$ es el porcentaje de puntos cuya altura es superior a 1 m, $p_{0.75-1}$ es el porcentaje de puntos con altura entre 0.75 y $1 \mathrm{~m} ; \mathrm{p}_{0.5-0.75}$ es el porcentaje de puntos con altura entre 0.50 y $0.75 \mathrm{~m}$; $\mathrm{G}_{\mathrm{d}}$ es la desviación estándar de la banda verde; $\mathrm{IR}_{\max }$ es el valor máximo de la banda infrarrojo; $N D V I_{m}$ es el valor medio de la imagen NDVI.

\section{$\underline{\text { Subparcelas }}$}

La Tabla 30 presenta diferentes modelos para la estimación del volumen por subparcelas. Aunque no hay muchas diferencias entre los modelos, los parámetros con los que se consiguen las máximas correlaciones son los percentiles 90 y 95 de las alturas calculadas a partir de los datos LiDAR incluidos en un radio de 1,5 m. También se han probado modelos cuadráticos y combinación de parámetros, obteniendo resultados similares. Con los tamaños de subparcelas utilizados no se han podido calcular otras variables, 
como los obtenidos en el caso de la estimación del volumen por parcelas (las extraídas de la imagen aérea y las relacionadas con la distribución de los puntos LiDAR por alturas). Se puede observar que la precisión en la predicción del volumen es menor a la estimación de la biomasa en las subparcelas. Este hecho podría ser explicado considerando que los valores de volumen obtenido a partir de los datos de campo fueron medidas indirectas. En cambio, los valores de biomasa fueron medidas directas.

Tabla 30. Estimación del volumen en 83 subparcelas considerando modelos lineales.

\begin{tabular}{ccccc}
\hline Variable independientes & Modelo & $\mathrm{R}^{2}$ & $\mathrm{P}$-valor & $\mathrm{RMSE}\left(\mathrm{cm}^{3}\right)$ \\
\hline altura media & $\mathrm{Y}=1478,33+5253,57 \mathrm{x}$ & 0,31 & $<0,01$ & 1859,04 \\
percentil 80 & $\mathrm{Y}=1152,88+4175,14 \mathrm{x}$ & 0,34 & $<0,01$ & 1813,37 \\
percentile 90 & $\mathrm{Y}=900,25+3988,36 \mathrm{x}$ & 0,36 & $<0,01$ & 1790,40 \\
percentil 95 & $\mathrm{Y}=738,18+3876,77 \mathrm{x}$ & 0,36 & $<0,01$ & 1788,74 \\
Altura máxima & $\mathrm{y}=609,07+3427,28 \mathrm{x}$ & 0,35 & $<0,01$ & 1797,20 \\
\hline
\end{tabular}

\subsubsection{Factores que influyen en el cálculo del volumen por subparcelas}

De igual modo que para el caso de la biomasa, se han analizado los factores tipo de vegetación, densidad de puntos y errores asociados al MDE en las estimaciones de los volúmenes por subparcelas.

\section{Tipo de vegetación}

Como se puede apreciar en la Tabla 31, existen diferencias relevantes entre los modelos calculados según el tipo de vegetación. Para el caso de la vegetación Quercus coccifera, vegetación dominante en la zona de estudio, los valores de $\mathrm{R}^{2}$ y RMSE fueron superiores a los valores obtenidos para el caso del resto de vegetación siendo 0,51 y $1756,10 \mathrm{~cm}^{3}$, respectivamente.

Tabla 31. Estimación del volumen por subparcelas con presencia de Quercus coccifera $(n=47)$ y para el resto de vegetación $(n=36)$.

\begin{tabular}{cccccc}
\hline Tipo vegetación & Variable independiente & Modelo & $\mathrm{R}^{2}$ & P-valor & $\left.\mathrm{RMSE}_{(\mathrm{cm}}{ }^{3}\right)$ \\
\hline Quercus coccifera & percentil 95 $(\mathrm{n}=47)$ & $\mathrm{y}=-453,85+4674,01 \times$ & 0,51 & $<0,01$ & 1756,10 \\
Otras especies & percentil 95 $(\mathrm{n}=36)$ & $\mathrm{y}=1994,68+2984,38 \times$ & 0,20 & $<0,01$ & 1716,67 \\
\hline
\end{tabular}

Densidad de datos LiDAR

Según la Tabla 32, la densidad de datos también influye en la estimación del volumen de la vegetación arbustiva por subparcelas, obteniendo un valor máximo de $\mathrm{R}^{2} \quad(0,54)$, al utilizar una densidad superior a 8 puntos $/ \mathrm{m}^{2}$

Tabla 32. Estimación del volumen por subparcelas con densidad superior $(n=47)$ e inferior $(n=36)$ a 8 puntos $/ \mathrm{m}^{2}$

\begin{tabular}{cccccc}
\hline $\begin{array}{c}\text { Densidad } \\
\left(\text { puntos } / \mathrm{m}^{2}\right)\end{array}$ & Variable independiente & Modelo & $\mathrm{R}^{2}$ & P-valor & $\begin{array}{c}\text { RMSE } \\
\left(\mathrm{cm}^{3}\right)\end{array}$ \\
\hline $\mathrm{d}<8$ & Altura máxima $(\mathrm{n}=36)$ & $\mathrm{y}=1458,37+3076,36 \times$ & 0,24 & $<0,01$ & 1801,00 \\
$\mathrm{~d}>8$ & Altura máxima $(\mathrm{n}=47)$ & $\mathrm{y}=-810,83+4255,36 \times$ & 0,50 & $<0,01$ & 1700,28 \\
\hline
\end{tabular}




\section{Errores asociados al MDE}

En cuanto al factor error asociado al MDE se ha detectado que las subparcelas en las que este error es menor, los modelos de predicción presentan valores superiores en los coeficientes de determianción $(0,54)$ y valores menores de RMSE $\left(1611,74 \mathrm{~cm}^{3}\right)$ (Tabla 33). Será por tanto importante elegir unos parámetros adecuados para el cálculo del MDE analizándose, como se ha hecho en este trabajo, cómo afecta la presencia de vegetación a la precisión del MDE.

Tabla 33. Estimación del volumen en las subparcelas considerando el factor error asociado al MDE menor a 0,20 m $(n=52)$ y mayor $(n=31)$.

\begin{tabular}{ccccc}
\hline Variable independiente & Modelo & $\mathrm{R}^{2}$ & P-valor & ${\text { RMSE }\left(\mathrm{cm}^{3}\right)}^{\text {Altura máxima }(n=52)}$ \\
Altura máxima $(\mathrm{n}=31)$ & $\mathrm{Y}=-715,92+4255,98 \times$ & 0,54 & $<0,01$ & 1611,74 \\
& $\mathrm{Y}=2451,51+2176,41 \times$ & 0,13 & $<0,01$ & 1911,67 \\
\hline
\end{tabular}

De igual modo que para el caso de la biomasa, también se analizó si la combinación de los factores anteriores mejoraba la predicción del volumen ocupado por la vegetación arbustiva en subparcelas. En la Tabla 34 se puede observar que el mejor modelo se obtiene al combinar las subparcelas con vegetación Quercus coccifera y error inferior a 0,20 en el MDE. Estos resultados indican la relevancia del tipo de vegetación en las prediccciones del volumen de la vegetación arbustiva. Aunque la vegetación dominante de la zona de estudio está formada por Quercus coccifera , pudiéndose aplicar los modelos de esta tabla, mejores predicciones podrían obenterse en el caso de incluir varibles derivadas de información espectral lo que permitiría distinguir diferentes especies de vegetación.

Tabla 34. Estimación del volumen en subparcelas combinando los factores vegetación Quercus coccifera, densidad mayor a 8 puntos $/ \mathrm{m}^{2}$ y error asociado al MDE menor a $0,20 \mathrm{~m}$.

\begin{tabular}{|c|c|c|c|c|c|}
\hline Factores & $\begin{array}{c}\text { Variable } \\
\text { independiente }\end{array}$ & Modelo & $R^{2}$ & P-valor & $\begin{array}{c}\text { RMSE } \\
\left(\mathrm{cm}^{3}\right)\end{array}$ \\
\hline $\begin{array}{l}\text { Densidad mayor a } 8 \text { puntos } / \mathrm{m}^{2} \text { y error asocia- } \\
\text { do al MDE inferior a } 0,20 \mathrm{~m}(n=39)\end{array}$ & Altura máxima & $y=-1562,82+4818,95 x$ & 0,58 & & 1650,89 \\
\hline $\begin{array}{l}\text { Densidad mayor a } 8 \text { puntos } / \mathrm{m} 2 \text { y vegetación } \\
\text { Quercus coccifera }(n=32)\end{array}$ & Altura máxima & $y=-1439,44+4463,72 x$ & 0,60 & & 1601,13 \\
\hline $\begin{array}{l}\text { Errror asociado al MDE inferior a 0,20 m y ve- } \\
\text { getación Quercus coccifera }(n=30)\end{array}$ & Altura máxima & $y=-1550,91+4662,53 x$ & 0,65 & $<0,01$ & 1573,98 \\
\hline
\end{tabular}

\subsubsection{Validación del método de cálculo de volumen de biomasa a partir de volúmenes modelos obtenidos de los datos LiDAR.}

El objetivo de este apartado fue analizar la existencia de diferencias significativas entre los volúmenes reales obtenidos en los trabajos de campo a partir de la aplicación de mediciones dendrométricas (aplicando ecuación 1) y los calculados aplicando el FO (ecuación 3) a los volúmenes modelos obtenidos de la superficie cubierta y la altura de la vegetación estimada a partir de los datos LiDAR. Como volumen modelo se utilizó el cilindro cuya altura se obtuvo de los datos LiDAR. Para ello, se aplicó un contraste para las diferencias de medias pareadas con un nivel de significación $\alpha=0,05$. 
En la Tabla 35 se puede observar los resultados de la prueba t de Student cuya hipótesis nula fue que la media de la diferencia entre los valores de las dos muestras de volúmenes fuera igual a 0 frente a la hipótesis alternativa en la que fuera distinto a 0 . Dado que la significación obtenida $(p=0,064)$ es mayor al nivel de significación $(\alpha=0,05)$, el contraste no es significativo y por lo tanto no se rechaza la hipótesis nula.

De estos análisis se deduce que no hay diferencias entre los volúmenes obtenidos a partir de los trabajos dendrométricos y los obtenidos aplicando el FO y los datos LiDAR para el cálculo del volumen real.

Tabla 35. Prueba de muestras relacionadas entre los volúmenes medidos en campo y los calculados a partir del FO y de los datos LiDAR.

volumen $_{\text {campo }}$ - volumen calculado $_{\text {of }}$

Media

$-1,875$

gl

p-valor 

6. CONCLUSIONES 



\subsection{Cálculo del MDE}

Para el cálculo de un MDE, a partir de procesos iterativos basados en la selección de elevaciones mínimas en ventanas decrecientes, es necesario tener en cuenta las condiciones de la zona de estudio y de los datos disponibles. En el caso de zonas arbustivas con pendientes elevadas y presencia de vegetación arbustiva, se demostró que el RMSE disminuye al utilizar valores a partir de $1.5 \mathrm{~m}$ en los dos umbrales, existiendo un umbral con el que se consigue un error mínimo y constante. Aún así, es recomendable no utilizar umbrales mayores para evitar seleccionar puntos pertenecientes a la vegetación en el cálculo de un MDE. Esto podría ocurrir cuando la pendiente no es tan elevada o cuando existan árboles. El umbral óptimo depende del tamaño de ventana utilizado y de la pendiente media del terreno.

En cuanto al tamaño de ventana, se logran mejores resultados con la utilización de ventanas intermedias (10, 5, 2,5 m; 12, 6, 3 m). En cuanto a la información de partida, los MDEs calculados a partir de imágenes de entrada dan mejores resultados frente a los calculados a partir de los puntos originales, que tienden a sobreestimar el MDE. Estos resultados se confirmaron al estudiar el efecto de la pendiente, densidad de puntos y presencia de vegetación en la precisión del MDE. Por otra parte, la pendiente del terreno tiende a incrementar el RMSE. Por lo que se refiere al factor densidad de puntos, el RMSE disminuye al aumentar la densidad de puntos hasta un valor en el que el RMSE se hace mínimo y constante. Al analizar la presencia de la vegetación, se comprobó que el RMSE aumenta ligeramente en zonas arbustivas. Además se puede comprobar que la utilización de las ventanas más pequeñas (8, 4, 2 m; 5, 2,5, 1 m) genera importantes errores en el cálculo del MDE. El valor de RMSE mínimo se produce para ventanas intermedias, datos de entrada la imagen y umbrales medios. Estos resultados indicarían que la selección de estos parámetros son adecuados para el cálculo de MDE en zonas con vegetación arbustiva densa. Según los resultados obtenidos, es desaconsejable utilizar ventanas muy pequeñas $(8,4,2 \mathrm{~m} ; 5,2,5,1 \mathrm{~m})$ o muy grandes $(20,15,10 \mathrm{~m} ; 15,10,5 \mathrm{~m})$ en zonas con vegetación arbustiva.

Sin embargo, para zonas arboladas y con pendientes bajas, se demostró que la utilización de ventanas pequeñas y umbrales altos genera mayores RMSE. Esta zona de estudio está caracterizada por presencia densa de árboles que unido a la baja densidad de puntos, produce que se seleccionen puntos que pertenecen a las partes altas de los árboles. Por este motivo, es conveniente la utilización de ventanas más grandes, aumentando la probabilidad de seleccionar puntos que realmente pertenezcan al suelo. Igualmente se demostró que cuando se utilizan umbrales grandes aumenta el RMSE. En este caso se debe utilizar un umbral que permita preservar el microrelieve de la zona, siendo importante disponer de una mayor densidad de puntos.

Para estudiar la vegetación arbustiva es necesario, entre otros factores, obtener un MDE preciso. En este sentido, la precisión obtenida en este trabajo con áreas de elevada pendiente, orografía irregular y con presencia de vegetación arbustiva podría permitir la estimación de la biomasa, volumen y altura de la ve- 
getación arbustiva. Para ello, se deben considerar los parámetros óptimos obtenidos en este trabajo: ventanas intermedias (10, 5 y $2,5 \mathrm{~m}$ ), umbrales medios ( $1,5 \mathrm{~m}$ ) y una imagen, como datos de entrada. Como se ha demostrado en el caso de zonas arboladas y llanas, los parámetros a utilizar son diferentes. En zonas con pendientes menores y poco rugosas sería recomendable utilizar umbrales más pequeños a los utilizados en este trabajo, para evitar la inclusión de puntos de vegetación. En cuanto al tamaño de las ventanas interesará fijarse en las dimensiones de los elementos por encima de la superficie del terreno para evitar la selección de puntos que no pertenezcan al suelo. En estos casos, la utilización de una densidad alta de puntos incrementaría la probabilidad de que algún pulso alcanzara el suelo. En este trabajo se demostró que los errores decrecen al aumentar la densidad de puntos hasta un valor en el cual el RMSE se mantiene mínimo y constante.

\subsection{Estimación de los parámetros forestales altura, biomasa y volumen}

\section{Altura}

En este trabajo, se estudió la altura de la vegetación arbustiva por parcelas y por subparcelas. Las correlaciones más altas se obtuvieron en el caso de las parcelas, siendo el percentil 95 la variable que mejor explicó la variabilidad de la altura de la vegetación. Esto ha quedado demostrado en los coeficientes de determinación de los modelos calculados. Para las subparcelas, se comprobó que el RMSE es mínimo al seleccionar las alturas LiDAR incluidas en un área de influencia de radio entre 1,5 m y 2,25 m alrededor del punto medido en campo. Estos radios pueden ser menores si el error correspondiente al MDE es bajo al igual que las pendientes. Para un radio de 1,5 m y una densidad superior a los 8 puntos $/ \mathrm{m}^{2}$ se observó que los valores de RMSE entre las alturas de la vegetación medidas en campo y las obtenidas de los datos LiDAR son los más bajos $(0,20 \mathrm{~m})$. Este resultado indicaría la importancia de utilizar una densidad de datos LiDAR adecuada para obtener buenas predicciones de la altura de vegetación por subparcelas. En cuanto a la relación entre las alturas medidas en campo y la imagen del MDV, se demostró que al utilizar un tamaño de celda de 2,5 m se obtiene el mínimo RMSE. Este valor se aproxima al radio con el que se consiguió la máxima correlación cuando se utiliza la información sin rasterizar (nube de puntos original). Finalmente, para la detección de la capa de vegetación arbustiva, los mejores resultados obtenidos se lograron al combinar la imagen espectral aérea y los datos LIDAR.

Los resultados obtenidos en la estimación de la altura de la vegetación por parcelas indican que, en el caso de analizar crecimiento de vegetación, se podría llevar a cabo si éste fuera superior a 0,13 m. En el caso de las subparcelas sería necesario definir el tamaño de las mismas. En este trabajo se demostró que cuando se utilizan áreas concéntricas de radio $1,5 \mathrm{~m}$, las diferencias entre los datos LiDAR y los datos de campo son más pequeñas (RMSE $=0,26 \mathrm{~m}$ ). Detectar crecimientos por debajo de este valor sería difícil. Sin embargo, se ha detectado que los datos LiDAR generan una subestimación de la vegetación arbustiva, lo que podría afectar de la misma manera al utilizar otros datos. También se pudo comprobar que, al utilizar una mayor densidad de puntos, el RMSE es de 0,20 m. Por lo tanto, es un importante aspecto que 
debería ser considerado en un estudio de crecimiento de vegetación arbustiva.

Los resultados obtenidos en este estudio relacionados con la precisión en la estimación de la altura de la vegetación y su cobertura podrán ser utilizados para calcular el volumen aparente ocupado por la vegetación arbustiva de la zona de estudio. Para ello, se utilizarán las alturas del MDV y la presencia de vegetación arbustiva obtenida a partir de la combinación del MDV y de la imagen aérea. A partir de los factores de ocupación definidos de los trabajos dendrométricos y dasométricos, el volumen real y biomasa pueden ser calculados.

\section{Biomasa}

Este estudio demostró el potencial de los datos LiDAR y los datos espectrales en la estimación de la vegetación arbustiva seca y de la biomasa húmeda por parcelas. Se ha demostrado que las mejores correlaciones se han obtenido por parcelas cuando se han combinado parámetros obtenidos de la imagen aérea y los datos LIDAR, siendo más altas para el caso de la vegetación seca. Los valores de $R^{2}$ más bajos se obtienen al utilizar datos espectrales. Es de destacar la importancia de las variables derivadas de los porcentajes de puntos por intervalos de alturas en la predicción de la biomasa. Los resultados de este estudio muestran la posibilidad de realizar estimaciones y cartografiado de biomasa en zonas forestales mediterráneas ocupadas por vegetación arbustiva utilizando una densidad media de datos LiDAR, bandas del visible de imágenes aéreas y aplicando una apropiada selección de variables. Los modelos obtenidos podrían ser utilizados en áreas similares: zonas con alta presencia de vegetación arbustiva con poca variación de especies y baja altura. A partir de estos resultados se pueden realizar mapas de biomasa que permitan mejorar el conocimiento de los bosques mediterráneos y puedan ser aplicados en la creación de mapas de combustibles forestales para definir modelos de comportamiento espacial de incendios, gestión forestal y dinámica del carbono.

En cuanto al cálculo de la vegetación seca y de la biomasa húmeda por subparcelas, las mejores correlaciones se obtuvieron al utilizar modelos cuadráticos y los percentiles 90 y 95 . De igual modo que en el caso de la estimación de las alturas, se demostró que los modelos de predicción mejoraron al seleccionar los datos LiDAR en áreas concéntricas de radio 1,5 m y centro el de las subparcelas. Se comprobó que los resultados pueden mejorar al separar las subparcelas por tipo de vegetación, al aumentar la densidad de puntos y para MDE calculados con precisión. Para el caso de la zona de estudio, con una densiadad media superior a los 8 puntos $/ \mathrm{m}^{2}$ y RMSE del MDE de 0,20 m, se obtuvieron unos valores altos en términos de $\mathrm{R}^{2}$. Estos resultados indicarían la posibilidad de estimar la biomasa de la vegetación arbustiva en zonas de reducida área cuando la densidad de datos es adecuada (8 puntos $/ \mathrm{m}^{2}$ ) y cuando la precisión del MDE es elevada.

No obstante, en los casos en los que no se cumplan estas condiciones, se recomienda utilizar un tamaño de subparcela de radio superior a 1,5 m que permita el cálculo de variables extraídas de la información 
espectral, estadísticos de la distribución de los datos LiDAR así como de los derivados de los porcentajes de puntos por intervalos de alturas, obtenidos a partir de los datos LiDAR.

\section{Volumen}

De igual modo que para el caso de la biomasa por parcelas, se obtuvieron las mejores correlaciones al combinar datos LIDAR y la imagen aérea. Los parámetros relacionados con los porcentajes de puntos por intervalos de alturas, obtenidos a partir de los datos LiDAR, explicaron un porcentaje alto de la variabilidad del modelo. Las correlaciones más bajas se obtienen cuando se utilizan solamente estadísticos calculados a partir de la imagen aérea. Sin embargo, hay que destacar la relevancia de añadir esta información a las variables derivadas de los datos LiDAR en la estimación del volumen de biomasa arbustiva. Estos resultados indican cómo al utilizar datos LiDAR y bandas del visible y del infrarrojo cercano de una imagen aérea se pueden realizar estimaciones y mapas del volumen de la vegetación arbustiva en zonas forestales mediterráneas.

La precisión en la estimación de volúmenes por subparcelas es inferior a la obtenida en el caso de la biomasa. Estos resultados se pueden explicar teniendo en cuenta la variabilidad de la vegetación y el tamaño de las subparcelas utilizados en estos ensayos. Con estos tamaños no es posible incorporar información espectral extraída de la imagen aérea y de los datos LiDAR, como los calculados para el caso de las parcelas. Además, mientras el volumen observado es una medida indirecta realizada a partir del diámetro de la base y de la altura de la vegetación dentro de una subparcela, la biomasa es una medida directa.

Por otro lado, se demostró que la estimación del volumen para el caso de la vegetación Quercus coccifera fue más precisa que al considerar todas las especies. También se demostró que el error asociado al MDE y la densidad de datos LiDAR influyen en la estimación de los volúmenes. En estos casos, se recomienda utilizar parámetros adecuados que minimicen el error del MDE cuando hay presencia de vegetación, como los seleccionados en este estudio. De esta manera se evita subestimar la altura de la vegetación. Dados los modestos resultados de estas estimaciones y considerando los resultados de los análisis en los que se comparan las diferencias entre los volúmenes obtenidos a partir de los trabajos dendrométricos y los obtenidos aplicando el factor de ocupación y los datos LiDAR, se podría utilizar esta metodología para el cálculo del volumen real. Para ello sería necesario disponer de un mapa de la vegetación arbustiva, aplicar la altura máxima en el interior de cada celda y los FO ya estudiados.

Este trabajo de investigación es un primer paso para conocer y estudiar las masas arbustivas mediante datos LiDAR e información espectral en los ecosistemas forestales mediterráneos. Los resultados relacionados con los mapas de vegetación arbustiva y su altura pueden ser herramientas importantes para la simulación de modelos de propagación de incendios así como para mejorar el conocimiento de los hábi- 
tats de la Comunidad Valenciana. En cuanto a la biomasa, se han desarrollado herramientas que permitirán conocer el potencial de biomasa existente en los sistemas mediterráneos y orientar mejor las políticas de promoción del uso y conservación de la superficie forestal arbustiva. La metodología seguida en este trabajo de investigación también puede significar un nuevo método para cuantificar recursos alimenticios en los estudios de carga ganadera. 

7. LIINEAS FUTURAS DE INVESTIGACIÓN 

Existen investigaciones con resultados significativos en las que se han utilizado los valores de intensidad de los datos LiDAR en la separación de clases de vegetación arbórea (Lim et al., 2003; Kim et al., 2009). Esta información se podría utilizar en el caso de le vegetación arbustiva para separar las clases de vegetación arbustiva y la separación suelo-vegetación. Estos resultados podrían mejorar las correlaciones encontradas en este trabajo. La utilización de los valores de intensidad conlleva la puesta a punto de algoritmos que permitieran definir respuestas espectrales de este tipo de vegetación y homogeneizar los valores de reflectividad de los puntos LiDAR tomados en una zona de estudio. Estas operaciones son necesarias ya que en la adquisición de los datos LiDAR hay diferentes líneas de vuelo generando variaciones de la respuesta espectral en una misma cubierta según las condiciones en la toma de los datos (ángulo de incidencia, ángulo solar, altura de vuelo).

Una de las aplicaciones básicas de teledetección es estudiar los cambios que se producen en la cubierta terrestre. La comparación de modelos digitales de vegetación, derivados de los datos LiDAR de dos fechas diferentes, podría permitir analizar cambios que se producen en la estructura de la vegetación. De esta manera se podrían detectar crecimientos y evoluciones de la biomasa. Para el caso de análisis de estos cambios en subparcelas, se podrían aplicar los resultados obtenidos en esta investigación como los relacionados con la selección de radios adecuados para comparar los datos medidos en campo y los obtenidos de los datos LiDAR.

La metodología seguida en este trabajo se podría aplicar a otros tipos de vegetación como es el caso de los árboles frutales para estudiar su biomasa. Estos estudios se podrían realizar considerando la unidad de estudio el árbol o la parcela, siendo necesario una previa caracterización dendrométrica de algunos árboles. En el primer caso, se calucularían variables derivadas de los datos LiDAR en parcelas, como las calculadas en este trabajo, que se relacionarían con parámetros dasométricos obtenidos a partir de mediciones realizadas en campo. En el segundo caso, se aplicarían algoritmos basados en la segmentación de imágenes espectrales o modelos digitales de vegetación. A partir de estos algoritmos, se podrían obtener características de árboles individuales, como por ejemplo diámetros de copas. En estudios precedentes se ha demostrado que existe una elevada correlación de este parámetro y la altura de los árboles, derivados de los datos LiDAR, con la biomasa (Popescu, 2007).

Por otro lado, el uso de sistemas láser escáner (LiDAR terrestre) permiten registrar una alta densidad de puntos desde diferentes estaciones, que son utilizados para la reconstrucción de objetos en 3D, como son los casos de levantamientos arquitectónicos, minería y diseño industrial. También es un sistema que es utilizado en el ámbito forestal y en agricultura. Para su aplicación en estos campos, nuevas investigaciones serían necesarias para desarrollar algoritmos que permitan extraer parámetros de la vegetación con hojas y sin hojas a partir de la nube de puntos registrada por el sensor. De esta manera se podría obtener información sobre la biomasa leñosa y foliar, estructura de la ramificación y sobre la interferencia de la biomasa foliar en la medición. 

8. Referencias bibliográficas 

Ackermann, F. (1999). Airborne laser scanning - present status and future expectations. ISPRS Journal of Photogrammetry and Remote Sensing, Vol. 54 (2-3), pp. 64-67.

Ahokas, E., Kaartinen, H. y Hyyppa, J (2003). A quality assessment of airborne laser scanner data. ISPRSInternational Archives of Photogrammetry, Remote Sensing and Spatial Information Sciences, Vol. XXXIV, Part 3/W13.

Andersen, H-E., McGaughey, R. J. y Reutebuch, S. E. (2005). Estimating forest canopy fuel parameters using LiDAR data. Remote Sensing of Environment, Vol. 94 (4), pp. 441-449.

Andersen, H.-E. y Breidenbachb, J. (2007). Statistical properties of mean stand biomass estimators in a LiDAR-based double sampling forest survey design. ISPRS- International Archives of Photogrammetry, Remote Sensing and Spatial Information Sciences, Vol. XXXVI, Part 3/W52, pp. 8-13.

Axelsson, P. (2000). DEM generation from laser scanner data using adaptive TIN models. ISPRSInternational Archives of Photogrammetry, Remote Sensing and Spatial Information Sciences, Vol. XXXIII, Part B4, pp. 110-117.

Baltsavias, E. P. (1999). A comparison between photogrammetry and laser scanning: existing systems and firms and other resources. ISPRS Journal of Photogrammetry and Remote Sensing, Vol. 54 (2-3), pp.8394.

Bork, E. W. y Su, J. G. (2007). Integrating LiDAR data and multispectral imagery for enhanced classification of rangeland vegetation: A meta analysis. Remote Sensing of Environment, Vol. 111 (1), pp. 11-24.

Bortolot, Z. J. y Wynne, R. H. (2005). Estimating forest biomass using small footprint LiDAR data: An individual tree-based approach that incorporates training data. ISPRS Journal of Photogrammetry and Remote Sensing, Vol. 59 (6), pp.342-360

Bosque, J. (1997). Sistemas de Información Geográfica (2ª ed.). Madrid: Ediciones Rialp.

Brandtberg, T., Warner, T. A., Landenberger, R. E. y McGraw, J. B. (2003). Detection and analysis of individual leaf-off tree crowns in small footprint, high sampling density LiDAR data from the eastern deciduous forest in North America. Remote Sensing of Environment, Vol. 85 (3), pp. 290-303.

Brovelli, M.A., Cannata, M. y Longoni, U.M. (2002). Managing and processing LiDAR data within GRASS En M. Ciolli y P. Zatelli (Eds.), Open Source Free Software GIS-GRASS users Conference 2002, 11-13 Septiembre, Trento, Italia.

Burrough, P.A. y McDonnell, R.A. (1998). Principals of Geographical Information Systems. Oxford University Press.

Carlson, T. N. y Riziley D. A. 1997. On the Relation between NDVI, Fractional Vegetation Cover, and Leaf Area Index. Remote Sensing of Environment, Vol. 62 (3), pp. 241-252.

Casas, A., Benito, G., Thorndycraft, V. R. y Rico, M. (2006). The topographic data source of digital terrain models as a key element in the accuracy of hydraulic flood modelling. Earth Surface Processes and Landforms, Vol. 31(4), pp. 444-456

Charlton, M. E., Large, A. R. G. y Fuller, I. C. (2003). Application of airborne LiDAR in river environments: the river Coquet, Northumberland, UK. Earth Surface Processes and Landforms, Vol. 28 (3), pp. 299-306.

Chuvieco, E. (2010). Teledetección Ambiental. La observación de la Tierra desde el espacio. Barcelona Editorial Ariel S.A

Clark, M. L., Clark, D. B. y Roberts, D. A. (2004). Small-footprint LiDAR estimation of sub-canopy elevation and tree height in a tropical rain forest landscape. Remote sensing of environment, Vol. 91 (1), pp. 68-89. 
Cobby, D. M., Mason, D. C. y Davenport, I. J. (2001). Image processing of airborne scanning laser altimetry data for improved river flood modelling. ISPRS Journal of Photogrammetry and Remote Sensing, Vol. 56 (2), pp. 121-138.

Donoghue, D. N. M., Watt, P. J., Cox, N. J. y Wilson, J. (2007). Remote sensing of species mixtures in conifer plantations using LiDAR height and intensity data. Remote Sensing of Environment, Vol. 110 (4), pp. 509-522.

Doyle, F. J. (1978). Digital Terrain Models: an Overview. Photogrammetric Engineering and Remote Sensing, Vol. 44 (12), pp. 1481-1485.

Elmqvist, M., Jungert, E., Lantz, F., Persson, A. y Soderman, U. (2002). Terrain modelling and analysis using laser scanner data. ISPRS- International Archives of Photogrammetry, Remote Sensing and Spatial Information Sciences, Vol. XXXIV, Part 3/W4, pp. 219-226

Erdody, T. L. y Moskal, L. M. (2010). Fusion of LiDAR and imagery for estimating forest canopy fuels. Remote Sensing of Environment, Vol. 114 (4), pp.725-737.

Estornell, J. y Ruiz L. A. (2007). Generación de MDE y MDS en una zona de vegetación arbórea y arbustiva mediante datos LiDAR e imágenes de satélite QuickBird. VII Semana Geomática, 20-22 Febrero, Barcelona. España.

Estornell, J., Ruiz, L. A. y Velazquez-Marti, B. (2011). Study of shrub cover and height using LiDAR data in a Mediterranean area. Forest Science, Vol. 57 (4), pp. 171-179.

Estornell, J., Ruiz, L. A., Velázquez-Martí, B. y Hermosilla, T. (2010). Analysis of the factors affecting LiDAR DTM accuracy in a steep shrub area. International Journal of Digital Earth, doi:10.1080/17538947.2010.533201

Evans, J. S. y Hudak, A. T. (2007). A mustiscale curvature algorithm for classifying discrete return LiDAR in forested environments. IEEE Transactions on Geoscience and Remote Sensing, Vol. 45 (4), pp. 1029-1038.

Falkowski, M. J., Smith, A. M. S., Hudak, A. T., Gessler, P. E., Vierling, L. A. y Crookston, N. L. (2006). Automated estimation of individual conifer tree height and crown diameter via two-dimensional spatial wavelet analysis of LiDAR data. Canadian Journal of Remote Sensing, Vol. 32 (2), pp. 153-161.

Felicísimo, A. M. (1994). Modelos digitales del terreno: principios y aplicaciones en las ciencias ambientales. Oviedo: Ediciones Pentalfa.

García, M., Riaño, D., Chuvieco, E. y Danson, F. M. (2010). Estimating biomass carbon stocks for a Mediterranean forest in central Spain using LiDAR height and intensity data. Remote Sensing of Environment, Vol. 114 (4), pp.816-830.

Gaveau, D. L. A. y Hill, R. A. (2003). Quantifying canopy height underestimation by laser pulse penetration in small-footprint airborne laser scanning data. Canadian Journal of Remote Sensing, Vol. 29 (5), pp. 650657.

Gómez, F. et al. (1998). Los bosques ibéricos (1 ${ }^{\text {a }}$ ed.). Barcelona. Editorial Planeta S.A.

Haala, N. y Brenner, C. (1999). Extraction of buildings and trees in urban environments. ISPRS Journal of Photogrammetry and Remote Sensing, Vol. 54 (2-3), pp. 130-137.

Hill, R. A. y Thomson, A. G. (2005). Mapping woodland species composition and structure using airborne spectral and LiDAR data. International Journal of Remote Sensing, Vol. 26 (17), pp. 3763-3779.

Hodgson, M. E., Jensen, J., Raber, G., Tullis, J., Davis, B. A., Thompson, G. y Schuckman, K. (2005). An evaluation of LiDAR-derived elevation and terrain slope in leaf-off conditions. Photogrammetric Engineering and Remote Sensing, Vol. 71 (7), pp.817-823. 
Hollaus, M., Wagner, W., Eberhöfer, C. y Karel, W (2006). Accuracy of large-scale canopy heights derived from LiDAR data under operational constraints in a complex alpine environment. ISPRS journal of photogrammetry and remote sensing, Vol. 60 (5), pp. 323-338.

Holmgren, J., Nilsson, M. y Olsson, H. (2003). Estimation of tree height and stem volume on plots using airborne laser scanning. Forest Science, Vol. 49 (3), pp. 419-428.

Holmgren, J. y Jonsson, T. 2004.Large scale airborne laser scanning of forest resources in sweden. ISPRS- International Archives of Photogrammetry, Remote Sensing and Spatial Information Sciences, Vol. XXXVI, Part 8/W2, pp. 157-160

Hopkinson, C., Chasmer, L., Young-Pow, C. y Treitz, P. (2004). Assessing forest metrics with a groundbased scanning LiDAR. Canadian Journal of Forest Research, Vol. 34 (3), pp. 573-583.

Hopkinson, C., Chasmer, L. E., Sass, G., Creed, I. F., Sitar, M., Kalbfleisch, W. y Treitz, P. (2005). Vegetation class dependent errors in LiDAR ground elevation and canopy height estimates in a boreal wetland environment. Canadian Journal of Remote Sensing, Vol. 31 (2), pp. 191-206.

Hudak, A. T., Crookston, N. L., Evans, J. S., Falkowski, M. J., Smith, A. M. S., Gessler, P. E. y Morgan, P. (2006). Regression modeling and mapping of coniferous forest basal area and tree density from discrete-return LiDAR and multispectral satellite data. Canadian Journal of Remote Sensing, Vol. 32 (2), pp. 126-138.

Huising, E. J. y Gomes Pereira, L.M. (1998). Errors and accuracy estimates of laser data acquired by various laser scanning systems for topographic applications. ISPRS Journal of Photogrammetry and Remote Sensing, Vol. 53 (5), pp. 245-261.

Hyde, P., Dubayah, R., Walker, W., Blair, J.B., Hofton, M. y Hunsaker, C. (2006). Mapping forest structure for wildlife habitat analysis using multi-sensor (LiDAR, SAR/InSAR, ETM+, QuickBird) synergy. Remote Sensing of Environment, Vol. 102 (1-2), pp. 63-73.

Hyyppä, J. e Inkinen, M. (1999). Detecting and estimating attributes for single trees using laser scanner The Photogrammetric Journal of Finland, Vol. 16 (2), pp. 27-42.

Hyyppä J, Pyysalo U, Hyyppä H, Samberg A. (2001). Elevation accuracy of laser scanning-derived digital terrain and target models in forest environment. In Proceedings of the European Association of Remote Sensing Laboratories (EARSeL), Vol. 1 (1), pp.139-147.

Hyyppä, J., Kelle, O., Lehikoinen, M. y Inkinen, M. (2001b). A segmentation-based method to retrieve stem volume estimates from $3-d$ tree height models produced by laser scanners. IEEE Transactions on Geoscience and Remote Sensing, Vol. 39 (5), pp. 969-975.

Hyyppa, H., Yu, X., Hyyppa, J., Kaartinen, H., Honkavaara, E. y Rönnholm, P. (2005). Factors affecting the quality of MDE generation in forested areas. ISPRS- International Archives of Photogrammetry, Remote Sensing and Spatial Information Sciences, Vol. 36, Part 3/W19, pp. 85-90.

Hyyppä, J., Hyyppä, H., Leckie, D., Gougeon, F., Yu, X. y Maltamo, M. (2008). Review of methods of smallfootprint airborne laser scanning for extracting forest inventory data in boreal forests. International Journal of Remote Sensing, Vol. 29 (5), pp. 1339-1366.

Kilian, J., Haala, N. y Englich, M. (1996). Capture and evaluation of airborne laser scanner data. ISPRSInternational Archives of Photogrammetry, Remote Sensing and Spatial Information Sciences, Vol. XXXI, part B3, pp. 383-388. 
Kim, Y., Yang, Z., Cohen, W. B, Pflugmacher, D., Lauver, C. L. y Vankat, J. L.(2009). Distinguishing between live and dead standing tree biomass on the North Rim of Grand Canyon National Park, USA using small-footprint LiDAR data. Remote Sensing of Environment, Vol. 113 (11), pp.2499-2510.

Kobler, A., Pfeifer, N., Ogrinc, P., Todorovski, L., Oštir, K. y Džeroski, D. (2007). Repetitive interpolation: A robust algorithm for MDE generation from aerial laser scanner data in forested terrain. Remote Sensing of Environment, Vol. 108 (1), pp. 9-23.

Korte, G.B.(1997). The GIS book (4⿳a ed). Santa Fe (EEUU). Onword Press.

Koukoulas, S. y Blackburn G. A. (2004). Quantifying the spatial properties of forest canopy gaps using LiDAR imagery and GIS. International Journal of Remote Sensing, Vol. 25 (15), pp. 3049-3071.

Kraus, K. y Pfeifer, N. (1998). Determination of terrain models in wooded areas with airborne laser scanner data. ISPRS Journal of Photogrammetry and Remote Sensing; Vol. 53 (4), pp. 193-203.

Lee, H. S. y Younan, N. H. (2003). DTM extraction of LiDAR returns via adaptive processing. IEEE Transactions on Geoscience and Remote Sensing, Vol. 41 (9), pp. 2063-2069.

Lefsky, M.A., Cohen, W.B., Acker, S. A., Parker, G., Spies, T. y Harding, D. (1999). LiDAR remote sensing of the canopy structure and biophysical properties of Douglas-fir western hemlock forests. Remote Sensing of Environment, Vol.70 (3), pp. 339-361.

Li, Y., Andersen, H.-E. y McGaughey, R. (2008). A comparison of statistical methods for estimating forest biomass from light detection and ranging data. Western Journal of Applied Forestry, Vol. 23 (4), pp.223231.

Lim, K., Treitz, P., Groot, A. y St-Onge, B. (2001). Estimation of individual tree heights using LIDAR remote sensing. Proceedings of the 23rd Annual Canadian Symposium on Remote Sensing, Quebec, 20-24 Agosto, 2001.

Lim, K. S., Treitz, P., Baldwin, K. y Morrison, I. (2003). Estimating above-ground biomass using LiDAR remote sensing. En M. Owe, G. D'Urso y L Toulios (Eds.), IV Conference of the International Society of Photo-Optical Instrumentation Engineers (SPIE), 23-27, Agia Pelagia, Creta, Vol. 4879, pp. 289-296.

Lohmann, P., Koch, A., y Schaeffer, M. (2000). Approaches to the filtering of laser scanner data. ISPRSInternational Archives of Photogrammetry, Remote Sensing and Spatial Information Sciences, Vol. XXXIII, Part B3, pp. 540-547.

Magnussen, S., Eggermont, P. y LaRiccia, V. N. (1999). Recovering tree heights from airborne laser scanner data. Forest Science, Vol. 45 (3), pp. 407-422.

Maltamo, M., Eerikäinen, K., Pitkänen, J., Hyyppä, J. y Vehmas, M. (2004). Estimation of timber volume and stem density based on scanning laser altimetry and expected tree size distribution functions. Remote Sensing of Environment, Vol. 90 (3), pp. 319-330.

Martinuzzi S., Vierling, L. A., Gould, W. A., Falkowski, M. J., Evans, J. S., Hudak, A. T. y Vierling, K. T. (2009). Mapping snags and understory shrubs for a LiDAR-based assessment of wildlife habitat suitability. Remote Sensing of Environment, Vol. 113 (12), pp. 2533-2546.

McCombs, J. W., Roberts, S. D. y Evans, D. L. (2003). Influence of fusing LiDAR and multispectral imagery on remotely sensed estimates of stand density and mean tree height in a managed loblolly pine plantation. Forest Science, Vol. 49 (3), pp.457-466.

Means, J. E., Acker, S. A., Brandon, J. F., Renslow, M., Emerson, L. y Hendrix, C. J. (2000). Predicting forest stand characteristics with airborne scanning LiDAR. Photogrammetric Engineering and Remote Sensing, Vol. 66 (11), pp. 1367-/1371. 
Meng, X., Currit, N. y Zhao, K. (2010). Ground filtering algorithms for airborne LiDAR data: a review of critical issues. Remote Sensing, Vol. 2 (3), pp. 833-860.

Mikšys, V., Varnagiryte-Kabasinskiene, I., Stupak, I., Armolaitis, K., Kukkola, M. y Wójcik, J.(2007). Above-ground biomass functions for Scots pine in Lithuania. Biomass and Bioenergy, Vol 31 (10), pp. 685692.

Morsdorf, F., Meier, E., Kötz, B., Itten, K. I., Dobbertin, M. y Allgöwer B. (2004). LiDAR-based geometric reconstruction of boreal type forest stands at single tree level for forest and wildland fire management. Remote Sensing of Environment, Vol. 92 (3), pp. 353-362.

Mutlu, M., Popescu, S. C., Stripling, C. y Spencer, T. (2008). Mapping surface fuel models using LiDAR and multispectral data fusion for fire behavior. Remote Sensing of Environment, Vol. 112 (1), pp. 274-285.

Mundt, J. T., Streutker, D. R. y Glenn, N. F. (2006). Mapping sagebrush distribution using fusion of hyperspectral and LiDAR classifications. Photogrammetric Engineering and Remote Sensing, Vol. 72 (1), pp. 47-54.

Næsset, E. (1997). Determination of mean tree height of forest stands using airborne laser scanner data. ISPRS Journal of Photogrammetry and Remote Sensing, Vol. 52 (2), pp. 49-56.

Næsset, E. (2002). Predicting forest stand characteristics with airborne scanning laser using a practical two-stage procedure and field data. Remote Sensing of Environment, Vol. 80 (1), pp. 88-99.

Næsset E. (2004). Accuracy of forest inventory using airborne laser scanning: evaluating the first nordic full-scale operational project. Scandinavian Journal of Forest Research, Vol. 19 (6), pp. $554-557$.

Nelson, R., Krabill, W. y Tonelli J. (1998). Estimating forest biomass and volume using airborne LiDAR data. Remote Sensing of Environment, Vol. 24 (2), pp. 247-267.

Nelson, R., Short, A. y Valenti, M. (2004). Measuring biomass and carbon in delaware using an airborne profiling LiDAR. Scandinavian Journal of Forest Research, Vol. 19 (6), pp. 500-511.

Pascual, C., García-Abril, A., García-Montero, L. G., Martín-Fernández, S. y Cohen, W. B.

(2008). Object-based semi-automatic approach for forest structure characterization using LiDAR data in heterogeneous Pinus sylvestris stands. Forest Ecology and Management; Vol. 255 (11), pp.3677-3685.

Persson, A., Holmgren, J. y Söderman, U. (2002). Detecting and measuring individual trees using an airborne laser scanner. Photogrammetric Engineering and Remote Sensing, Vol. 68 (9), pp. 925-932.

Popescu S.C., Wynne R.H., Nelson R.F. (2002). Estimating plot-level tree heights with LiDAR: local filtering with a canopy-height based variable window size. Computers and Electronics in Agriculture, Vol. 37 (1-3), pp.71-95.

Popescu, S. C., Wynne, R. H. y Nelson, R. F. (2003). Measuring individual tree crown diameter with LiDAR and assessing its influence on estimating forest volume and biomass. Canadian Journal of Remote Sensing, Vol. 29 (5), pp. 564-577.

Popescu, S. C., Wynne, R. H. y Scrivani, J. A. (2004). Fusion of small-footprint LiDAR and multispectral data to estimate plot-level volume and biomass in deciduous and pine forests in Virginia, USA. Forest Science, Vol. 50 (4), pp. 551-565.

Popescu, S. C. (2007). Estimating biomass of individual pine trees using airborne LiDAR. Biomass \& Bioenergy, Vol. 31 (9), no. 9, pp. 646-655.

Priestnall, G., Jaafar, J. y Duncan A. (2000). Extracting urban features from LiDAR digital surface models. Computers, Environment and Urban Systems, Vol., 24 (2), pp. 65-78. 
Raber, G. T., Jensen, J. R., Schill, S. R y Schuckman, K. (2002). Creation of digital terrain models using an adaptive LiDAR vegetation point removal process. Photogrammetric Engineering and Remote Sensing, Vol. 68 (12), pp. 1307-1315.

Rango, A., Chopping, M., Ritchie, J., Havstad, K., Kustas, W. y Schmugge, T. (2000). Morphological characteristics of shrub coppice dunes in desert grasslands of southern New Mexico derived from scanning LIDAR. Remote Sensing of Environment, Vol.74 (1), pp. 26-44.

Reutebuch, S. E., Andersen, H.-E. y McGaughey, R. J. (2005). Light detection and ranging (LiDAR): An emerging tool for multiple resource inventory. Journal of Forestry, Vol. 103 (6), pp. 286-292.

Riaño, D., Chuvieco, E., Condés, S., González-Matesanz, J. y Ustin, S. L. (2004). Generation of crown bulk density for pinus sylvestris I. from LiDAR. Remote Sensing of Environment, Vol. 92 (3), pp. 345-352.

Riaño, D., Chuvieco, E., Ustin, S. L., Salas, J., Rodríguez-Pérez, J. R., Ribeiro, L. M., Viegas, D. X., Moreno, J. M. y Fernández, H. (2007). Estimation of shrub height for fuel-type mapping combining airborne LiDAR and simultaneous color infrared ortho imaging. International Journal of Wildland Fire, Vol. 16 (3), pp. 341 348.

Roggero, M. (2002). Airborne laser scanning: clustering in raw data. ISPRS- International Archives of Photogrammetry, Remote Sensing and Spatial Information Sciences, Vol. 34, Part 3/W4, pp. 227-232.

Shrestha, R., Carter, W., Slatton, K., Luzum, B. y Sartori, M. (2005). Airborne Laser Swath Mapping: Quantifying changes in sandy beaches over time scales of weeks to years. ISPRS Journal of Photogrammetry and Remote Sensing, Vol. 59 (4), pp. 222-232.

Sithole, G. (2002). Filtering of laser altimetry data using a slope adaptive filter. ISPRS- International Archives of Photogrammetry, Remote Sensing and Spatial Information Sciences, Vol. 34, Part 3/W4, pp. 203-210.

Sithole, G. y Vosselman, G. (2004). Experimental comparison of filter algorithms for bare-Earth extraction from airborne laser scanning point clouds. ISPRS Journal of Photogrammetry and Remote Sensing, Vol. 59 (1-2), pp. 85-101.

Sohn, G. y Dowman, I. (2007). Data fusion of high-resolution satellite imagery and LiDAR data for automatic building extraction. ISPRS Journal of Photogrammetry and Remote Sensing, Vol. 62 (1), pp. 4363.

St-Onge, B., Jumelet, J., Cobello, M. y Véga, C. (2004). Measuring individual tree height using a combination of stereophotogrammetry and LiDAR. Canadian Journal of Forest Research, vol. 34 (10), pp. 2122 2130.

Streutker, D. R. y Glenn, N. F. (2006). LiDAR measurement of sagebrush steppe vegetation heights. Remote Sensing of Environment, vol. 102 (1-2), pp. 135-145.

Su, J. G. y Bork, E. W. (2006). Influence of vegetation, slope, and LiDAR sampling angle on DEM accuracy. Photogrammetric Engineering and Remote Sensing, Vol. 72, (11), pp.1265-1274.

Su, J. G. y Bork, E. W. (2007). Characterization of diverse plant communities in Aspen Parkland rangeland using LiDAR data. Applied Vegetation Science, Vol. 10 (3), pp. 407-416.

Suárez, J. C., Snape, S., Ontiveros, C. y Smith, S. (2005). Use of airborne LiDAR and aerial photography in the estimation of individual tree heights in forestry. Computers \& geosciences, Vol. 31 (2), pp. 253-262.

Takahashi, T., Yamamoto, K., Senda, Y. y Tsuzuku, M. (2005). Estimating individual tree heights of sugi (cryptomeria japonica d. don) plantations in mountainous areas using small-footprint airborne LiDAR. Journal of Forest Research, Vol. 10 (2), pp. 135-142. 
Takhtajan, A. (1986). Floristic regions of the world. Los Ángeles. University of California Press.

Van Aardt, J.A.N., Wynne, R. H. y Oderwald, R. G. (2006). Forest volume and biomass estimation using small-footprint LiDAR-distributional parameters on a per-segment basis. Forest Science, Vol. 52 (6), pp. 636-649.

Velázquez-Martí B., Fernández-González, E., Estornell, J. y Ruiz, L. A. (2010). Dendrometric and dasometric analysis of the bushy biomass in Mediterranean forests. Forest Ecology and Management, Vol. 259 (5), pp.875-882.

Verrelst, J., Geerling, G. W., Sykora, K. V. y Clevers, J. G. P. W. (2009). Mapping of aggregated floodplain plant communities using image fusion of CASI and LiDAR data. International Journal of Applied Earth Observation and Geoinformation, Vol. 11 (1), pp. 83-94.

Vosselman, G., (2000). Slope based filtering of laser altimetry data. ISPRS- International Archives of Photogrammetry, Remote Sensing and Spatial Information Sciences, In International Archives of Photogrammetry and Remote Sensing, Vol. XXXIII, Part B3, pp. 935-942.

Wack, R. y Wimmer, A. 2002. Digital terrain models from airborne laser scanner data - a grid based approach. ISPRS- International Archives of Photogrammetry, Remote Sensing and Spatial Information Sciences, Vol. XXXIV, Part 3 A+B, pp. 293-296

Wang, C., Menenti, M., Stoll, M.-P., Feola, A., Belluco, E. y Marani, M. (2009) Separation of Ground and Low Vegetation Signatures in LiDAR Measurements of Salt-Marsh Environments. IEEE Transactions on Geoscience and Remote Sensing, Vol. 47 (7), pp. 2014-2023.

Yu, X., Hyyppä, J., Kaartinen, H. y Maltamo, M. (2004) Automatic detection of harvested trees and determination of forest growth using airborne laser scanning. Remote Sensing of Environment, Vol. 90 (4), pp. $451-462$.

Zhang, K., Chen, S-C., Whitman, D., Shyu, M-L., Yan, J. y Zhang, C. (2003) A progressive morphological filter for removing nonground measurements from airborne LIDAR data. IEEE Transactions on Geoscience and Remote Sensing, Vol. 41, (4), pp.872-882.

Zheng, D., Rademacher, J., Chen, J., Crow, T., Bresee, M., Le Moine, J. y Ryu, S-R. (2004). Estimating aboveground biomass using Landsat 7 ETM + data across a managed landscape in northern Wisconsin, USA. Remote Sensing of Environment, Vol. 93 (3), pp. 402-411.

Zimble, D. A., Evans, D. L., Carlson, G. C., Parker, R. C., Grado, S. C. y Gerard, P. D. (2003). Characterizing vertical forest structure using small-footprint airborne LiDAR. Remote Sensing of Environment, Vol. 87 (2-3), pp. 171-82. 
Además de esta memoria de tesis doctoral, el presente trabajo ha dado lugar a las siguientes publicaciones científicas:

- $\quad$ Estornell, J., Ruiz, L. A. y Velazquez-Marti, B. (2011). Study of shrub cover and height using LiDAR data in a Mediterranean area. Forest Science, Vol. 57 (4), pp. 171-179.

- Velázquez-Martí B., Fernández-González, E., Estornell, J. y Ruiz, L. A. (2010). Dendrometric and dasometric analysis of the bushy biomass in Mediterranean forests. Forest Ecology and Management, vol. 259, pp.875-882.

- $\quad$ Estornell, J., Ruiz, L. A., Velazquez-Marti, B. y Hermosilla, T. (2010). Analysis of the factors affecting LiDAR DTM accuracy in a steep shrub area. International Journal of Digital Earth doi:10.1080/17538947.2010.533201.

- $\quad$ Estornell, J., Ruiz, L.A., Velázquez-Martí, B., Hermosilla, T. Estimation of biomass and volume of shrub vegetation using LiDAR and spectral data in a Mediterranean environment. Biomass and Bionergy. (Enviado: 10-Julio-2010).

- $\quad$ Estornell, J., Ruiz, L.A., Velázquez-Martí, B., Fernández-Sarría, A. Estimation of shrub biomass by airborne LiDAR data in small forest stands. Forest Ecology and Management (Enviado: 5-Mayo-2011). 
ANEJOS 

ANEJO 1. TRANSFORMACIÓN DE COORDENADAS

Coordenadas UTM vértices de la zona

\begin{tabular}{ccccccc}
\hline Vértices & \multicolumn{3}{c}{ ED50 } & \multicolumn{3}{c}{ ETRS89 } \\
\hline & $\mathrm{x}$ & $\mathrm{Y}$ & $\mathrm{H}$ & $\mathrm{x}$ & $\mathrm{y}$ & $\mathrm{H}$ \\
\hline 4032 & 689827,494 & 4375072,983 & 527,566 & 689718,722 & 4374864,174 & 578,211 \\
4033 & 687044,331 & 4374632,382 & 834,523 & 686935,547 & 4374423,611 & 885,275 \\
4038 & 687177,240 & 4372234,909 & 814,617 & 687068,505 & 4372026,13 & 865,154 \\
4039 & 688871,963 & 4371516,045 & 742,277 & 688763,259 & 4371307,255 & 792,684 \\
\hline
\end{tabular}

Parámetros de transformación planimétrica y sus errores, Modelo de 4 parámetros.

\begin{tabular}{ccc}
\hline Parámetros & Valor & Errores \\
\hline Traslación x (m) & 688230,29950 & 0,018500 \\
Traslación y (m) & 4373363,98860 & 0,018500 \\
Rotación (") & $-5007,70725$ & 1,995050 \\
Escala & $36,6263 \mathrm{ppm}$ & 0,0000091 \\
\hline
\end{tabular}

Parámetros de transformación altimétricos y sus errores.

\begin{tabular}{ccc}
\hline Parámetros & Valores & Errores \\
\hline Inclinación en $x(\mathrm{~m})$ & $-0,0000835$ & 0,0000033 \\
Inclinación en y $(\mathrm{m})$ & 0,0000468 & 0,0000042 \\
Traslación altura $(\mathrm{m})$ & $-50,58540$ & 0,0049 \\
\hline
\end{tabular}

Tabla de los errores en las coordenadas de los vértices.

\begin{tabular}{cccc}
\hline Vértice & Ex $(m)$ & Ey $(m)$ & Ez $(m)$ \\
\hline 4033 & $-0,02900$ & 0,035 & 0,005 \\
4035 & 0,03600 & $-0,002$ & 0,005 \\
5002 & 0,00200 & 0,011 & $-0,007$ \\
6003 & $-0,01000$ & $-0,044$ & $-0,003$ \\
\hline
\end{tabular}


ANEJO 2. Matriz de correlación de los estadísticos de las alturas derivadas de los datos LiDAR.

\begin{tabular}{|c|c|c|c|c|c|c|c|c|c|c|c|c|c|c|c|c|c|c|c|}
\hline Variable & $\mathrm{h}_{\text {max }}$ & $\mathrm{h}_{\mathrm{m}}$ & $h_{s}$ & Skew & Kur & $P_{05}$ & $P_{10}$ & $P_{20}$ & $P_{25}$ & $P_{30}$ & $P_{40}$ & $P_{50}$ & $P_{60}$ & $P_{70}$ & $P_{75}$ & $P_{80}$ & $P_{90}$ & $P_{95}$ & cv \\
\hline $\mathrm{h}_{\max }$ & 1,00 & 0,71 & 0,76 & 0,39 & 0,51 & 0,70 & 0,62 & 0,56 & 0,56 & 0,55 & 0,56 & 0,59 & 0,63 & 0,67 & 0,70 & 0,71 & 0,74 & 0,77 & $-0,04$ \\
\hline $\mathrm{h}_{\mathrm{m}}$ & 0,71 & 1,00 & 0,83 & $-0,27$ & $-0,10$ & 0,79 & 0,84 & 0,88 & 0,90 & 0,91 & 0,94 & 0,96 & 0,98 & 0,99 & 0,98 & 0,97 & 0,92 & 0,89 & $-0,38$ \\
\hline$h_{s}$ & 0,76 & 0,83 & 1,00 & 0,09 & $-0,05$ & 0,51 & 0,46 & 0,49 & 0,51 & 0,52 & 0,59 & 0,65 & 0,74 & 0,84 & 0,89 & 0,92 & 0,97 & 0,98 & 0,17 \\
\hline$g_{1}$ & 0,39 & $-0,27$ & 0,09 & 1,00 & 0,78 & $-0,02$ & $-0,23$ & $-0,37$ & $-0,39$ & $-0,41$ & $-0,44$ & $-0,43$ & $-0,40$ & $-0,32$ & $-0,27$ & $-0,23$ & $-0,11$ & 0,00 & 0,61 \\
\hline$g_{2}$ & 0,51 & $-0,10$ & $-0,05$ & 0,78 & 1,00 & 0,23 & 0,12 & 0,00 & $-0,03$ & $-0,05$ & $-0,11$ & $-0,15$ & $-0,17$ & $-0,18$ & $-0,18$ & $-0,17$ & $-0,14$ & $-0,07$ & 0,10 \\
\hline$P_{05}$ & 0,70 & 0,79 & 0,51 & $-0,02$ & 0,23 & 1,00 & 0,95 & 0,87 & 0,85 & 0,83 & 0,81 & 0,77 & 0,75 & 0,72 & 0,70 & 0,67 & 0,62 & 0,61 & $-0,53$ \\
\hline$P_{10}$ & 0,62 & 0,84 & 0,46 & $-0,23$ & 0,12 & 0,95 & 1,00 & 0,97 & 0,96 & 0,95 & 0,92 & 0,88 & 0,84 & 0,77 & 0,74 & 0,70 & 0,61 & 0,58 & $-0,66$ \\
\hline$P_{20}$ & 0,56 & 0,88 & 0,49 & $-0,37$ & 0,00 & 0,87 & 0,97 & 1,00 & 1,00 & 0,99 & 0,97 & 0,94 & 0,90 & 0,83 & 0,79 & 0,75 & 0,65 & 0,60 & $-0,69$ \\
\hline$P_{25}$ & 0,56 & 0,90 & 0,51 & $-0,39$ & $-0,03$ & 0,85 & 0,96 & 1,00 & 1,00 & 1,00 & 0,98 & 0,96 & 0,92 & 0,86 & 0,82 & 0,77 & 0,68 & 0,63 & $-0,68$ \\
\hline$P_{30}$ & 0,55 & 0,91 & 0,52 & $-0,41$ & $-0,05$ & 0,83 & 0,95 & 0,99 & 1,00 & 1,00 & 0,99 & 0,97 & 0,93 & 0,87 & 0,83 & 0,79 & 0,68 & 0,63 & $-0,68$ \\
\hline$P_{40}$ & 0,56 & 0,94 & 0,59 & $-0,44$ & $-0,11$ & 0,81 & 0,92 & 0,97 & 0,98 & 0,99 & 1,00 & 0,99 & 0,97 & 0,92 & 0,88 & 0,84 & 0,74 & 0,69 & $-0,64$ \\
\hline$P_{50}$ & 0,59 & 0,96 & 0,65 & $-0,43$ & $-0,15$ & 0,77 & 0,88 & 0,94 & 0,96 & 0,97 & 0,99 & 1,00 & 0,99 & 0,95 & 0,92 & 0,89 & 0,80 & 0,74 & $-0,58$ \\
\hline$P_{\infty 0}$ & 0,63 & 0,98 & 0,74 & $-0,40$ & $-0,17$ & 0,75 & 0,84 & 0,90 & 0,92 & 0,93 & 0,97 & 0,99 & 1,00 & 0,98 & 0,96 & 0,94 & 0,87 & 0,81 & $-0,49$ \\
\hline$P_{70}$ & 0,67 & 0,99 & 0,84 & $-0,32$ & $-0,18$ & 0,72 & 0,77 & 0,83 & 0,86 & 0,87 & 0,92 & 0,95 & 0,98 & 1,00 & 0,99 & 0,98 & 0,94 & 0,90 & $-0,35$ \\
\hline$P_{75}$ & 0,70 & 0,98 & 0,89 & $-0,27$ & $-0,18$ & 0,70 & 0,74 & 0,79 & 0,82 & 0,83 & 0,88 & 0,92 & 0,96 & 0,99 & 1,00 & 1,00 & 0,96 & 0,93 & $-0,28$ \\
\hline$P_{80}$ & 0,71 & 0,97 & 0,92 & $-0,23$ & $-0,17$ & 0,67 & 0,70 & 0,75 & 0,77 & 0,79 & 0,84 & 0,89 & 0,94 & 0,98 & 1,00 & 1,00 & 0,98 & 0,95 & $-0,20$ \\
\hline$P_{90}$ & 0,74 & 0,92 & 0,97 & $-0,11$ & $-0,14$ & 0,62 & 0,61 & 0,65 & 0,68 & 0,68 & 0,74 & 0,80 & 0,87 & 0,94 & 0,96 & 0,98 & 1,00 & 0,99 & $-0,05$ \\
\hline$P_{95}$ & 0,77 & 0,89 & 0,98 & 0,00 & $-0,07$ & 0,61 & 0,58 & 0,60 & 0,63 & 0,63 & 0,69 & 0,74 & 0,81 & 0,90 & 0,93 & 0,95 & 0,99 & 1,00 & 0,04 \\
\hline $\mathrm{cV}$ & $-0,04$ & $-0,38$ & 0,17 & 0,61 & 0,10 & $-0,53$ & $-0,66$ & $-0,69$ & $-0,68$ & $-0,68$ & $-0,64$ & $-0,58$ & $-0,49$ & $-0,35$ & $-0,28$ & $-0,20$ & $-0,05$ & 0,04 & 1,00 \\
\hline
\end{tabular}


ANEJO 3. Matriz de correlación de las variables extraídas de las bandas espectrales de la imagen aérea.

\begin{tabular}{|c|c|c|c|c|c|c|c|c|c|c|c|c|c|c|c|c|}
\hline Variable & $\mathbb{R}_{\text {min }}$ & $\mathbb{I R}_{\text {max }}$ & $\mathbb{I R}_{\mathrm{m}}$ & $\mathbb{R}_{\mathrm{d}}$ & $R_{\text {min }}$ & $R_{\text {max }}$ & $\mathrm{R}_{\mathrm{m}}$ & $R_{d}$ & $G_{\min }$ & $G_{\text {max }}$ & $G_{m}$ & $G_{d}$ & $\mathrm{NDVI}_{\text {min }}$ & $N D V I_{\text {max }}$ & $\mathrm{NDVI}_{\mathrm{m}}$ & $\mathrm{NDVI}_{\mathrm{d}}$ \\
\hline $\mathbf{I} \mathbf{R}_{\text {min }}$ & 1,00 & $-0,07$ & 0,53 & $-0,69$ & 0,63 & $-0,26$ & $-0,12$ & $-0,38$ & 0,82 & $-0,25$ & $-0,07$ & $-0,38$ & 0,33 & $-0,22$ & 0,35 & $-0,37$ \\
\hline $\mathbb{I}_{\max }$ & $-0,07$ & 1,00 & 0,44 & 0,60 & 0,17 & 0,85 & 0,36 & 0,70 & 0,02 & 0,86 & 0,34 & 0,72 & $-0,65$ & $-0,20$ & $-0,10$ & 0,50 \\
\hline $\mathbb{I}_{\mathrm{m}}$ & 0,53 & 0,44 & 1,00 & 0,09 & 0,44 & 0,30 & 0,36 & 0,42 & 0,46 & 0,32 & 0,47 & 0,42 & $-0,14$ & $-0,07$ & 0,19 & 0,34 \\
\hline $\mathbb{R}_{\mathrm{d}}$ & $-0,69$ & 0,60 & 0,09 & 1,00 & $-0,19$ & 0,76 & 0,63 & 0,86 & $-0,49$ & 0,76 & 0,61 & 0,88 & $-0,66$ & $-0,17$ & $-0,54$ & 0,49 \\
\hline $\mathrm{R}_{\min }$ & 0,63 & 0,17 & 0,44 & $-0,19$ & 1,00 & 0,27 & 0,47 & 0,13 & 0,91 & 0,27 & 0,46 & 0,14 & $-0,29$ & $-0,78$ & $-0,30$ & $-0,12$ \\
\hline $\mathrm{R}_{\text {max }}$ & $-0,26$ & 0,85 & 0,30 & 0,76 & 0,27 & 1,00 & 0,68 & 0,86 & 0,00 & 0,99 & 0,65 & 0,87 & $-0,88$ & $-0,43$ & $-0,51$ & 0,51 \\
\hline $\mathrm{R}_{\mathrm{m}}$ & $-0,12$ & 0,36 & 0,36 & 0,63 & 0,47 & 0,68 & 1,00 & 0,71 & 0,20 & 0,67 & 0,98 & 0,73 & $-0,70$ & $-0,65$ & $-0,84$ & 0,22 \\
\hline$R_{d}$ & $-0,38$ & 0,70 & 0,42 & 0,86 & 0,13 & 0,86 & 0,71 & 1,00 & $-0,14$ & 0,85 & 0,71 & 0,99 & $-0,77$ & $-0,25$ & $-0,44$ & 0,72 \\
\hline$G_{\min }$ & 0,82 & 0,02 & 0,46 & $-0,49$ & 0,91 & 0,00 & 0,20 & $-0,14$ & 1,00 & 0,02 & 0,22 & $-0,14$ & $-0,03$ & $-0,56$ & $-0,02$ & $-0,22$ \\
\hline$G_{\max }$ & $-0,25$ & 0,86 & 0,32 & 0,76 & 0,27 & 0,99 & 0,67 & 0,85 & 0,02 & 1,00 & 0,65 & 0,87 & $-0,86$ & $-0,42$ & $-0,49$ & 0,50 \\
\hline $\mathrm{G}_{\mathrm{m}}$ & $-0,07$ & 0,34 & 0,47 & 0,61 & 0,46 & 0,65 & 0,98 & 0,71 & 0,22 & 0,65 & 1,00 & 0,74 & $-0,66$ & $-0,58$ & $-0,76$ & 0,25 \\
\hline$G_{d}$ & $-0,38$ & 0,72 & 0,42 & 0,88 & 0,14 & 0,87 & 0,73 & 0,99 & $-0,14$ & 0,87 & 0,74 & 1,00 & $-0,77$ & $-0,27$ & $-0,47$ & 0,67 \\
\hline $\mathrm{NDVI}_{\min }$ & 0,33 & $-0,65$ & $-0,14$ & $-0,66$ & $-0,29$ & $-0,88$ & $-0,70$ & $-0,77$ & $-0,03$ & $-0,86$ & $-0,66$ & $-0,77$ & 1,00 & 0,42 & 0,64 & $-0,54$ \\
\hline$N D V I_{\max }$ & $-0,22$ & $-0,20$ & $-0,07$ & $-0,17$ & $-0,78$ & $-0,43$ & $-0,65$ & $-0,25$ & $-0,56$ & $-0,42$ & $-0,58$ & $-0,27$ & 0,42 & 1,00 & 0,68 & 0,25 \\
\hline $\mathrm{NDVI}_{\mathrm{m}}$ & 0,35 & $-0,10$ & 0,19 & $-0,54$ & $-0,30$ & $-0,51$ & $-0,84$ & $-0,44$ & $-0,02$ & $-0,49$ & $-0,76$ & $-0,47$ & 0,64 & 0,68 & 1,00 & 0,02 \\
\hline $\mathrm{NDVI}_{\mathrm{d}}$ & $-0,37$ & 0,50 & 0,34 & 0,49 & $-0,12$ & 0,51 & 0,22 & 0,72 & $-0,22$ & 0,50 & 0,25 & 0,67 & $-0,54$ & 0,25 & 0,02 & 1,00 \\
\hline
\end{tabular}


ANEJO 4

En este anejo se representa la distribución de las alturas de cada parcela. A partir de estos datos se calcularon las variables asociadas a los perfiles de densidad para las estimaciones de la biomasa y volumen por parcelas. Se pudo observar que las parcelas con mayor porcentaje de puntos con altura superior a 1 $\mathrm{m}$ tuvieron más biomasa y volumen (parcelas 9,12 y 20). En cambio las parcelas con mayor porcentaje de puntos con alturas en el intervalo 0-0.25 m presentaron menos biomasa y volumen (parcelas 3, 6, 28 y 29).

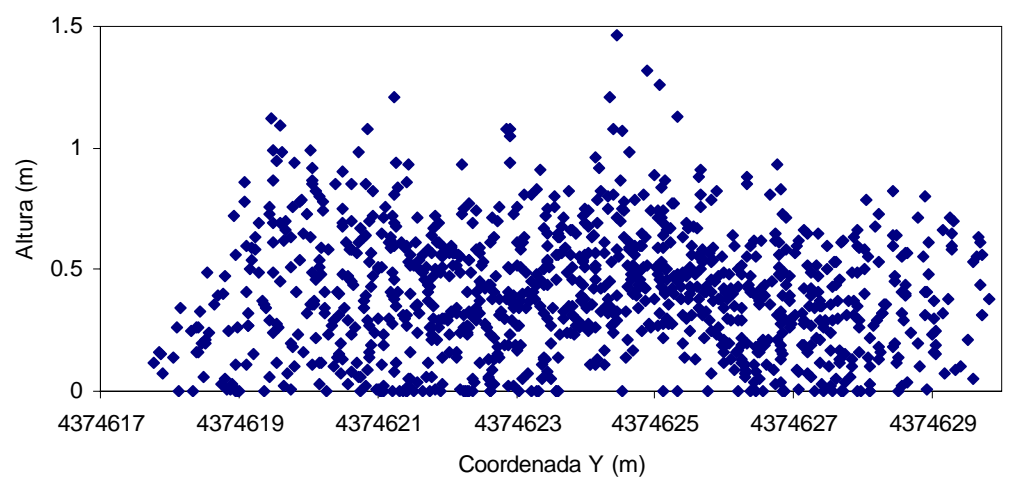

Parcela 1

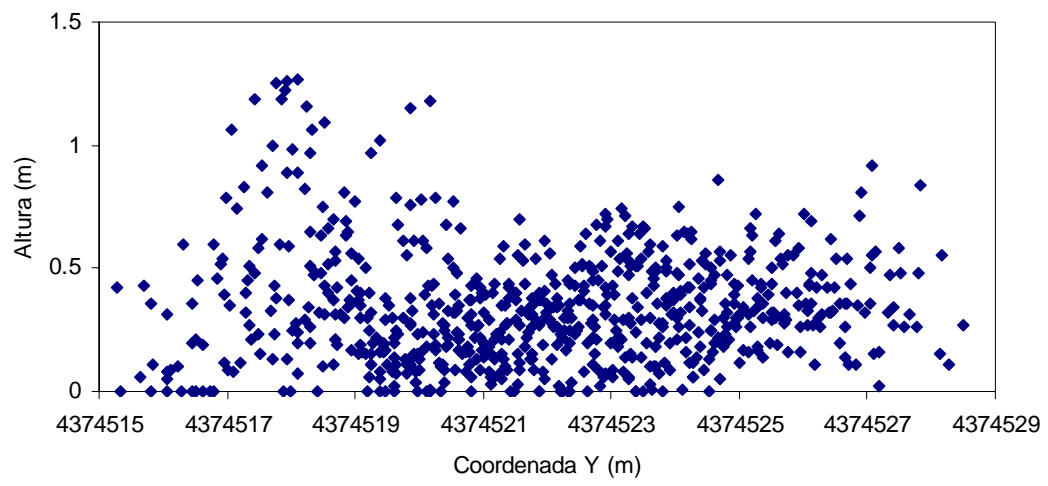

Parcela 2 


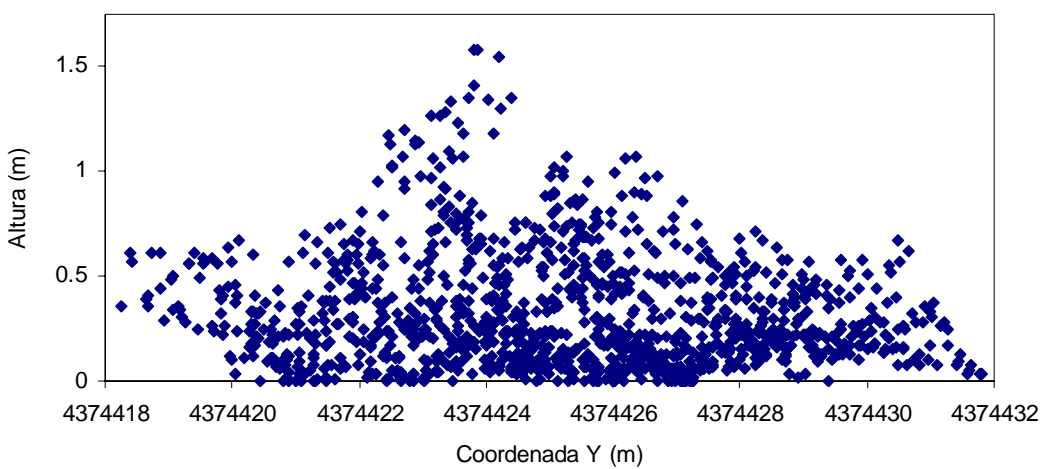

Parcela 3

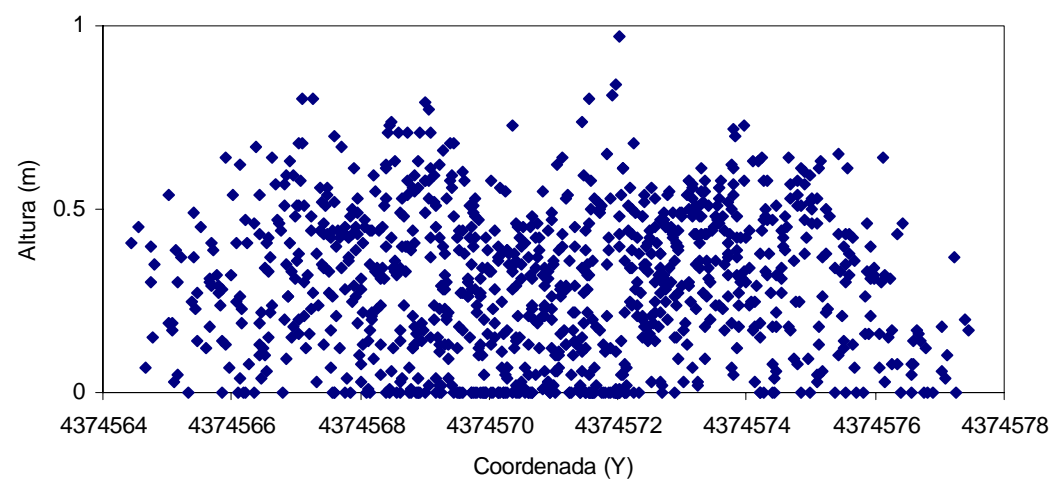

Parcela 4

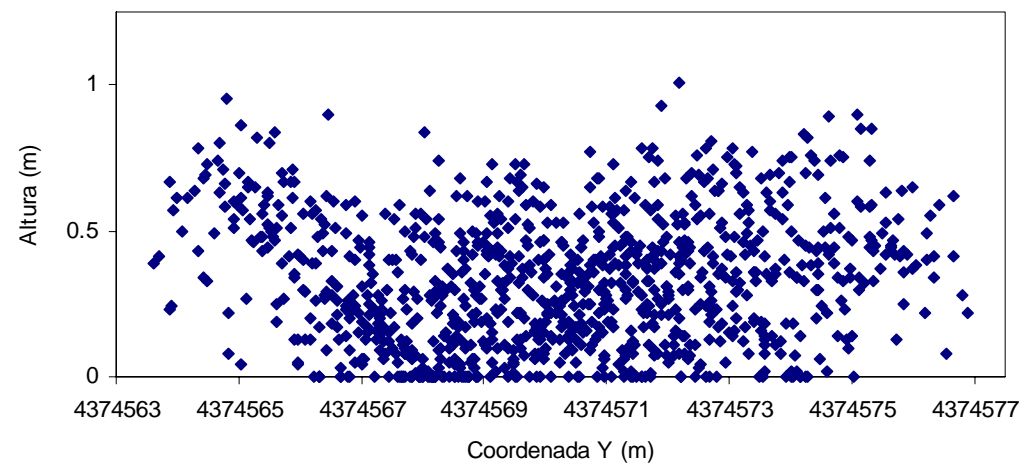

Parcela 5 


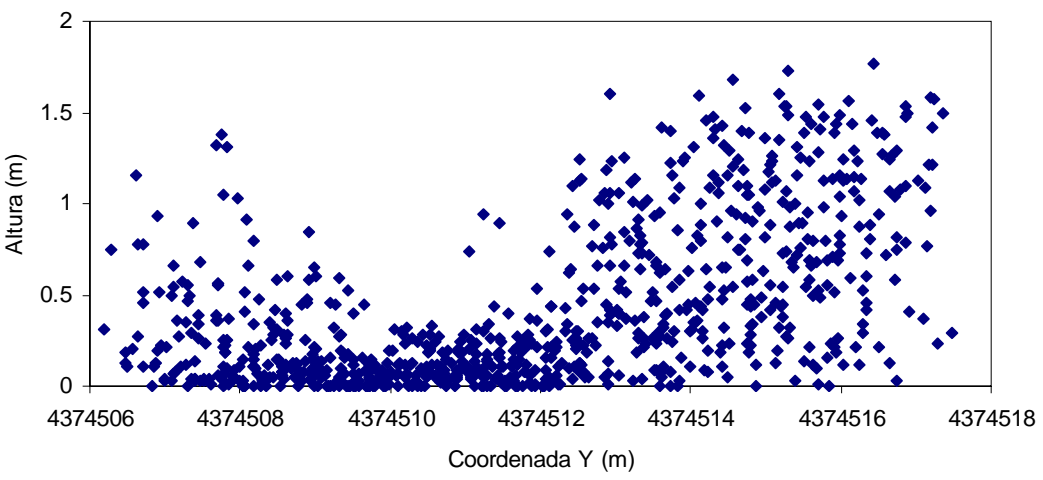

Parcela 6

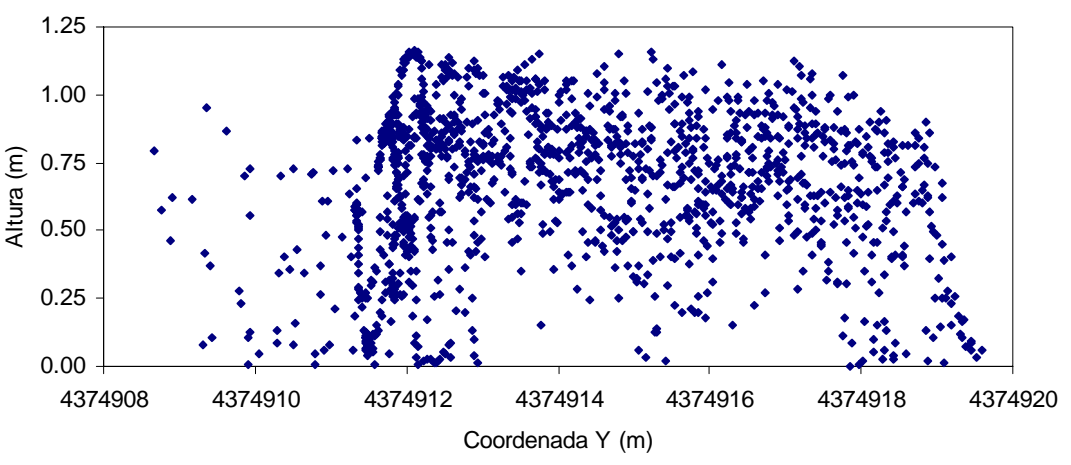

Parcela 7

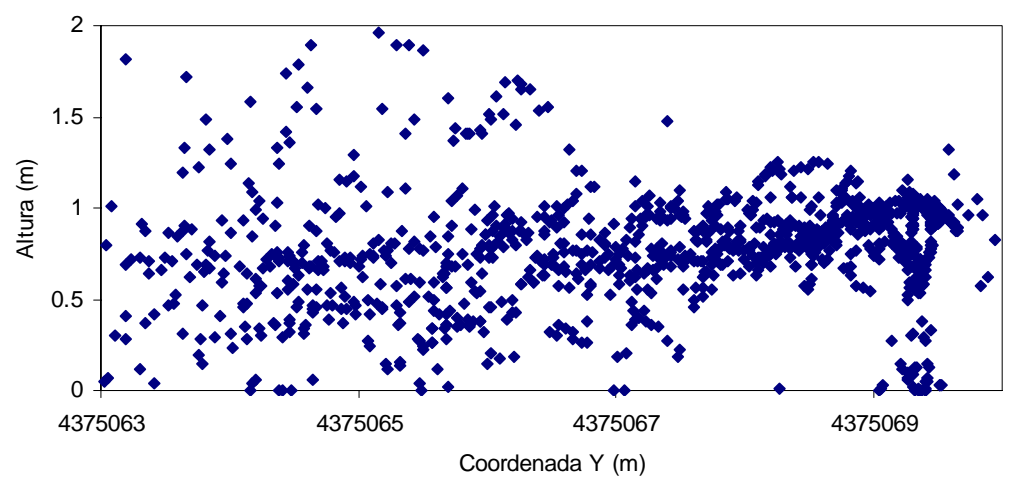

Parcela 8 


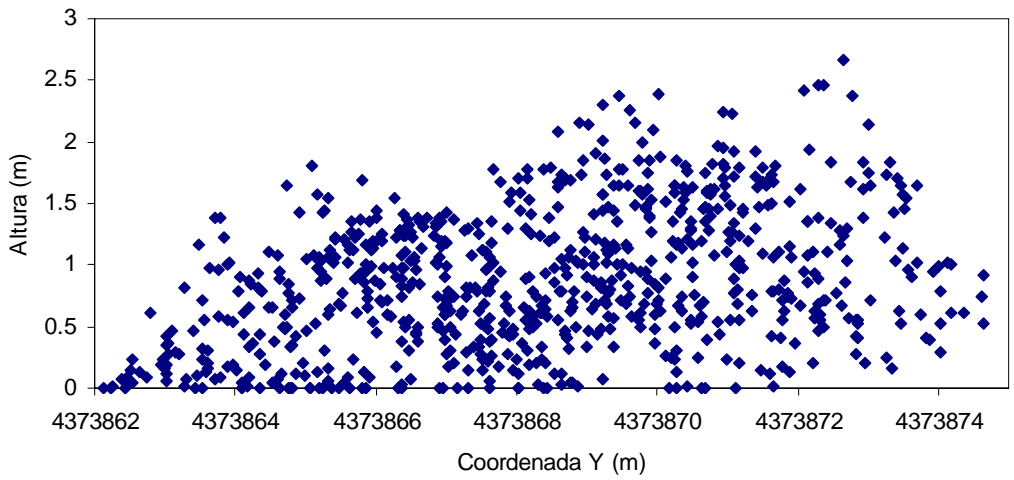

Parcela 9

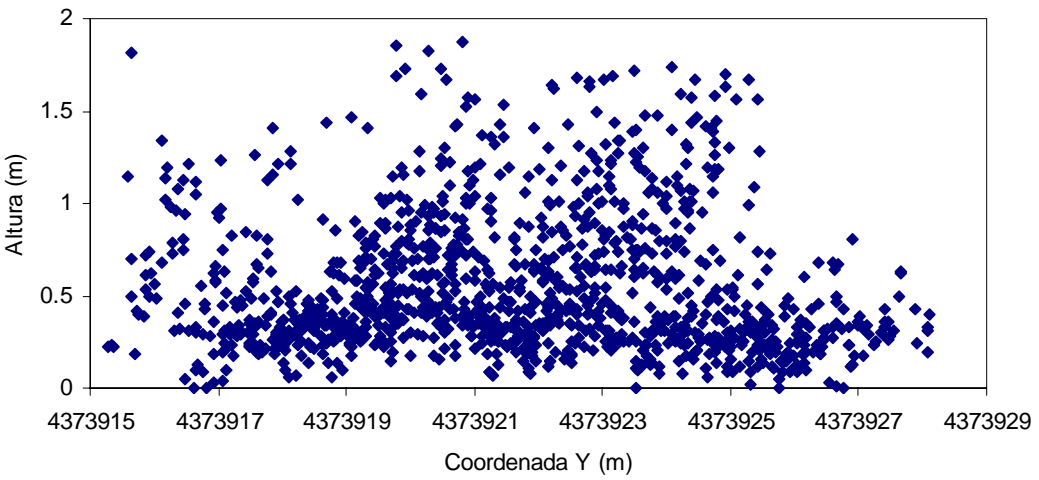

Parcela 10

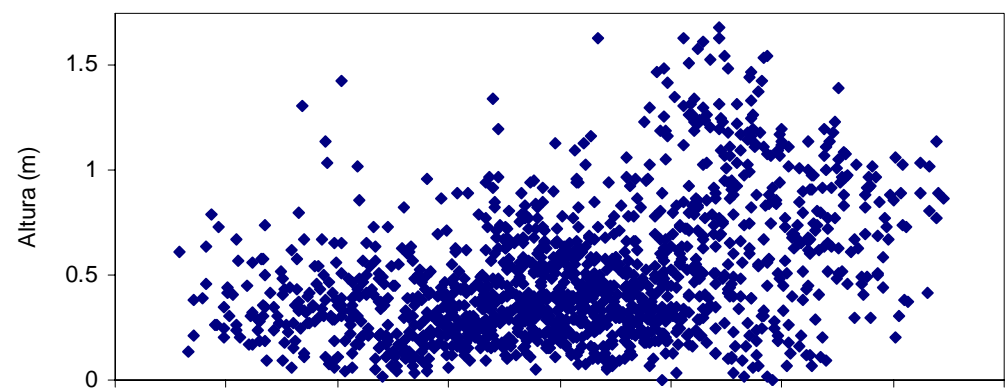

$\begin{array}{lllllllll}4373912 & 4373914 & 4373916 & 4373918 & 4373920 & 4373922 & 4373924 & 4373926 & 4373928\end{array}$ Coordenada $Y(m)$

Parcela 11 


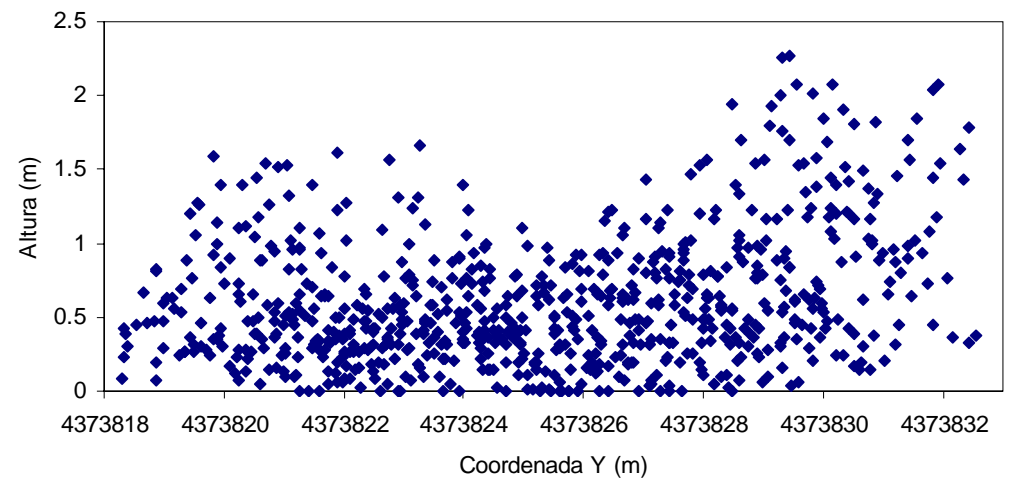

Parcela 12

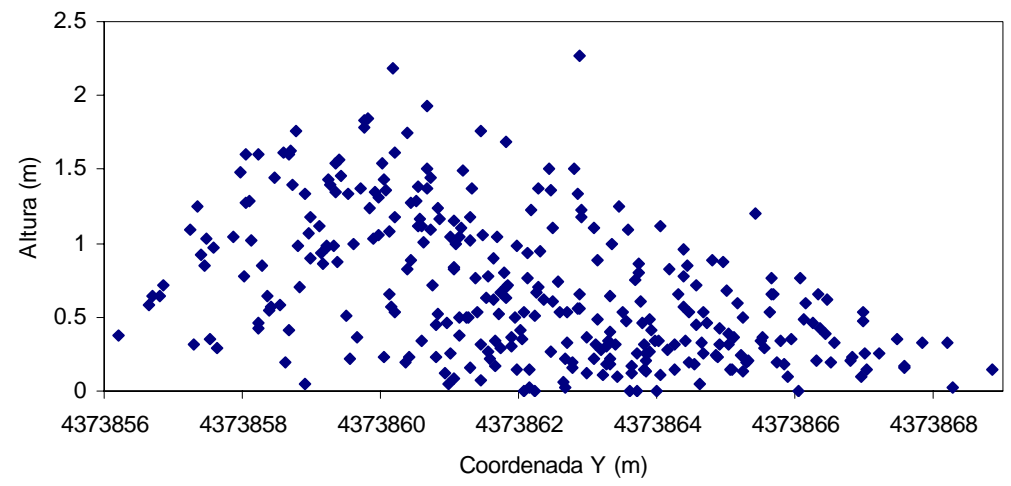

Parcela 13

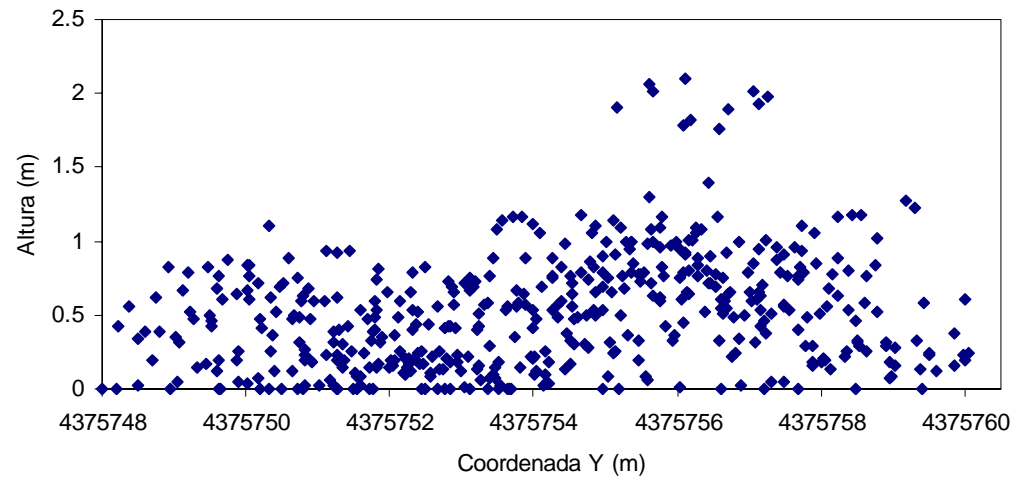

Parcela 14 


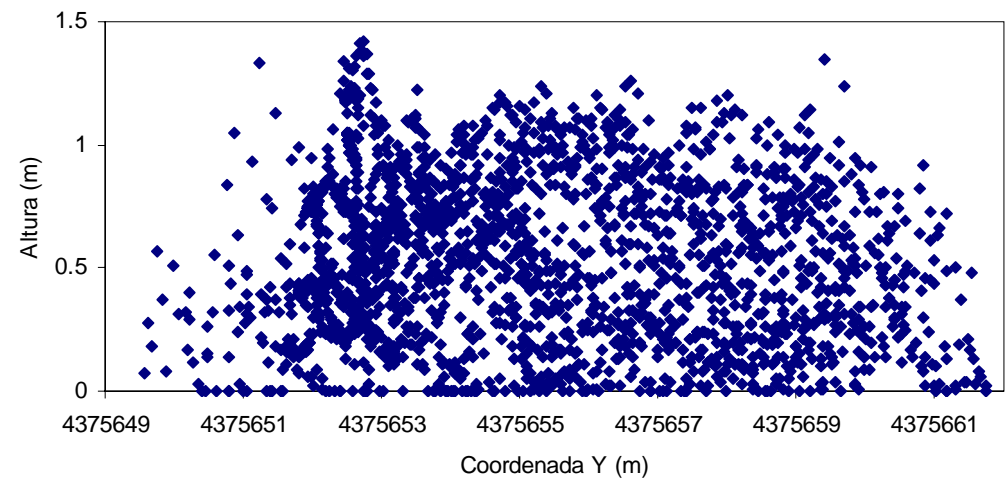

Parcela 15

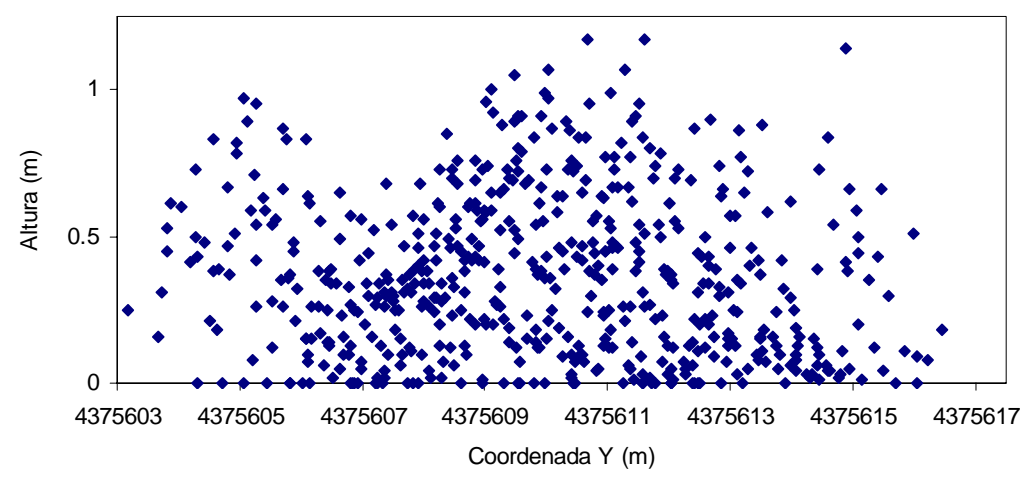

Parcela 16

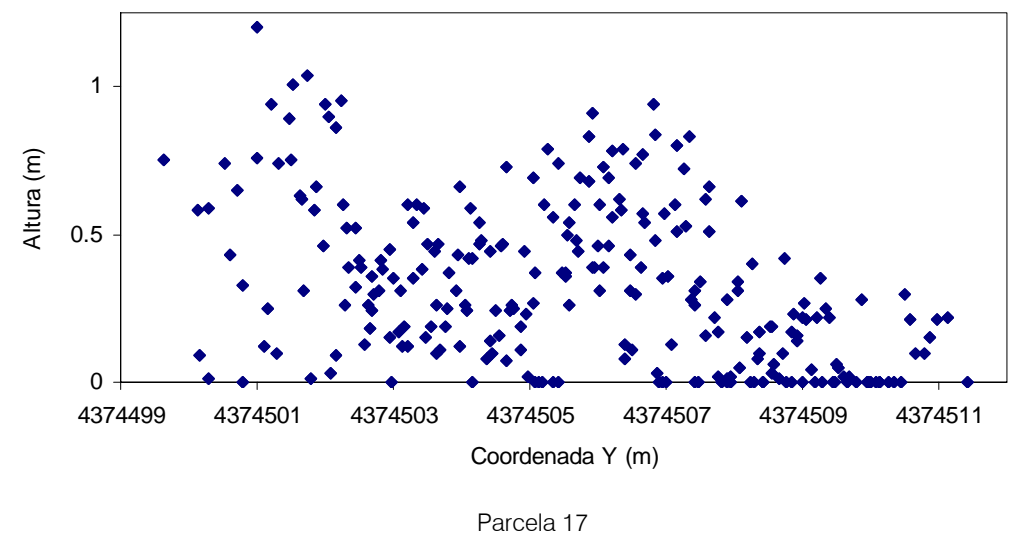




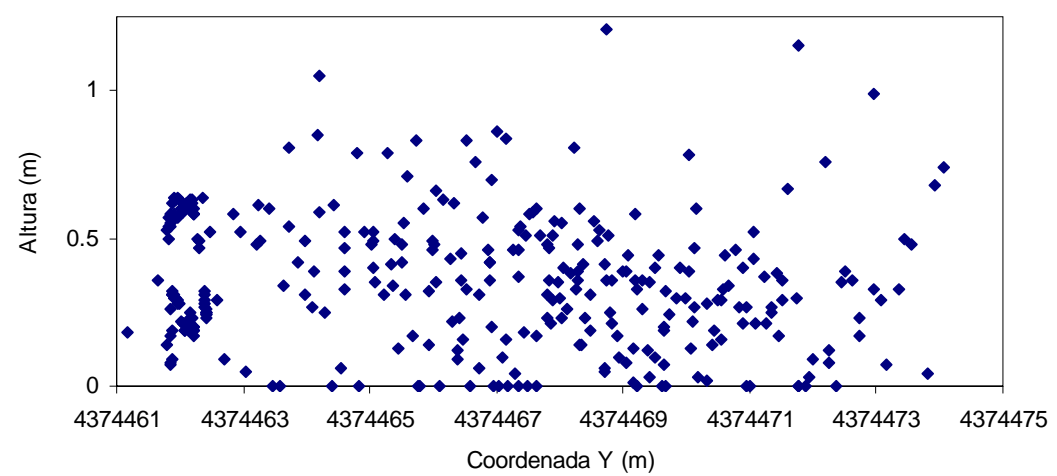

Parcela 18

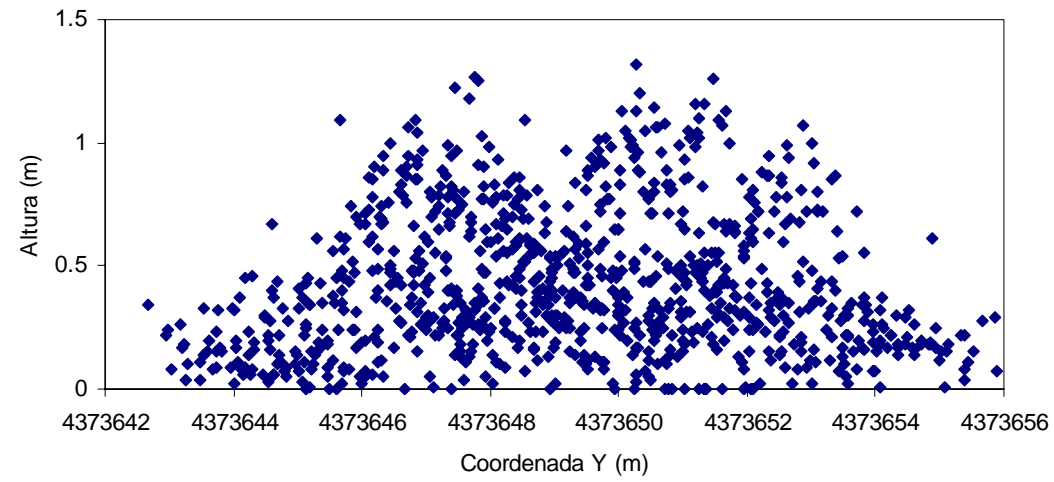

Parcela 19

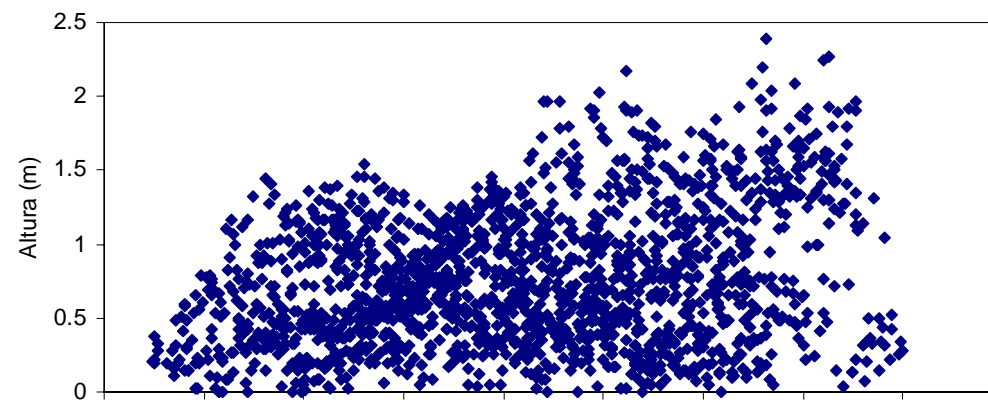

4373813437381543738174373819437382143738234373825437382743738294373831 Coordenada $Y(m)$

Parcela 20 


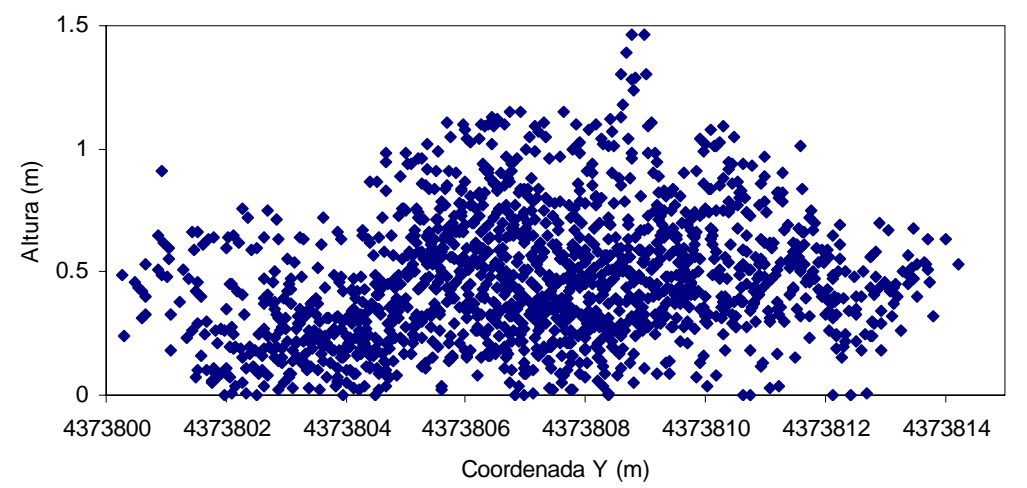

Parcela 21

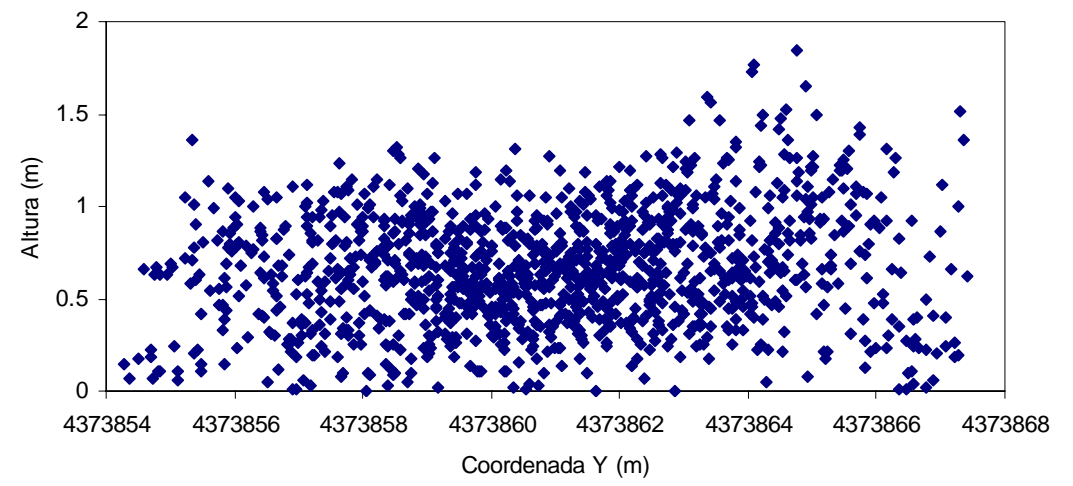

Parcela 22

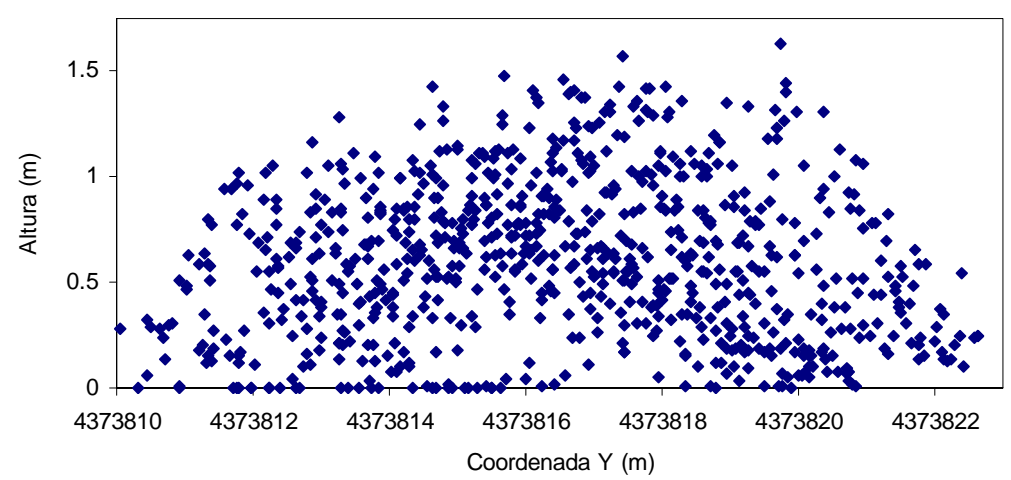

Parcela 23 


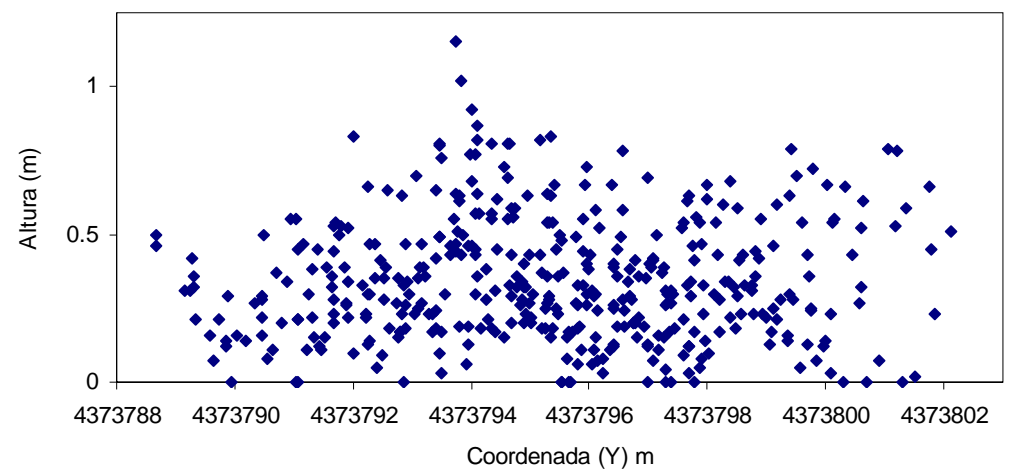

Parcela 24

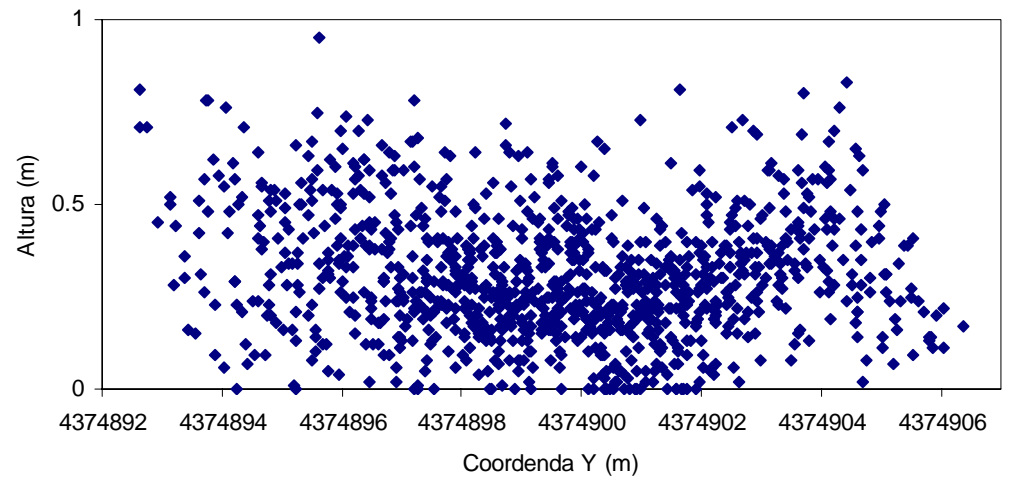

Parcela 25

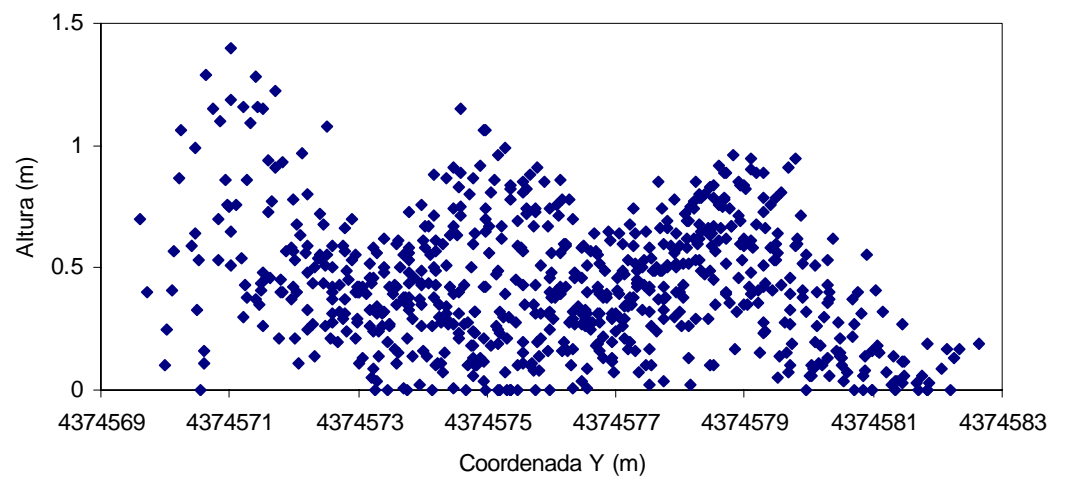

Parcela 27 


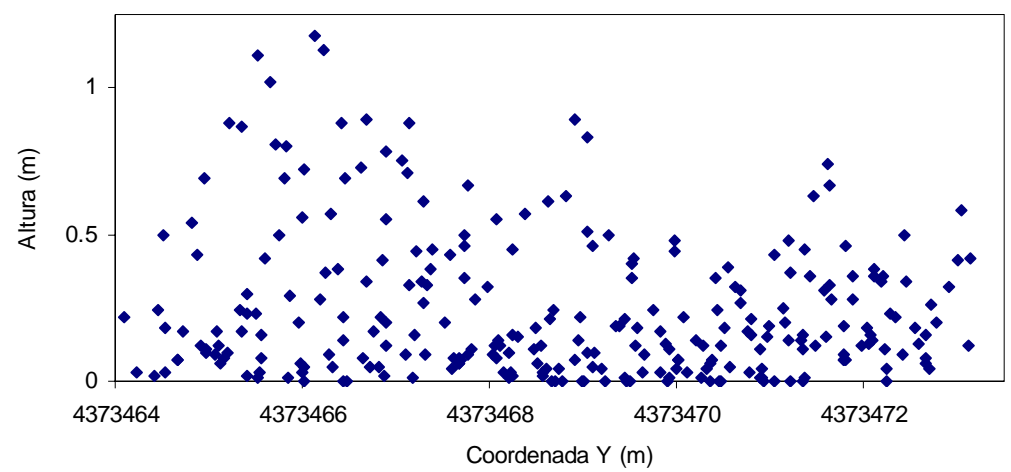

Parcela 28

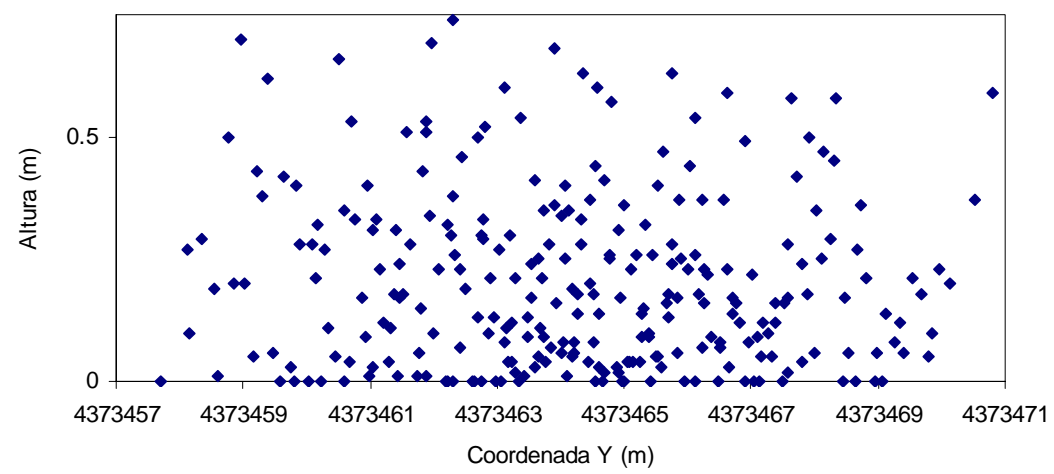

Parcela 29

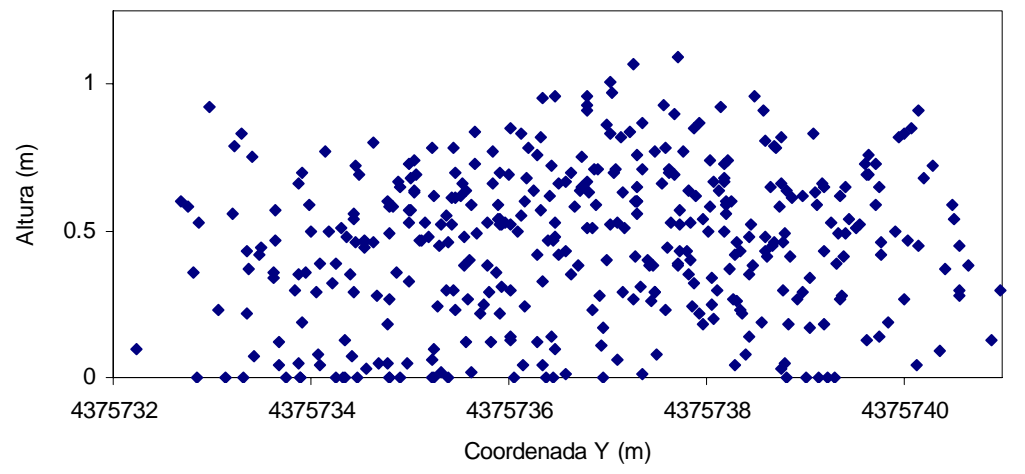

Parcela 30 
ANEJO 5

En este anejo se representan las imágenes de las parcelas y los histogramas de la banda verde de la imagen aérea. Las tonalidades claras de las imágenes representan zonas sin vegetación. Las parcelas con mayor porcentaje de ocupación de suelo desnudo corresponden con histogramas con mayor dispersión (parcelas 3, 6, 19, 28 y 29). En cambio, los tonos oscuros de las imágenes indican presencia de vegetación. Las parcelas con mayor porcentaje de cubierta vegetal presentan histogramas con menor dispersión. En el primer caso las desviaciones estándar son mayores a las del segundo caso. Esta variable se utilizó en los modelos de predicción de biomasa y volumen. Existe una relación física con la biomasa y volumen. A mayor desviación estándar (mayor dispersión) más porcentaje de suelo sin vegetación y por lo tanto menos biomasa y volumen.

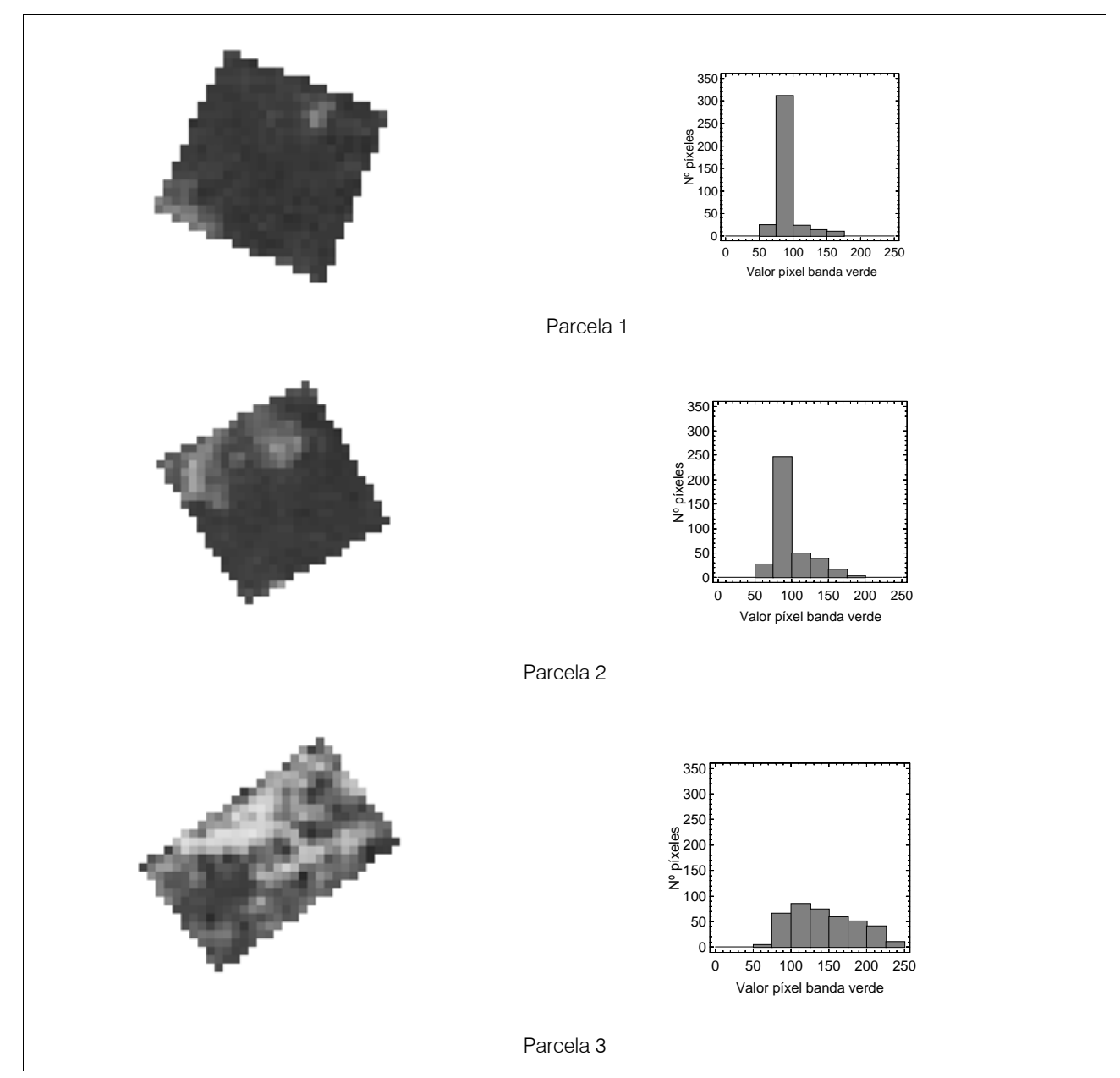



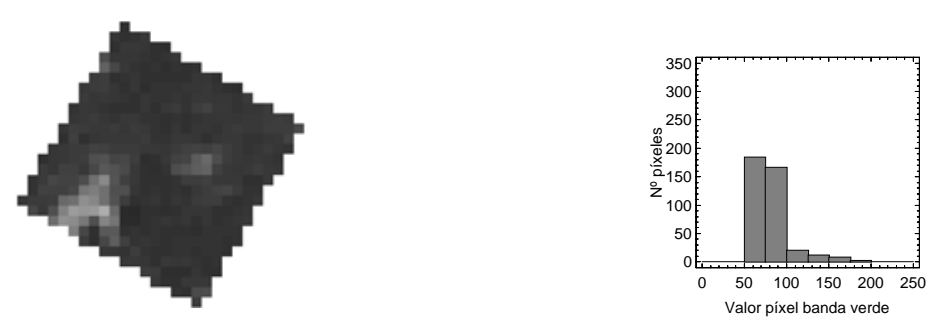

Parcela 4
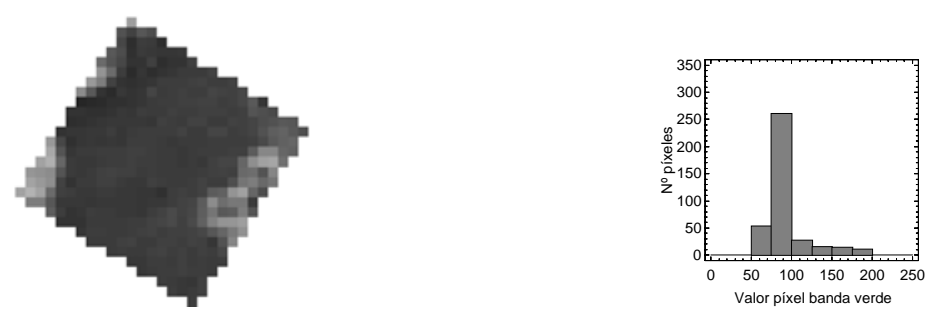

Parcela 5
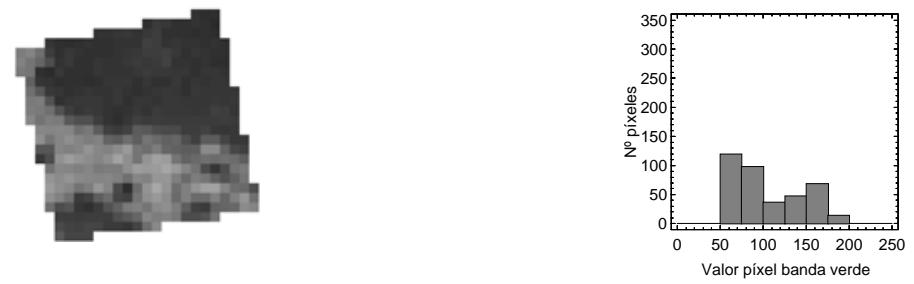

Parcela 6
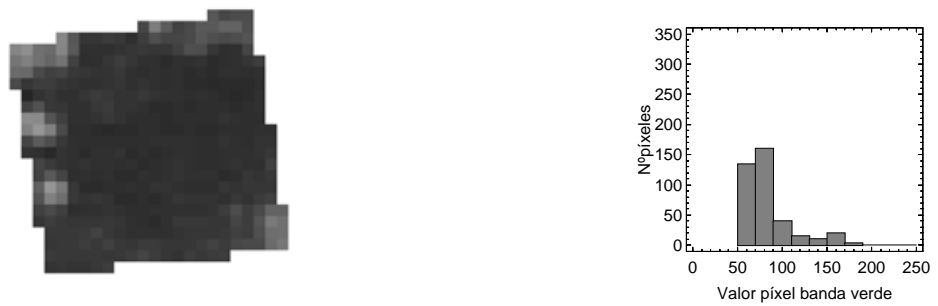

Parcela 7 

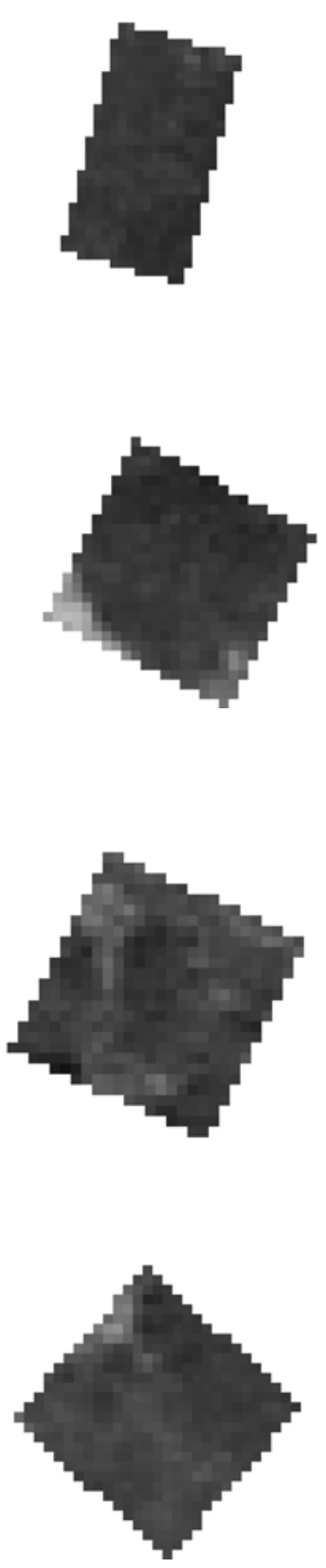

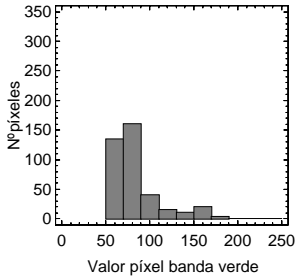

Parcela 8

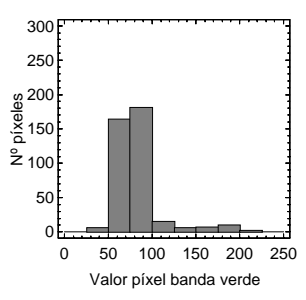

Parcela 9

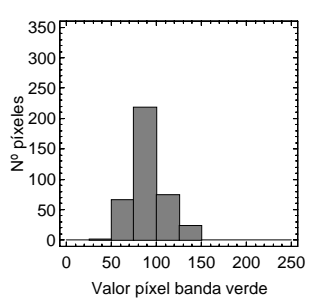

Parcela 10

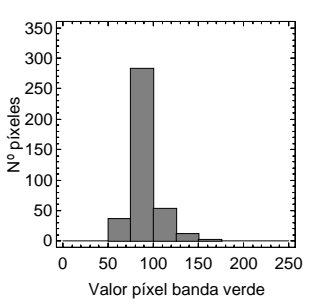



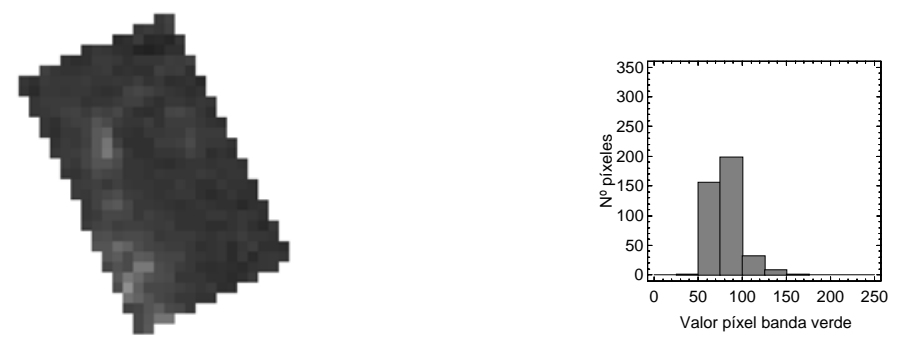

Parcela 12
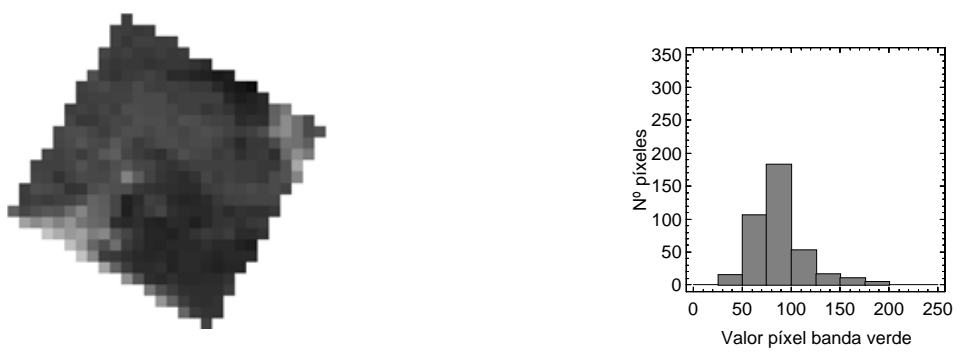

Parcela 13
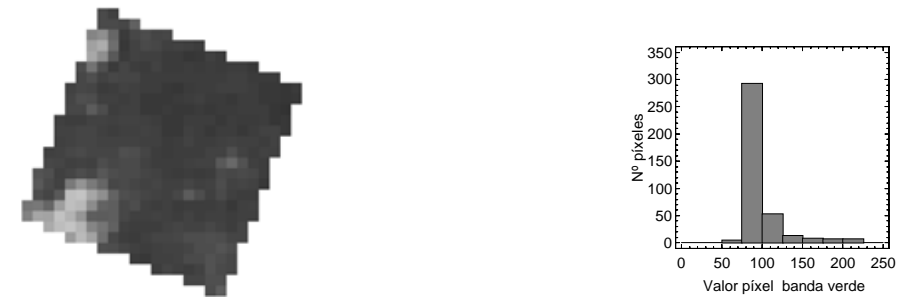

Parcela 14
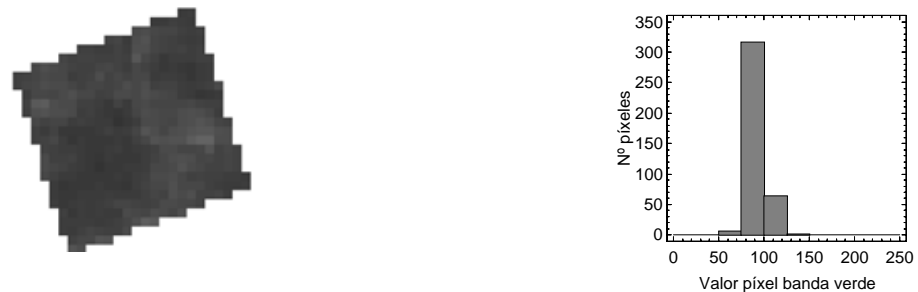

Parcela 15 

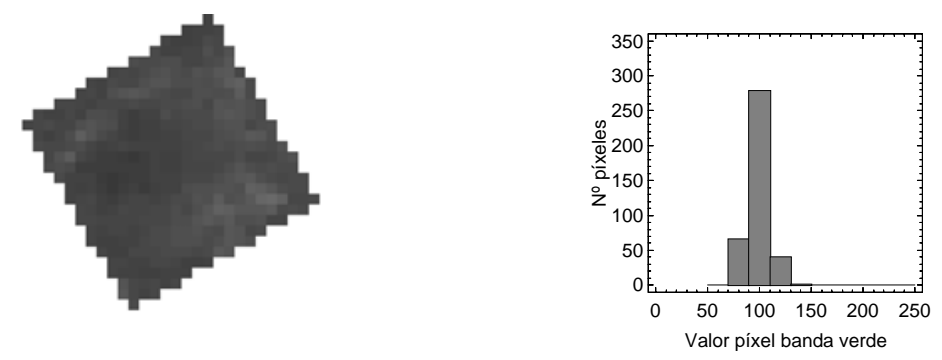

Parcela 16
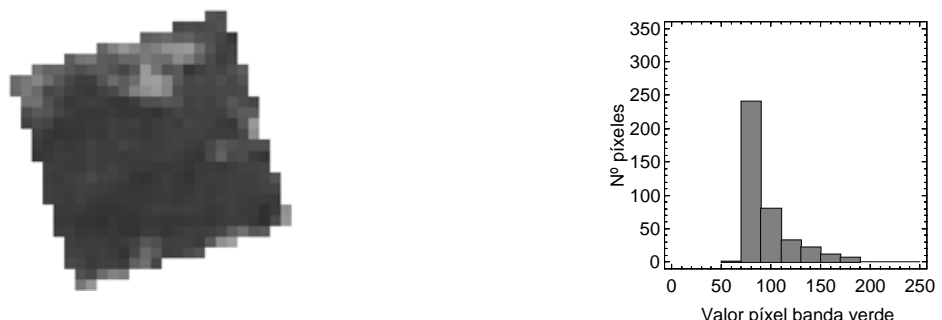

Parcela 17
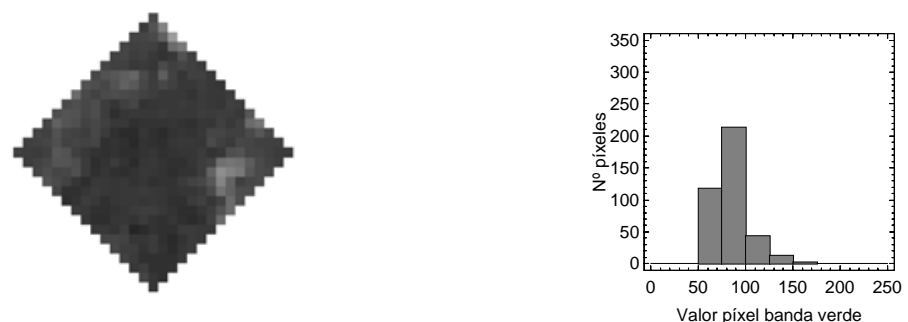

Parcela 18
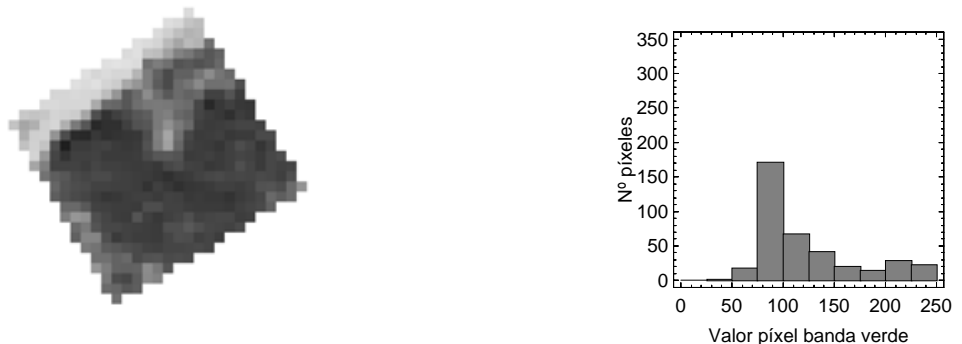

Parcela 19 

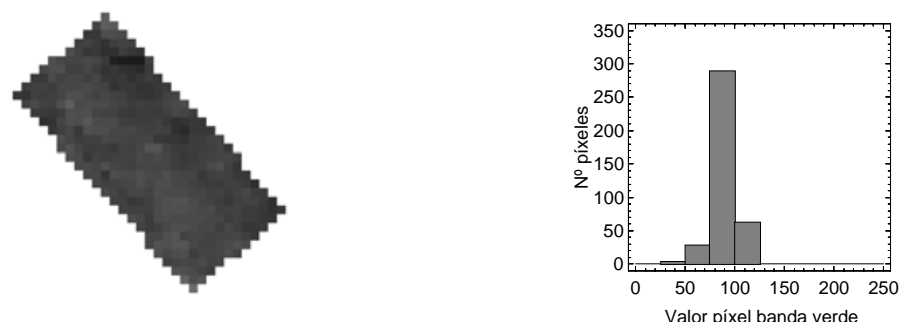

Parcela 20
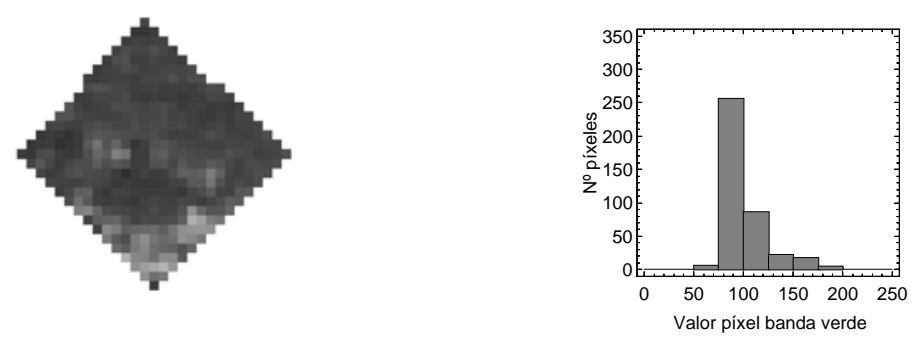

Parcela 21
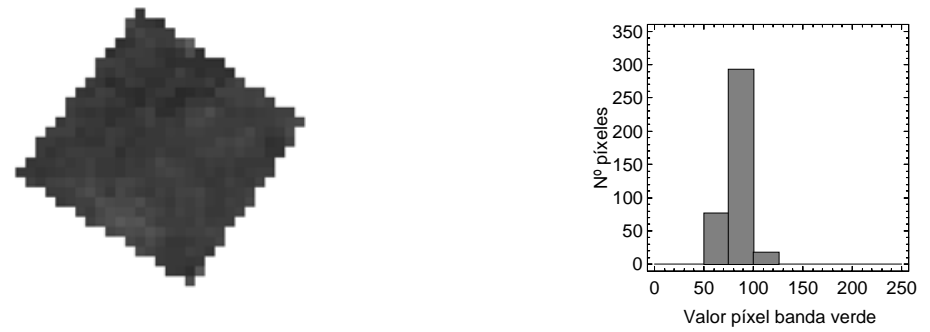

Parcela 22
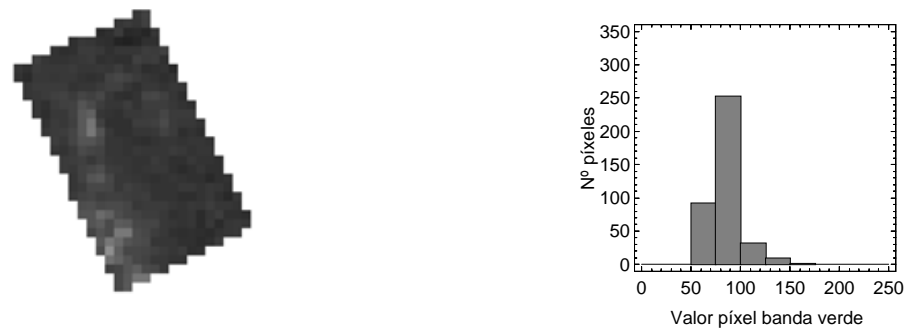

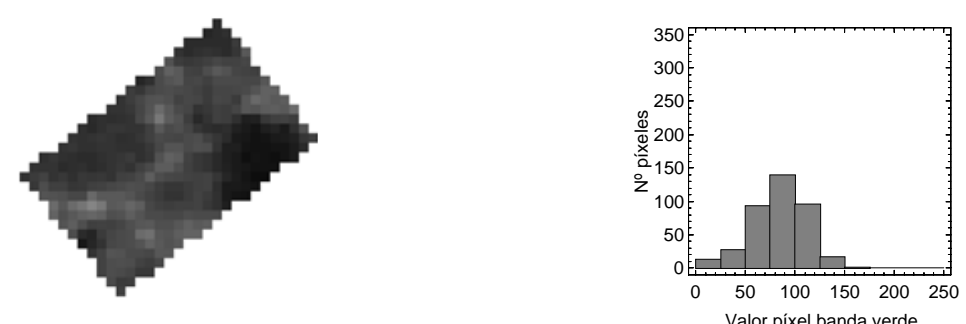

Parcela 24
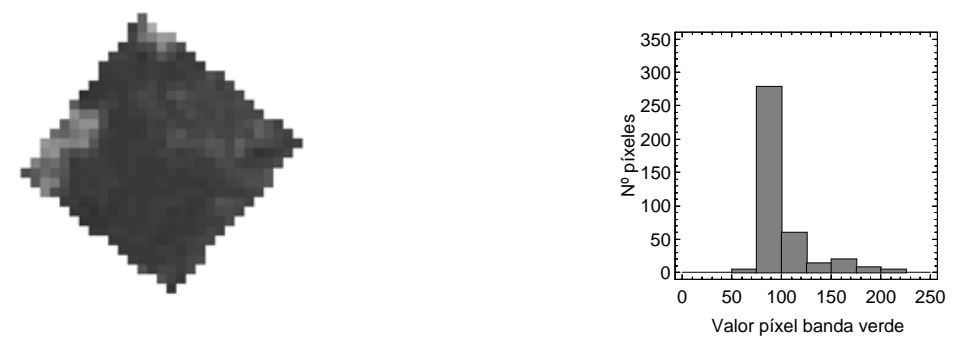

Parcela 25
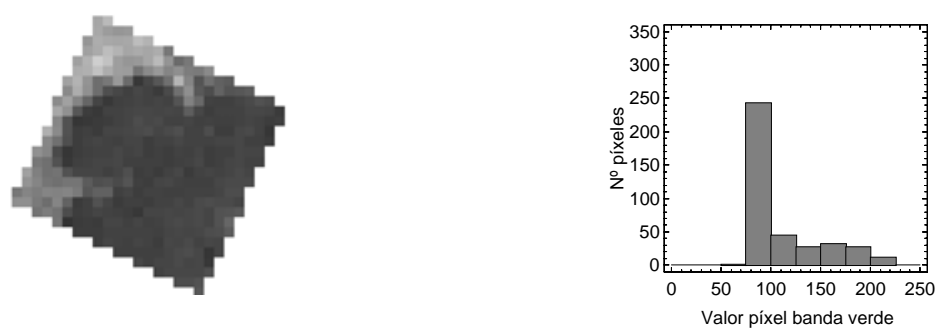

Parcela 27
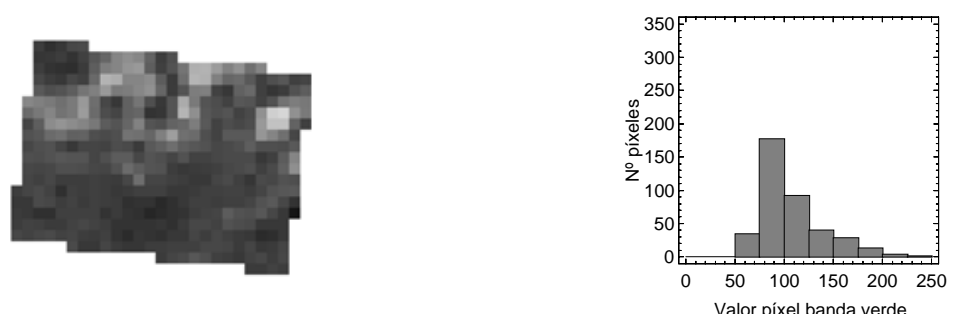


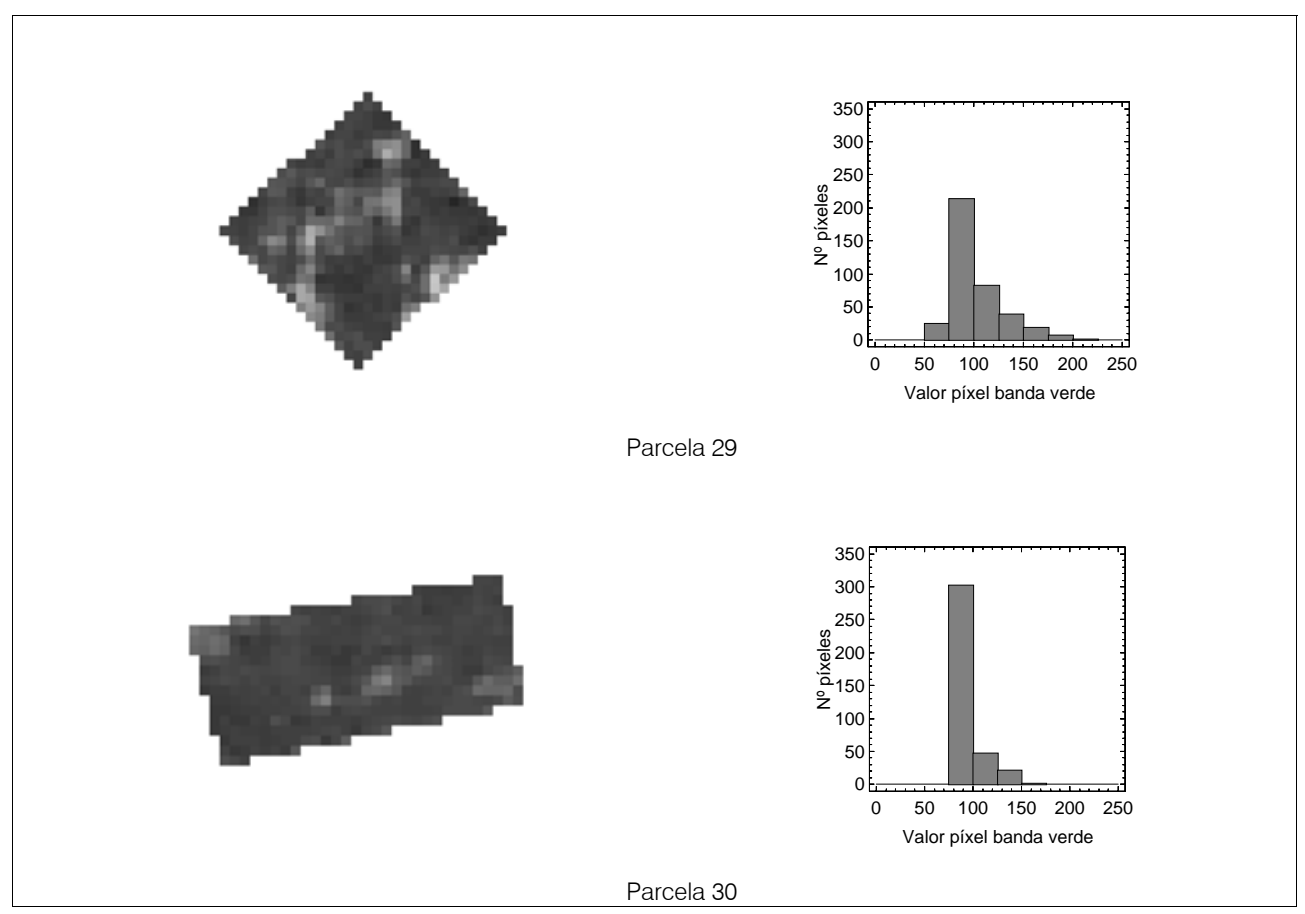


ANEJO 6. DATOS DE LAS SUBPARCELAS.

\begin{tabular}{|c|c|c|c|c|c|c|c|c|c|c|}
\hline \multirow{2}{*}{ Pacela } & \multirow{2}{*}{ Rodal } & \multicolumn{5}{|c|}{ Porcentajes especies } & \multirow{2}{*}{ Altura (m) } & \multirow{2}{*}{$\begin{array}{c}\text { biomasa } \\
\text { húmeda (kg) }\end{array}$} & \multirow{2}{*}{$\begin{array}{c}\text { vegetación } \\
\text { seca }(\mathrm{kg})\end{array}$} & \multirow{2}{*}{$\begin{array}{c}\begin{array}{c}\text { volumen } \\
\mathrm{cm}^{3}\end{array}\end{array}$} \\
\hline & & coscoja & Jara & Erica & Romero & Ulex & & & & \\
\hline 1 & 1 & 87,50 & & & 6,25 & 6,25 & 1,50 & 2,65 & 1,80 & 1725,64 \\
\hline 1 & 2 & 88,89 & & & & 11,11 & 1,10 & 3,91 & 2,60 & 2261,45 \\
\hline 1 & 3 & 61,54 & 7,69 & & & 30,77 & 0,90 & 6,39 & 3,82 & 3738,26 \\
\hline 2 & 1 & 68,97 & & 31,03 & & & 1,00 & 7,63 & 5,13 & 5481,30 \\
\hline 2 & 2 & 100,00 & & & & & 1,30 & 4,94 & 3,36 & 2264,24 \\
\hline 2 & 3 & 78,95 & & 21,05 & & & 1,10 & 2,52 & 1,69 & 1450,83 \\
\hline 3 & 1 & 3,03 & 51,52 & 36,36 & & 9,09 & 1,10 & 1,67 & 0,99 & 3332,76 \\
\hline 3 & 2 & 79,17 & & 4,17 & & 16,67 & 0,90 & 2,44 & 1,59 & 1130,76 \\
\hline 3 & 3 & 70,59 & & & & 29,41 & 0,80 & 3,86 & 2,57 & 2303,64 \\
\hline 4 & 1 & 90,91 & & & & 9,09 & 0,85 & 7,21 & 4,77 & 3381,11 \\
\hline 4 & 2 & 100,00 & & & & & 1,00 & 3,72 & 2,53 & 4622,32 \\
\hline 4 & 3 & 95,45 & & & & 4,55 & 0,90 & 5,36 & 3,63 & 2211,47 \\
\hline 5 & 1 & 91,67 & & & 8,33 & & 1,50 & 5,18 & 3,55 & 4306,98 \\
\hline 5 & 2 & 93,33 & & & & 6,67 & 0,90 & 2,88 & 1,93 & 1545,68 \\
\hline 5 & 3 & 50,00 & & & 50,00 & & 1,20 & 5,97 & 4,43 & 2817,51 \\
\hline 6 & 1 & 100,00 & & & & & 1,60 & 10,82 & 7,36 & 9285,02 \\
\hline 6 & 2 & 100,00 & & & & & 1,80 & 8,59 & 5,84 & 6740,57 \\
\hline 6 & 3 & 85,71 & & & 14,29 & & 1,80 & 4,16 & 2,91 & 3840,79 \\
\hline 7 & 1 & 100,00 & & & & & 1,45 & 4,60 & 3,13 & 2743,92 \\
\hline 7 & 2 & 100,00 & & & & & 1,25 & 4,75 & 3,23 & 3234,67 \\
\hline 7 & 3 & 39,29 & & & & 60,71 & 1,35 & 6,84 & 4,11 & 5978,58 \\
\hline 8 & 1 & 88,46 & & & & 11,54 & 1,80 & 9,93 & 6,49 & 7354,77 \\
\hline 8 & 2 & 85,19 & & & & 14,81 & 1,45 & 6,53 & 4,37 & 3677,98 \\
\hline 8 & 3 & 56,67 & 10,00 & & & 33,33 & 1,35 & 9,68 & 6,14 & 7488,82 \\
\hline 9 & 1 & 78,57 & 21,43 & & & & 1,90 & 13,77 & 9,28 & 11095,16 \\
\hline 9 & 2 & 96,30 & & & & 3,70 & 1,50 & 11,97 & 8,13 & 10784,26 \\
\hline 9 & 3 & 96,55 & & & 3,45 & & 1,40 & 8,22 & 5,60 & 6061,32 \\
\hline 10 & 1 & 92,31 & & & 7,69 & & 1,50 & 8,97 & 7,09 & 7194,07 \\
\hline 10 & 2 & 94,12 & & & 5,88 & & 1,35 & 10,83 & 7,42 & 7258,94 \\
\hline 10 & 3 & 81,82 & 13,64 & & 4,55 & & 1,25 & 7,42 & 5,13 & 4581,53 \\
\hline 11 & 1 & 92,00 & 8,00 & & & & 1,52 & 1,89 & 1,12 & 4199,34 \\
\hline 11 & 2 & & 53,85 & & 46,15 & & 1,35 & 2,22 & 1,54 & 2952,26 \\
\hline 11 & 3 & 78,26 & 17,39 & & 4,35 & & 1,40 & 4,36 & 2,99 & 2920,32 \\
\hline 12 & 1 & 87,50 & & & & 12,50 & 2,50 & 15,90 & 10,65 & 7224,16 \\
\hline 12 & 2 & 45,45 & 22,73 & & 31,82 & & 1,50 & 4,37 & 3,15 & 3081,05 \\
\hline 12 & 3 & 100,00 & & & & & 1,20 & 8,66 & 5,89 & 5911,91 \\
\hline 13 & 1 & 71,88 & 21,88 & & & 6,25 & 1,58 & 9,21 & 6,15 & 5387,82 \\
\hline 13 & 2 & 50,00 & 30,00 & & & 20,00 & 1,40 & 5,80 & 3,70 & 4881,41 \\
\hline 13 & 3 & 52,17 & 21,74 & 8,70 & & 17,39 & 1,79 & 9,16 & 6,01 & 6470,25 \\
\hline 14 & 1 & 60,00 & & & & 40,00 & 1,30 & 9,47 & 6,17 & 7942,02 \\
\hline 14 & 2 & 53,13 & 6,25 & & & 40,63 & 1,25 & 11,58 & 7,15 & 6415,54 \\
\hline 14 & 3 & 42,11 & 15,79 & & & 42,11 & 1,55 & 4,90 & 3,12 & 3976,59 \\
\hline
\end{tabular}




\begin{tabular}{|c|c|c|c|c|c|c|c|c|c|c|}
\hline \multirow{2}{*}{ Pacela } & \multirow{2}{*}{ Rodal } & \multicolumn{5}{|c|}{ Porcentajes especies } & \multirow{2}{*}{ Altura (m) } & \multirow{2}{*}{$\begin{array}{c}\text { biomasa } \\
\text { húmeda (kg) }\end{array}$} & \multirow{2}{*}{$\begin{array}{l}\text { vegetación } \\
\text { seca }(\mathrm{kg})\end{array}$} & \multirow{2}{*}{$\begin{array}{c}\text { volumen } \\
\mathrm{cm}^{3}\end{array}$} \\
\hline & & Coscoja & Jara & Erica & Romero & Ulex & & & & \\
\hline 15 & 1 & 75,86 & 13,79 & & & 10,34 & 1,20 & 6,79 & 4,33 & 4491,25 \\
\hline 15 & 2 & 75,00 & & & & 25,00 & 1,25 & 5,45 & 3,46 & 4264,90 \\
\hline 15 & 3 & 28,57 & 71,43 & & & & 1,32 & 6,19 & 3,65 & 6217,55 \\
\hline 16 & 1 & 72,00 & & & & 28,00 & 1,50 & 11,27 & 7,39 & 8017,95 \\
\hline 16 & 2 & 100,00 & & & & & 1,20 & 6,17 & 4,20 & 4591,47 \\
\hline 16 & 3 & 33,33 & 66,67 & & & & 1,10 & 5,47 & 3,27 & 6723,96 \\
\hline 17 & 1 & 82,76 & 6,90 & & & 10,34 & 0,90 & 9,83 & 6,57 & 3325,22 \\
\hline 17 & 2 & 68,75 & 18,75 & & & 12,50 & 0,90 & 5,20 & 3,38 & 2440,97 \\
\hline 17 & 3 & 90,91 & & & & 9,09 & 0,90 & 10,34 & 6,96 & 5718,21 \\
\hline 18 & 1 & 30,00 & 66,67 & & & 3,33 & 0,90 & 5,80 & 3,50 & 5516,62 \\
\hline 18 & 2 & 60,71 & 21,43 & & & 17,86 & 1,10 & 5,20 & 3,91 & 3896,83 \\
\hline 18 & 3 & 38,24 & 32,35 & & & 29,41 & 1,00 & 5,31 & 3,38 & 4486,76 \\
\hline 19 & 1 & 80,00 & & & & 20,00 & 1,20 & 6,75 & 4,47 & 4123,39 \\
\hline 19 & 2 & 86,36 & & & & 13,64 & 1,20 & 6,83 & 4,27 & 4072,06 \\
\hline 19 & 3 & 81,25 & & & & 18,75 & 1,07 & 5,76 & 3,82 & 3927,81 \\
\hline 20 & 1 & & 50,00 & & & 50,00 & 1,20 & 7,94 & 4,55 & 6872,55 \\
\hline 20 & 2 & & 67,74 & & & 32,26 & 1,60 & 8,93 & 5,12 & 10216,13 \\
\hline 20 & 3 & 92,31 & & & & 7,69 & 1,80 & 13,21 & 8,88 & 8591,53 \\
\hline 21 & 1 & 54,55 & 9,09 & & 27,27 & 9,09 & 1,10 & 4,28 & 3,14 & 3231,22 \\
\hline 21 & 2 & 75,00 & 12,50 & & & 12,50 & 1,00 & 2,02 & 1,32 & 1711,30 \\
\hline 21 & 3 & 50,00 & 50,00 & & & & 1,20 & 3,32 & 2,02 & 5041,69 \\
\hline 22 & 1 & 89,74 & 2,56 & & & 7,69 & 1,10 & 4,30 & 2,91 & 2529,23 \\
\hline 22 & 2 & 66,67 & 28,57 & & & 4,76 & 1,46 & 7,69 & 4,92 & 5091,42 \\
\hline 22 & 3 & 73,33 & 13,33 & & 13,33 & & 1,20 & 6,10 & 4,20 & 3650,87 \\
\hline 23 & 1 & 88,89 & & & & 11,11 & 1,50 & 9,84 & 6,67 & 6695,14 \\
\hline 23 & 2 & 90,00 & & & & & 1,60 & 7,98 & 5,39 & 5318,85 \\
\hline 23 & 3 & 83,33 & & & & 16,67 & 1,40 & 4,93 & 3,34 & 2187,96 \\
\hline 24 & 1 & 85,00 & 15,00 & & & & 1,35 & 5,57 & 3,70 & 4467,87 \\
\hline 24 & 2 & 68,97 & 6,90 & 6,90 & & 17,24 & 1,30 & 4,10 & 2,66 & 2332,80 \\
\hline 25 & 1 & 50,00 & 5,88 & & & 44,12 & 0,95 & 4,99 & 3,06 & 3744,99 \\
\hline 25 & 2 & 86,67 & & & & 13,33 & 1,00 & 2,35 & 1,49 & 1594,85 \\
\hline 25 & 3 & 41,67 & & & 58,33 & & 1,00 & 4,85 & 3,53 & 2812,93 \\
\hline 27 & 1 & 87,50 & 12,50 & & & & 0,80 & 2,73 & 1,85 & 1620,38 \\
\hline 27 & 2 & 43,48 & 30,43 & & 26,09 & & 1,10 & 2,30 & 1,59 & 1439,28 \\
\hline 27 & 3 & 90,48 & 0,00 & & & 9,52 & 1,10 & 3,08 & 2,05 & 1678,78 \\
\hline 28 & 1 & 84,62 & 15,38 & & & & 1,40 & 4,31 & 2,90 & 4203,66 \\
\hline 28 & 2 & & 18,18 & & & 81,82 & 1,30 & 8,89 & 5,07 & 5295,20 \\
\hline 28 & 3 & & 100,00 & & & & 1,05 & 3,52 & 2,04 & 4687,55 \\
\hline 29 & 1 & & 11,76 & & 70,59 & 17,65 & 0,98 & 4,66 & 3,22 & 3238,81 \\
\hline 29 & 2 & 38,10 & 19,05 & & & 42,86 & 0,98 & 4,56 & 2,90 & 4192,67 \\
\hline 29 & 3 & & 50,00 & & 50,00 & & 1,25 & 5,09 & 3,74 & 4762,71 \\
\hline 30 & 1 & & 10,00 & & & 90,00 & 1,10 & 7,37 & 4,20 & 3265,71 \\
\hline 30 & 2 & & 22,73 & & 36,36 & 40,91 & 1,15 & 5,02 & 3,17 & 3755,84 \\
\hline 30 & 3 & & 23,33 & & 13,33 & 63,33 & 1,20 & 7,25 & 4,29 & 5618,08 \\
\hline
\end{tabular}


ANEJO 7. DATOS DE LAS PARCELAS

\begin{tabular}{|c|c|c|c|c|c|c|c|c|}
\hline & & & Especies & & & biomasa & vegetación & 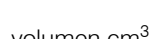 \\
\hline & $\%$ Coscoja & \% Jara & \% Erica & $\%$ Romero & $\%$ Ulex & húmeda (kg) & seca $(k g)$ & volumen cm \\
\hline Parcela 1 & 79,17 & 0,49 & - & 0,49 & 14,84 & 327,91 & 212,27 & 203570,94 \\
\hline Parcela 2 & 70,00 & - & 15,00 & - & - & 619,52 & 419,27 & 342420,81 \\
\hline Parcela 3 & 45,00 & 7,50 & 7,50 & - & 15,00 & 274,41 & 177,52 & 192297,87 \\
\hline Parcela 4 & 66,11 & - & - & - & 18,89 & 905,29 & 568,52 & 526241,07 \\
\hline Parcela 5 & 56,00 & - & - & 12,00 & 12,00 & 528,69 & 358,36 & 294833,58 \\
\hline Parcela 6 & 40,00 & 5,00 & - & 15,00 & - & 394,37 & 275,52 & 317273,90 \\
\hline Parcela 7 & 80,00 & - & - & 5,00 & 10,00 & 589,19 & 385,30 & 395926,29 \\
\hline Parcela 8 & 69,27 & 3,96 & - & 1,98 & 19,79 & 829,30 & 527,09 & 567071,07 \\
\hline Parcela 9 & 76,00 & 9,50 & 1,90 & 2,85 & 4,75 & 1233,51 & 821,27 & 963317,65 \\
\hline Parcela 10 & 52,94 & 10,59 & - & 21,18 & 5,29 & 1109,54 & 809,92 & 710640,41 \\
\hline Parcela 11 & 40,00 & 40,00 & - & 10,00 & - & 646,00 & 407,63 & 448312,56 \\
\hline Parcela 12 & 76,00 & 9,50 & - & 8,55 & 0,95 & 1060,16 & 724,12 & 608162,01 \\
\hline Parcela 13 & 37,89 & 12,63 & 3,16 & - & 6,32 & 626,40 & 413,49 & 432513,50 \\
\hline Parcela 14 & 41,54 & 6,92 & - & - & 41,54 & 987,43 & 600,70 & 682066,09 \\
\hline Parcela 15 & 28,50 & 42,75 & - & 4,75 & 19,00 & 909,26 & 528,92 & 686563,03 \\
\hline Parcela 16 & 37,78 & 18,89 & - & - & 28,33 & 824,01 & 495,90 & 825060,16 \\
\hline Parcela 17 & 48,53 & 17,65 & - & - & 8,82 & 698,14 & 458,61 & 372025,70 \\
\hline Parcela 18 & 39,67 & 34,00 & - & 5,67 & 5,67 & 488,98 & 309,80 & 422326,28 \\
\hline Parcela 19 & 42,67 & 5,33 & - & 10,67 & 21,33 & 625,09 & 377,71 & 403502,67 \\
\hline Parcela 20 & 30,00 & 30,00 & 5,00 & 5,00 & 30,00 & 1204,08 & 723,03 & 1078995,95 \\
\hline Parcela 18 & 39,67 & 34,00 & - & 5,67 & 5,67 & 488,98 & 309,80 & 422326,28 \\
\hline Parcela 19 & 42,67 & 5,33 & - & 10,67 & 21,33 & 625,09 & 377,71 & 403502,67 \\
\hline Parcela 20 & 30,00 & 30,00 & 5,00 & 5,00 & 30,00 & 1204,08 & 723,03 & 1078995,95 \\
\hline Parcela 21 & 35,00 & 45,00 & - & 5,00 & 10,00 & 321,18 & 207,06 & 403901,60 \\
\hline Parcela 22 & 64,29 & 14,29 & - & 7,14 & 14,29 & 702,13 & 465,44 & 408330,73 \\
\hline Parcela 23 & 60,00 & - & 10,00 & 15,00 & 10,00 & 663,86 & 447,78 & 414715,57 \\
\hline Parcela 24 & 16,00 & 56,00 & - & 4,00 & 4,00 & 350,44 & 213,65 & 406567,84 \\
\hline Parcela 25 & 48,91 & 1,96 & - & 4,89 & 34,24 & 584,17 & 354,77 & 377320,70 \\
\hline Parcela 27 & 40,00 & 20,00 & - & 16,00 & 4,00 & 245,63 & 166,84 & 155431,69 \\
\hline Parcela 28 & 15,29 & 30,59 & - & 3,82 & 15,29 & 381,41 & 220,07 & 344522,65 \\
\hline Parcela 29 & 3,24 & 25,88 & - & 6,47 & 19,41 & 400,92 & 233,85 & 396246,66 \\
\hline Parcela 30 & 18,00 & 18,00 & - & 9,00 & 45,00 & 593,13 & 332,26 & 397784,58 \\
\hline
\end{tabular}




